\title{
Harvesting and Cell Disruption of Microalgae
}

Gerard Pieter 't Lam 


\section{Thesis committee}

\section{Promotors}

Prof. Dr R.H. Wijfels

Professor of Bioprocess Engineering

Wageningen University \& Research

Prof. Dr M.H.M. Eppink

Special professor Biorefinery on Mild Separation Technologies of Complex Biomolecules

Wageningen University \& Research

\section{Co-promotor}

Dr M.H. Vermuë

Assistant professor, Bioprocess Engineering

Wageningen University \& Research

\section{Other members}

Prof. Dr H.H.M. Rijnaarts, Wageningen University \& Research

Dr U. Schmid-Staiger, Fraunhofer Institüt, Stuttgart, Germany

Prof. Dr L.A.M. van der Wielen, Delft University of Technology

Dr G.A. de Ruiter, Wageningen University and Research

This research was conducted under the auspices of the Graduate School VLAG (Advanced studies in Food Technology, Agrobiotechnology, Nutrition and Health Sciences) 


\title{
Harvesting and Cell Disruption of Microalgae
}

\author{
Gerard Pieter 't Lam
}

Thesis

submitted in fulfilment of the requirements for the degree of doctor

at Wageningen University

by the authority of the Rector Magnificus

Prof. Dr A.P.J. Mol,

in the presence of the

Thesis Committee appointed by the Academic Board

to be defended in public

on Friday 16 June 2017

at 4 p.m. in the Aula. 
G.P. 't Lam

Harvesting and Cell Disruption of Microalgae 206 pages

PhD-thesis, Wageningen University, Wageningen, the Netherlands, (2017) With references, with summaries in English and Dutch

ISBN: 978-94-6343-173-6

DOI: $10.18174 / 412263$ 


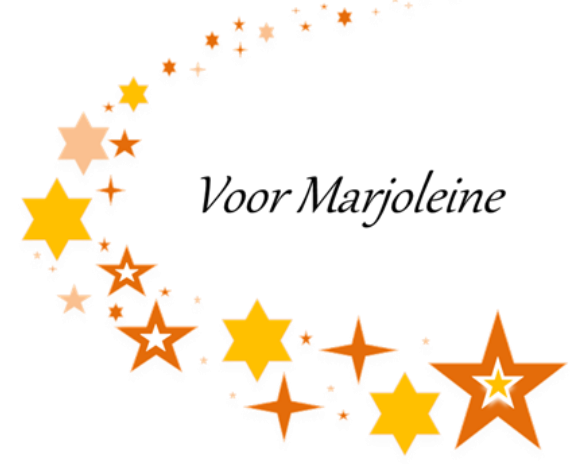




$$
\text { - }
$$




\section{Table of Contents}

Chapter 1 Introduction and thesis outline

\section{Part I: Harvesting of marine microalgae}

Chapter 2 Cationic polymers for successful flocculation of marine microalgae.

Chapter 3 Dosage effect of cationic polymers on the flocculation efficiency of the marine microalga Neochloris oleoabundans.

Chapter 4 Understanding the salinity effect on cationic polymers in inducing flocculation of the microalga Neochloris oleoabundans.

\section{Part II: Cell disruption of microalgae}

Chapter 5 Pulsed Electric Field for protein release of the microalgae Chlorella Vulgaris and Neochloris oleoabundans.

Chapter 6 Microalgae biorefinery for bulk and high value products Design and current bottlenecks in product extraction within cell disruption.

Chapter 7 Mild and selective protein release of cell wall deficient microalgae with Pulsed Electric Field.

Chapter 8 General discussion 


$$
\text { - }
$$


Chapter 1

General introduction

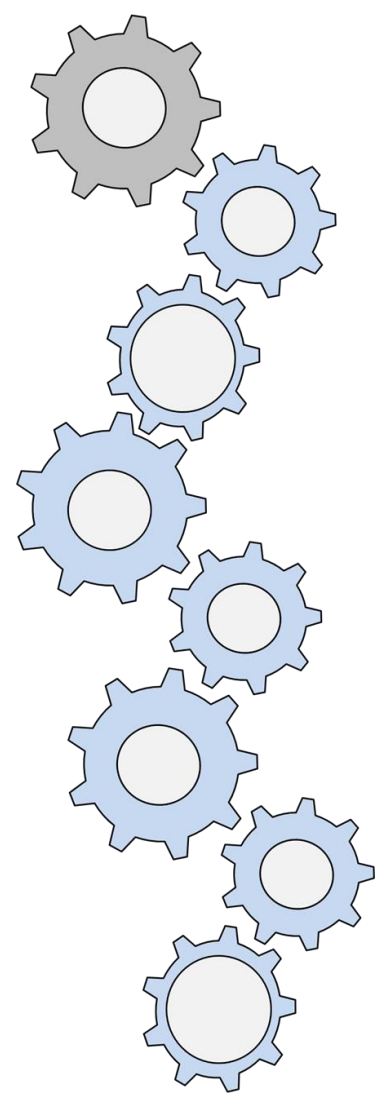




\subsection{Microalgae as renewable feedstock}

With the growing demand for food and fossil-fuel derived products, the pressure on our current resources is increasing (Amulya et al., 2016; Godfray et al., 2010; Rogner, 2007). The increasing need for feedstocks has a negative environmental impact, such as the emission of greenhouse gasses. There is thus an ongoing search for renewable resources and more environmental friendly production processes (Amulya et al., 2016; Godfray et al., 2010; Rogner, 2007).

Microalgae are regarded as a highly potential renewable feedstock (Moncada et al., 2014). They can utilize sunlight and $\mathrm{CO}_{2}$ for their growth while not competing with agricultural crops for arable land, as they can grow on sea- or wastewater. Currently, microalgae are already used for commercial production of some high value products. Examples are natural pigments and anti-oxidants ( $\beta$-carotene and astaxanthin) as well as the utilization of the whole biomass as a feedstock in the aquaculture hatcheries (Spolaore et al., 2006; Williams \& Laurens, 2010) (Figure 1.1).

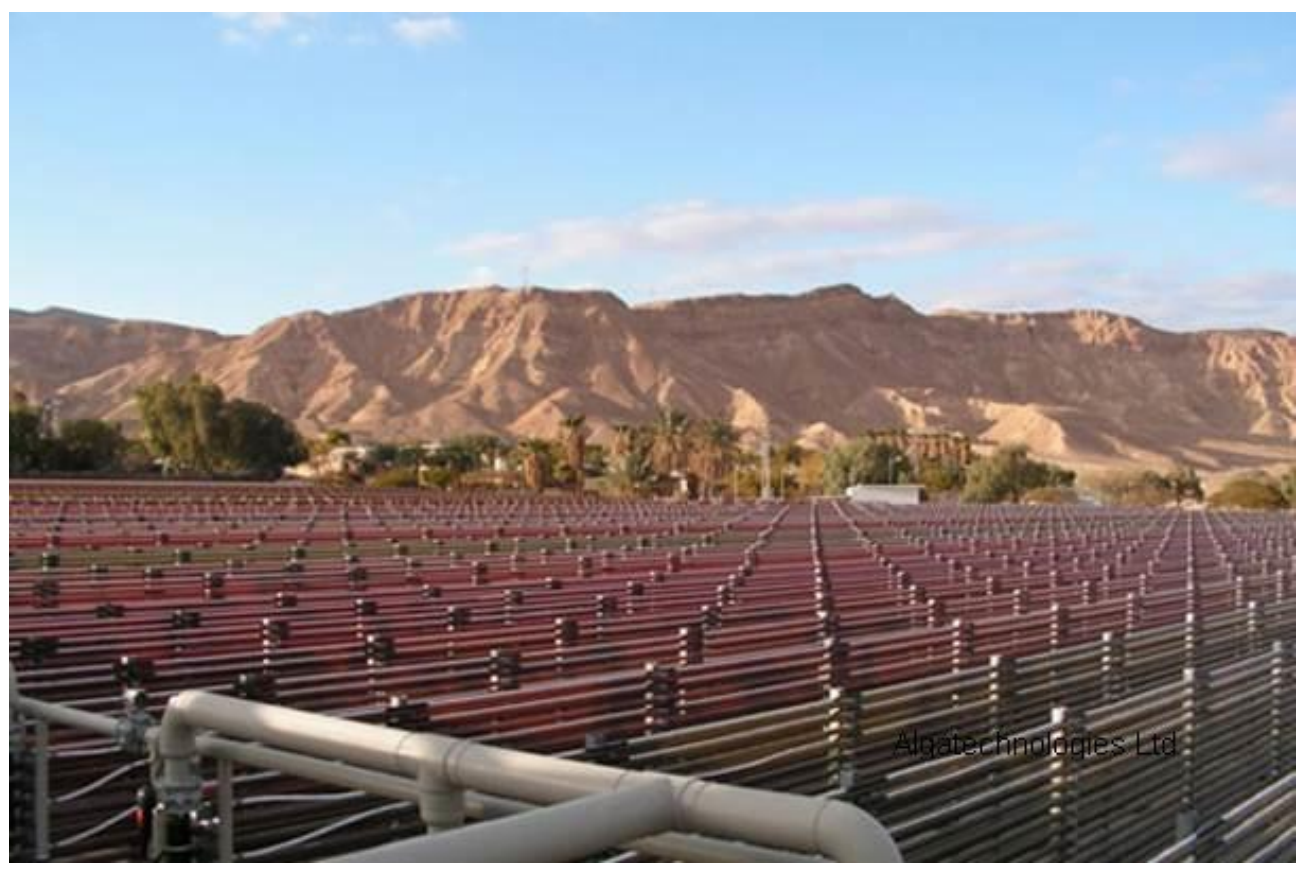

Figure 1.1: Full scale photo-bioreactors for the production of the red pigment Astaxanthin in Israel using microalgae. Picture from the cultivation facilities of AlgaTechnologies Ltd. Picture kindly received from AlgaTechnologies Ltd. 
Besides serving niche applications, microalgae are a promising feedstock for various bulk-products (Chisti, 2007; Wijffels \& Barbosa, 2010). Microalgae contain large amounts of proteins, carbohydrates and lipids (Carioca et al., 2009; VanthoorKoopmans et al., 2013; Wijffels et al., 2010). As an indication, it was assumed that a typical biomass composition consists of $40 \%$ lipids, $50 \%$ proteins and $10 \%$ carbohydrates (Wijffels et al., 2010). The exact composition depends on the used microalgae species and the applied culture conditions (Vanthoor-Koopmans et al., 2013; Wijffels \& Barbosa, 2010).

At the moment, production of bulk commodities from microalgae is not economically feasible. In the scenario study of Ruiz et al., (2016) it was predicted that the current cultivation costs of a large-scale facility in the south of Spain are about $3.4 € / \mathrm{kg}_{\mathrm{DW}}$ (flat-panel type of photobioreactor at a 100 ha scale). They also predicted that a downstream process for bulk products ('fuel', 'chemical', or a 'food/feed' scenario) costs between 0.9 and $1.1 € / \mathrm{kg}_{\mathrm{Dw}}$. At the same time, however, the revenues of these scenarios ranged between 0.3 and $2 € / \mathrm{kgDw}_{\mathrm{DW}}$. This clearly illustrates that there is still a large step to be taken towards economic feasible production of bulk commodities using microalgae.

\subsection{Challenges in implementing a large-scale microalgae biorefinery}

By minimizing the production and processing costs, the feasibility of a microalgae based production process for bulk commodities will increase. In the design of downstream processes (DSP), it is thus important to focus on cost decrease. Novel DSP technologies should thus not only be easily scalable, but the operational costs (energy, chemicals) and investment costs need to be lower than the costs of the existing benchmark technologies.

In addition to a cost reduction, a biorefinery approach has been proposed to increase the value of the cultivated biomass. In a biorefinery, multiple biomass-components are valorised instead of a single one (Eppink et al., 2012; Kamm \& Kamm, 2007; Vanthoor-Koopmans et al., 2013; Wijfels et al., 2010). By valorising all biomass fractions for both bulk-applications and higher-value co-products ('specialties'), the 
revenues will increase, resulting in economic feasible production of bulk-commodities (Figure 1.2) (Günerken et al., 2015).

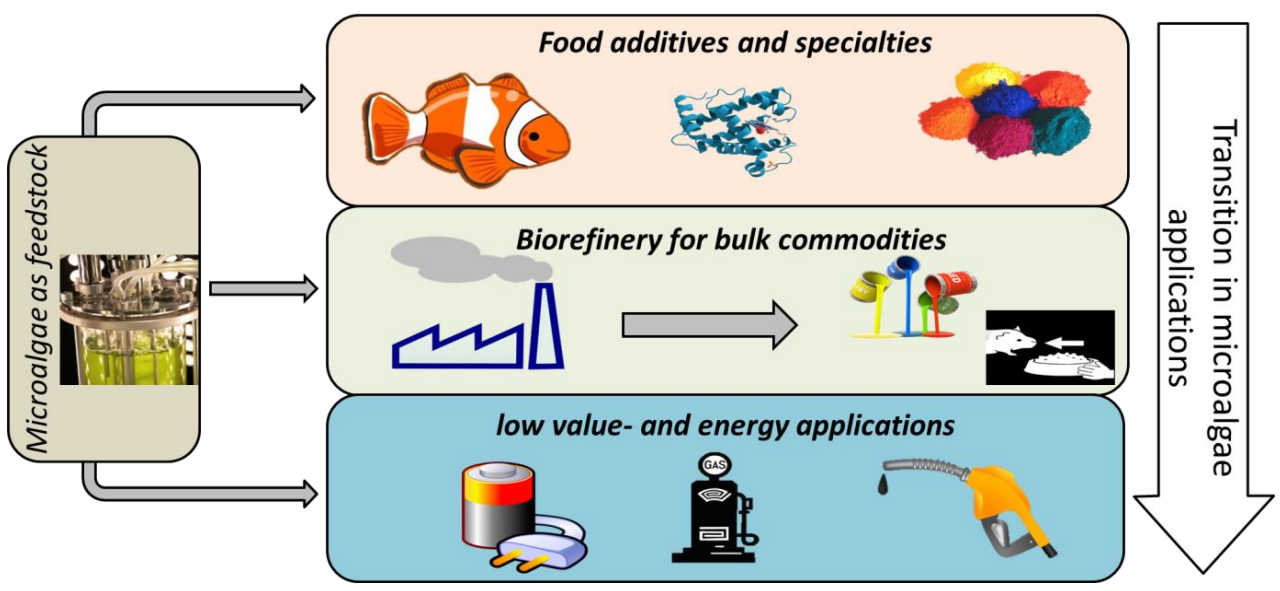

Figure 1.2: Overview of current- and future applications of microalgae as feedstock. At the moment microalgae serve various high value- and specialties industries. Production of microalgae for production of bulk commodities such as a biofuel scenario is not economically feasible. By placing a biorefinery between those two applications, we can bridge the gap in feasibility. A biorefinery aims on producing both bulk- and higher valued products, resulting in higher revenues, compared to merely serving bulk applications.

To successfully valorise all biomass fractions, $\underline{\text { mild }}$ processing technologies are required. When non-mild conditions are used, vulnerable components may be damaged, resulting in a loss in value (Wijfels et al. 2010, Günerken et al. 2015, Vanthoor-Koopmans et al. 2013). For example, the soluble protein fraction of microalgae are very suitable for techno-functional applications (Schwenzfeier et al., 2013a; Schwenzfeier et al., 2013b; Schwenzfeier et al., 2011). When used for techno-functional applications (3-3.5 €/ $\mathrm{kg}_{\text {proteins }}$ ), the value of the soluble proteins is about 3 times higher compared to nutritional proteins for food and feed (1-1.5 $€ / \mathrm{kg}_{\text {proteins) }}$ (Ruiz et al., 2016). However, proteins are typically vulnerable for denaturation (Desai et al., 2016). Non-mild processing conditions will result in a lower yield of soluble and native proteins, causing a loss in value.

Besides the above mentioned criteria, marine cultivated microalgae should be processed, while producing as minimal as possible waste or by-streams. There will be no competition for the already scarce freshwater resources when there is only a limited use of freshwater.

Typically, a microalgae DSP consists out of a biomass harvesting step followed by cell disruption before extraction and later fractionation of the various biomass 
components can take place (Figure 1.3). Microalgae are commonly cultivated in biomass concentrations ranging from 0.5 to $5 \mathrm{~g} / \mathrm{L}$ (Vandamme et al., 2013). Besides these low biomass concentrations, single cells typically have a diameter up to $20 \mu \mathrm{m}$ (Vandamme et al., 2013). As a result, harvesting of microalgae using existing technologies such as centrifugation is costly, and hampers the economic feasibility (Granados et al., 2012; Vandamme et al., 2013).

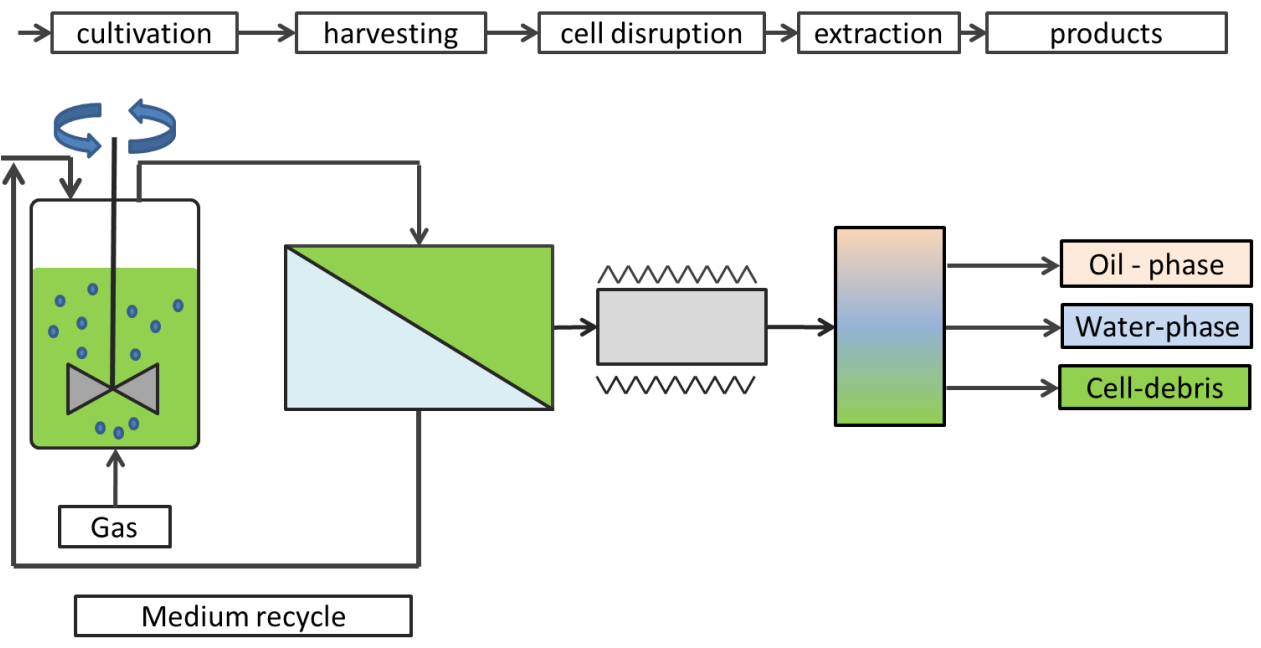

Figure 1.3: Simplified overview of a conventional downstream process.

Not only harvesting, but also cell disruption is challenging. Most microalgae have a rigid cell wall (Gerken et al., 2013; Scholz et al., 2014). The rigid cell wall is beneficial in large scale cultivation, as it makes the microalgae more robust. At the same time, however, these cell walls form a barrier to access the vulnerable intracellular components (Günerken, et al. 2015).

For the development of a low-cost microalgae biorefinery, it is thus important to overcome the existing limitations in microalgae harvesting and disruption (VanthoorKoopmans et al., 2013).

\subsubsection{Harvesting of microalgae}

Currently, harvesting of microalgae is done by mechanical solid-liquid separation technologies such as filtration and centrifugation. Although these conventional techniques are proven to be very efficient, they are energy-intensive. The studies of (Granados et al., 2012; Molina Grima et al., 2003) stated that 20 to 30\% of the total 
processing costs can be attributed to harvesting when centrifugation is used in combination with an open pond type of cultivation system. In the study of (Salim et al., 2012), it was even reported that $50 \%$ of the total energy content of microalgae has only been used by harvesting using a disk stacked centrifuge. To reduce processing costs, either a (pre-)concentration step, or an alternative harvesting technology is desired.

Instead of using merely technologies such as filtration or centrifugation, applying a (pre-)concentration technology like flocculation-sedimentation (Figure 1.4) can result in a lower energy consumption. With flocculation, single cells become aggregated into larger particles or 'flocs' which settle to the bottom of a harvesting tank ('sedimentation'). Salim et al., (2012) predicted that flocculation followed by sedimentation and centrifugation results in a 10 times energy reduction compared to only centrifugation using disk stacked centrifuges. Similar advantages of using flocculation (assisted) harvesting are reported in other studies (Molina Grima et al., 2003; Uduman et al., 2010; Vandamme et al., 2013).

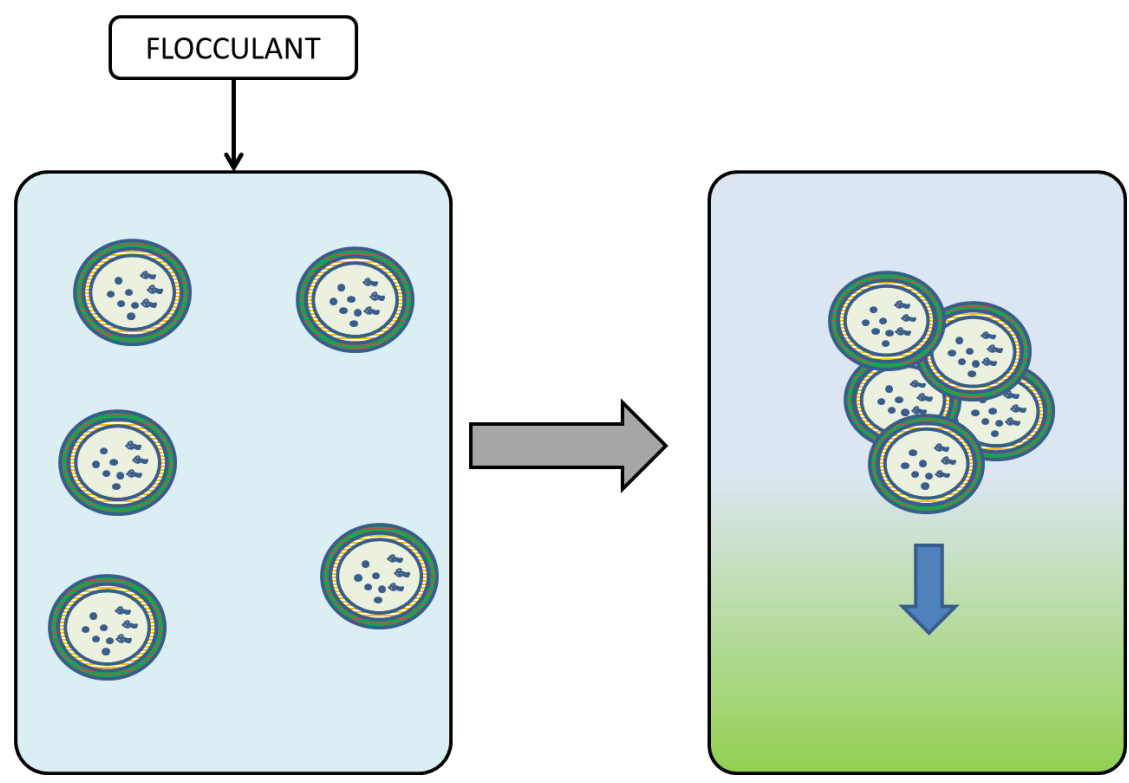

Figure 1.4: Simplified overview of harvesting using flocculation-sedimentation. With chemically induced flocculation, first a floc-inducing agent ('flocculant') is added to the cultivation broth. After a short mixing time, floc formation and subsequent sedimentation of those flocs is allowed. 
Although flocculation followed by sedimentation is already a proven- and often applied technology in wastewater treatment and in microalgae-biotechnology, it is still challenging to harvest microalgae grown in seawater. Generally, there are only a few microalgal species have the ability to form flocs by itself, or act as a bioflocculant due to e.g. environmental pressure (Salim et al., 2013). Therefore, chemically induced flocculation is often proposed (Chatsungnoen \& Chisti, 2016; Granados et al., 2012; Vandamme et al., 2010). Due to the high salt concentration present in seawater, however, most types of flocculants cannot be applied, or require high flocculant dosages (Bilanovic et al., 1988; Greenwell et al., 2010; Lam \& Lee, 2012; Milledge \& Heaven, 2013; Sukenik \& Shelef, 1984; Uduman et al., 2010; Vandamme et al., 2013). When using inorganic flocculants, for example, 5-10 higher dosages compared to freshwater conditions are required (Uduman et al. 2010). At the same time, there is little knowledge available on the flocculation mechanisms involved at high salinities. This makes it difficult to understand and to develop methods to overcome the current limitations in flocculating marine microalgae. There is thus a need for a better mechanistic understanding, which may lead to alternative flocculants and towards the ability to design general applicable harvesting processes.

\subsubsection{Cell disruption to assist extraction of intracellular compounds}

There are already a great variety of technologies present that are proven to be successful to disrupt microalgae (Günerken et al., 2015). Examples are mechanical $\underline{\text { technologies such as high pressure homogenization or bead milling, chemical }}$ technologies such as alkali-heat treatments and physical technologies such as microwave cell disruption (Günerken et al., 2015).

Mechanical and physical technologies are often studied for microalgae cell disruption. However, they are regarded as energy intensive. According to the study of Coons et al., (2014), not more than $10 \%$ of the total energy content of the algal biomass should be used for cell disruption, when focussing on low value products such as fuels. This corresponds with an estimated energy usage of maximum $0.68 \mathrm{kWh} / \mathrm{kg}_{\mathrm{DW}}$ (Coons et al., 2014). However, current mechanical technologies commonly still have a higher energy consumption (ranging between 1-100 kWh/kgDW) (Günerken et al., 2015). This high energy consumption limits the economic feasibility of a microalgae biorefinery. 
In addition, the above mentioned technologies commonly involve high temperatures shear, high pressures or other harsh conditions. Although the cell wall is successfully dis-integrated, often intracellular components like proteins are damaged resulting in a loss of potential value (Postma et al., 2015). It is for this reason that there is a need for cell disruption technologies, that are harsh enough to disrupt the microalgal cell wall but are at the same time sufficiently mild to maintain the integrity of the intracellular vulnerable components (Postma et al., 2015)

So far, bead milling seems to be the only potential feasible option. Optimization studies on mild cell disruption of microalgae by bead milling resulted in required energy inputs lower than $0.5 \mathrm{kWh} / \mathrm{kg}_{\mathrm{DW}}$ (Postma et al., 2017).

Although the energy input of bead milling is already strongly reduced, mechanical disruption typically has a high degree of disruption, resulting in the presence of fine particles, that are difficult to separate afterwards. In addition, the high degree of disruption is also associated with a non-selective release of hydrophobic (e.g. pigments) and hydrophilic (e.g. proteins) components (Postma et al. 2015).

A possible technology that is regarded as highly potential to disrupt cells is 'Pulsed Electric Field' (PEF) (Günerken et al. 2015). As illustrated in Figure 1.5, during a PEF-treatment, cells are subjected to electrical pulses resulting in opening of the cells (Kotnik et al., 2015; Weaver \& Chizmadzhev, 1996) On small scale, PEF is proposed in the medical sector for treatment of tumors (Miklavcic \& Davalos, 2015). At large scale, PEF is already applied in the food industry for mild pasteurization of juices as it inactivates bacterial contaminations (Timmermans et al., 2014).

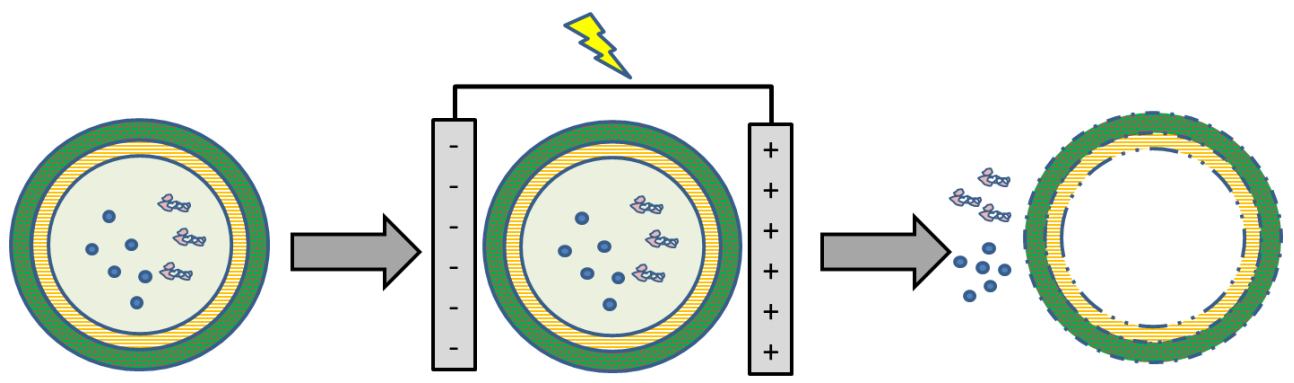

Figure 1.5: Schematic overview of the hypothesized principle of PEF on microalgae. Due to the application of short, high voltage pulses, the cells will be permeabilized, allowing the release of intracellular components. 
Due to the application of only a few electrical pulses with a short pulse-length, the energy consumption of this technology is presumed to be lower as with other celldisruption technologies (Goettel et al., 2013). Moreover, with PEF only short electrical pulses are applied and therefore no undesired side effects such as high temperature increases are expected, making it a potential mild technology as well (Goettel et al. 2013.

In addition to the named process advantages, the electrical pulses perforate the cells instead of completely disintegrate them. As a result, a selective release ('leakage') of hydrophilic components should be possible (Kotnik et al. 2015, Goettel et al. 2013). This selective release circumvents the formation of an emulsion that later needs to be separated

Although PEF has multiple presumed advantages over other technologies, a successful application of PEF for mild cell disruption at very low energy costs is not established yet. There is a need for further research to understand and develop this technology for a microalgae biorefinery application.

When it is possible to advance the current PEF state-of-development, presumably a technology that combines a low energy consumption and a high degree of mildness becomes available. In addition, as the cells are hypothesized to become only perforated, a selective release of components may be possible.

\subsection{Goal of this thesis}

To further develop biorefinery of microalgae, bottlenecks in harvesting and disruption of the biomass need to be overcome. The overall goal of this thesis is therefore to contribute to the development of alternative harvesting and cell disruption technologies with a focus on microalgae biorefinery.

\subsection{Outline of this thesis}

This thesis consists out of two parts as being illustrated in (Figure 1.6). 


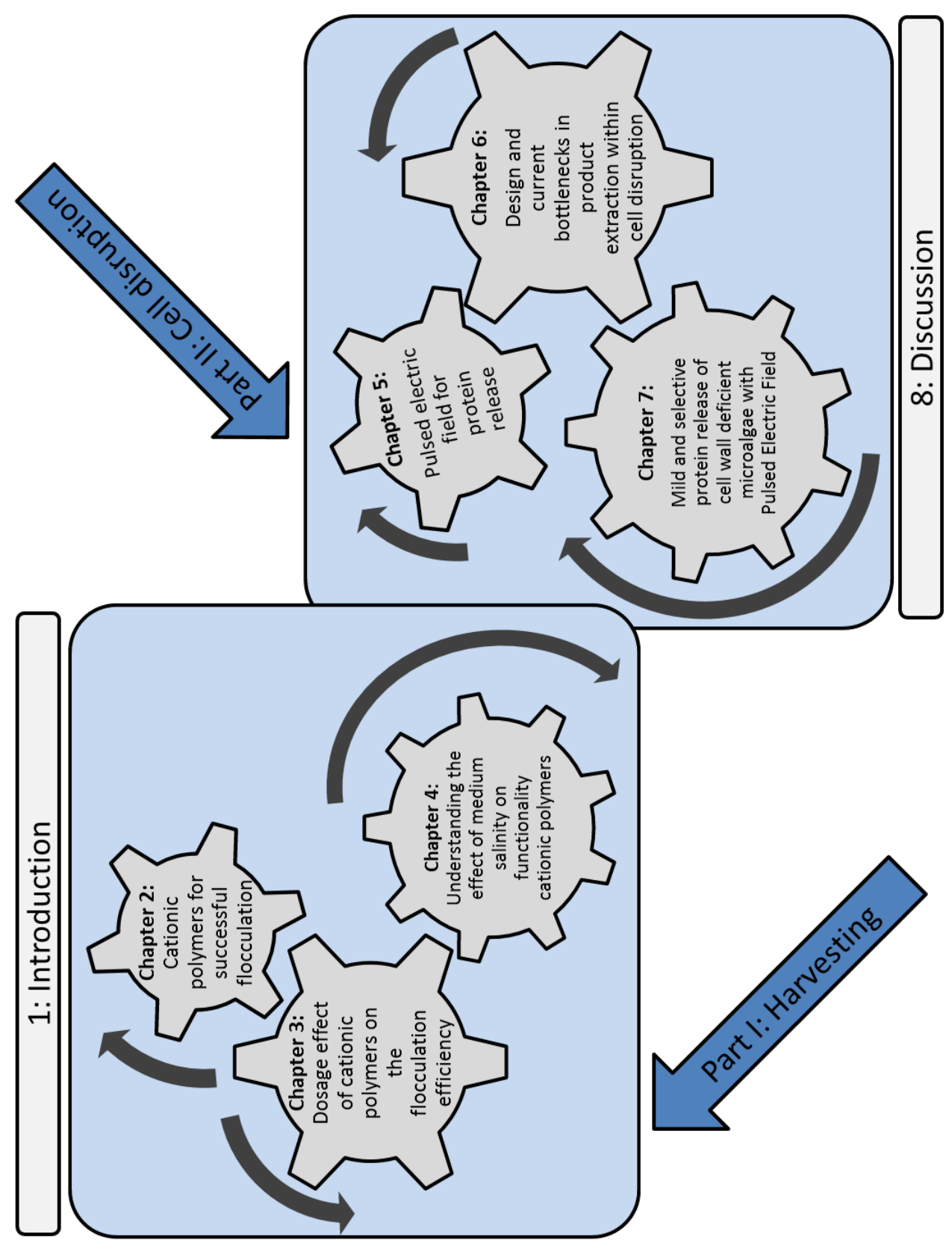

Figure 1.6: Thesis outline 
In the first part of this thesis, flocculation of microalgae at seawater salinities is studied. In chapter 2, a screening of various flocculants is performed to elucidate which type of flocculant can successfully induce flocculation at seawater salinities. After concluding that cationic polymeric flocculants are promising at high medium salinities, chapter 3 describes the dosage effect of cationic polymers as flocculants on the biomass recovery. It also presents a mechanistic model that has been used for predicting optimal flocculant dosages. In chapter 4 the aim was to understand the effect of salinity on the cationic polymers. The results of chapter 4 may be relevant for future selection- or design of alternative flocculants

The second part of this thesis is aimed to further develop Pulsed Electric Field (PEF) as alternative cell disruption technology for microalgae. By applying PEF on two different microalgae, the current state of development has been determined (chapter 5). Chapter 6 continues with a literature review presenting an overview of potential biorefinery approaches in production of bulk commodities. In particular, the role of cell disruption and PEF will be addressed. As chapter 6 concludes that PEF could be an interesting technology, chapter 7 aims to better understand the role of the cell wall in disrupting microalgae with PEF. Chapter 7 also presents a case study to determine the potential of PEF and discusses future solutions to overcome the encountered limitations of applying PEF on microalgae with a rigid cell wall.

The discussion and general conclusions (chapter 8) starts with evaluating polymeric flocculation for harvesting of marine microalgae and PEF for cell disruption. The evaluation provides a comprehensive overview of the strengths and weaknesses of both technologies. After evaluating polymeric flocculation for harvesting of marine microalgae and PEF for cell disruption, chapter 8 continues with an outlook on future steps in the development of novel downstream technologies for a microalgae biorefinery. 


$$
\text { - }
$$




\section{Part I: Harvesting marine microalgae}

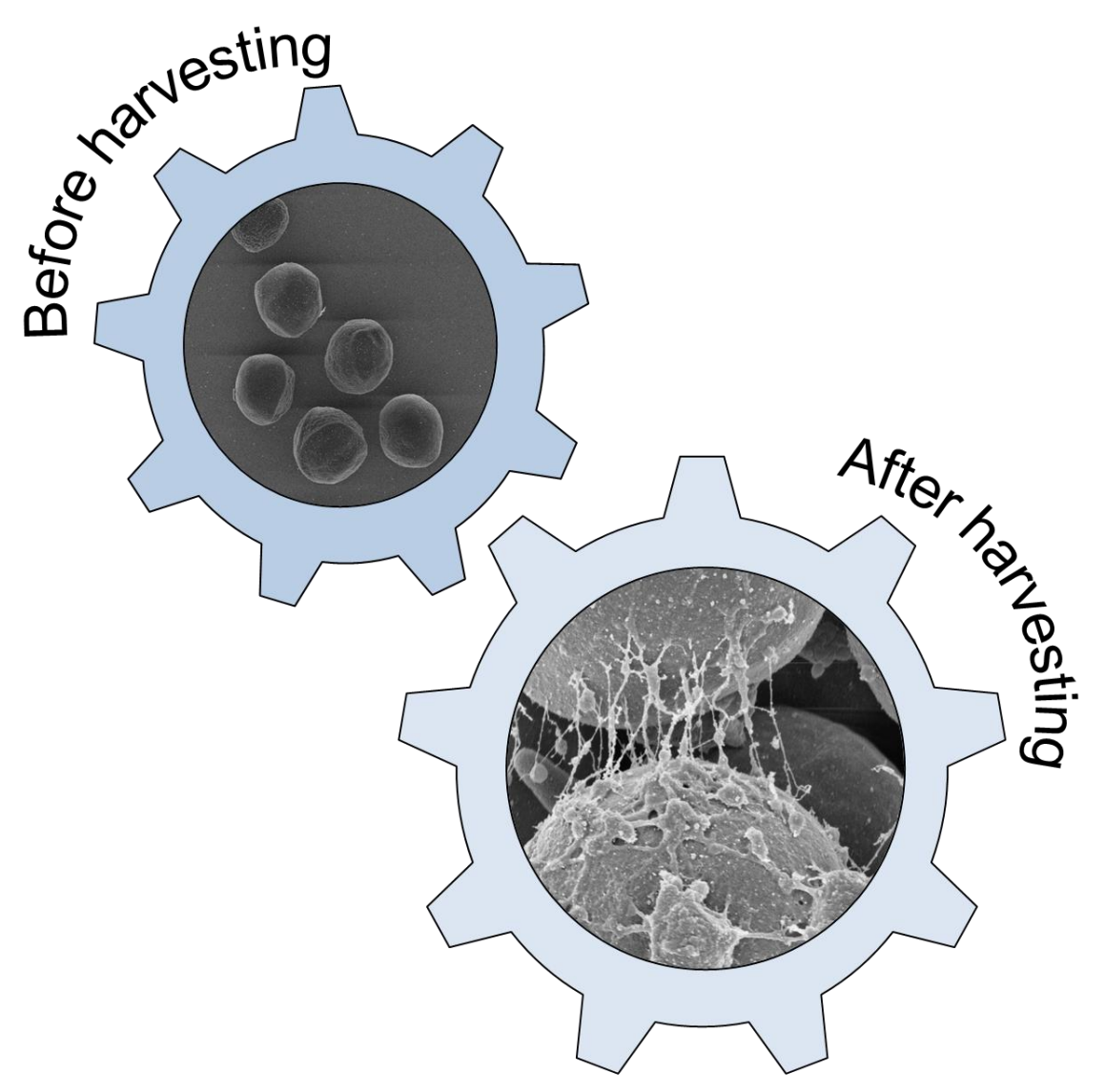





\section{Abstract}

Microalgal flocculation has been regarded as a promising harvesting technique. However flocculation in seawater still is challenging, due to the presence of a surplus of ions in the salt water medium. A screening of polymeric flocculants showed that positive charged polymers can induce flocculation at seawater salinities (Chapter 2).

Increasing the dosage of the flocculants initially had a positive effect on the biomass recovery, but further increasing the dosage resulted in lower recoveries. From this observation, we hypothesized that at exceedingly high dosages of cationic polymeric flocculant an over-coverage of the microalgal cells with the flocculant occurred, causing re-stabilisation of the microalgal suspension. The proposed mechanism has been translated into a mathematical model and validated (Chapter 3). The simulations with the validated model revealed an optimal flocculant dosages of 70 $\mathrm{mg}_{\text {flocculant }} / \mathrm{g}_{\text {biomass }}$ for Neochloris oleoabundans cultivated in seawater (Chapter 3).

At the optimum dosage, the cationic poly(acryl)amides showed biomass recoveries exceeding $90 \%$ at elevated salinities. Other cationic polymers such as Chitosan were substantially less successful. Further investigation revealed that this success was due to differences in the polymeric charge density (Chapter 4).

Considering an assumed cost price for cationic poly(acryl)amides ranging between $€ 3.00$ and $€ 3.56$ per $\mathrm{kg}$ (Wong et al., 2006), the use of flocculants would account for $€ 0.21$ to $€ 0.25$ per $\mathrm{kg}$ of biomass (Chapter 3 ). The costs for applying cationic poly(acryl)amides are thus substantial. In addition, they are not allowed in the foodand feed industry. The insights obtained from our studies should be used for selection or design of cheaper, food grade cationic polymeric flocculants.

\section{Presented as:}

't Lam, G.P., Vermuë, M.H, Olivieri, G., Eppink, M.H.M., Wijffels, R.H. (2016) Microalgae flocculation in seawater: from understanding towards application. Oral presentation at the Netherlands Biotechnology Conference: Next level biotechnology (NBC-16), Wageningen the Netherlands. 



\section{chapter 2}

Cationic polymers for successful flocculation of marine microalgae

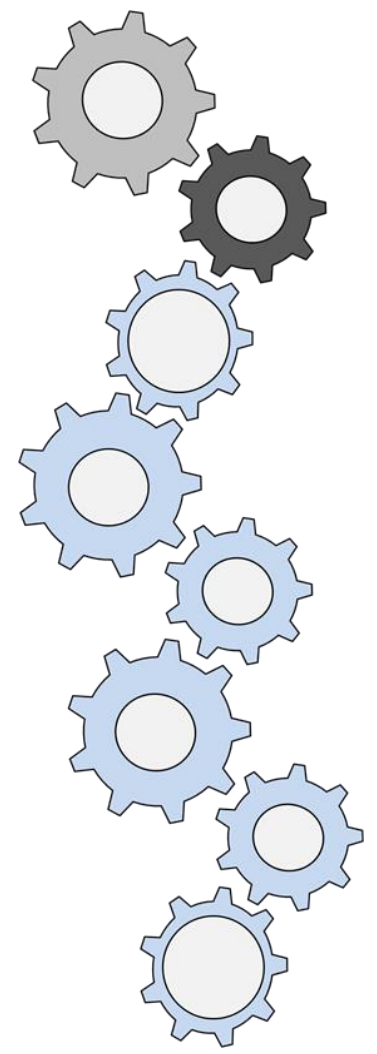

\section{Published as:}

't Lam, G. P., M. H. Vermuë, G. Olivieri, L. A. M. van den Broek, M. J. Barbosa, M. H. M. Eppink, R. H. Wijffels and D. M. M. Kleinegris (2014) Cationic polymers for successful flocculation of marine microalgae. Bioresour. Technol. 169: 804-807. 
locculation of microalgae is a promising technique to reduce the costs and energy required for harvesting microalgae. Harvesting marine microalgae requires suitable flocculants to induce the flocculation under marine conditions. This study demonstrates that cationic polymeric flocculants can be used to harvest marine microalgae. Different organic flocculants were tested to flocculate Phaeodactylum tricornutum and Neochloris oleoabundans grown under marine conditions. Addition of $10 \mathrm{ppm}$ of the commercial available flocculants Zetag 7557 and Synthofloc $5080 \mathrm{H}$ to $P$. tricornutum showed a recovery of, respectively, $98 \pm 2.0 \%$ and $94 \% \pm 2.9$ after flocculation followed by $2 \mathrm{~h}$ sedimentation. Using the same flocculants and dosage for harvesting $N$. oleoabundans resulted in a recovery of $52 \% \pm 1.5$ and $36 \% \pm 11.3$. This study shows that cationic polymeric flocculants are a viable option to pre-concentrate marine cultivated microalgae via flocculation prior to further dewatering. 


\section{Introduction}

Over the years, microalgae have been regarded as one of the most promising resources for various bulk commodities like lipids, proteins and other chemicals (Wijffels \& Barbosa, 2010; Wijffels et al., 2010). Before marine microalgae can be successfully implemented as a resource for bulk commodities, major hurdles need to be overcome in both cultivation and biorefinery of microalgae.

One of the major bottlenecks in the production of microalgal-based bulk commodities is the harvesting of microalgae. Due to the small cell sizes and low biomass concentrations, conventional harvesting methods like filtration and centrifugation require high amounts of energy and are therefore cost-intensive (Salim et al., 2011). As an alternative, flocculation has been identified as a low-cost harvesting technology. Salim et al. (2012) reported that flocculation in combination with sedimentation using bioflocculants can reduce the energy demand of centrifugation from 13.8 MJ kg/DW up to 1.34 MJ kg/DW (Salim et al., 2012).

To induce flocculation, two types of flocculants can be distinguished: organic and inorganic flocculants (Vandamme et al., 2013). Most of the studies reported in literature showed that induced flocculation was only successful for freshwater species (Vandamme et al., 2013), while flocculation of microalgae from marine environments was considered to be not-feasible (Bilanovic et al., 1988; Vandamme et al., 2010; Vandamme et al., 2013).

At marine conditions, ions present in the culture medium can shield the charged sites of both the flocculant and the microalgae (Bilanovic et al., 1988; Şirin et al., 2012) causing ionic hindrance during flocculation (Pushparaj et al., 1993; Vandamme et al., 2013). That makes inorganic flocculants inappropriate flocculants for flocculation of microalgae in marine cultivation medium, because these flocculants only induce flocculation via ionic interactions (charge neutralization or sweeping). Polymeric flocculants are able to conglomerate individual cells by using a combination of two mechanisms: charge neutralization and polymeric bridging. In addition to these charge interactions polymeric bridging may occur circumventing the steric hindrance between microalgae cells. Due to the ability of polymeric bridging next to charge neutralization, the assumption is made that polymeric flocculants have a higher probability to harvest marine microalgae. 
In this study a screening of organic polymeric flocculants was performed to investigate if these flocculants are a viable option to flocculate marine microalgae. The diatom Phaeodactylum tricornutum and the green microalgae Neochloris oleoabundans were selected for this screening study. Both marine microalgal species are regarded as very promising for the production of bulk commodities according to the biorefinery approach (Chauton et al., 2013; Popovich et al., 2012; Silva Benavides et al., 2013).

\section{Materials and methods}

\subsection{Strain selection and cultivation}

The used strains were Phaeodactylum tricornutum CCY0033, kindly provided by the Royal Netherlands Institute for Sea Research, NIOZ and Neochloris oleoabundans UTEX1185.

P. tricornutum was cultivated in artificial seawater: $\mathrm{NaCl}: 437.2 \mathrm{mM} ; \mathrm{MgSO}_{4} .7 \mathrm{H}_{2} \mathrm{O}$ : $26.78 \mathrm{mM} ; \mathrm{MgCl}_{2} .6 \mathrm{H}_{2} \mathrm{O}: 27.55 \mathrm{mM} ; \mathrm{CaCl}_{2} .2 \mathrm{H}_{2} \mathrm{O} 10.20 \mathrm{mM} ; \mathrm{NaNO}_{3}: 20 \mathrm{mM}$; $\mathrm{Na}_{2}$ EDTA. $2 \mathrm{H}_{2} \mathrm{O}: 5.10^{*} 10^{-4} \mathrm{mM}$; $\mathrm{ZnSO}_{4} \cdot 7 \mathrm{H}_{2} \mathrm{O}: 8.93^{*} 10^{-5} \mathrm{mM}$; $\mathrm{CoCl}_{2} \cdot 6 \mathrm{H}_{2} \mathrm{O}: 4.20^{*} 10^{-5}$ $\mathrm{mM} ; \mathrm{MnCl}_{2} 2 \mathrm{H}_{2} \mathrm{O}: 9.14^{*} 10^{-4} \mathrm{mM} ; \mathrm{Na}_{2} \mathrm{MoO}_{4} 2 \mathrm{H}_{2} \mathrm{O}: 1.40^{*} 10^{-4} \mathrm{mM} ; \mathrm{CuSO}_{4} \cdot 5 \mathrm{H}_{2} \mathrm{O}$ : $4.01 * 10^{-5} \mathrm{mM}$; EDTA-Fe(III)-Na-Salt: $1.17^{*} 10^{-2} \mathrm{mM} ; \mathrm{K}_{2} \mathrm{HPO}_{3}: 0.746 \mathrm{mM} ; \mathrm{KH}_{2} \mathrm{PO}_{4}$ : 0.294mM; HEPES: $50.02 \mathrm{mM}$ and $\mathrm{NaHCO}_{3}: 9.99 \mathrm{mM}$.

$N$. oleoabundans was also cultivated in artificial seawater with the composition: $\mathrm{NaCl}$ : 448.3 mM; $\mathrm{KNO}_{3}$ : 16.8 mM; $\mathrm{Na}_{2} \mathrm{SO}_{4}$ : 3.5 mM; HEPES: $100.1 \mathrm{mM} ; \mathrm{MgSO}_{4} .7 \mathrm{H}_{2} \mathrm{O}: 5.0$ $\mathrm{mM} ; \mathrm{CaCl}_{2} .2 \mathrm{H}_{2} \mathrm{O}: 2.4 \mathrm{mM} ; \mathrm{K}_{2} \mathrm{HPO}_{4}: 2.5 \mathrm{mM} ; \mathrm{Na}_{2} \mathrm{EDTA} .2 \mathrm{H}_{2} \mathrm{O}: 0.08 \mathrm{mM} ; \mathrm{MnCl}_{2} .4 \mathrm{H}_{2} \mathrm{O}$ : $0.02 \mathrm{mM} ; \mathrm{ZnSO}_{4} .7 \mathrm{H}_{2} \mathrm{O}: 0.004 \mathrm{mM} ; \mathrm{CoCl}_{2} .6 \mathrm{H}_{2} \mathrm{O}: 0.001 \mathrm{mM} ; \mathrm{CuSO}_{4} .5 \mathrm{H}_{2} \mathrm{O}: 0.001 \mathrm{mM}$; $\mathrm{Na}_{2} \mathrm{MoO}_{4} \cdot 2 \mathrm{H}_{2} \mathrm{O}: 0.0001 \mathrm{mM}$; NaFeEDTA: $0.028 \mathrm{mM}$.

Both strains were cultivated in fully controlled photobioreactors under constant conditions at a temperature of $25{ }^{\circ} \mathrm{C}$ and $\mathrm{pH} 7.5$ using $\mathrm{CO}_{2}$ sparging. Daily fresh microalgae were obtained from the cultivation system and used to perform the flocculation experiments.

\subsection{Flocculants}

The flocculants were grouped according to their charge properties into non-ionic, anionic and cationic organic flocculants . The used non-ionic flocculants were: $22 \mathrm{~N}$, 
H22N (kindly provided by SNF-Floerger) and Magnafloc 351 (a gift from BASF). The anionic flocculants were: H51, H53, H57, H149 and H159 (SNF-Floerger) and VAMFloc 106 (Van Antwerpen Milieutechniek BV). Finally, the cationic flocculants were: H522, H524, H528, H536, H538 (SNF-Floerger); Synthofloc 5080H (Sachtleben Wasserchemie), Zetag 7557 (BASF), the cationic starch Greenfloc 120 (Hydra 2002), the polysaccharide chitosan (Aldrich) and VAMfloc 704 (Van Antwerpen Milieutechniek BV).

A stock solution of 1000 ppm was prepared in de-ionized water of each flocculant. Except for chitosan, this was dissolved overnight in $0.1 \%(\mathrm{v} / \mathrm{v})$ acetic acid and subsequently the $\mathrm{pH}$ was adjusted to $\mathrm{pH} 7$ and 9. For both VAMFloc 106 and VAMFloc 704 a freshly prepared $0.1 \%(\mathrm{w} / \mathrm{v})$ stock solution was made: Therefor, the flocculant $(0.1 \mathrm{~g})$ was added into a small amount of water and was dissolved under intensive mixing. After dissolving the flocculant, de-ionized water was added up to a final volume of $100 \mathrm{~mL}$. After 1 hour of mixing the stock solution was ready for use.

\subsection{Flocculation and sedimentation experiments}

The flocculant was added up to a final concentration of $10 \mathrm{ppm}$, except for chitosan. For testing chitosan, a concentration of 40 ppm was applied. Next, the algae suspension was severely mixed for 5 min at a stirring speed of $700 \mathrm{rpm}$ using a magnetic stirrer. After 5 minutes of mixing, duplicate samples of $5 \mathrm{~mL}$ of the homogeneous suspension were transferred into pre-weighed $15 \mathrm{~mL}$ tubes and the biomass was allowed to settle for two hours at room temperature. Afterwards, the supernatant and pellet were separated using pipetting. The pellet was re-suspended in the same volume as the collected supernatant. The $O D_{750}$ of the supernatant was determined and used to calculate the biomass recovery (\%).

For the optical densities analysis, a Hach Lange DR5000 photometer was used with Sarstedt acryl cuvettes. Based on the difference in optical density between the initial $P$. tricornutum suspension $\left(\mathrm{OD}_{750} 3.6 \pm 0.7\right)$ and the supernatant, the recovery was calculated according to Salim et al. 2011 (Salim et al., 2011):

$\operatorname{Recovery}(\%)=\frac{O D_{750(\mathrm{t} 0)}-O D_{750\left(t_{\text {supernatant }}\right)}}{O \mathrm{D}_{750(\mathrm{t} 0)}} * 100$ 
Also the weight of the pellet and the initial suspension were determined. The concentration factor was calculated using the weight of the initial suspension and the weight of the pellet:

Concentration factor $(C F)=\frac{M_{\text {initial suspension }(\text { gram })}}{M_{\text {pellet }}(\text { gram })}$

In this expression the assumption is made that the density of all the fractions are equal to water. In combination with the provided biomass recovery and the initial biomass recovery it is also possible to calculate the amount of biomass that is present in the pellet

To compare the results obtained with $P$. tricornutum with other marine microalgae, additional experiments with $N$. oleoabundans cultivated under marine conditions were performed. The flocculation experiments with $N$. oleoabundans were performed with an initial optical density of $\mathrm{OD}_{750} 0.7 \pm 0.1$. Here, Zetag 7557 and Synthofloc $5080 \mathrm{H}$ were added to the algal suspension at a dosage of $10 \mathrm{ppm}$. After 5 minutes of severe mixing at $500 \mathrm{rpm}, 10$ minutes of gentle mixing at $100 \mathrm{rpm}$ was applied to keep the algal flocs in suspension. Afterwards the suspension was pipetted in $4 \mathrm{~mL}$ cuvettes and the photometric method of Salim et al. (Salim et al., 2012) was used to follow the biomass recovery over time in a Beckmann Coulter DU730 photometer. 


\section{Results and discussion}

\subsection{Flocculation using non-ionic and anionic flocculants}

At a concentration of $10 \mathrm{ppm}$, the non-ionic flocculants ' $22 \mathrm{~N}, \mathrm{H} 22 \mathrm{~N}$ and Magnafloc 351 ' and the anionic flocculants 'H53, H57, H149, H159 and VAMFloc 106' showed a recovery and concentration factor that was similar to the results obtained without addition of the flocculant (data not shown). This reveals that both non-ionic and anionic flocculants cannot be applied for harvesting P. tricornutum. Granados et al. (2012) reported that non-ionic and anionic flocculants were also not suitable for flocculation of the freshwater microalgae Chlorella vulgaris, Chlorella fusca, Scenedesmus subspicatus and Scenedesmus sp. (Granados et al., 2012). In the same study was reported that cationic polymeric flocculants were successful in harvesting microalgae (Granados et al., 2012). Granados et al. also reported that with an increasing charge density or molecular weight the recovery with cationic polymeric flocculants was increasing (Granados et al., 2012). Tenney et al. obtained similar results using a mixed freshwater culture using a sedimentation time of 1 hour (Tenney et al., 1969). Tenney et al. suggested that flocculation is hindered by the electrostatic interactions between the negatively charged groups of the anionic polymeric flocculants and the negative charged cell wall of microalgae. In addition, the negative charged cell surface seems to prevent flocculants to approach the microalgal cells and to form polymeric bridges (Tenney et al., 1969).

\subsection{Flocculation using cationic polymeric flocculants}

Biomass recoveries higher than $80 \%$ were obtained when the suspension of $P$ tricornutum was mixed with cationic polymeric flocculants (Figure 2.1). These biomass recoveries are similar or higher than the biomass recoveries that Farid et al. (2013) obtained with chitosan and nano-chitosan at pH 7 to harvest Nannochloropsis sp. (Farid et al., 2013). Exceptions were the cationic starch Greenfloc 120 (data not shown) and H522. Greenfloc 120 had a biomass recovery similar to microalgae without flocculant. With $\mathrm{H} 522$ a biomass recovery of $31 \%$ was obtained. Application of the different cationic polymeric flocculants resulted in large differences in concentration factors. All flocculants, except the polysaccharide chitosan at $\mathrm{pH} 7$ and 9 showed a concentration factor equal or higher than 3.5. The highest concentration factor (14.1) was obtained using VAMfloc 704. 


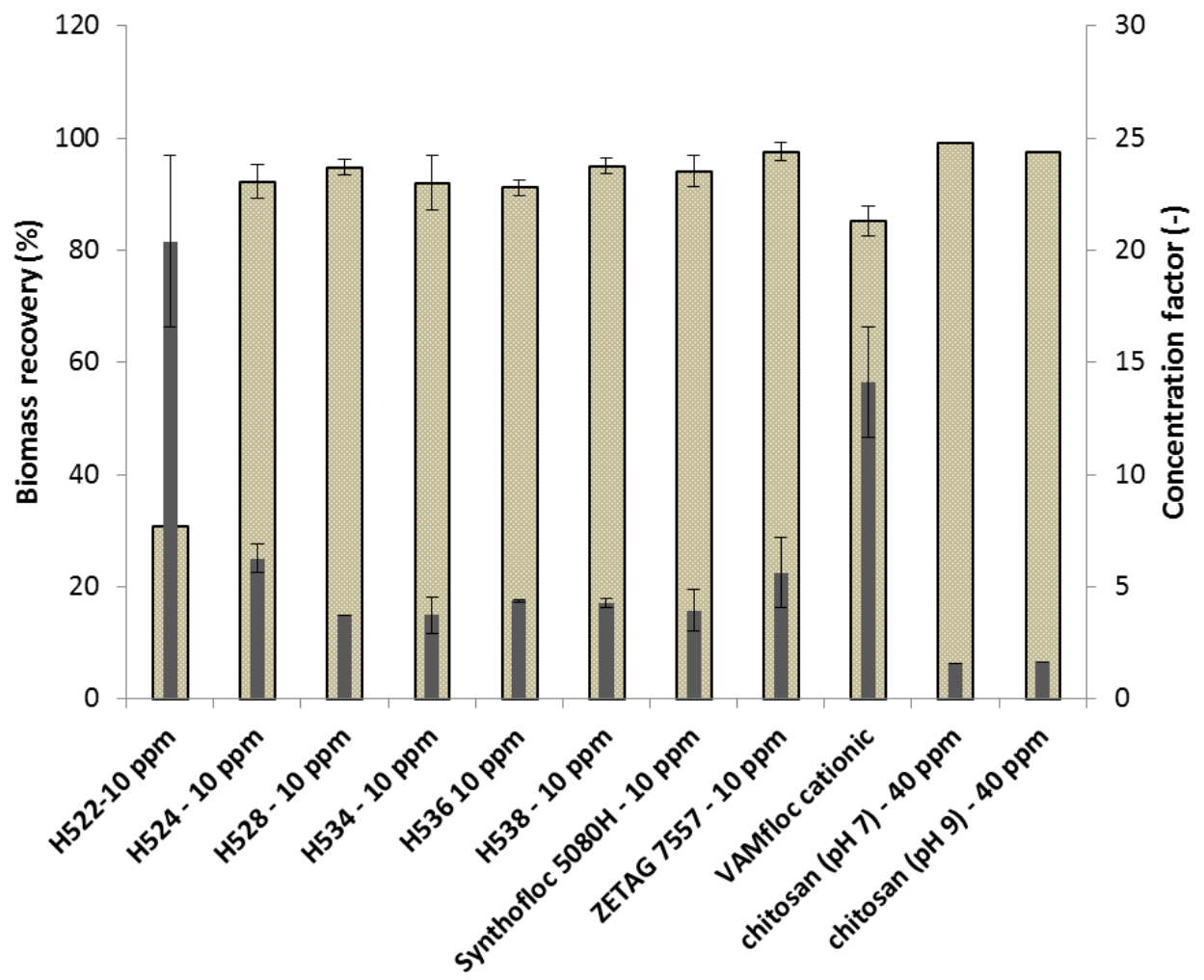

Figure 2.1: Biomass recoveries of Phaeodactylum tricornutum (light brown bars) and concentration factors (small, dark grey bars) after induced flocculation with cationic flocculants. All experiments were performed in duplicate except the recovery of $\mathrm{H} 522$, the complete experiment with chitosan at $\mathrm{pH} 7$ and 9 (single tests) and the complete experiment with Zetag 7557 (triplicate).

The obtained recoveries and concentration factors confirm that cationic charged polymers induce floc formation. The negative charge of the cell wall is neutralized by the cationic groups, causing destabilization and the possibility to form polymeric bridges (Vandamme et al., 2010), (Salim et al., 2014). These results in combination with the results obtained with the anionic and non-ionic flocculants underline the hypothesis that indeed both polymeric bridging and charge neutralization are involved in flocculation using cationic polymers (Henderson et al., 2008; Vandamme et al., 2013). The lack of functionality of Greenfloc 120 and H522 may be caused due to coiling of the polymers in marine conditions, leading to a lower functionality (Bilanovic et al., 1988; Şirin et al., 2012). 
The results show that cationic polymeric flocculants are a promising type of flocculant to harvest the marine microalgae $P$. tricornutum.

To investigate if these cationic polymers can be used to harvest other marine species as well, Zetag 7557 and Synthofloc $5080 \mathrm{H}$ were tested as flocculant for flocculation and subsequent sedimentation of $N$. oleoabundans (Figure 2.2). A biomass recovery of $52 \% \pm 1.5$ and $36 \% \pm 11.2$ was obtained when applying 10 ppm Zetag 7557 and Synthofloc $5080 \mathrm{H}$, respectively. Although the recovery of $N$. oleoabundans is lower than in the case when $P$. tricornutum was used, our results illustrate that these cationic polymeric flocculants are suitable candidates to flocculate and harvest the diatom $P$. tricornutum and the chlorophyta $N$. oleoabundans cultured at marine conditions.

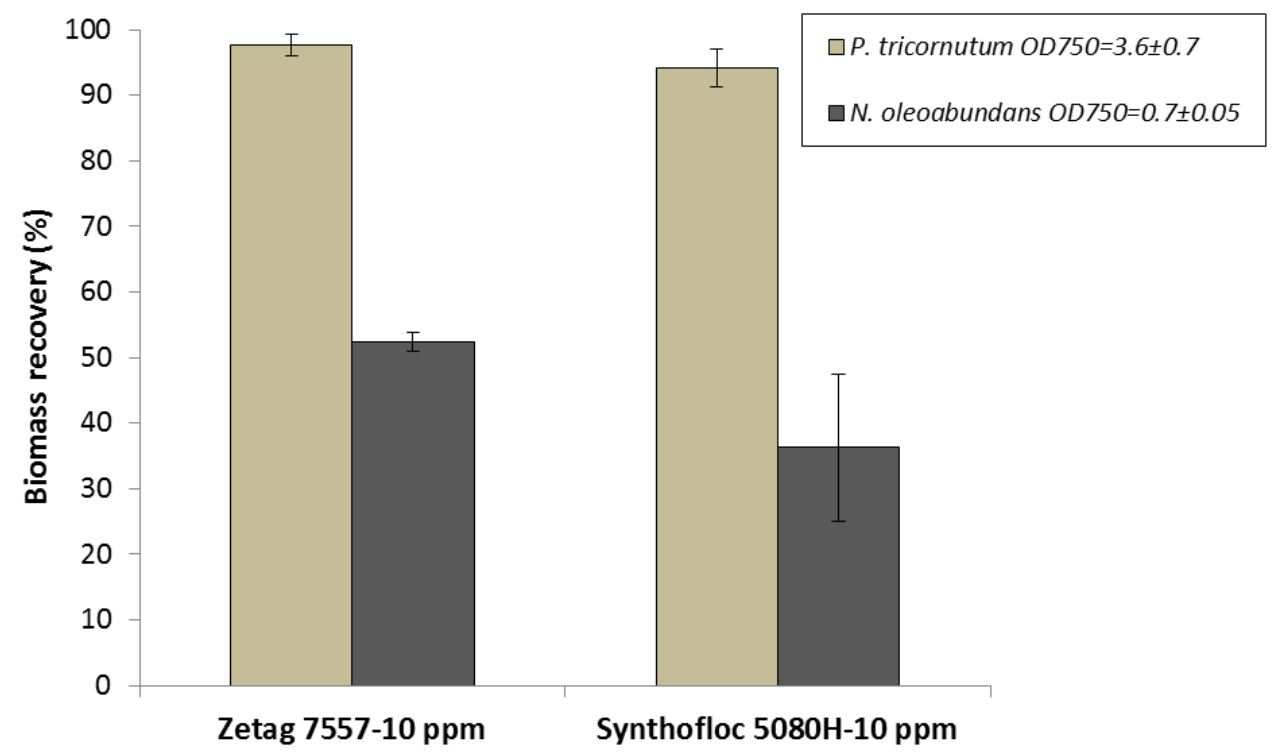

Figure 2.2: Comparison of biomass recovery between Phaeodactylum tricornutum and Neochloris oleoabundans using two different cationic polymeric flocculants at a dosage of $10 \mathrm{ppm}$.

A literature study revealed that cationic polymeric flocculants were used before for harvesting marine microalgae (Table 2.1). 
Table 2.1: Summary of marine microalgal species that have been reported to be successfully harvested by using cationic polymeric flocculants.

\begin{tabular}{|c|c|c|c|c|c|c|}
\hline $\begin{array}{l}\text { Microalgal } \\
\text { species }\end{array}$ & & flocculant & $\mathrm{pH}$ & $\begin{array}{l}\text { maximum } \\
\text { recovery }\end{array}$ & $\begin{array}{l}\text { flocculant } \\
\text { dosage }\end{array}$ & reference \\
\hline $\begin{array}{l}\text { Nannochloropsis } \\
\text { sp. }\end{array}$ & marine & $\begin{array}{l}\text { chitosan at pH9, } \\
\text { nano-chitosan }\end{array}$ & 9 & $90 \%$ and $97 \%$ & $\begin{array}{l}100 \mathrm{mg} / \mathrm{L} \text { and } \\
60 \mathrm{mg} / \mathrm{L}\end{array}$ & $\begin{array}{l}\text { Farid et al. } \\
\text { (2013) }\end{array}$ \\
\hline Isochrysis galbana & marine & $\begin{array}{l}\text { Chitosan, Zetag } \\
63 \text {, Zetag } 92\end{array}$ & 7.5 & $\begin{array}{l}\text { between } 65 \% \\
\text { and } 95 \%\end{array}$ & 5 and $15 \mathrm{mg} / \mathrm{L}$ & $\begin{array}{l}\text { Bilanovic et } \\
\text { al. (1988) }\end{array}$ \\
\hline $\begin{array}{l}\text { Chlorella } \\
\text { stimatophora }\end{array}$ & marine & $\begin{array}{l}\text { Chitosan, Zetag } \\
63 \text {, Zetag } 93\end{array}$ & 7.5 & $\begin{array}{l}\text { between } 65 \% \\
\text { and } 95 \%\end{array}$ & 5 and $15 \mathrm{mg} / \mathrm{L}$ & $\begin{array}{l}\text { Bilanovic et } \\
\text { al. (1988) }\end{array}$ \\
\hline $\begin{array}{l}\text { Chaetorceros } \\
\text { calcitrans }\end{array}$ & marine & $\begin{array}{l}\text { Magnafloc }^{\circledR} \text { LT } \\
25 \text { and Chitosan }\end{array}$ & $\begin{array}{l}10.3 \\
\text { and } 8\end{array}$ & $98 \%$ and $83 \%$ & $\begin{array}{l}0.1 \mathrm{mg} / \mathrm{L} \text { and } \\
20 \mathrm{mg} / \mathrm{L}\end{array}$ & $\begin{array}{l}\text { Harith et al. } \\
\text { (2009) }\end{array}$ \\
\hline $\begin{array}{l}\text { Phaeodactylum } \\
\text { tricornutum }\end{array}$ & marine & $\begin{array}{l}\text { various cationic } \\
\text { polymers }\end{array}$ & 7.5 & up to $98 \% \pm 2$ & $10 \mathrm{mg} / \mathrm{L}$ & this study \\
\hline $\begin{array}{l}\text { Neochloris } \\
\text { oleoabundans }\end{array}$ & marine & Zetag 7557 & 7.5 & up to $52 \% \pm 1.5$ & $10 \mathrm{mg} / \mathrm{L}$ & this study \\
\hline
\end{tabular}

Four other marine microalgal species were reported to be successfully harvested when applying cationic polymeric flocculants (Table 1.1). This confirms that cationic polymeric flocculants are a viable method to harvest marine microalgae However, in the study of Bilanovic et al. (1988) salinity levels lower than $5 \mathrm{~g} / \mathrm{L}$ were applied. The study of Bilanovic et al. (1988) and this study, are the only studies that did not use cationic polymeric flocculants in combination with an elevated $\mathrm{pH}$. Earlier studies showed that solely a pH increase also can induce microalgal flocculation (Spilling et al., 2011). Table 2.1 also showed that the lowest flocculant dosage is obtained in this study. 


\section{Conclusions}

Our results show that cationic polymeric flocculants can be successfully applied for harvesting two different marine microalgae. With the diatom $P$. tricornutum as well as with the relatively small green microalga $N$. oleoabundans high biomass recoveries were obtained after 2 hours of sedimentation. Flocculation and sedimentation of marine microalgae using cationic polymeric type of flocculants may be a viable alternative for conventional harvesting methods like centrifugation and filtration.

\section{Acknowledgement}

Part of this research was carried out within the EU project InteSusAI. InteSusAl has received funding from the European Union's Seventh Programme for research, technological development and demonstration under grant agreement No 268164 . Part of this work is performed within the TKI AlgaePARC Biorefinery program with financial support from the Netherlands' Ministry of Economic Affairs in the framework of the TKI BioBased Economy under contract nr. TKIBE01009. The authors thank in particular TKI AlgaePARC Biorefinery consortium partner BASF for kindly providing the flocculant Zetag 7557. The authors thank M. van Vuuren and R. Barten for their contributions. 



\section{Chapter 3}

Dosage effect of cationic polymers on the flocculation efficiency of the marine microalga Neochloris oleoabundans

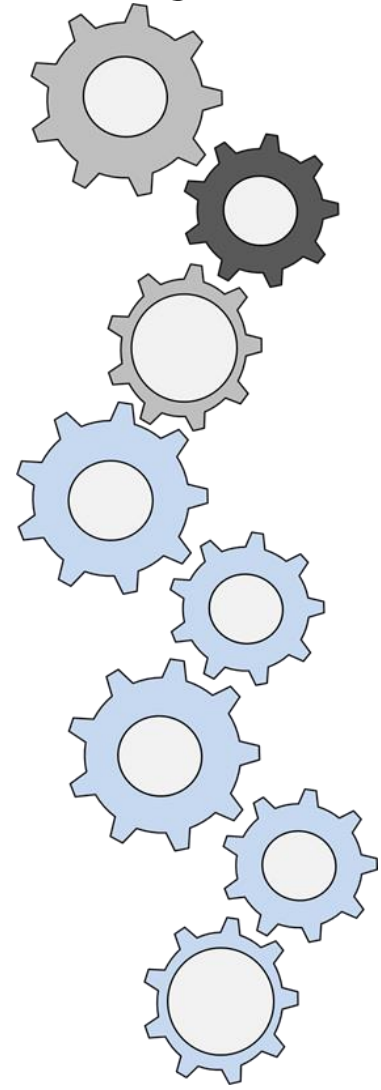

Published as:

't Lam G. P., Zegeye E. K., Vermuë M .H., Kleinegris D. M .M., Eppink M. H. M., Wijffels R. H., Olivieri G. (2015) Dosage effect of cationic polymers on the flocculation efficiency of the marine microalga Neochloris oleoabundans, Bioresour. Technol. 198: 797-802. 

mechanistic mathematical model was developed to predict the performance
of cationic polymers for flocculating salt water cultivated microalgae. The
model was validated on experiments carried out with Neochloris oleoabundans and three different commercial flocculants (Zetag $7557^{\circledR}$, Synthofloc $5080 \mathrm{H}^{\circledR}$ and SNF $\mathrm{H} 536^{\circledR}$ ). For a wide range of biomass concentrations (0.49-1.37 $\mathrm{g}$ $\left.\mathrm{L}^{-1}\right)$ and flocculant dosages $\left(0-150 \mathrm{mg} \mathrm{L}^{-1}\right)$ the model simulations predicted well the optimal flocculant-to-biomass ratio between 43 to $109 \mathrm{mg}_{\text {flocculant }} / \mathrm{g}_{\text {biomass }}$. At optimum conditions biomass recoveries varied between $88 \%$ and $99 \%$. The cost of the usage of commercial available flocculants is estimated to range between $0.15 \$ / \mathrm{kg}_{\text {biomass }}$ and $0.49 \$ / \mathrm{kg}_{\text {biomass. }}$ 


\section{Introduction}

In microalgae cultivation and processing, harvesting using conventional centrifugation and filtration is energy demanding and expensive (Schenk, et al. 2008, Salim et al. 2011, Salim et al. 2012, Milledge and Heaven 2013). Centrifugation of a $0.5 \mathrm{~g}$ Dw/L suspension using a conventional disk-stack centrifuge for example, requires up to $13.8 \mathrm{MJ} / \mathrm{kg}_{\mathrm{DW}}$ (Salim et al. 2012). Induced flocculation has been proposed as an effective way for reducing the energy cost considerably (Uduman et al. 2010, Vandamme et al. 2013). By using flocculation as treatment prior to further centrifugation, a 10-fold energy reduction for harvesting the microalgae can be obtained (Salim et al. 2012).

In previous studies, already a variety of flocculants has been tested on microalgae (Vandamme et al. 2013). Flocculation of algae from a marine medium, however, is challenging as ions present in the culture medium shield the flocculant from interaction with microalgae and hinder floc formation (Pushparaj et al. 1993, Uduman et al. 2010, Vandamme et al. 2013). Recently, 't Lam et al. (2014) described the use of cationic polymers for flocculation of marine microalgae. It is described in literature that a microalgal suspension of single cells is stable due to the repulsive forces induced by the charges present on the cell wall (Vandamme et al. 2013). We suggested that the success of cationic polymeric flocculants can be attributed to the ability of these flocculants to interact with individual cells and induce floc formation. Flocs are formed because the cationic groups of the polymeric flocculant adsorb to the negative charged wall of stable cells. The final effect is the destabilisation of the cell suspension (Zahrim 2010, Uduman et al. 2010, Granados et al. 2012, Vandamme et al. 2013). Consequently, both the flocculant and biomass concentrations must affect the performance of flocculation.

The goal of the present study is to characterise and predict this effect of the flocculant dosage on the final biomass recovery obtained after flocculation. Based on experimentally obtained results, a mathematical model is developed to predict the optimal flocculant dosage required at different biomass concentrations. To test and validate the model three different commercially available cationic polymeric flocculants were used to flocculate $N$. oleoabundans cultivated under marine conditions. 


\section{Materials and methods}

\subsection{Microalgal strain and cultivation}

Neochloris oleoabundans UTEX1185 was cultivated in salt water medium. The composition of the medium was: $\mathrm{NaCl}: 448.3 \mathrm{mM} ; \mathrm{KNO}_{3}: 16.8 \mathrm{mM} ; \mathrm{Na}_{2} \mathrm{SO}_{4}: 3.5 \mathrm{mM}$; HEPES: $100.1 \mathrm{mM}$; $\mathrm{MgSO}_{4} .7 \mathrm{H}_{2} \mathrm{O}: 5.0 \mathrm{mM}$; $\mathrm{CaCl}_{2} .2 \mathrm{H}_{2} \mathrm{O}: 2.4 \mathrm{mM} ; \mathrm{K}_{2} \mathrm{HPO}_{4}: 2.5 \mathrm{mM}$; $\mathrm{Na}_{2}$ EDTA. $2 \mathrm{H}_{2} \mathrm{O}: 80 \mu \mathrm{M} ; \mathrm{MnCl}_{2} .4 \mathrm{H}_{2} \mathrm{O}: 20 . \mu \mathrm{M} ; \mathrm{ZnSO}_{4} .7 \mathrm{H}_{2} \mathrm{O}: 4.0 \mu \mathrm{M} ; \mathrm{CoCl}_{2} .6 \mathrm{H}_{2} \mathrm{O}: 1.0$ $\mu \mathrm{M}$; CuSO ${ }_{4} .5 \mathrm{H}_{2} \mathrm{O}: 1.0 \mu \mathrm{M} ; \mathrm{Na}_{2} \mathrm{MoO}_{4} .2 \mathrm{H}_{2} \mathrm{O}: 0.1 \mu \mathrm{M}$; NaFeEDTA: $28 \mu \mathrm{M}$. Constant supply of fresh biomass was ensured by cultivation of the microalgae in an Applikon 2L fermentor (Applikon, the Netherlands), operated at chemostat conditions. Continuous stirring at $175 \mathrm{rpm}$ and air sparging at a flow of $7 \mathrm{~L} / \mathrm{min}$ was applied. The temperature was controlled at $25 \pm 0.1^{\circ} \mathrm{C}$ and the $\mathrm{pH}$ was kept at 7.5 by $\mathrm{CO}_{2}$ supply. The reactor was continuously illuminated with LED lamps at $625 \mathrm{~nm}$ with an average incident light intensity of $244 \mu \mathrm{mol} \cdot \mathrm{m}^{-2} \cdot \mathrm{s}^{-1}$. The microalgae were collected in a dark harvesting vessel and stored at $4{ }^{\circ} \mathrm{C}$ for one day before the flocculation experiments were performed.

The biomass concentration in the reactor was monitored via daily analysis of the optical density at $750 \mathrm{~nm}$. At various moments, samples were taken. The biomass dry weight of these samples was determined according to Lamers et al. (2010). Using these biomass concentrations, an $\mathrm{OD}_{750}$ versus $\mathrm{DW}$ curve was made for determination of the biomass concentrations based on the $\mathrm{OD}_{750}$.

\subsection{Flocculants}

The polymeric flocculants Zetag $7557^{\circledR}$ (provided BASF, Germany), Synthofloc $5080 \mathrm{H}^{\circledR}$ (provided by Sachtleben, Germany) and SNF H536 ${ }^{\circledR}$ (SNF-Floerger, France) were used. These flocculants are often used in the wastewater industry (Renault et al. 2009). All the flocculants are commercial available polyacrylamide-based flocculants with quoted high cationic charge density and polymer length. Stock solutions (1000 ppm) of each flocculant were made in de-ionized (Milli- $\left.Q^{\circledR}\right)$ water and stored in the dark at $4{ }^{\circ} \mathrm{C}$. 


\subsection{Flocculation tests}

In this study a standard flocculant mixing protocol was used (Bilanovic et al. 1988, Divakaran and Pillai 2002, Vandamme et al. 2010, Granados et al. 2012). $10 \mathrm{ml}$ homogeneous samples were taken in duplicate at an optical density $\mathrm{OD}_{750}$ of: $0.70 \pm$ 0.1 . This $O D_{750}$ corresponds with a biomass concentration of $D W$ of $0.46 \pm 0.06 \mathrm{~g} / \mathrm{L}$. The samples were transferred into a beaker glass and stirred using a magnetic stirrer at a stirring speed of $500 \mathrm{rpm}$. Flocculant was added from the stock solutions to the stirred suspension using pipetting at a dosage that varied between 0 and 100 ppm. After addition of the flocculant, the mixture of biomass and flocculant was stirred for 5 minutes at a stirring speed of $500 \mathrm{rpm}$ and subsequently gently mixed at $100 \mathrm{rpm}$ for 10 minutes.

After mixing, $4 \mathrm{ml}$ samples were transferred into $4 \mathrm{ml}$ polystyrene cuvettes (10x10x45 $\mathrm{mm}$, Sarstedt AG\&Co). During the 2 hours sedimentation time the $\mathrm{OD}_{750}$ was measured in the upper layer of the cuvette at 20 seconds intervals. The recovery was calculated according to (Salim, et al. 2011):

$\operatorname{Recovery}(\%)=\frac{O D_{750}\left(t_{0}\right)-O D_{750}(\mathrm{t})}{O D_{750}\left(t_{0}\right)} * 100$

\subsection{Modelling and parameter determination}

The computational scripts for the mathematical model were made in Mathworks Matlab 2013a. The model has three variable input parameters: biomass concentration, flocculant dosages and cell diameter. The variable input parameters were experimentally determined. To convert the optical density $O D_{750}$ to the particles concentration (number of particles $/ \mu \mathrm{L}$ ), a conversion factor is needed. This conversion factor was determined using cell counting with a Coulter counter (Multisizer 3, Beckman). All the experiments were performed in both technical and biological duplicates.

To determine the diameter of the $N$. oleoabundans cells, the Coulter counter (Multisizer 3, Beckman) was used according to the method described by de Winter et al. (2013). 
Next to the input parameters, the model also has four different collision rate constants. These constants were fitted using a sum of squared errors method with the experimentally results obtained with the cationic polymers Zetag 755 and, SNF H536 at a flocculant dosage ranging between 0 to $100 \mathrm{ppm}$ and a fixed initial biomass concentration of $0.46 \pm 0.06 \mathrm{~g} / \mathrm{L}$.

\subsection{Model validation}

After determining the kinetic parameters by fitting the model on the experimental data obtained with two flocculants (Zetag 7557 and SNF H536), model simulations were first compared with the experimental data obtained with a third flocculant (Synthofloc $5080 \mathrm{H})$ at the same biomass concentrations and flocculant dosages $(0.46 \pm 0.06 \mathrm{~g} / \mathrm{L}$ and flocculant dosage ranging between 0 and 100 ppm).

After this initial validation, flocculation experiments were performed at higher biomass concentrations for all three different flocculants. The used flocculant dosages were 50, 100 and 150 ppm and the used biomass concentrations were 0.46; 0.91 and 1.37 $\mathrm{g} / \mathrm{L}\left(\mathrm{OD}_{750}\right.$ of $0.8,1.6$ and 2.4$)$ resulting in 9 experimental points per flocculant. The 27 experimental points were compared with the predicted biomass recoveries using the model. The relative error between the experimental data and the predicted biomass recoveries were calculated:

$\partial_{x}(\%)=\frac{R_{\text {experimental }}-R_{\text {predicted }}}{R_{\text {experimental }}} * 100$

\section{Results and Discussion}

\subsection{Effect of the flocculant dosage on the biomass recovery}

Based on the results of the screening of polymeric flocculants two cationic polymeric flocculants were selected for further study on predicting the effect of flocculant dosage on final biomass recovery obtained after flocculation ('t Lam, et al. 2014). The biomass recovery after 2 hours of sedimentation was determined as a function of the flocculant dosage (Figure 3.1). Both flocculants showed a similar trend; a fast increase of biomass recovery is observed upon increasing the flocculant dosage from 
0 to 20 ppm. The biomass recovery is about constant at 20 to $50 \mathrm{ppm}$, followed by a decreased recovery at dosages higher than $50 \mathrm{ppm}$.

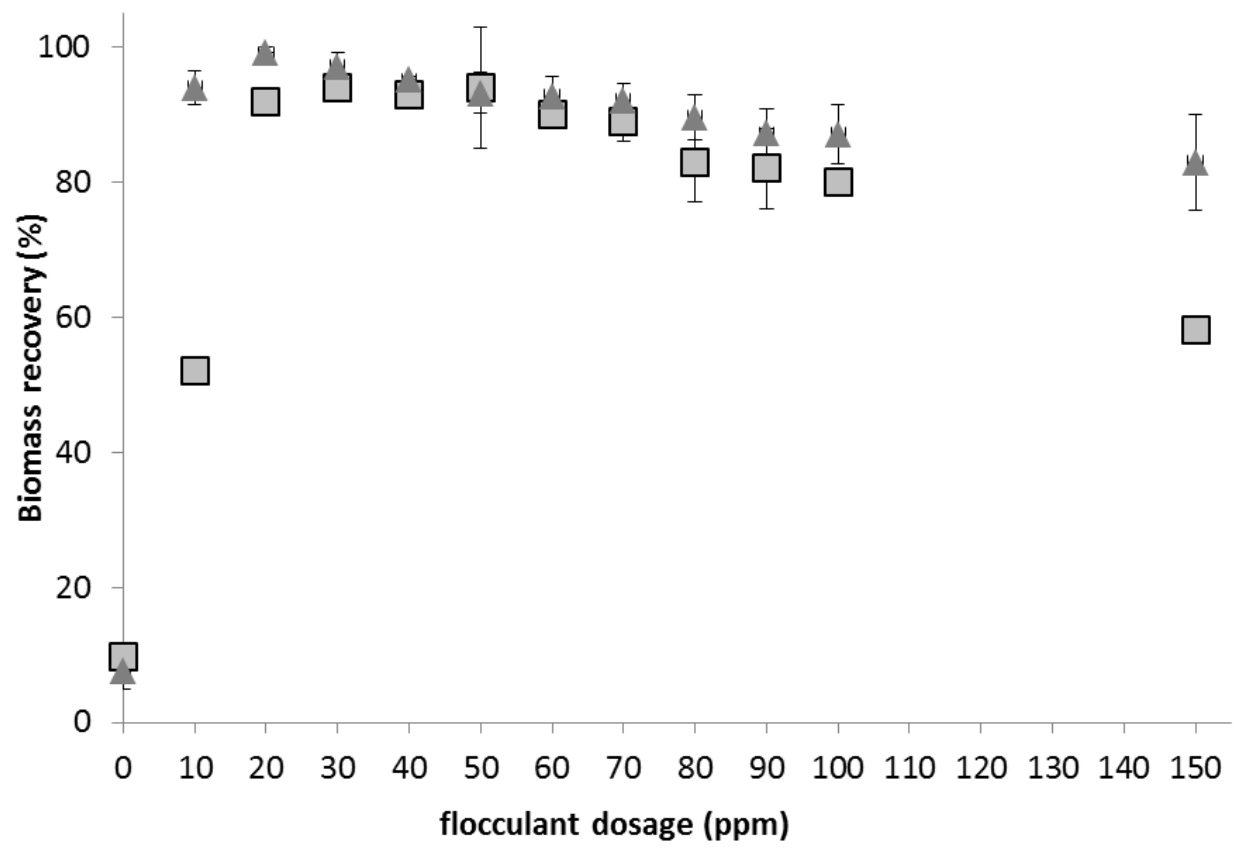

Figure 3.1: Biomass recoveries after 2 hours of sedimentation with Zetag 7557( () ) and SNF H536 ( $\Delta)$. Error bars represent biological replicates $(n=2)$.

At a biomass concentration of $0.46 \mathrm{~g} / \mathrm{L}$, dosages of 20 to $50 \mathrm{ppm}$ represent a dosage range of $43 \pm 0.6 \mathrm{mg}_{\text {flocculant }} / \mathrm{g}_{\text {biomass }}$ and $109 \pm 1.4 \mathrm{mg}_{\text {flocculant }} / \mathrm{g}_{\text {biomass. }}$. The recoveries and dosages in this study are similar to the recoveries obtained by others under freshwater conditions. Vandamme et al. (2010) used cationic starch as a polymeric flocculant to harvest the freshwater species Parachlorella kessleri. After 30 minutes of sedimentation the reported recoveries are higher than $80 \%$ using 167 to $200 \mathrm{mg}_{\text {flocculant }} / \mathrm{g}_{\text {biomass. }}$ Similar recoveries were reported by Banerjee, et al. (2013). In their study synthesized cationic guar gum was used to flocculate the freshwater algae Chlorella sp. at an initial biomass concentration of $0.78 \mathrm{~g} / \mathrm{L}$ and Chlamydomonas $s p$. at an initial biomass concentration of $0.89 \mathrm{~g} / \mathrm{L}$. With a dosage of $51 \mathrm{mg}_{\text {flocculant }} / \mathrm{g}_{\text {biomass }}$ and $112 \mathrm{mg}_{\text {flocculant }} / \mathrm{g}_{\text {biomass }}$, recoveries of $94.5 \%$ and $92.15 \%$ were obtained after 30 and 15 minutes of sedimentation. 
Similar results at seawater salinities where obtained in the study of Farid et al. (2013). By using cationic polymeric flocculants, the marine microalgae Nannochloropsis sp. was harvested with biomass recoveries of $80 \%$. As a flocculant, they used modified chitosan in combination with a $\mathrm{pH}$-increase. Although this approach was successful, it is not known if the induced flocculation is caused merely by the modified chitosan or by the $\mathrm{pH}$-increase. At elevated $\mathrm{pH}$, divalent salts such as calcium and magnesium salts can precipitate and 'sweep' the algal biomass which causes an enhanced biomass recovery (Vandamme et al. 2013).

To understand the decrease in biomass recovery obtained at elevated flocculant dosages that is presented in Figure 3.1, we propose the mechanism presented in Figure 3.2 .

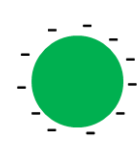

stable particle or

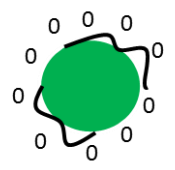

destabilized particle

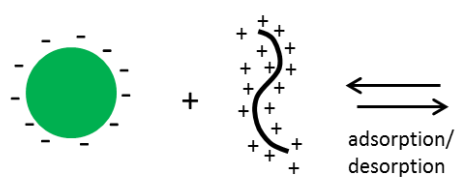

flocculant
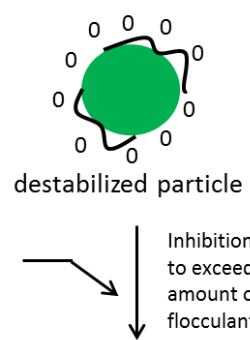

Inhibition due to exceeding amount of flocculant

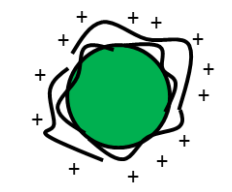

inhibited particle

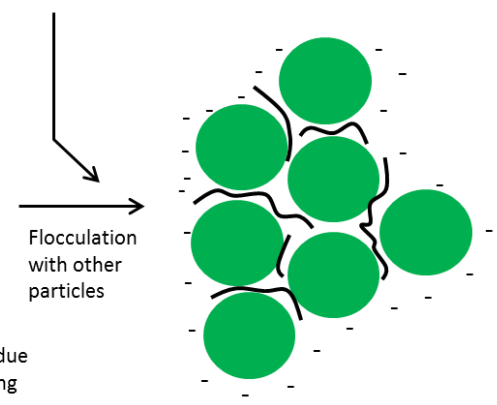

formed floc

flocculant 
Figure 3.2 depicts the mechanism describing the starting of the floc formation: a small amount of flocculant reversibly adsorbs on a part of the cell wall, resulting in a locally destabilised cell. These destabilised cells can collide with each other or with other cells. This results in the formation of the first floc consisting of a few cells (Gregory 1973, Mabire et al. 1984, Rattanakawin and Hogg 2001). The floc can further grow under the same sequence of events of destabilisation and collision.

Exceeding amount of flocculant, however, can cover the whole cell wall, resulting in a reversion of the charge of the particle. This results in a stabilized cell suspension due to the repulsive forces among the adsorbed polymers. Eventually, this class of particles are inhibited to further flocculate.

Although this phenomenon has already been proposed in previous experimental studies (Gregory 1973, Mabire et al. 1984, Tenney et al., 1969), existing flocculation models (Runkana et al. 2004, Thomas et al. 1999, Rattanakawin and Hogg 2001) do not include the formation of these inhibited particles. Our model takes over-coverage of the cell wall by the flocculant into account.

The sequence of destabilisation and collision is a chain of events in which a recent formed floc will be destabilized again in order to further collide forming a new, larger floc. Eventually, this chain of events will result in a steady state. At this steady state, a constant particle size distribution will be present.

\subsection{Model development}

The proposed mechanism of Figure 3.2 was incorporated in a mathematical model. This model was used to understand the effect of the flocculant dosage. In the model, three different classes of particles are taken into account: stable particle $\left(C^{S}\right)$, destabilised particle $\left(C^{D}\right)$ and inhibited particles $\left(C^{\prime}\right)$. The particle size distributions of these classes are described classifying the particles by their number of cells. The detailed translation of the mechanism into a model is presented in the Appendix.

Both individual microalgal cells and formed flocs are considered as rigid homogeneous spherical particles. The density of all the particles present is equal and the size of the flocculant molecules is not taken into account to calculate the size/mass of a floc. 
For each population of particles, the reactions involved in the flocculation mechanism i.e.: Adsorption, Desorption, Inhibition and Flocculation, are assumed to follow first order kinetics with kinetic constants, respectively: $\beta^{A}, \beta^{\mathrm{D}}, \beta^{\mathrm{l}}, \beta^{\mathrm{F}}$.

We hypothesized that the values of $\beta$ depend on the sizes of particles involved in the specific step of the flocculation network.

The adsorption constant $\beta_{i}^{A}$ is dependent on the surface area of the particles. With an increasing particle size, the chance of a flocculant being adsorbed on the surface is increasing as well.

$\beta_{i}^{A}=\beta_{0}^{A} \cdot d_{i}^{2}$

Desorption is often dependent on the absorbed quantity. However, in our model the desorption rate is limited by the mass transfer of flocculants through the external layer surrounding the particle. Therefore, $\beta_{i}^{D}$ is assumed to be independently of the particle size, and constant:

$\beta_{i}^{D}=\beta_{0}^{D}$

The formation of inhibited particles depends by the capacity of the flocculant to completely cover the destabilised particle "i". With an increasing particle surface, more flocculant are needed. The chance of forming inhibited particles thus decreases with increasing particle surface areas and the rate constant $\beta_{i}^{I}$ is described by

$\beta_{i}^{I}=\beta_{0}^{I} \cdot \frac{1}{d_{i}^{2}}$

In which $\beta_{0}^{I}$ is the maximum inhibition constant.

The flocculation of the particles is assumed to follow the orthokinetic collision mechanism as described by Smulochowski (1917). With orthokinetic collisions, the volume of the particles is the predominant factor influencing the collision rate. The rate constant for formation of larger flocs $\beta_{i j}^{F}$ is thus expressed in terms of the volume of the individual particles involved.

$\beta_{i j}^{F}=\frac{G}{6}\left(d_{i}+d_{j}\right)^{3}$ 
From the reaction network and the involved kinetics, the mass balances are derived for each element ' $i$ ' of the three classes. According to the mass balances, the elements element ' $i$ ' and ' 'j' can collide forming larger particles of class ' $k$ ' up to the largest size class ' $\mathrm{N}$ '.

$\frac{d C_{i}^{S}}{d t}=\beta_{i}^{D} * C_{i}^{D}-\beta_{i}^{A} * C_{i}^{S} * C_{F}-\left(\sum_{j=1}^{j=N} \beta_{i j}^{F} * C_{j}^{D}\right) \cdot C_{i}^{S}+\sum_{k=1}^{k=i-1} \beta_{k(k-i)}^{F} *\left(C_{k-1}^{S}+C_{k-i}^{D}\right) * C_{k}^{D}$

$\frac{d C_{i}^{D}}{d t}=\beta_{i}^{A} * C_{i}^{S} * C_{F}-\beta_{i}^{D} * C_{i}^{D}-\beta_{i}^{I} * C_{i}^{D} * C_{F}-\left(\sum_{j=1}^{j=N} \beta_{i j}^{F} *\left(C_{j}^{S}+C_{j}^{D}\right)\right) * C_{i}^{D}$

$\frac{d C_{i}^{I}}{d t}=\beta_{i}^{I} * C_{i}^{D} * C_{F}$

Finally the mass balance of the flocculant is also taken into account:

$\frac{d C_{F}}{d t}=\sum_{i=1}^{i=N} \beta_{i}^{D} * C_{i}^{D}-\beta_{i}^{A} * C_{i}^{S} * C_{F}-\sum_{i=1}^{i=N} \beta_{i}^{I} * C_{i}^{D} * C_{F}$

To determine the biomass recovery from the population balances, it is assumed that after flocculation all the particles present at least in the second size class of the particle size distribution are able to settle (Tenney et al. 1969).

The experimental results obtained with Zetag 7557 and SNF H536 (Figure 3.1) are used to fit the four collision rate constants. Next to the fitting, the input parameters $\left(O D_{750}\right.$-cell number conversion factor, $C_{i}, C_{F}$ and $\left.d_{c e l l}\right)$ of the model were experimentally determined (Table 3.1). An overview of the input parameters and the determined values of the collision rate constants are provided in Table 3.1. 
Table 3.1: Input of the model: Next to the four collision rate constants (' $\beta$ ') that were determined using experimental determined data, also the biomass specific parameters (cell size and cell number conversion factor) are presented.

\begin{tabular}{ccc}
\hline Parameter & Value & Unit \\
\hline \hline $\mathrm{OD}_{750}$-Cell number conversion factor & 23192 & $O D_{750-\frac{\text { cells }}{\mu L}}$ \\
$C_{i}$ & variable & $\frac{g}{L}$ \\
$C_{F}$ & variable & $p p m$ \\
$d_{\text {cell }}$ & 3.5 & $\mu m$ \\
$\beta_{0}^{D}$ & $0.631 * 10^{-5}$ & $\frac{1}{\text { second }}$ \\
$\beta_{0}^{A}$ & $1.035 * 10^{-5}$ & $\left(\frac{1}{\text { second }}\right) *\left(\frac{L}{\mu g r a m}\right) *\left(\frac{1}{\mu m^{2}}\right)$ \\
$\beta_{0}^{I}$ & $0.589 * 10^{-5}$ & $\left(\frac{1}{\text { second }}\right) *\left(\frac{L}{\mu g r a m}\right) * \mu m^{2}$ \\
$G$ & $0.008 * 10^{-5}$ & $\left(\frac{1}{\text { second }}\right) *\left(\frac{\mu L}{\text { number of particles }}\right) *\left(\frac{1}{\mu m^{3}}\right)$ \\
\hline
\end{tabular}

With the fitted values for the kinetic constants the model was used to predict biomass recoveries at different flocculant dosages. After fitting the average relative errors between predicted and observed biomass recovery was 5\% for SNF H536 and 8\% for Zetag 7557.

\subsection{Model validation at one biomass concentration}

The goal of the model is to describe a general trend in the biomass recovery as a function of the flocculant dosage that is applicable for a large variety of cationic polymeric flocculants. Therefore, after the calibration of the model with the flocculants Zetag 7557 and SNF H536, the model was used to simulate the biomass recoveries at different dosages of a third flocculant at a constant biomass concentration of $0.46 \mathrm{~g} / \mathrm{L}$ (Figure 3.3). As a third flocculant Synthofloc $5080 \mathrm{H}$ was used. Figure 3.3 shows that a decrease in biomass recovery at elevated dosages is observed, just as with the other flocculants (Figure 3.1). The model showed a similar trend in predicting the biomass recoveries as a function of the flocculant dosage. 


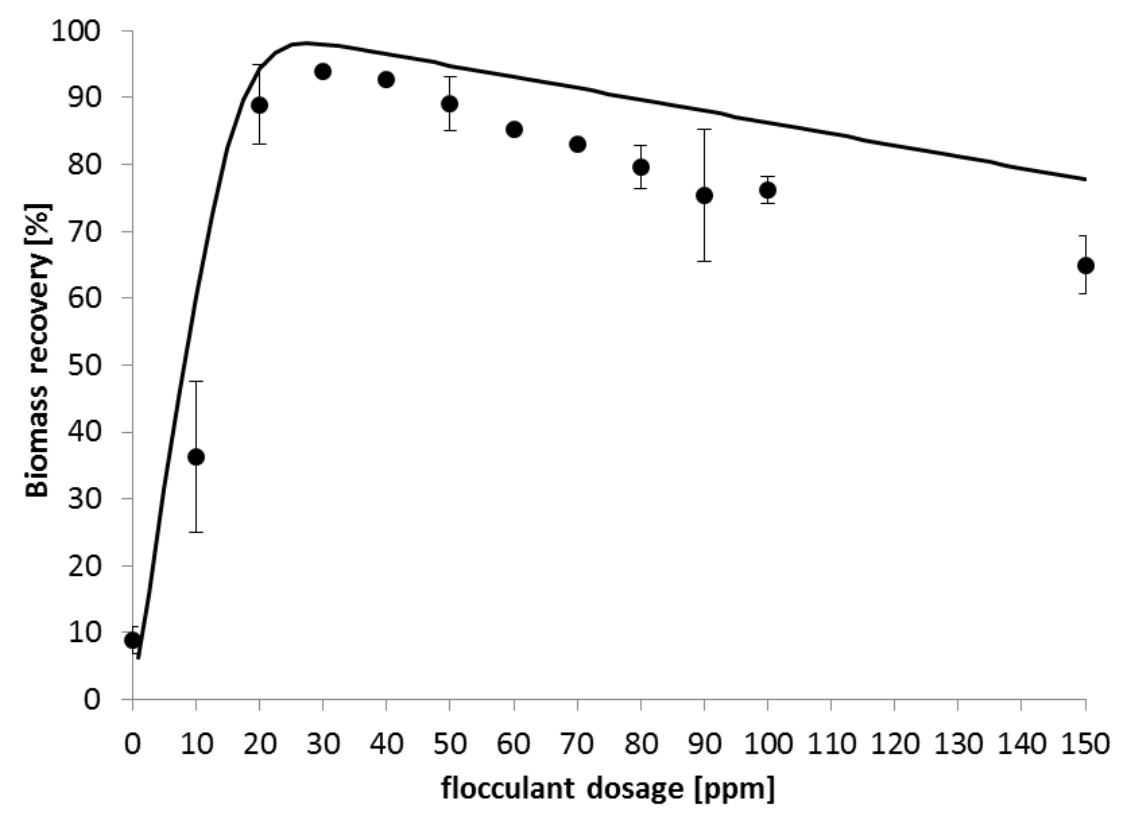

Figure 3.3: Experimental data with initial DW of $0.46 \pm 0.06 \mathrm{~g} / \mathrm{L}(\bullet)$. All the experimental results were obtained in biological duplicates $(n=2)$ by using Synthofloc $5080 \mathrm{H}$. The simulations are performed with the fitted collision rate constants and similar biomass concentration.

The predicted biomass recoveries are on average slightly higher than the experimental results with a relative error of $15 \%$. This error is caused by our assumption that all flocculants behave similar. This resulted in similar parameters for the use of different flocculants. In reality these input parameters may deviate causing differences in predicted biomass recoveries. However, at the optimal flocculant dosage range of 20 to $50 \mathrm{ppm}$, the relative error is only $5 \%$. This illustrates the ability to predict optimal flocculant dosages for multiple flocculants with the model.

\subsection{Model validation at different biomass concentrations}

Although the model is in agreement with the experimental data obtained at an initial DW of $0.46 \pm 0.06 \mathrm{~g} / \mathrm{L}$, it is not known if the input parameters are also valid when higher biomass concentrations are applied. Additional simulations were therefore performed at an initial DW of $0.46 \pm 0.06 \mathrm{~g} / \mathrm{L}, 0.91 \pm 0.005 \mathrm{~g} / \mathrm{L}$ and $1.37 \pm 0.005 \mathrm{~g} / \mathrm{L}$ and at 50100 and 150 ppm and compared with experimental data obtained with all three flocculants (Figure 3.4). 


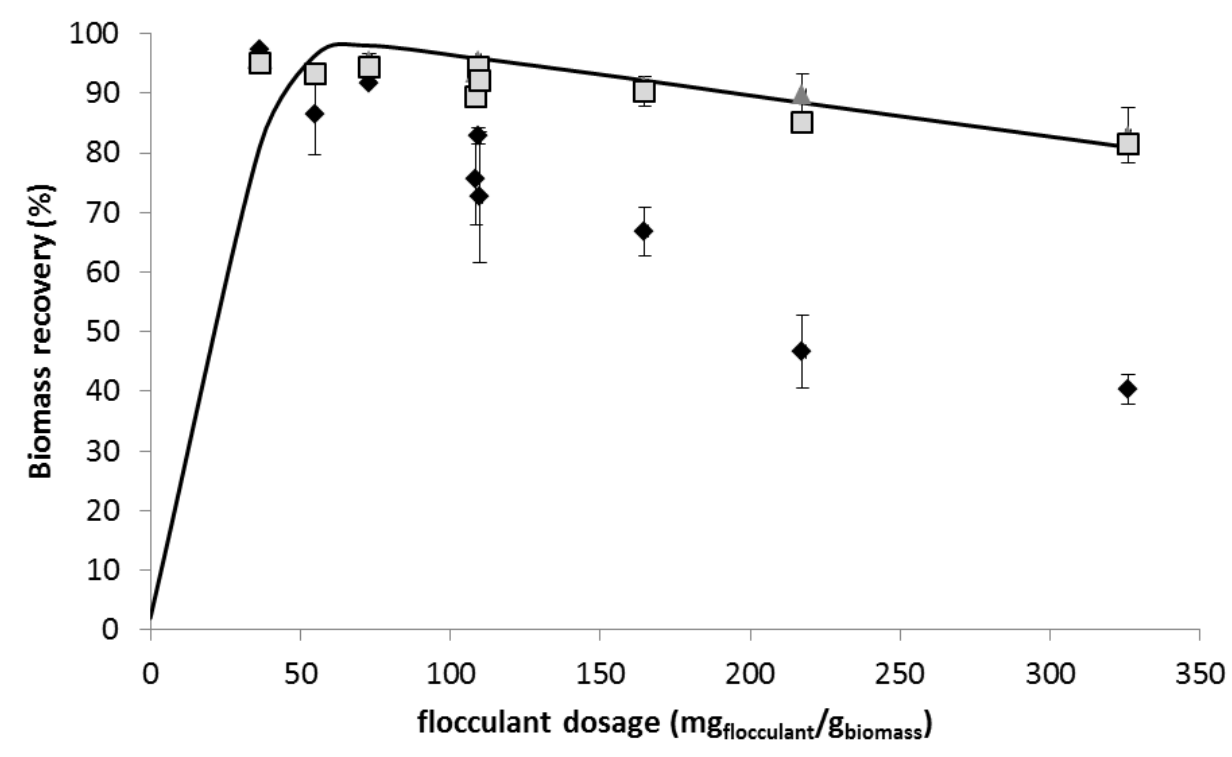

Figure 3.4: Comparison between simulations and experimental according to the study design. Applied biomass concentration $0.46 \mathrm{~g} / \mathrm{L}, 0.91 \mathrm{~g} / \mathrm{L}$ and $1.37 \mathrm{~g} / \mathrm{L}$. Solid line are predicted biomass recoveries and Zetag 7557( $\bullet)$, Synthofloc $5080 \mathrm{H}(\square)$ and SNF H536 $(\Delta)$. Error bars represent biological replicates $(n=2)$.

In Figure 3.4, the flocculant dosages and used biomass recoveries of the 27 experimental points were used to calculate a flocculant-to-biomass ratio $\left(\mathrm{mg}_{\text {flocculant }} / \mathrm{g}_{\text {biomass }}\right)$. By doing so, we were able to present all the experimental data, obtained at different biomass concentrations in a single figure.

According to the proposed mechanism there is an optimal ratio between flocculant dosage and biomass recovery. When this ratio is exceeded, the recoveries are decreasing again. This is in accordance with both the experimental and simulated optimal dosage of $70 \mathrm{mg}_{\text {flocculant }} / \mathrm{g}_{\text {biomass }}$, followed by a decrease in biomass recovery.

The biomass recoveries obtained with Zetag 7557 are lower than the predictions at dosages from $70 \mathrm{mg}$ flocculant $/ \mathrm{g}_{\text {biomass }}$ onwards. In addition, these recoveries are also lower than the biomass recoveries obtained with the two other flocculants. This illustrates, that although only cationic polyacrylamides were used as flocculants, the individual flocculants have different flocculation properties. In this model, no flocculant characteristics were included. All flocculants were considered as equal. 
To simulate properties of different flocculants in harvesting marine microalgae, the model should be extended by including some flocculant unique parameters. This can be done by including these characteristics in the kinetic constants (' $\beta$ '). Implementing flocculant dependent characteristics can be done by replacing the collision rate parameters ' $\beta_{0}^{D}, \beta_{0}^{A}, \beta_{0}^{I}$ and $\mathrm{G}$ ' for other expressions. A possible improvement in the collision rate parameters is including flocculant dependent parameters such as flocculant length or cationic charge density. When these specific parameters are included, no generalisation in cationic polymers is needed, which might result in a more accurate prediction of biomass recoveries.

The goal of the model was to confirm our proposed mechanism in order to create a better understanding of marine flocculation. In addition, the model can be used to perform some basic simulations to estimate the optimal flocculant dosage. Based on the average relative error of $15 \%$ that is calculated by including all 27 experimental points, it appears that the proposed mechanism is in agreement with the experimental observations. This novel model can be used to simulate flocculation efficiency at flocculant limiting conditions (low dosages). Moreover, it also predicts the flocculant inhibiting effects at dosages that exceed the optimal flocculant dosage ratio. This model is there for usable in further evaluations to determine optimal flocculant dosages

\subsection{Evaluating marine flocculation}

Both the experimental work and simulations presented in this study shows that the optimum flocculant dosage to harvest the microalgae $N$. oleoabundans cultivated in saltwater medium ranges between 43 to $109 \mathrm{mg}$ flocculant $/ g_{\text {biomass. }}$ In other applications of cationic polymers such as removal of contaminants in the wastewater industry, the flocculant demand is 5 to 10 times lower (Lee et al., 2010, Wong et al. 2006)

Although it is possible to harvest marine microalgae using flocculation, it is not known yet if flocculation can contribute in lowering the cost price of algal harvesting. Wong et al. (2006) used in his study multiple commercial available cationic polyacrylamides. According to his study, the cost price of cationic polyacrylamides ranges between 3.45 and $4.50 \$ / \mathrm{kg}$. When the optimal flocculant dosage of 43 to 109 $\mathrm{mg}_{\text {flocculant }} / \mathrm{g}_{\text {biomass }}$ is taken into account, the price of $1 \mathrm{~kg}$ of harvested biomass would 
range between $0.15 \$ / \mathrm{kg}_{\text {biomass }}$ and $0.49 \$ / \mathrm{kg}_{\text {biomass. }}$ In this estimation only the flocculant usage is taken into account.

This cost estimation is slightly higher than the evaluation reported in the screening study of Roselet et al. (2015). In that screening, using the marine microalgae Nannochloropsis oculata and cationic polyacrylamides, the applied flocculant dosage was slightly lower than the dosages applied in this study: between 18 and 27 $\mathrm{mg}_{\text {flocculant }} / \mathrm{g}_{\text {biomas. }}$. This dosage resulted in a chemical cost up to $0.22 \$ / \mathrm{kg}_{\text {biomass }}$ for cationic poly(acry)amides (Roselet et al., 2015). These results underline that the flocculant demand can account for a considerable cost in harvesting.

To decrease the flocculant demand and belonging costs of the flocculants, more efforts should be taken to further understand the role of the flocculant in inducing flocculation. When this role is known, optimized flocculants can be designed that are suited to the requirements of microalgal flocculation. Optimized flocculants will result in a lower necessity of flocculants to destabilise cells, while maintaining the biomass concentration (Roselet et al., 2015). One example of flocculant optimization is the study of Morrissey et al. (2014). In that study, recyclable flocculants have been proposed. Although this is not a direct optimization of the flocculant resulting in a lower optimal dosage ratio, the recyclability of the flocculant will result in a lower flocculant demand. Next to the development of recyclable flocculants, new types of flocculants such as cellulose nanocrystals have been reported. These type of flocculants are potentially cheaper than current studied poly(acryl)amidic ones, and may be feasible for in food- and feed applications (Eyley et al., 2015).

\section{Conclusions}

In this study an experimental and modelling approach were used to propose a mechanism for flocculation. The mechanism enabled us to understand flocculation under various conditions. By predicting optimal flocculant dosages and comparing with the experimental results, this study revealed that there is an optimal ratio between flocculants and biomass that determines the needed amount of flocculant at various biomass concentrations. For $N$. oleoabundans this ratio is between 43 to 109 $\mathrm{mg}_{\text {flocculant }} / \mathrm{g}_{\text {biomass. }}$ Although this is similar to dosages reported in other micro algal studies, it is approximately 10 times higher than the dosage used in the wastewater industry. 


\section{Acknowledgement}

This work is performed within the TKI AlgaePARC Biorefinery program with financial support from the Netherlands' Ministry of Economic Affairs in the framework of the TKI BioBased Economy under contract nr. TKIBE01009. The authors thank in particular TKI AlgaePARC Biorefinery consortium partner BASF for kindly providing the flocculant Zetag 7557, as well as Sachtleben Wasserchemie GmbH (Germany) for kindly providing the flocculant Synthofloc $5080 \mathrm{H}$. The authors thank Ton van Boxtel, Farnoosh Fasaei and Benjamin von Kleist-Retzow for their valuable input during the development and validation of the model. 


\section{Appendix}

In this appendix, the translation from the qualitative mechanism into the mass balances is described in more detail.

The mechanism of flocculation can be regarded as a chain of events. In this chain, stabilized particles will initially get destabilised, when they collide with the cationic flocculant. After destabilisation, the particles can flocculate and form a floc. This floc is regarded as a stable particle that needs to be destabilized with additional flocculant before it can flocculate again. In addition to the floc formation, a destabilized particle can also become irreversibly inhibited by adsorption of a surplus of flocculant to the cell wall. Over time, a particle size distribution develops and eventually, the overall flocculation process will reach a steady state with a constant particle size distribution.

This general mechanism has been translated in a collision balance scheme (Figure $\mathrm{S})$ :

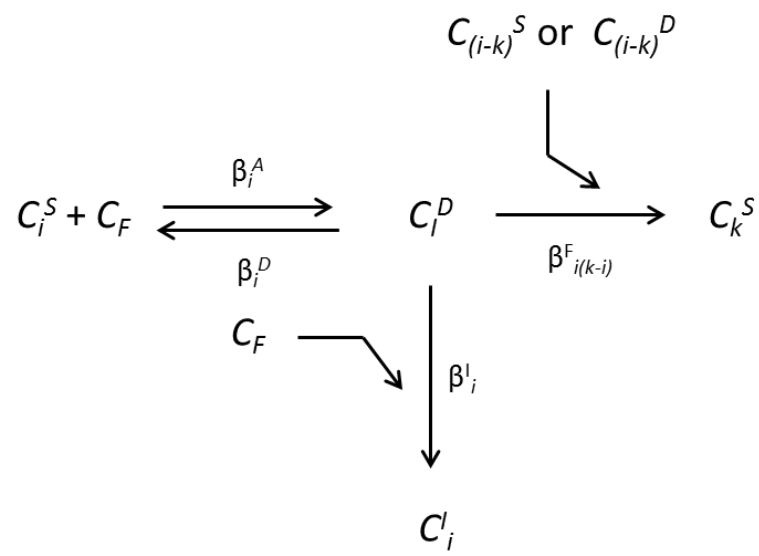

Figure S: Collision balance scheme of the flocculation mechanism

In the scheme, the concentration of stable particles of size class $i$ and $k{ }^{\prime}{ }^{S}$ ' ' and ' $\mathrm{C}_{\mathrm{k}}^{\mathrm{s}}$, destabilized particles of size class $i, \mathrm{C}_{\mathrm{i}}^{\mathrm{D}}$ ' and the concentration of inhibited particles of size class $i$ ' $\mathrm{C}_{i}$ ', can be recognized. The flocculant concentration is given by ' $\mathrm{C}_{\mathrm{F}}$ '. In the reaction scheme, $\beta_{\mathrm{i}}$ represents the first order kinetic parameters for the collision of the different particles in size class $i$. From this reaction scheme the mass balances of the four different types of particles were derived: 
stabilized particles $\left(\mathrm{C}^{S_{i}}\right)$ :

$$
\left(\begin{array}{c}
\text { The change in } \\
\text { amount of } \\
\text { stabilized } \\
\text { particles } \\
\text { over time }
\end{array}\right)=\left(\begin{array}{c}
\text { The loss and gain } \\
\text { of stabilized particles } \\
\text { due to interactions } \\
\text { with flocculants }
\end{array}\right)-\left(\begin{array}{c}
\text { The loss of } \\
\text { stabilized } \\
\text { particles due to } \\
\text { collissions with } \\
\text { destabilized } \\
\text { particles }
\end{array}\right)+\left(\begin{array}{c}
\text { The formation of } \\
\text { stabilized particles } \\
\text { due to collissions } \\
\text { between destabilized } \\
\text { particles and } \\
\text { (de)stabilized)particle }
\end{array}\right)
$$

destabilized particles $\left(\mathrm{C}_{\mathrm{i}}{ }^{\mathrm{d}}\right)$ :

$$
\left(\begin{array}{c}
\text { the change in } \\
\text { amount of } \\
\text { destabilized } \\
\text { particles } \\
\text { over time }
\end{array}\right)=\left(\begin{array}{c}
\text { The loss and gain } \\
\text { of destabilized } \\
\text { particles due to } \\
\text { interactions with } \\
\text { flocculants }
\end{array}\right)-\left(\begin{array}{c}
\text { the loss of } \\
\text { destabilized } \\
\text { particles due to collisions } \\
\text { with either stabilized or } \\
\text { destabilized particles }
\end{array}\right)
$$

inhibited particles $\left(\mathrm{C}_{i}^{\prime}\right)$ :

$$
\left(\begin{array}{c}
\text { The change in } \\
\text { amount of } \\
\text { restabilized } \\
\text { particles } \\
\text { over time }
\end{array}\right)=\left(\begin{array}{c}
\text { The gain of } \\
\text { restabilized particles } \\
\text { due to interactions } \\
\text { between destabilized particles } \\
\text { and flocculants }
\end{array}\right)
$$

Flocculant $\left(\mathrm{C}_{\mathrm{F}}\right)$

$$
\left(\begin{array}{c}
\text { The change in } \\
\text { amount of } \\
\text { flocculant } \\
\text { over time }
\end{array}\right)=\left(\begin{array}{c}
\text { The loss and gain } \\
\text { of flocculants due } \\
\text { to interactions } \\
\text { with stabilized and } \\
\text { destabilized particles }
\end{array}\right)-\left(\begin{array}{c}
\text { The loss of flocculant } \\
\text { due to interactions with } \\
\text { destabilized particles to } \\
\text { form inhibited particles }
\end{array}\right)
$$

These mass balances are translated in the model that will be used to predict the particle size distribution at steady state.

With respect to the particle size distribution, 100 size classes are defined. The first size class consists of single cells and the final size class is defined as one single floc that contains all the cells that were initially present. Every size class contains a number of particles with a specific characteristic diameter of the particle $d_{i}$.Every formed floc is assumed to be a rigid and homogeneous sphere consisting of $n_{i}$ single cells with a diameter $d_{\text {cell }}$. The specific characteristic particle diameter is calculated, using $d_{i}=d_{\text {cell }} * n_{i}^{1 / 3}$. 



\section{Chapter 4}

Understanding the salinity effect on cationic polymers in inducing flocculation of the microalga Neochloris oleoabundans

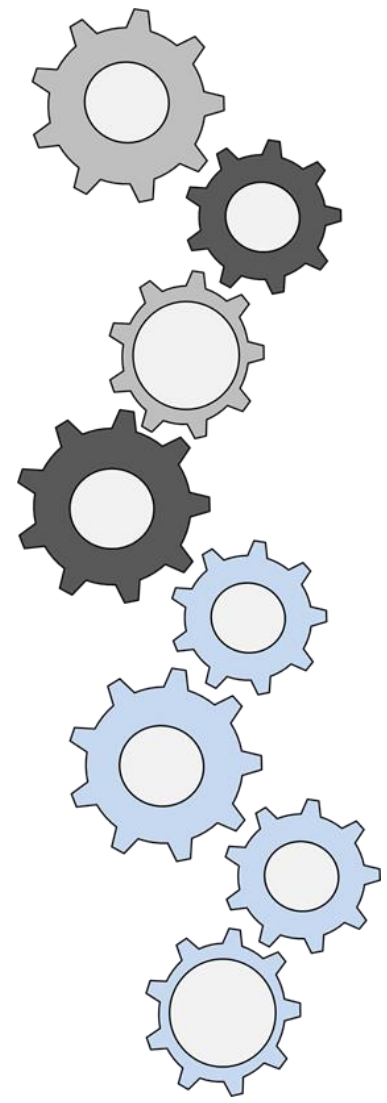

\section{Published as:}

't Lam, G.P., Giraldo, J.B., Vermuë, M.H, Olivieri, G., Eppink, M.H.M., Wijffels, R.H. (2016) Understanding the salinity effect on cationic polymers in inducing flocculation of the microalga Neochloris oleoabundans. J. Biotechnol. 225: 10-17. 


\begin{abstract}
1 mechanistic study was performed to evaluate the effect of salinity on cationic polymeric flocculants, that are used for the harvesting of microalgae. The polyacrylamide Synthofloc $5080 \mathrm{H}$ and the polysaccharide Chitosan were employed for the flocculation of Neochloris oleoabundans. In seawater conditions, a maximum biomass recovery of $66 \%$ was obtained with a dosage of $90 \mathrm{mg} / \mathrm{L}$ Chitosan. This dosage was approximately $25 \%$ lower compared to Synthofloc $5080 \mathrm{H}$ reaching recoveries greater than $90 \%$ with dosages of $30 \mathrm{mg} / \mathrm{L}$. Although different recoveries were obtained with both flocculants, the polymers exhibit a similar apparent polymer length, as was evaluated from viscosity measurements. While both flocculants exhibit similar polymer lengths in increasing salinity, the zeta potential differs. This indicates that polymeric charge dominates flocculation. With increased salinity, the effectivity of cationic polymeric flocculants decreases due to a reduction in cationic charge. This mechanism was confirmed through a SEM analysis and additional experiments using flocculants with various charge densities.
\end{abstract}




\section{Introduction}

The low energy requirements for flocculation establishes it as a promising technique for concentrating microalgae (Uduman et al., 2010; Vandamme et al., 2013). Flocculation of seawater cultivated microalgae, however, is still very challenging. In sea-water, ionic hindrance occurs which inhibits the interaction of the flocculant molecules with the microalgae (Bilanovic et al., 1988; Uduman et al., 2010; Vandamme et al., 2010; Vandamme et al., 2013). Unfortunately, only a small number of techniques are reported to be successful for flocculation of marine species: i.e. $\mathrm{pH}$-increase, inorganic flocculation, and polymeric flocculation (Wu et al. 2012; Chatsungnoen and Chisti, 2016; 't Lam et al., 2014). A pH-increase induces the precipitation of salts. Those precipitates will settle and, meanwhile, will sweep the biomass (Wu et al., 2012, ). In their study, several microalgae have been succesfully flocculated by increasing the $\mathrm{pH}$, resulting in a precipitation of the divalent ion magnesium. The use of inorganic flocculants in seawater salinities has also been reported (Chatsungnoen and Chisti, 2016). However, as mentioned by Uduman et al. (2010), the use of inorganic flocculants in seawater salinities commonly requires high dosages that are about 5 to 10 times higher compared to polymeric flocculants. With polymeric flocculation, polymeric bridges between individual cells are formed and, subsequently, aggregates of biomass evolve (Vandamme et al., 2013; 't Lam et al., 2014).

Among polymeric flocculants, cationic polymers are regarded as successful, though not all are equally efficient in inducing flocculation of marine microalgae. Currently, only polyacrylamides are reported to be successful ('t Lam et al., 2014; König et al., 2014; Roselet et al. 2015).

Despite the success of cationic polyacrylamides in harvesting marine microalgae, ' $t$ Lam et al. (2015) reported that, when commercially available cationic polymers are applied as flocculants, the required flocculant dosages is quite high (40 - 100 $\left.\mathrm{mg}_{\text {flocculant }} / \mathrm{g}_{\text {biomass }}\right)$, resulting in a lower economic feasibility. Additionally, the use of polyacrylamides is forbidden for food and feed applications as several of these flocculants are reported to be toxic and non-food grade petroleum processing techniques are commonly used to manufacture them (Lee et al., 2014). To overcome these limitations, other flocculants that preferably have an equal of even better performance and that are allowed in the food and feed industry should be selected or 
designed. To allow the rational selection or design of novel flocculants, the mechanism that is responsible for successful flocculation of marine microalgae needs to be revealed.

One of the mechanisms that was proposed by Tenney et al. (1969) and by Bilanovic et al. (1988) is that adsorption is mainly due to charge attraction between flocculant and cells. These studies suggest that repulsive forces within the polymer decrease in elevated salinities due to high ionic strength, resulting in the coiling of the flocculants. Due to this coiling, flocculants lose their ability to form polymeric bridges between individual cells and this subsequently results in decreased flocculation efficiency (Tenney et al., 1969; Bilanovic et al., 1988). The lack of polymeric coiling in elevated salinities could thus be an explanation for the success of charged polymeric flocculants such as cationic polyacrylamides.

However, recent studies of Roselet et al. (2015) showed that the cationic charge of the polymeric flocculants had a positive effect on the biomass recovery where the polymer length was of minor importance and that is not in accordance with the previously specified explanation of polymeric coiling. It is, therefore, still difficult to explain why certain cationic polymers are successful in inducing flocculation in seawater salinities while others are not.

The goal of this study was to provide further information to better understand cationic polymeric flocculation in seawater salinities and possibly reveal why cationic polyacrylamides remain functional in high salinities while other cationic polymers do not. This gained insight also provided information that can be applied in optimizing the design of flocculants.

In this study, Synthofloc $5080 \mathrm{H}$ and Chitosan were exploited as flocculants. Synthofloc $5080 \mathrm{H}$ is a cationic polyacrylamide that is reported to be successful in flocculating marine microalgae ('t Lam et al., 2014). Chitosan is a natural polysaccharide which is recognized as being successful in inducing flocculation under freshwater conditions but becomes less successful in seawater salinities and in neutral pH (Bilanovic et al. 1988). The apparent polymer length and nett cationic charge of both flocculants were compared with each other as a function of salinity. 
The used microalga in this study was Neochloris oleoabundans which is able to grow in both fresh and salt water conditions. It has been reported to contain a high protein content and, under stressed conditions, a high lipid content. This makes $N$. oleoabundans an interesting species for several applications (Popovich et al., 2012; Breuer et al., 2012). In addition, N. oleoabundans is a spherical Chlorophyta, hence, its shape eliminates possible side-effects of the cell shape during flocculation.

\section{Material and methods}

\subsection{Biomass cultivation}

The microalgal strain Neochloris oleoabundans UTEX1185 was cultivated in artificial seawater medium with various salinities: $\mathrm{NaCl}: 15 \mathrm{~g} / \mathrm{L}$ (brackish), $25 \mathrm{~g} / \mathrm{L}$ (seawater), $35 \mathrm{~g} / \mathrm{L} \quad$ (saline); $\mathrm{KNO}_{3}: 1.7 \mathrm{~g} / \mathrm{L} ; \quad \mathrm{Na}_{2} \mathrm{SO}_{4}: 0.5 \mathrm{~g} / \mathrm{L} ; \quad$ 4-(2-hydroxyethyl)-1piperazineethanesulfonic acid (HEPES): $23.83 \mathrm{~g} / \mathrm{L} ; \mathrm{MgSO}_{4} .7 \mathrm{H}_{2} \mathrm{O}: 0.73 \mathrm{~g} / \mathrm{L}$; $\mathrm{CaCl}_{2} .2 \mathrm{H}_{2} \mathrm{O}: 0.36 \mathrm{~g} / \mathrm{L} ; \mathrm{K}_{2} \mathrm{HPO}_{4}: 0.43 \mathrm{~g} / \mathrm{L} ; \mathrm{Na}_{2} \mathrm{EDTA} .2 \mathrm{H}_{2} \mathrm{O}: 0.03 \mathrm{~g} / \mathrm{L} ; \mathrm{MnCl}_{2} .4 \mathrm{H}_{2} \mathrm{O}$ : $0.004 \mathrm{~g} / \mathrm{L} ; \mathrm{ZnSO}_{4} .7 \mathrm{H}_{2} \mathrm{O}: 0.0012 \mathrm{~g} / \mathrm{L} ; \mathrm{CoCl}_{2} .6 \mathrm{H}_{2} \mathrm{O}: 0.0003 \mathrm{~g} / \mathrm{L} ; \mathrm{CuSO}_{4} .5 \mathrm{H}_{2} \mathrm{O}: 0.0003$ $\mathrm{g} / \mathrm{L} ; \mathrm{Na}_{2} \mathrm{MoO}_{4} \cdot 2 \mathrm{H}_{2} \mathrm{O}: 0.00003 \mathrm{~g} / \mathrm{L} ; \mathrm{NaFeEDTA}: 0.01 \mathrm{~g} / \mathrm{L}$.

Biomass was cultivated in $100 \mathrm{ml}$ shake flasks in an Infors Multitron incubator (Infors AG, Bottmingen, Switzerland). The cultures were continuously illuminated at 120 $\mu \mathrm{mol} . \mathrm{m}^{-2} . \mathrm{s}^{-1}$ in atmospheric air enriched with $2.5 \% \mathrm{CO}_{2}$ at a temperature of $25^{\circ} \mathrm{C}$. The flasks were orbitally shaken at $90 \mathrm{rpm}$.

Part of the cultured biomass was harvested using pipetting two days after inoculation. On the seventh day, new cultures were inoculated for further cultivation. By reinoculating a new flask every seven days and taking biomass after two days of cultivation, we prevented using stressed biomass in the flocculation experiments. Prior to the flocculation experiments, two cultivation cycles of nine days were performed to allow the biomass to adapt to their salinity.

\subsection{Flocculants}

1000 ppm stock solutions were prepared according to 't Lam et al. (2014) whereby the low charged flocculant 'Synthofloc 5025H', the moderately charged flocculant 'Synthofloc 5040H', and the highly charged flocculant 'Synthofloc 5080H' were dissolved in de-ionized (Milli- $Q^{\circledR}$ ) water. The flocculants of the 'Synthofloc'-series were generously provided by Sachtleben Wasserchemie $\mathrm{GmbH}$, Germany. All 
flocculants are large polyacrylamides with various cationic charges and are commonly used in wastewater applications.

Chitosan (purchased from Sigma-Aldrich, product nr.: 448869-50G) was dissolved overnight in $0.1 \%(\mathrm{v} / \mathrm{v})$ acetic acid after which the $\mathrm{pH}$ was adjusted to $\mathrm{pH} 7 \pm 0.2$. Flocculants were stored at $4^{\circ} \mathrm{C}$ in a dark environment and were never stored longer than seven days.

\subsection{Biomass recovery}

After harvesting the biomass, the initial optical density at $750 \mathrm{~nm}$ was established at $0.8 \pm 0.01$ using culture medium (corresponds with a dry weight of $0.24 \pm 0.07 \mathrm{~g} / \mathrm{L}$ ). After setting the $O D_{750}, 10 \mathrm{ml}$ of the sample was transferred to a beaker glass and stirred at $500 \mathrm{rpm}$. From a stock solution, flocculant was added until the desired dose was achieved (ranging between 0 and 90 ppm). After five minutes of mixing at 500 rpm followed by a ten minute period of mixing at $100 \mathrm{rpm}$, samples were transferred to $4 \mathrm{ml}$ polystyrene cuvettes. The mixing protocol that was used first involved a severe mixing followed by a gentle mixing time and is in accordance with protocols reported in other studies (Bilanovic et al., 1988). Using the photometric method of Salim et al., (2012), the gradual biomass recovery was followed in a Beckman Coulter DU730 photometer. After two hours of sedimentation, the biomass recoveries were determined and calculated according to Salim et al. (2012). All experiments were performed in duplicate:

$\operatorname{Recovery}(\%)=\frac{\mathrm{OD}_{750(\mathrm{t} 0)}-O D_{750\left(t_{\text {supernatant }}\right)}}{\mathrm{OD}_{750(\mathrm{t} 0)}} * 100$

\subsection{Viscosity}

The viscosity of a polymeric solution is correlated with the apparent polymer length. To study the effect of the salinity on the apparent polymer length of the flocculants, the viscosity of the flocculant solutions in various salinities was measured. The flocculant concentrations ranged between 0 and $100 \mathrm{ppm}$. The viscosity was measured using a Physica MCR 301 Rheometer. Polymeric solutions were made with various salinities by varying the $\mathrm{NaCl}$-concentration $(0-10 \mathrm{~g} / \mathrm{L} \mathrm{NaCl})$. After the addition of the flocculant solution in the rotational cylinder, the viscosity was measured at shear rates ranging from 1 to $100 \mathrm{~s}^{-1}$. 


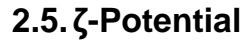

$\zeta$-Potential measurements were performed to determine the effect of salinity on the net cationic charge of the flocculant. Several flocculant solutions with different $\mathrm{NaCl}$ concentrations were prepared. Flocculant dosages ranged between 30 and 200 ppm. The salinity ranged between 0 and $4 \mathrm{~g} / \mathrm{L}$ of $\mathrm{NaCl}$. The charge was measured using a Malvern Zetasizer Nano.

\subsection{SEM imaging}

The scanning electron microscopy objects were prepared according to the protocol described in Salim et al. (2014). In this protocol, aliquots of the microalgae were mixed with the flocculant for five minutes of severe mixing $(500 \mathrm{rpm})$ followed by ten minutes of gentle mixing (100 rpm). Immediately after the mixing, a drop of suspended flocs was transferred to a poly-L-lysine coated microscopy cover slip. After one hour, the cover slip was rinsed, and the remaining cells on the cover slip were fixated in a $3 \%$ glutaraldehyde solution in a PBS-buffer for one hour. The cells were post-fixated in a $1 \% \mathrm{OsO}_{4}$ solution for another hour. Afterwards, the fixated cells were rinsed and dehydrated using ethanol. They were subsequently dried using critical point $\mathrm{CO}_{2}$ drying. After drying, the cover slips were coated with a $10 \mathrm{~nm}$ Iridium layer using sputter-coating. 


\section{Results and discussion}

\subsection{Flocculation}

The biomass recoveries were measured at various dosages of Synthofloc $5080 \mathrm{H}$ (Figure $4.1 \mathrm{~A}$ ) and Chitosan (Figure $4.1 \mathrm{~B}$ ) at three different salinities: 25, 35, and $45 \mathrm{~g} / \mathrm{L}$ of $\mathrm{NaCl}$.
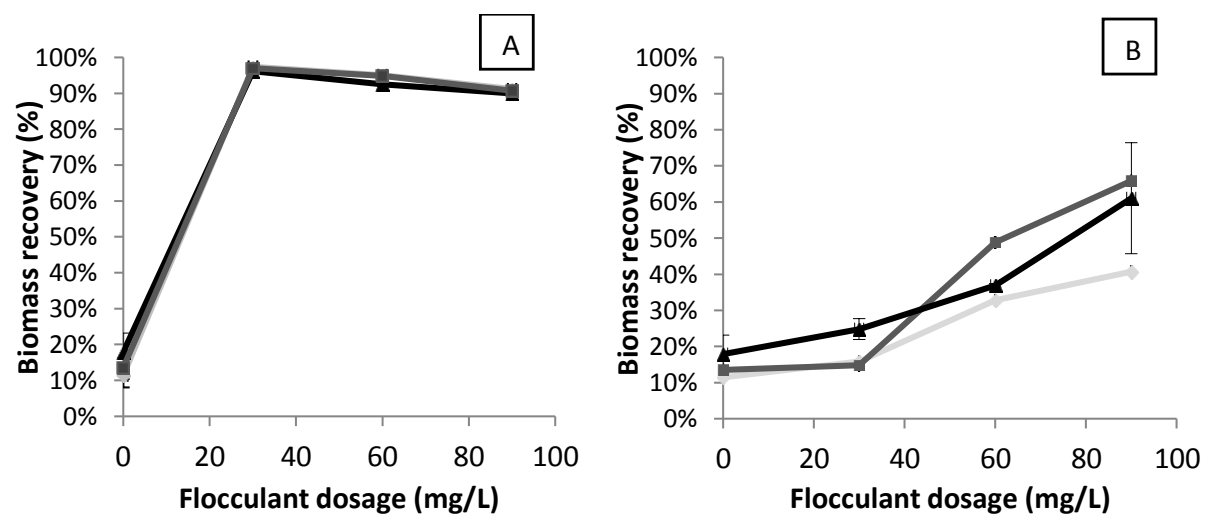

Figure 4.1: Biomass recovery as a function of the flocculant dosage at salinities of $25 \mathrm{~g} / \mathrm{L}(\diamond), 35 \mathrm{~g} / \mathrm{L}$

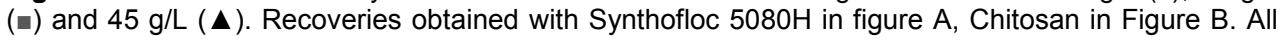
samples represent biological duplicates.

With Synthofloc $5080 \mathrm{H}$, the biomass recovery is always higher than $90 \%$ regardless of the salinity. A lower biomass recovery is recorded when Chitosan is applied as a cationic polymeric flocculant using a similar dosage.

At elevated dosages, the biomass recovery in all three salinities decreases with $7 \%$ recovery when using Synthofloc $5080 \mathrm{H}$ as a flocculant. This is in agreement with the model presented in previous work ('t Lam et al., 2015) in which there is an optimum flocculant-biomass ratio. When this ratio is exceeded, flocculation becomes inhibited due to restabilization.

The successful use of Chitosan in freshwater conditions has previously been reported (Table 4.1), and the obtained results of Figure 4.1B were compared with these studies. In all of the studies mentioned in Table 4.1, the biomass was cultivated in nutrient replete conditions. Possible biological effects such as the formation of extracellular polymeric substances due to nutrient stress (Salim et al., 2013), were thus eliminated. 
Table 4.1: Comparison of obtained biomass recoveries with Chitosan in various studies. The biomass concentration used in the different studies is given in $g / L$ (' $C_{x}$ ') and the flocculant dosage in $\mathrm{mg} / \mathrm{L}$.

\begin{tabular}{lcccccc}
\hline Species & $\mathbf{C x}(\mathrm{g} / \mathrm{L})$ & $\mathbf{p H}$ & dosage $(\mathbf{m g} / \mathrm{L})$ & fresh/marine & recovery & Reference \\
\hline \hline C. sorokiniana & $0.27 \pm 0.07$ & 7 & 5 & fresh & $>90 \%$ & (Xu, et al. 2013) \\
$\begin{array}{l}\text { C. vulgaris } \\
\text { N. oleoabundans }\end{array}$ & 0.5 & 7.2 & 100 & fresh & $95 \%$ & (Beach, et al. 2012) \\
$\begin{array}{l}\text { S. obliquus } \\
\text { N. salina }\end{array}$ & 0.54 & 7 & 80 & fresh & $95 \%$ & (Cheng, et al. 2011) \\
N. oleoabundans & $0.24 \pm 0.07$ & 7 & 90 & marine & $>90 \%$ & (Garzon-Sanabria et al., 2013)
\end{tabular}

The comparison between the biomass recoveries obtained with Chitosan in this study and other studies demonstrated that, in seawater salinities, a considerably lower biomass recovery is obtained using merely chitosan (Table 4.1). Although GarzonSanabria et al. (2013) did incite elevated biomass recoveries by using Chitosan in seawater salinities, it is not known if there was a possible $\mathrm{pH}$ effect involved as the $\mathrm{pH}$ after flocculant addition was adjusted to 8 in their study. In addition to the lower biomass recovery, other studies in Table 4.1 used substantial lower flocculant dosages. The use of lower flocculant dosages with higher biomass recoveries implies that, in other studies in freshwater conditions, Chitosan was a more efficient flocculant.

The differences in polymeric properties that were observed between Synthofloc $5080 \mathrm{H}$ and Chitosan in increasing salinities have been attributed to the degree of polymeric coiling (Bilanovic et al., 1988). They concluded that, as a function of the salinity, a polymer shrinks until it reaches it smallest dimensions.

\subsection{Viscosity measurements}

To verify if polymeric coiling provides an explanation for the lower biomass recovery observed with Chitosan compared to Synthofloc $5080 \mathrm{H}$, viscosity measurements of both flocculants dissolved in water with different salinities were performed.

The viscosity of a polymeric solution is proportional to the apparent length of the polymers (Yamakawa, 1971; Tricot et al. , 1984; Bilanovic et al., 1988). 
In Figure 4.2 and Figure 4.3, the two bar diagrams illustrate the viscosity as a function of the flocculant dosage and as a function of the salinity.

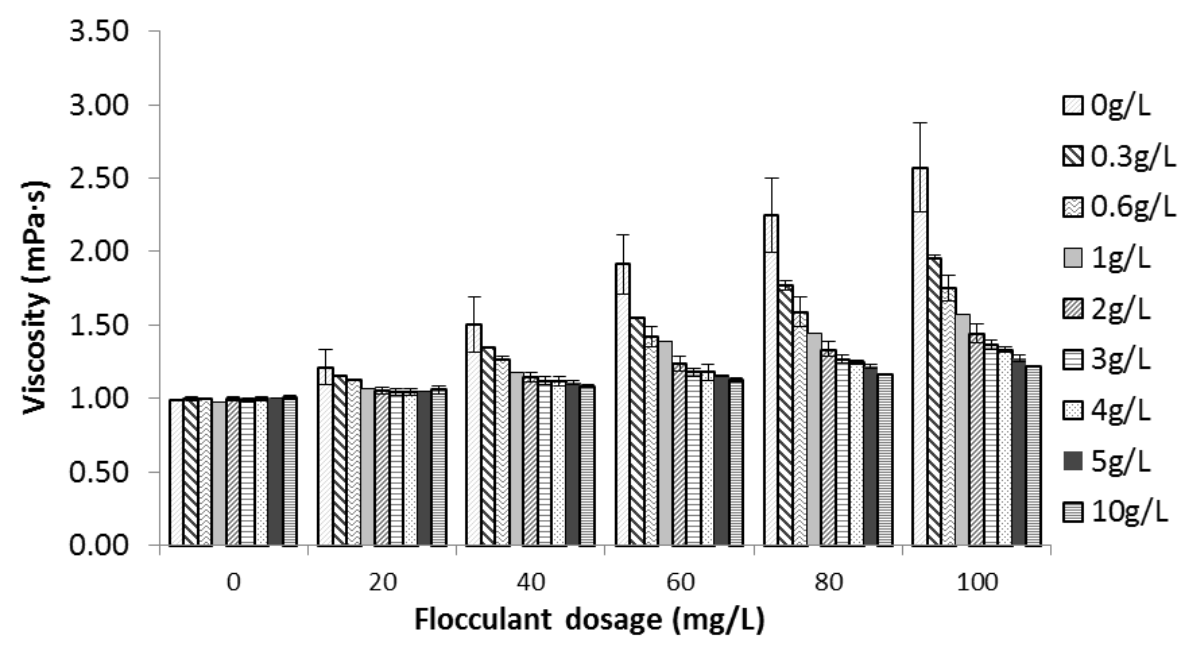

Figure 4.2: Viscosity of Synthofloc $5080 \mathrm{H}$ measured at a share rate of $100 \mathrm{~s}^{-1}$. Every cluster of bars represents a flocculant dosage. Within every cluster, the salinity was increased, corresponding with the legend at the right site of the figure. Error bars are duplicates.

In Figure 4.2, the decrease in viscosity obtained with Synthofloc $5080 \mathrm{H}$ is in agreement with the trend described by Bilanovic et al. (1988). In their study, also a decrease in viscosity as a function of the medium salinity was observed. But despite the observed substantial viscosity decrease of the Synthofloc $5080 \mathrm{H}$ suspension in high salinities, it still induces flocculation (Figure 4.1). Moreover, the viscosity of Synthofloc $5080 \mathrm{H}$ drops dramatically to values close to the viscosity of water already in medium with salt concentrations lower than $1 \mathrm{~g} / \mathrm{L}$ of $\mathrm{NaCl}$. This illustrates that Synthofloc $5080 \mathrm{H}$ polymer is very sensitive to surrounding ionic forces and becomes coiled.

With Chitosan (Figure 4.3), the viscosity remains similar to the viscosity of water regardless of the flocculant dosage and salinity that is applied. These results demonstrate that no coiling occurred to explain the lower biomass recoveries obtained in Figure 4.1 with Chitosan compared to Synthofloc $5080 \mathrm{H}$. In addition, both flocculants had a viscosity similar to water in salinities of $10 \mathrm{~g} / \mathrm{L} \mathrm{NaCl}$ and a flocculant dosage lower than $100 \mathrm{ppm}$. This result illustrates that both flocculants had a similar apparent polymer length in these conditions. 


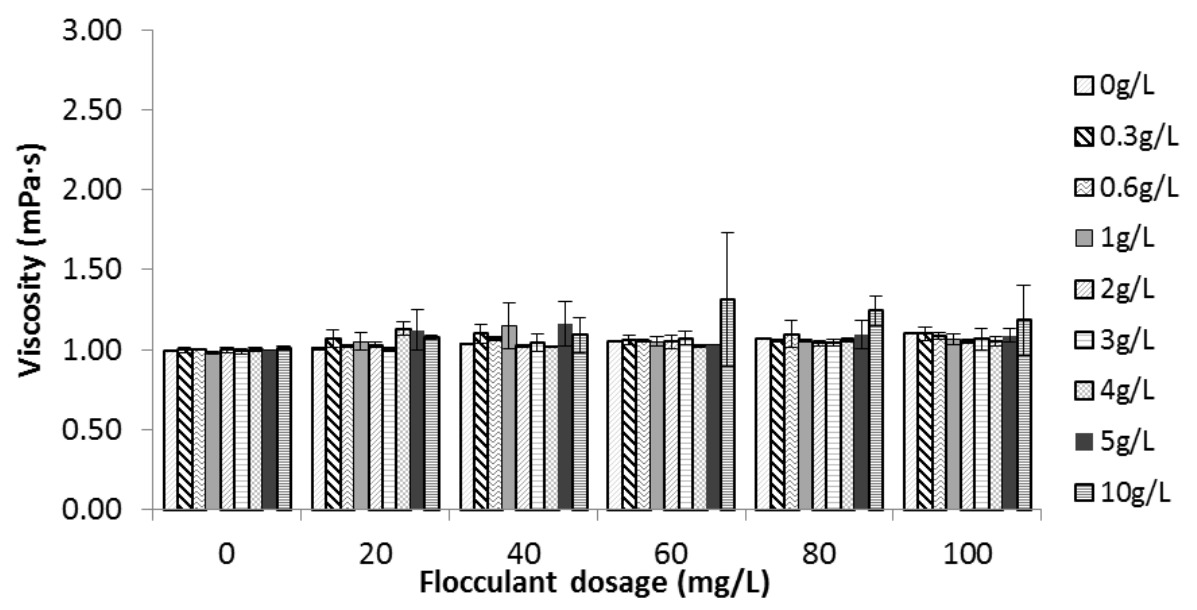

Figure 4.3: Viscosity of Chitosan measured at a share rate of $100 \mathrm{~s}^{-1}$. Every cluster of bars represent a flocculant dosage. Within every cluster, the salinity was increased, corresponding the legend at the right site of the figure. Error bars are duplicates.

Although polymeric coiling obviously occurs in elevated salinity, it does not explain the success of Synthofloc 5080H in high salinity and the decreasing functionality of Chitosan with increasing salinity as the salinity of seawater is approximately $35 \mathrm{~g} / \mathrm{L}$. These results illustrate that another characteristic of the flocculants should be responsible for the degree of success of flocculants in high salinities.

\section{3. -Potential}

In addition to the apparent length of the polymeric chain, the charge of cationic polymers may be an important feature. With increasing salinity, the net cationic charge of polymers should decrease due to the surrounding of anions. $\zeta$-Potential measurements were performed to measure the impact of increasing salinity on the nett charge of the cationic polymers (Figure 4.4). For both flocculants, the polymeric potential was measured as a function of salinity. The salinity was increased by an addition of $\mathrm{NaCl}$. These measurements were performed with various dosages (Figure 4.4). 


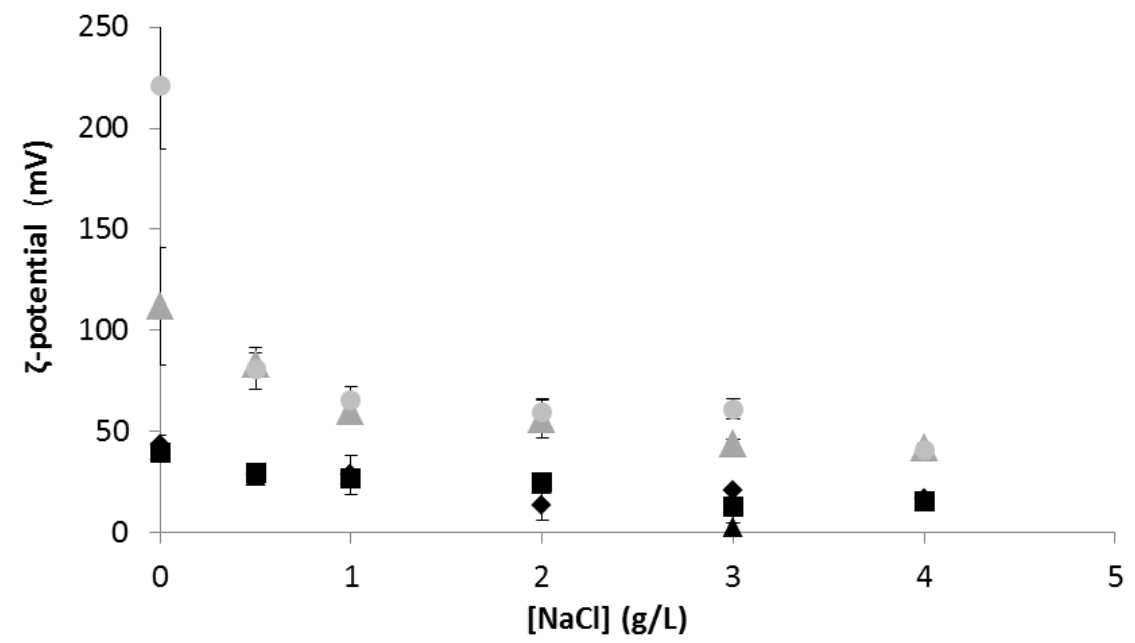

Figure 4.4: $\zeta$-potential as a function of $[\mathrm{NaCl}](\mathrm{g} / \mathrm{L})$. Synthofloc $5080 \mathrm{H}$, potentials measured at: 100 $\mathrm{mg} / \mathrm{L}(\Delta)$ and $200 \mathrm{mg} / \mathrm{L}(\bullet)$. Chitosan, potentials measured at: $30 \mathrm{mg} / \mathrm{L}(\triangleleft), 60 \mathrm{mg} / \mathrm{L}(\mathbf{\Delta})$ and $90 \mathrm{mg} / \mathrm{L}$ $(-$ ). Error bars are duplicates.

With both flocculants, the $\zeta$-potential decreases as a function of the salinity. When the $\zeta$-potential as a function of salinity of Synthofloc $5080 \mathrm{H}$ is compared with the $\zeta$ potential of Chitosan (Figure 4.4), it appears that the $\zeta$-potential of Synthofloc $5080 \mathrm{H}$ is generally more than twice as high regardless of the salinity. Both flocculants demonstrate an initial sharp decrease in $\zeta$-potential with salinity, but Synthofloc $5080 \mathrm{H}$ always has at least a $20 \mathrm{mV}$ or higher charge than Chitosan.

The combination of the observed difference in cationic charge for both flocculants with the observed similarities in viscosity with salinity suggests that the cationic charge is a predominant parameter influencing the flocculation efficiency of Neochloris oleoabundans under saline conditions.

\subsection{SEM Imaging}

In addition to viscosity- and $\zeta$-potential measurements, Scanning Electron Microscopy (SEM) was performed to verify if a difference between the two flocculants and any effect of salinity on the structure of the flocculated microalgae could be observed. The intention was to visualize if the flocculant is indeed adsorbed to the cell wall. In addition, the pictures can also reveal how individual cells are attached to each other: bridging, patching, a combination, or another possibility. 
In Figure 4.5, the cells and formed aggregates are depicted at brackish salinity (25 $\mathrm{g} / \mathrm{L}$, Figure 4.5-A,C and E) and at high salinity (45 g/L, Figure 4.5-B,D and F) after adding $60 \mathrm{mg} / \mathrm{L}$ of Synthofloc $5080 \mathrm{H}$.

Figure 4.5-A illustrates the cells without flocculant in brackish salinity. According to the figure, the cells are clustered which may be caused from the dehydration of the samples during the preparation. However, despite this clustering, the cells have smooth surfaces and are not bound to each other by a fibrous network of flocculants. After addition of the flocculant in brackish conditions, Synthofloc $5080 \mathrm{H}$ was strongly interacting with the single cells (Figure 4.5-C and E). The polymers adsorb to the surfaces and form a fibrous network between the single cells. As a result, large aggregates of flocs are formed. In addition, all of the flocculants appear to be adsorbed to the cells as no non-adsorbed flocculants are observed.

Figure 4.5-B shows that the single cells also have a smooth surface in very saline conditions. According to Figures 4.5-D and F, large agglomerates are formed just as those in brackish conditions. However, in this high salinity, Synthofloc $5080 \mathrm{H}$ appears to experience a weaker interaction with the cells as the large polymeric fibrous networks were not observed between individual cells. It appears that the flocculants are still adsorbed to the surface (Figure 4.5-F), however, they locally cover the cell surface which allow cells to interact and form small bridges. 

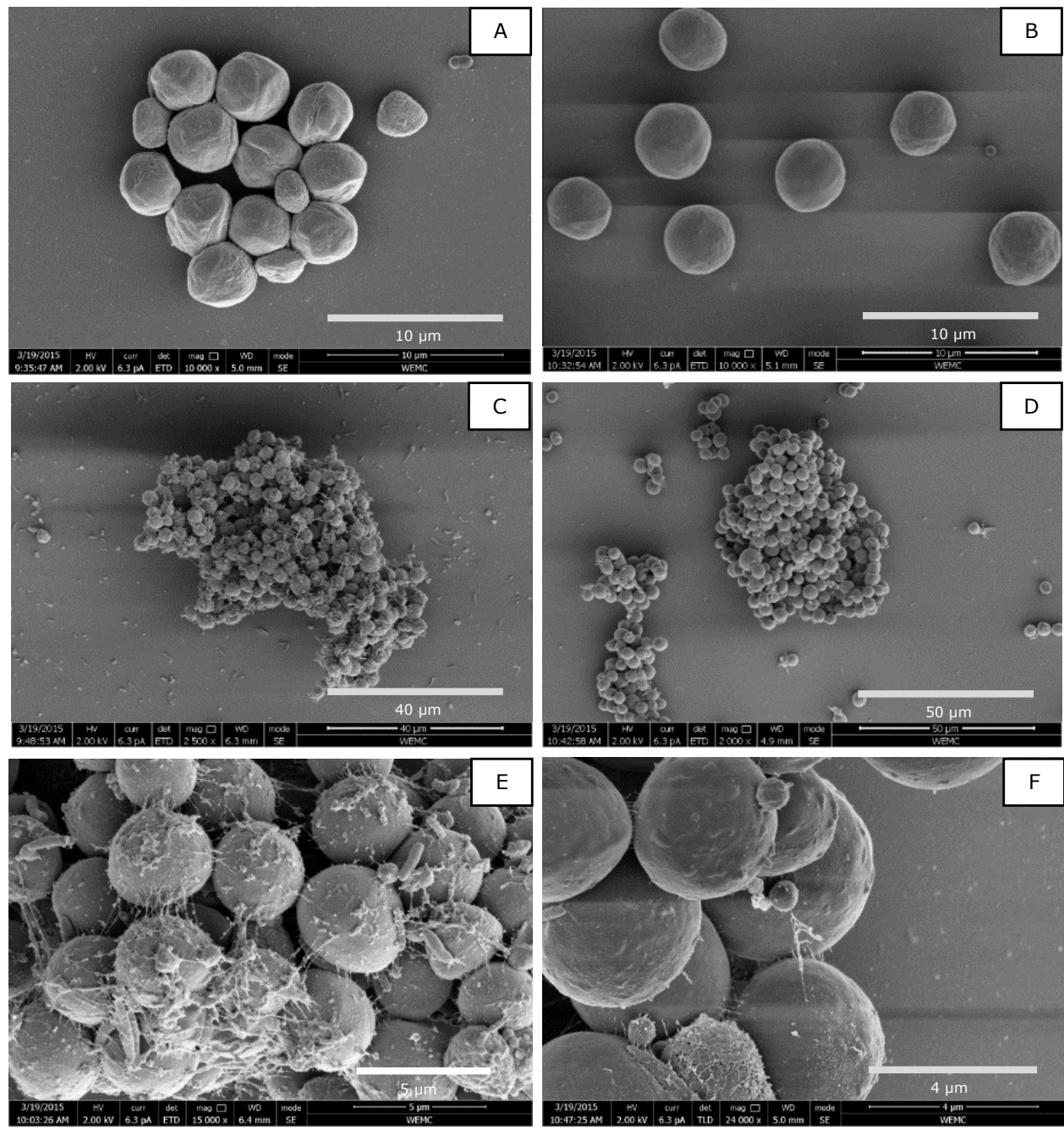

Figure 4.5: SEM imaging, A: control at $25 \mathrm{~g} / \mathrm{L}$ salinity. B: control at $45 \mathrm{~g} / \mathrm{L}$ salinity. C: Floc with Synthofloc at $25 \mathrm{~g} / \mathrm{L}$. D: floc with Synthofloc at $45 \mathrm{~g} / \mathrm{L}$. E: zoom in on the bridges with Synthofloc at 25 $\mathrm{g} / \mathrm{L}$. F: zoom in on the bridges with Synthofloc at $45 \mathrm{~g} / \mathrm{L}$. Used flocculant concentration was $60 \mathrm{mg} / \mathrm{L}$ 
In Figure 4.6, the floc formation after an addition of $60 \mathrm{mg} / \mathrm{L}$ of Chitosan is shown. Figure 4.6-A, C, and $E$ are pictures taken in brackish salinity ( $25 \mathrm{~g} / \mathrm{L})$, and Figure 4.6$B, D$, and $F$ are taken in very saline conditions ( $45 \mathrm{~g} / \mathrm{L})$.

The control picture in Figure 4.6-A is the same control picture that was taken in brackish salinities for Figure 4.5. Figure 4.6-C exhibits that, although $60 \mathrm{mg} / \mathrm{L}$ of Chitosan was added, no large aggregates are formed in brackish conditions. There are several small aggregates formed, but those contain no more than approximately three to four cells. In comparison with Figure $4.6 \mathrm{C}$ a relatively large amount of nonadsorbed flocculant was observed in the form of white small aggregates between the algal cells.

There were similar observations in very saline conditions. In Figure 4.6-B, the same control that was depicted in Figure 4.5 is shown. Also, small algal flocs are depicted in Figures 4.6-D and F. Just as was observed in brackish conditions, a relatively large amount of non-absorbed flocculant remains next to the small flocs.

In both salinities, the cationic polymers of Chitosan appear to be more entangled with each other than those of Synthofloc $5080 \mathrm{H}$. Despite this entanglement, the polymers were adsorbed to the cell wall. This is in accordance with the observed biomass recoveries obtained with Chitosan (Figure 4.1-B). 

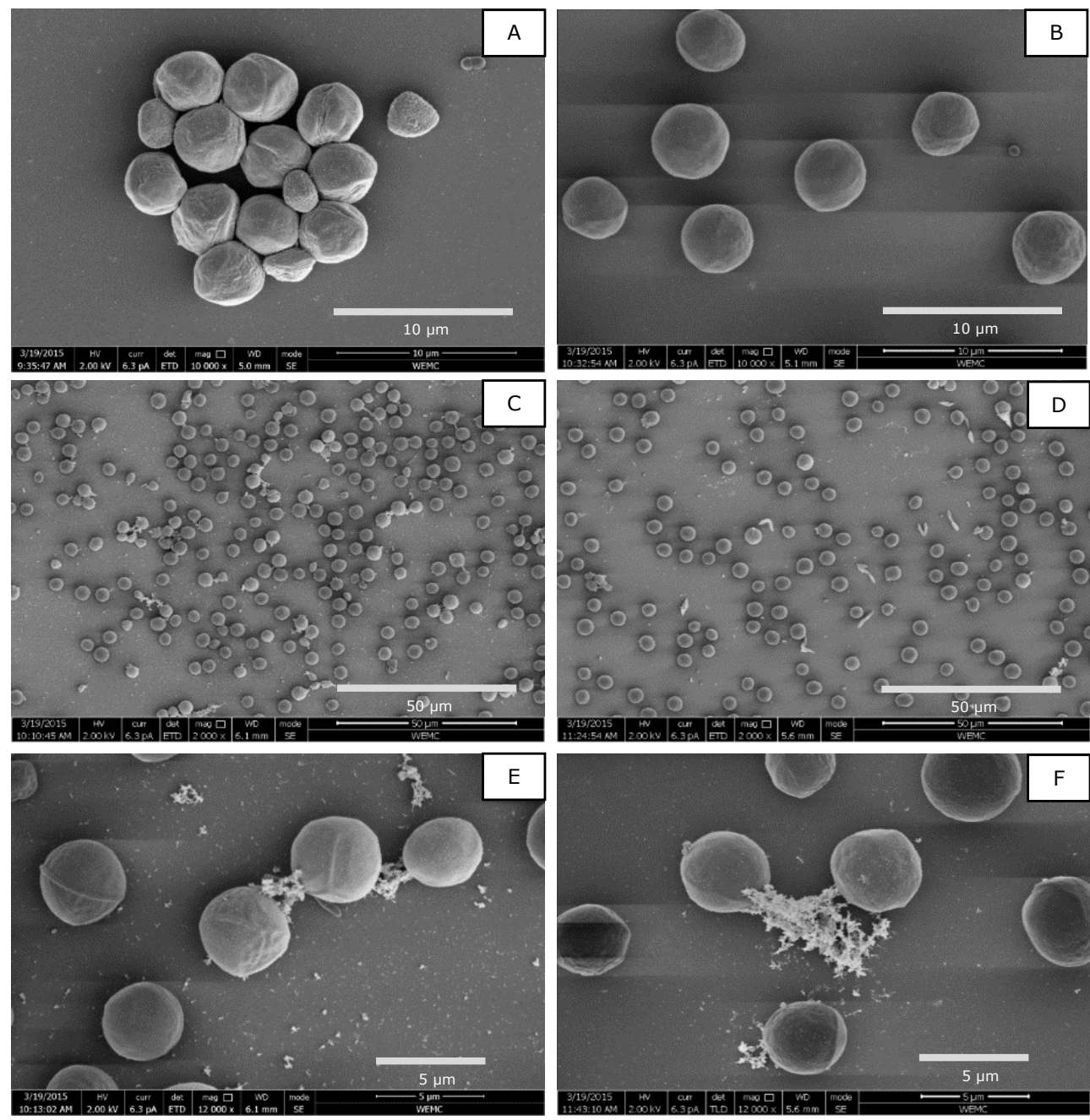

Figure 4.6: SEM imaging A: control at $25 \mathrm{~g} / \mathrm{L}$. B: control at $45 \mathrm{~g} / \mathrm{L}$. C: Floc with Chitosan at $25 \mathrm{~g} / \mathrm{L}$. D: floc with Chitosan at $45 \mathrm{~g} / \mathrm{L}$. E: zoom in on the bridges with Chitosan at $25 \mathrm{~g} / \mathrm{L}$. F: zoom in on the bridges with Chitosan at $45 \mathrm{~g} / \mathrm{L}$. Used flocculant concentration was $60 \mathrm{mg} / \mathrm{L}$ 
The observations (Figure 4.5 and Figure 4.6) correspond well with the results of the $\zeta$ -potential measurements. It was hypothesized that polymeric flocculants must be absorbed to the cell wall before inducing flocculation. After 15 minutes of mixing, all of the Synthofloc $5080 \mathrm{H}$ polymers appear to be adsorbed since white aggregates are no longer detected. However, with Chitosan, a relatively large amount of nonabsorbed polymers are still observed outside the flocs.

Our previous work ('t Lam et al., 2015) mathematically confirmed a proposed floc forming mechanism that, just as in other, earlier studies, assumes polymeric adsorption (Vandamme et al., 2013). The SEM analysis in this study supports the proposed mechanism of adsorption of a flocculant on a cell wall.

Polymeric adsorption to a surface can be enhanced by charge differences (Bolto and Gregory, 2007). The larger the charge difference between polymers and the cell wall, the quicker the polymer will be adsorbed (Al-Hashmi and Luckham 2010; Tekin et al. 2010). These results obtained in other studies suggest the necessity of a high charge difference between polymer and surface (in this case, the microalgal cell wall). Ensuing from this conclusion, the results reported in Figure 4.4 suggest that the decrease in cationic charge caused a decreased efficiency of cationic polymers in elevated salinities.

In addition to a lower degree of adsorption of polymers on the cell wall, Tenney, et al. (1969) suggested that charge neutralization plays a role in inducing floc formation. When charge neutralization is actually taking place during floc formation, a polymer with a higher cationic charge will be more efficient in locally neutralizing the charge of individual cells.

The decrease in cationic charge that caused a lower degree of adsorption in combination with a decreased ability to neutralize cell wall charges plausibly caused the decreased flocculation of Chitosan in elevated salinities (Figure 4.1). It may also explain the remaining amount of polymers that were observed after 15 minutes of mixing (Figure 4.6).

\subsection{Flocculation at various cationic charge densities}

To confirm that a decrease in cationic charge due to an increasing salinity is causing a decrease in flocculation, additional tests were performed with flocculants from the 
Synthofloc 50-series. By keeping the polymeric structure (and size) constant and varying the charge density from a low charge $(5025 \mathrm{H})$ through a moderate cationic charge $(5040 \mathrm{H})$ up to a highly charged cationic polymer $(5080 \mathrm{H})$, the effect of cationic charge could be confirmed (Figure 4.7). The applied salinity in this experiment was $35 \mathrm{~g} / \mathrm{L}$.

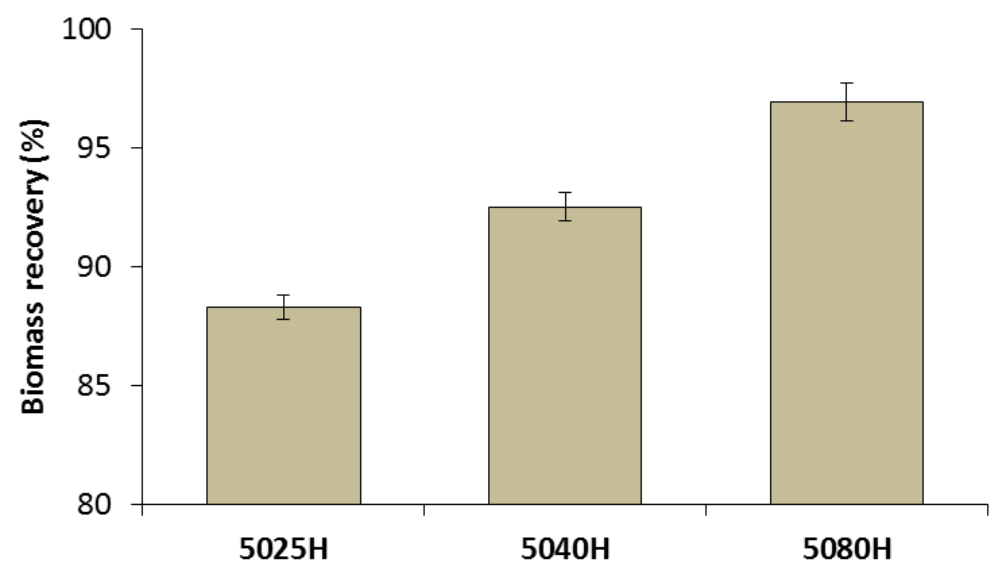

Figure 4.7: Biomass recoveries as a function of the charge density $(5025 \mathrm{H} ; 5040 \mathrm{H}$ and $5080 \mathrm{H})$. All experiments are performed in biological duplicates. Synthofloc $5080 \mathrm{H}$ is adapted from Figure 4.1.

According to Figure 4.7 , with a flocculant dosage of $30 \mathrm{mg} / \mathrm{L}$, the flocculant with the highest charge density $(5080 \mathrm{H})$ was the most efficient in harvesting the biomass in marine conditions. On average, a $9 \%$ higher biomass recovery was obtained with $5080 \mathrm{H}$ compared to $5025 \mathrm{H}$. These results demonstrate that a higher charge density results in greater biomass recoveries. The combination of the results presented in Figure 4.7 with the observed decrease in $\zeta$-potential as a function of medium salinity (Figure 4.4) and apparent independence of the biomass recovery on the degree of coiling of a flocculant suggest that, due to a decrease in cationic charge in elevated salinities, flocculants become less functional.

A change in biomass recovery as a function of the charge density, similar to the results in Figure 4.7, was previously observed by Roselet et al. (2015). In their study, the freshwater microalga Chlorella vulgaris and the seawater microalga Nannochloropsis oculata were flocculated with cationic poly(acryl)amides of the 'Flopam' series. By maintaining a constant polymeric size and varying the charge density from $0 \%$ to $100 \%$, the effect of the cationic charge on the biomass recovery 
was determined. The biomass recovery increased from recoveries lower than $10 \%$ to recoveries higher than $90 \%$ with both microalgae as a function of the charge density.

\section{Conclusion}

The decrease in nett cationic charge in elevated salinities incites decreased functionality of cationic polymers and induces flocculation of Neochloris oleoabundans. In high salinities, the resulting lower charge caused diminished efficiency in forming polymeric bridges between individual cells. This insight resulted in the conclusion that the cationic charge is an important criterion in selecting cationic polymers as a flocculant for marine applications where the apparent polymer length is of minor significance. This study also revealed that, in both brackish and marine conditions, polymeric bridging is a dominant mechanism in floc formation for cationic polymers.

\section{Acknowledgement}

This work is performed within the TKI AlgaePARC Biorefinery program with financial support from the Netherlands' Ministry of Economic Affairs in the framework of the TKI BioBased Economy under contract nr. TKIBE01009. The authors thank the department of Food Process Engineering (Wageningen University) and, in particular, Jos Sewalt for his assistance in analysing the flocculants. The authors thank Marcel Giesbers of the Wageningen Electron Microscopy Centre of Wageningen University for his support with SEM imaging. The authors are grateful for receiving the poly(acryl)amidic flocculants from Sachtleben Wasserchemie GmbH (Germany). 


$$
\text { - }
$$




\section{Part II: Cell disruption of microalgae}

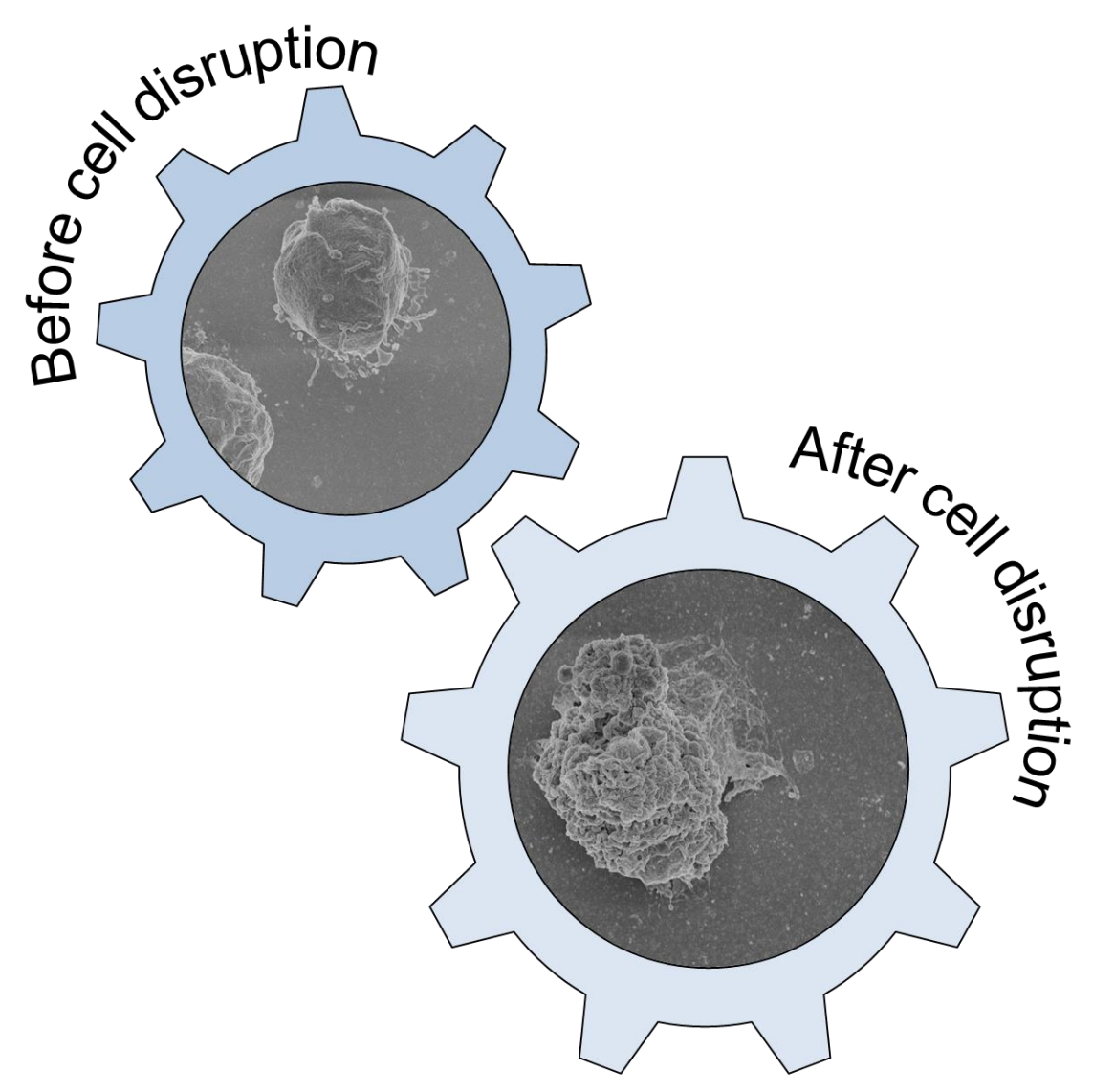





\section{Abstract}

Pulsed Electric Field (PEF) has been considered as a promising technology to disrupt microalgae in a biorefinery framework. Applying PEF on $C$. vulgaris and the marine cultivated $N$. oleoabundans, however, showed that at maximum only $13 \%$ of proteins were released where bead milling yielded in a $40-50 \%$ proteins release. Similar low yields were reported by others as well, illustrating that PEF is not competitive yet with this benchmark technology (Chapter 5).

Despite the low protein yields, a literature review revealed that PEF treatment seem to enhance the lipid extractability (Chapter 6). Although direct lipid extraction is not desired for an integrated biorefinery, these results do underline that PEF may be feasible for other, specific applications.

Performing PEF on $C$. reinhardtii and its cell-wall deficient mutant showed that only the cell membrane is susceptible for PEF where the outer cell wall is not (Chapter 7 ). Applying PEF on the mutant strain resulted in substantial higher protein yields. Additional experiments under simulated conditions showed that PEF in combination with a pre-treatment could be a viable option for cell disruption. After PEF-treatment, the cell-wall deficient mutant exhibited a $\sim 70 \%$ protein release compared with bead beating, while the maximum required energy input is only $0.05 \mathrm{kWh} / \mathrm{kg} \mathrm{DW}$. Moreover, PEF is a selective technology as the hydrophobic pigments remained entrapped. Additional Native-PAGE showed that PEF can be considered a mild technology that leaves the valuable proteins intact (Chapter 7).

In the search for a pre-treatment, treatment of the cells with potential cell-wall degrading enzymes appeared feasible. Pre-treatment with protease followed by PEF enhanced the protein yield obtained from the wild type $C$. reinhardtii by a three-fold. More research on the cell wall composition and structure is required, to develop the enzyme-assisted PEF into a mature technology for targeted cell disruption (Chapter 7). 



\section{Chapter}

Pulsed Electric Field for protein release of the microalgae Chlorella vulgaris and Neochloris oleoabundans

\section{Published as:}

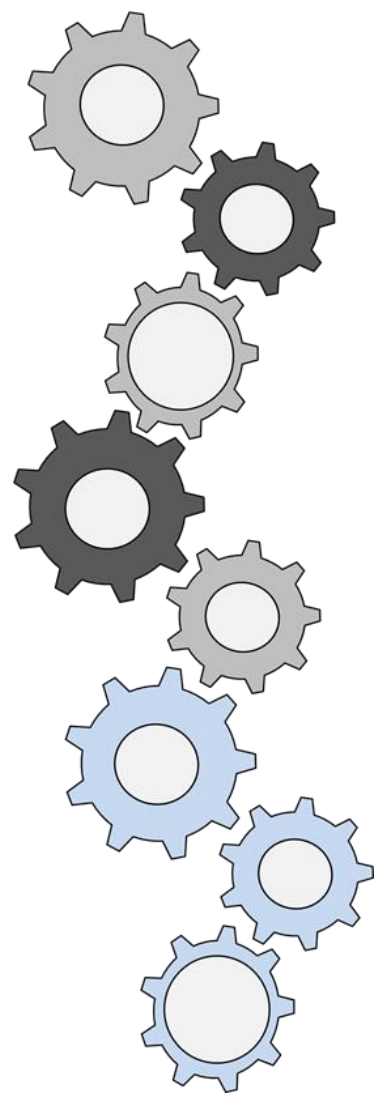

't Lam, G.P.*, Postma P.R.*, Fernandes D.A., Timmermans R.A.H., M.H. Vermuë, M.J. Barbosa, M.H.M. Eppink, Wijffels R.H. Olivieri G. (2017) Pulsed Electric Field for protein release of the microalgae Chlorella vulgaris and Neochloris oleoabundans. Algal Res. 24A: 181-187

*equal contributions 
ulsed Electric Field (PEF) is currently discussed as promising technology for mild and scalable cell disruption of microalgae. In this study Chlorella vulgaris and Neochloris oleoabundans have been subjected to batch and continuous PEF treatments under a wide range of operating conditions (1 - 40 pulses, $0.05-5$ ms pulses, $\left.7.5-30 \mathrm{kV} \mathrm{cm}^{-1}, 0.03-150 \mathrm{kWh} \mathrm{kgDw}^{-1}\right)$. In many cases after treatment, both algal species show release of ions, which indicates that PEF treatment resulted in permeabilization of the algal cell. However, the electroporation effect was not sufficient to substantially release intracellular proteins. Even at severe energy input (10 to 100 times higher than the benchmark bead milling) only up to $13 \%$ of proteins released from the cells in comparison to $45-50 \%$ after bead milling. 


\section{Introduction}

Microalgae are a promising feedstock for the production of bulk commodities because of their interesting composition (Becker 2007; Wijffels et al. 2010; Popovich et al. 2012). It has been proposed in literature to increase the potential value of the biomass by adopting a biorefinery approach instead of a single-product isolation (Wijffels et al. 2010; Singh et al. 2010; Yen et al. 2013; Vanthoor-Koopmans et al. 2013; Eppink et al. 2012). By applying a biorefinery, all the components, such as proteins, pigments and carbohydrates, can be valorised (Vanthoor-Koopmans et al. 2013). Though, the biorefinery should be mild to maintain the integrity of the components (Vanthoor-Koopmans et al. 2013, Günerken et al. 2015; Eing et al. 2009; Kotnik et al. 2015; Luengo et al. 2014).

The majority of these components are present in the cytoplasm or in internal organelles (e.g. chloroplast) and they are difficult to access due to the rigid algae cell walls (Coustets et al. 2013). However, harsh cell disruption technologies are not preferred if especially proteins are foreseen to be extracted in their native form (Vanthoor-Koopmans et al. 2013).

PEF has already been mentioned as a promising technology for mild cell disruption in literature (Eing et al. 2013; Goettel et al. 2013; Grimi et al. 2014). By applying short electrical pulses (in the order of magnitude of ms or even $\mu \mathrm{s}$ ), the cell membrane can be charged sufficiently to cause a rearrangement of the lipid membrane, resulting in pore formation (Goettel et al. 2013). Due to the short electrical pulses applied, this technology requires a low energy input (even lower than $1 \mathrm{kWh} \mathrm{kgow}^{-1}$, see Table 1). In addition, the method is mild for the molecules that should be released because they are subjected to a limited temperature increase and limited shear forces during the treatment.

An overview of studies on the application of PEF for disruption of microalgal and cyanobacterial biomass for the release of proteins and lipids is presented in Table 5.1. From this overview, it can be deduced that not only various experimental approaches, but also various results have been obtained. When looking to the protein yields, it can be seen that over a wide range of specific energy inputs (0.02 $239 \mathrm{kWh} \mathrm{kgDw}^{-1}$ ) very low to low protein yields have been obtained. 
Table 5.1: Literature overview of previous performed PEF studies.

\begin{tabular}{|c|c|c|c|c|}
\hline Microorganism & Product & Conditions & Outcome & Reference \\
\hline Nannochloropsis salina & Proteins & $\begin{array}{l}15.4 \text { - } 30.9 \mathrm{kWh} / \mathrm{kg}, 37 \\
{ }^{\circ} \mathrm{C} \text { outflow } \\
\text { temperature, } 0.0545 \text { - } \\
0.109 \% \mathrm{DCW}\end{array}$ & $\begin{array}{l}4 \text { fold more extraction } \\
\text { with water than } \\
\text { methanol extraction of } \\
\text { untreated cells }\end{array}$ & $\begin{array}{l}\text { Coustets et } \\
\text { al. (2013) }\end{array}$ \\
\hline Chlorella vulgaris & Proteins & $\begin{array}{l}2.3 \mathrm{kWh} / \mathrm{kg}, 37^{\circ} \mathrm{C} \\
\text { outflow temperature, } \\
0.73 \% \mathrm{DCW}\end{array}$ & $\begin{array}{l}2 \text { fold more extraction } \\
\text { with water than } \\
\text { methanol extraction of } \\
\text { untreated cells }\end{array}$ & $\begin{array}{l}\text { Coustets et } \\
\text { al. (2015) }\end{array}$ \\
\hline Auxenochlorella prothecoides & Lipids & $\begin{array}{l}0.15-0.6 \mathrm{kWh} / \mathrm{kg}, 10 \\
\% \mathrm{DCW}\end{array}$ & $\begin{array}{l}\text { Over } 3 \text { fold more } \\
\text { extraction with ethanol }\end{array}$ & $\begin{array}{l}\text { Eing et al. } \\
(2009)\end{array}$ \\
\hline Auxenochlorella prothecoides & Proteins & $\begin{array}{l}0.15-0.6 \mathrm{kWh} / \mathrm{kg}, 14- \\
22{ }^{\circ} \mathrm{C} \text { temperature } \\
\text { increase, } 3.6- \\
16.7 \% \mathrm{DCW}\end{array}$ & $\begin{array}{l}2 \mu \mathrm{g} / \mathrm{L} \text { of protein } \\
\text { release in the } \\
\text { supernatant }\end{array}$ & $\begin{array}{l}\text { Goettel et } \\
\text { al. (2013) }\end{array}$ \\
\hline Nannochloropsis salina & Proteins & $\begin{array}{l}0.4-1.5 \mathrm{kWh} / \mathrm{kg}, 1.0 \% \\
\text { DCW }\end{array}$ & $\begin{array}{l}3.6 \% \text { protein release } \\
\text { after PEF treatment }\end{array}$ & $\begin{array}{l}\text { Grimi et al. } \\
(2014)\end{array}$ \\
\hline Nannochloropsis salina & Proteins & $\begin{array}{l}0.02-14 \mathrm{kWh} / \mathrm{kg}, 5.74- \\
34.45^{\circ} \mathrm{C} \text { temperature } \\
\text { increase, } 1 \% \mathrm{DCW}\end{array}$ & $\begin{array}{l}\text { Protein release in the } \\
\text { supernatant of } 10 \%\end{array}$ & $\begin{array}{l}\text { Parniakov } \\
\text { et al. (2015) }\end{array}$ \\
\hline Chlorella vulgaris & $\begin{array}{l}\text { Proteins/ } \\
\text { Carbohydrates }\end{array}$ & 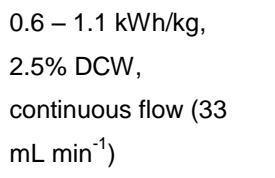 & $\begin{array}{l}4.9 \% \text { protein release after } \\
\text { PEF treatment }\end{array}$ & $\begin{array}{l}\text { Postma et } \\
\text { al. (2016) }\end{array}$ \\
\hline Synechocystis PCC 6803 & Lipids & $\begin{array}{l}59.7-239 \mathrm{kWh} / \mathrm{kg}, \\
0.03 \% \mathrm{DCW}\end{array}$ & $\begin{array}{l}25-75 \% \text { increased lipid } \\
\text { recovery }\end{array}$ & $\begin{array}{l}\text { Sheng et al. } \\
(2012)\end{array}$ \\
\hline Scenedesmus spp. & Lipids & $\begin{array}{l}6.9 \mathrm{kWh} / \mathrm{kg}, 0.44 \% \\
\text { DCW }\end{array}$ & $\begin{array}{l}3.1 \text { fold increase in } \\
\text { lipid recovery }\end{array}$ & $\begin{array}{l}\text { Lai et al. } \\
\text { (2014) }\end{array}$ \\
\hline
\end{tabular}

These low protein yields are in contradiction with the current consensus in literature on the general feasibility of PEF (Kotnik et al., 2015). It is therefore difficult to create a consensus about the performance of PEF for the disintegration of microalgae or cyanobacteria. In addition even though PEF is regarded as a promising technology for releasing hydrophilic proteins, an elaborate study that evaluates PEF over a similar range of processing conditions in direct comparison to benchmark disintegration technologies is not presented yet. Further, some studies applied marine cultivated microalgae, although the effect of desalination prior to the PEF 
treatment has not been addressed yet (Coustets et al. 2013; Goettel et al. 2013; Grimi et al. 2014; Parniakov et al., 2015).

This work therefore presents a systematic screening of the operating conditions required to spontaneously release ions and proteins from the fresh water species Chlorella vulgaris and the marine water cultivated species Neochloris oleoabundans using two different PEF devices in a wide range of operating conditions. The results obtained with PEF are compared with those found for bead milling as a mechanical benchmark (Postma et al. 2015). By doing so, a quantitative insight on the current state-of-development of PEF compared to a benchmark technology for both freshwater and marine cultivated microalgae is obtained.

\section{Material and Methods}

\subsection{Study Design}

This study is divided in three different parts: biomass pre-treatment, batch PEF operation and continuous PEF operation. The biomass pre-treatment describes the effect of washing and concentrating on the integrity of both microalgal strains. After the pre-treatment, using a batch mode PEF, various experiments were performed to determine the effect of operating conditions, and the energy input on the release of ions and proteins. Finally, to eliminate an effect of the equipment design, additional experiments using a continuous mode PEF were performed.

\subsection{Biomass supply and preparation}

C. vulgaris (SAG 211-11b, EPSAG Göttingen, Germany) was cultivated for 7 days according to Postma et al. (2015) using repeated batch cultivation in a fully controlled $12 \mathrm{~L}$ stirred tank reactor. The light intensity was increased during the cultivation from 400 up to $1100 \mu \mathrm{mol} \mathrm{m} \mathrm{m}^{-2} \mathrm{~s}^{-1}$. The temperature was kept constant at $25{ }^{\circ} \mathrm{C}$ and $\mathrm{C}$. vulgaris was cultivated in M8a medium at $\mathrm{pH} 7.0$ according to Kliphuis et al. (2010). The microalgae were harvested each time at late linear growth phase at an $\mathrm{OD}_{750 \mathrm{~nm}}$ of $\sim 15$.

N. oleoabundans (UTEX 1185, Austin, USA) was cultivated in a continuous mode operated $3 \mathrm{~L}$ stirred tank reactor. During cultivation the incident light intensity was kept constant at $200 \mu \mathrm{mol} \cdot \mathrm{m}^{-2} \cdot \mathrm{s}^{-1}$. Temperature and $\mathrm{pH}$ were kept constant at $25^{\circ} \mathrm{C}$ 
and 7.5 respectively. $N$. oleoabundans was cultivated in artificial sea-water according to Breuer et al. (2012). After harvesting, the biomass of both species was stored in a cooled $\left(4^{\circ} \mathrm{C}\right)$ and dark environment for maximum 72 hours.

Samples were centrifuged at $4000 \times \mathrm{g}$ for 15 minutes and the pellet was washed with Milli-Q water ( $N$. oleoabundans) or with a $0.04 \% \mathrm{NaCl}$ solution (C. vulgaris) to adjust the conductivity of the samples to an electrical conductivity of maximum $1.5 \mathrm{mS} \mathrm{cm}^{-1}$ prior to PEF treatment. After washing the biomass, the concentration was adjusted to the desired concentration. The effect of a possible osmotic shock after washing the algal biomass was determined by analysis of protein release before and after washing.

\subsection{Batch mode PEF treatment}

Batch mode screening of PEF conditions was performed in a lab-scale electroporator (Gene-Pulser Xcell ${ }^{\mathrm{TM}}$ Bio-Rad, USA), also commonly used for electrotransformation of algae cells (Kilian et al. 2011; Chow et al. 1999; Run et al. 2016), using cuvettes with gap distances of 1, 2 and $4 \mathrm{~mm}$ (Bio-Rad, Hercules, CA, USA). By altering the voltage between 1.6 and $3.0 \mathrm{kV}$ the electric field strength could be varied between 7.5 and $30 \mathrm{kV} \mathrm{cm}^{-1}$. Further, 1 - 40 square wave pulses with various lengths $(0.05-5$ $\mathrm{ms}$ ) were applied each $5 \mathrm{~s}$. For $N$. oleoabundans, the cuvettes they were cooled to a temperature of $4{ }^{\circ} \mathrm{C}$ after filling, before PEF treatment. Electroporation of $C$. vulgaris was always conducted at room temperature. After treatment, the temperature was measured and it never exceeded $40^{\circ} \mathrm{C}$ for all experiments of both algae.

The treated samples were gently mixed for 1 hour to allow intracellular components to diffuse out of the biomass. After mixing, the suspension was centrifuged $(20,000 x$ $\mathrm{g}, 10 \mathrm{~min}$ ) and the release of intracellular components was measured in the supernatant.

\subsection{Continuous flow PEF treatment}

Continuous flow PEF experiments were performed on a previously described labscale PEF system (Timmermans et al., 2014) as a downscaled copy of a pilot-scale PEF equipment (Timmermans et al., 2011). Special attention was paid to downscale criteria to guarantee electric field homogeneity. In short, the algae suspension was 
pumped at room temperature $\left(20^{\circ} \mathrm{C}\right)$ with a flowrate of $13 \mathrm{ml} \mathrm{min}^{-1}$ through two colinear treatment zones placed in series with a diameter of $1 \mathrm{~mm}$ and a gap distance of $2 \mathrm{~mm}$, resulting in a total residence time of $13.5 \mathrm{~ms}$ in the treatment chambers. Directly after leaving the treatment chambers, the suspension was cooled down by pumping through a coil placed in ice-water, to a temperature below $20^{\circ} \mathrm{C}$. PEF processing was applied using square wave monopolar pulses at an electric field strength of $20 \mathrm{kV} \mathrm{cm}^{-1}$ with a pulse duration of $2 \mu \mathrm{s}$. The pulse waveform, voltage and intensity were monitored with a digital oscilloscope (Rigol DS1102, Beaverton, USA). By varying the pulse frequency, the total number of applied pulsed was changed leading to different maximum temperatures (Table 5.2).

Table 5.2: Process conditions used for PEF treatment of algae suspensions on continuous flow system.

\begin{tabular}{lcccccr}
\hline Suspension & Frequency $\mathbf{( H z )}$ & $\begin{array}{l}\text { Number of } \\
\text { pulses }\end{array}$ & $\begin{array}{l}\text { Electrical field } \\
\text { strength }\left(\mathbf{k V ~} \mathbf{~ m}^{-1}\right)\end{array}$ & $\begin{array}{l}\mathbf{T}_{\text {in }} \\
\left({ }^{\circ} \mathbf{C}\right)\end{array}$ & $\begin{array}{l}\mathbf{T}_{\text {out }} \\
\left({ }^{\circ} \mathbf{C}\right)\end{array}$ & $\mathbf{d T ~}\left({ }^{\circ} \mathbf{C}\right)$ \\
\hline C. vulgaris & 964 & 14.0 & 20.6 & 21.7 & 30.4 & 8.7 \\
& 390 & 5.7 & 20.4 & 21.8 & 25.7 & 3.9 \\
& 120 & 1.7 & 20.1 & 21.8 & 23.2 & 1.4 \\
& 0 & 0.0 & 0.0 & 21.9 & 21.9 & 0.0 \\
N. oleoabundans & 964 & 14.0 & 19.7 & 20.8 & 31.4 & 10.6 \\
& 390 & 5.7 & 20.3 & 21.0 & 25.3 & 4.3 \\
& 120 & 1.7 & 20.7 & 21.2 & 22.7 & 1.5 \\
& 0 & 0.0 & 0.0 & 21.3 & 21.3 & 0.0 \\
\hline
\end{tabular}

Temperature increase for each condition was measured using thermocouples placed just before and after the treatment chambers. Furthermore, it could be calculated, based on:

$d T=\frac{E^{2} \cdot \sigma \cdot \tau}{\rho \cdot c_{p}}$

where $E$ is electric field strength $\left(\mathrm{V} \mathrm{m}^{-1}\right), \sigma$ is the electrical conductivity $\left(\mathrm{S} \mathrm{m}^{-1}\right), \tau$ is pulse duration (s), $\rho$ is density of the algae suspension, $c_{p}$ is the specific heat ( $\mathrm{kJ}$ $\left.(\mathrm{kg} \cdot \mathrm{K})^{-1}\right)$, being $4.12 \mathrm{~kJ}(\mathrm{~kg} \cdot \mathrm{K})^{-1}$. The used biomass concentration in this experiment was $25 \mathrm{~g} \mathrm{~kg}^{-1}$ for both algae, resulting in a specific energy input of $0,0.05,0.165$ and $0.41 \mathrm{kWh} \mathrm{kgDW}^{-1}$ (respectively 0, 180, 594 and $1476 \mathrm{~kJ} \mathrm{kgDW}^{-1}$ ). 


\subsection{Bead mill experiments}

The protein release after bead milling reported for $C$. vulgaris by Postma et al. (2015) was used to evaluate the performance of using PEF for this species. For $N$. oleoabundans, additional bead mill experiments were performed similar to Postma et al. (2015). A Dyno ${ }^{\circledR}$-Mill ECM-AP 05 bead mill was operated using zirconia beads with bead sizes of 0.3 and $0.5 \mathrm{~mm}$. The treatment chamber was filled for $70 \%$ and the applied tip speed was $8 \mathrm{~m} \mathrm{~s}^{-1}$. Biomass concentrations ranging between 50 and $100 \mathrm{gDW} \mathrm{kg}^{-1}$ were treated in different modes of operation: single pass, double pass and with a batch recirculation. In all experiments the liquid throughput was $10 \mathrm{~kg} \mathrm{~h}^{-1}$. After treatment, the protein release in the supernatant was measured. To determine the increase in conductivity, lab scale experiments using beat beating were performed.

\subsection{Electrical conductivity measurement}

Before and after every treatment, the electrical conductivity of the supernatant was measured at room temperature using a Mettler Toledo ${ }^{\circledR}$ SevenCompact ${ }^{\mathrm{TM}}$ probe without temperature compensation. All samples were analysed at the same temperature (room temperature). As a positive control, bead beated biomass was measured and results were used for further calculations.

\subsection{Protein analysis}

The total protein content on biomass dry weight (DW) was determined according to de Winter et al. (2013). In short, the biomass was freeze dried and then beat beated in a cell lysis buffer to solubilize all proteins. After bead beating the samples were incubated for $30 \mathrm{~min}$ at $100^{\circ} \mathrm{C}$.

Modified Lowry protein assay kits (Thermo Scientific and Bio-rad) were used to measure the total protein content and the soluble protein release before and after PEF treatment. The absorbance was measured at $750 \mathrm{~nm}$. Bovine serum albumin was used as a proteins standard. 


\subsection{Determination of the specific energy input}

The volumetric specific energy input $\left(W_{v}\right)$, previously described as the treatment intensity (TI) by Salerno et al. (2009) and Sheng et al. (2012), was calculated based on the operating conditions (electrical field strength, pulse number) and the conductivity before PEF as:

$W_{V}\left(\mathrm{kWh} \mathrm{m} \mathrm{m}^{-3}\right)=\frac{\mathrm{E}^{2} \cdot \mathrm{t}_{\mathrm{p}} \cdot \mathrm{N} \cdot \sigma}{3600000}$

In which $E$ is the electrical field strength in $\mathrm{V} \mathrm{m}^{-1}, t_{p}$ is the pulse length (s), $N$ are the number of pulses and $\sigma$ is the initial electrical conductivity at room temperature ( $\mathrm{S} \mathrm{m}$ $\left.{ }^{1}\right)$.

The mass specific energy input $\left(W_{M}\right)$ was subsequently calculated as:

$W_{M}\left(\mathrm{kWh} k g_{D W}^{-1}\right)=\frac{W_{V}}{C_{x}}$

In which $C_{x}$ is the biomass concentration $\left(\mathrm{kg}_{\mathrm{DW}} \mathrm{m}^{-3}\right)$.

\subsection{Determination of the relative ion yield and protein yields}

The permeabilization of the cell membrane was monitored by measurement of the electrical conductivity (Donsì et al. 2010). Similar to other studies, the relative ion yield $(\sigma R)$ was expressed as the specific increase in electrical conductivity with PEF over the specific electrical conductivity increase after bead beating. The increase in electrical conductivity was defined as the difference in electrical conductivity before and after treatment. In the reference beat beating experiments, the biomass concentrations were $25 \mathrm{~g} \mathrm{~kg}^{-1}$ (C. vulgaris) and $26 \mathrm{~g} \mathrm{~kg}^{-1}$ ( $N$. oleoabundans). The electrical conductivity increase after bead beating was measured to be $0.98 \mathrm{mS} \mathrm{cm}^{-1}$ for $C$. vulgaris and $1.06 \mathrm{mS} \mathrm{cm}^{-1}$ for $N$. oleoabundans.

$\sigma_{\mathrm{R}}(\%)=\frac{\left(\sigma_{\text {after PEF}}-\sigma_{\text {before PEF }}\right)}{\left(\sigma_{\text {after bead beating }}-\sigma_{\text {before beat beating }}\right)}$

Finally, the amount of released proteins was expressed as the increase in released proteins in the aqueous phase divided over the total protein concentration that was present in the treated suspension. The total protein concentration was calculated by multiplying the biomass concentration with the protein content of the biomass (\%Dw) (Postma et al., 2015): 
Protein yield (\%) $=\frac{C_{\text {soluble proteins after cell disruption }}-C_{\text {soluble proteins before disruption }}}{C_{\text {protein } \text { total }}} * 100 \%$

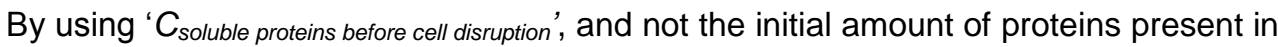
the aqueous phase, the effect of the osmotic shock can be distinguished from the effect of the PEF treatment.

\subsection{Experimental design and statistical analysis}

To exclude possible effects of the equipment design and to confirm the obtained results in the batch mode PEF, additional experiments were performed under continuous mode PEF. During continuous mode experiments, next to performing all analysis in technical replicates, drifts in the pulse delivery were eliminated by ensuring steady state operation prior to sampling.

To ensure reliability of the experimental data, all analytical procedures have been performed in at least technical duplicates. During the batch-electroporator campaign of experiments, additional tests at extreme conditions ( $\mathrm{E}>90 \mathrm{kWh} / \mathrm{kg} \mathrm{DW}$ ) were performed. An independent samples t-test with a significance level of $p=0.05$ (assuming equal variances) was used for statistical analysis.

\section{Results and Discussion}

In this section, first the results obtained using the batch mode PEF are presented followed by the results of the continuous flow PEF. Finally, the current state-ofdevelopment is discussed.

\subsection{Batch mode PEF}

\subsubsection{Effect of pulse parameters on PEF}

Pre-treatment of $C$. vulgaris by resuspending in $0.04 \% \mathrm{NaCl}$ did not release any proteins, even if an osmotic shock occurred. Figure 5.1 presents the specific ion release and the protein yield for $C$. vulgaris after applying a PEF treatment at three different energy consumptions for a fixed biomass concentration of $25 \mathrm{~g} \mathrm{~kg}^{-1}$. At each energy input, the pulse length, and number of pulses were changed to determine the effect of these individual parameters. The used energy inputs were; 0.4, 1.4 and 14 $\mathrm{kWh} \mathrm{kg} \mathrm{DW}^{-1}$. The field strength in these experiments was either 8 or $15 \mathrm{kV} \mathrm{cm}^{-1}$. With 
an increasing pulse length, the number of pulses was decreased proportionally at a given specific energy input. (Figure 5.1).

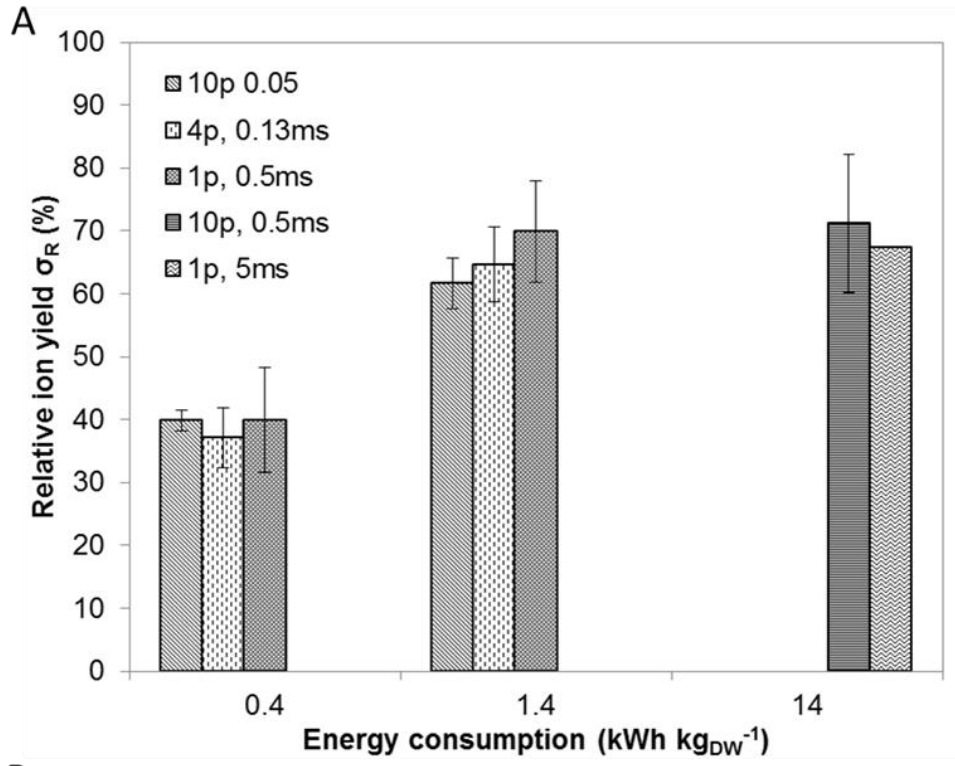

B

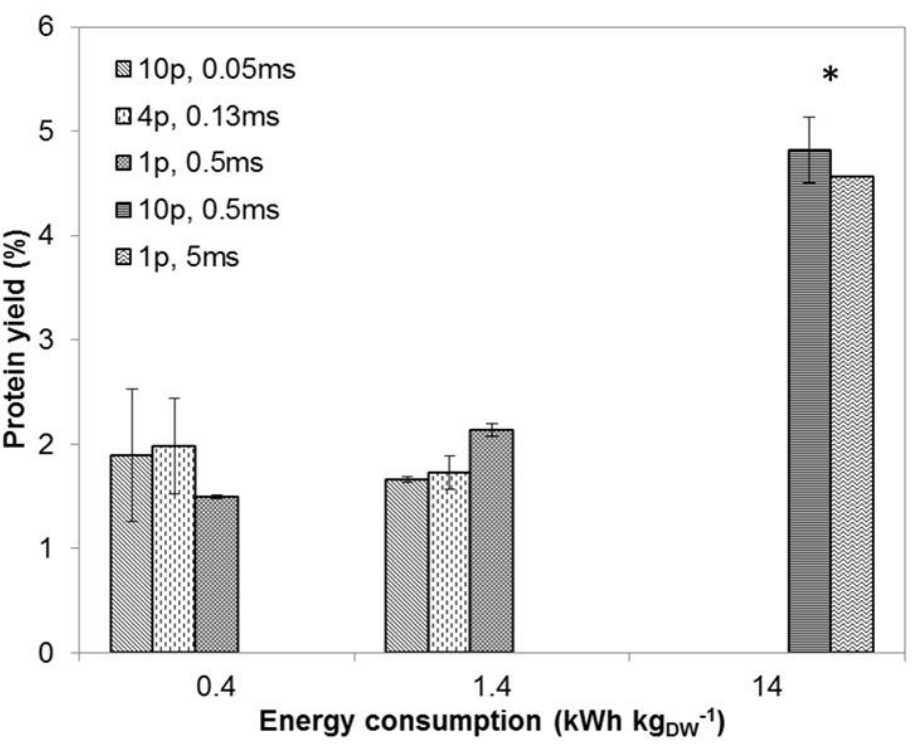

Figure 5.1: Relative ion yield $\left(\sigma_{R}\right)$ after PEF treatment as a function of pulse parameters for $C$. vulgaris (A). Protein yield measured $1 \mathrm{~h}$ after PEF as a function of pulse parameters for $C$. vulgaris (B). The electric field strengths was 8,15 and $15 \mathrm{kV} \mathrm{cm}^{-1}$ for $0.4,1.4$ and $14 \mathrm{kWh} \mathrm{kgDw}^{-1}$ respectively. * 14 $\mathrm{kWh} \mathrm{kg}_{\mathrm{DW}}{ }^{-1}$ significant different from 0.4 and $1.4 \mathrm{kWh} \mathrm{kg}_{\mathrm{DW}}{ }^{-1}$. Errors bars show standard deviation $(n=2)$. 
The results in Figure 5.1 show that with a specific energy input similar to the ones reported for bead milling (Postma et al. 2015), a substantial increase in electrical conductivity was obtained. These results imply that small components such as ions can be successfully released using PEF-treatments. Even though high amounts of ions were released, the protein yields were at best 6-8 fold lower in comparison to the mechanical benchmark bead milling (Postma et al. 2015). Noteworthy are the results by Sheng et al. (2011, 2012) and Ganeva et al. (2003), who treated the cyanobacteria Synechocystis PCC68003 and the yeast Saccharomyces cerevisiae, respectively. A volumetric specific energy input (i.e. treatment intensity) $W_{V}$ of $\sim 30$ $\mathrm{kWh} \mathrm{m}^{-3}$ appeared in their study sufficient to successfully disruption the cyanobacteria and yeast cells. Yet, this work showed that in the case of eukaryotic microalgae, a $W_{V}$ of $35 \mathrm{kWh} \mathrm{m}^{-3}\left(1.4 \mathrm{kWh} \mathrm{kgDW}^{-1}\right)$ or even $350 \mathrm{kWh} \mathrm{m}^{-3}(14 \mathrm{kWh}$ $\mathrm{kg}_{\mathrm{DW}}{ }^{-1}$ ) was merely enough to release small ionic substances.

Next to the release of proteins, Figure 5.1B also illustrates that individually varying the pulse length or number of pulses did not affect the protein yield. Instead, it appears that only the energy input affects the performance of PEF, as being illustrated the increase in release from about $1.8 \%$ at $0.4 \mathrm{kWh} \mathrm{kgDw}^{-1}$ up to $4.8 \%$ at $14 \mathrm{kWh} \mathrm{kgDW}^{-1}(p<0.05)$. No difference could be observed between 0.4 and $1.4 \mathrm{kWh}$ $\mathrm{kg}_{\mathrm{DW}}{ }^{-1}(p=0.82)$. This suggests that the specific energy input is the most important parameter affecting the operation. Similar results have been reported by Coustets et al. (2015). In their study 30 pulses of $1 \mathrm{~ms}$ and 15 pulses of $2 \mathrm{~ms}$ resulted in the same protein release at a fixed field strength of $4.5 \mathrm{kV} \mathrm{cm}^{-1}$.

\subsubsection{Release of intracellular components}

The results of Figure 5.1 showed that only the specific energy input affects the overall performance of PEF (under the same biomass concentration). ). Since a high release of ions was observed in all experiments, it is most likely that a sufficiently high field strength was applied to evoke a successful electroporation of the cells. Under these conditions, apparently the specific energy input is the pre-dominant operating parameter. Therefore, additional experiments were performed in which the ion release and the protein yield were investigated as a function of the energy input (electrical field strength ranged between 7.5 and $30 \mathrm{kV} \mathrm{cm}^{-1}$ ). The goal of these experiments was to identify operating conditions at which both a high release of ions 
and a high release of proteins could be obtained. This was done by extending the energy input range from 0.03 up to $150 \mathrm{kWh} \mathrm{kgDW}^{-1}$. In these experiments, both $C$. vulgaris and the seawater cultivated $N$. oleoabundans were subjected to a PEF treatment.

Prior to PEF-treatment, also N. oleoabundans was washed similar to the washing applied on $C$. vulgaris (see section 3.1.1). The washing resulted in a decrease of medium electrical conductivity from $45 \mathrm{mS} \mathrm{cm}^{-1}$ to less than $0.5 \mathrm{mS} \mathrm{cm}^{-1}$. The protein release caused by this pre-treatment was at maximum $4.8 \% \mathrm{DW}$ after washing (3.4\% DW) and concentrating (1.4\%DW).

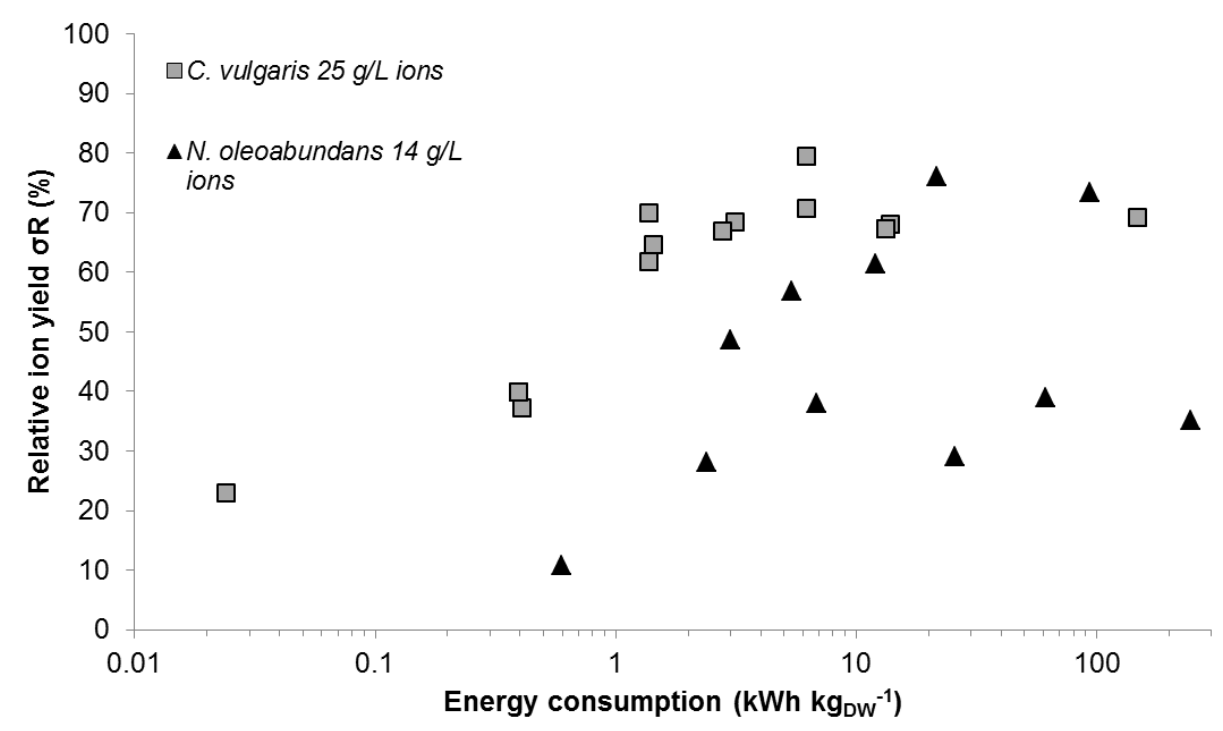

Figure 5.2: Relative ion yield $\left(\sigma_{R}\right)$ for $C$. vulgaris, and $N$. oleoabundans after PEF treatment. Part of $C$. vulgaris originates from Figure 5.1.

In Figure 5.2, the ion-yield for both microalgae is presented as a function of the mass specific energy input $W_{M}$. The results show that due to the PEF treatment, a relative increase up to $79 \%$ with $C$. vulgaris and up to $76 \%$ with $N$. oleoabundans compared to beat beating $(100 \%)$ as positive control was obtained. These results suggest that only small pores were formed in the cell membrane and cell wall allowing ions to be released.

Similar results were reported by Goettel et al. (2013), after PEF treatment and 6 hours of resting time, an increase in conductivity of $1 \mathrm{mS} \mathrm{cm}^{-1}$ was observed using 
biomass concentrations ranging between 36 and $167 \mathrm{~g} \mathrm{kgDw}^{-1}$. Also in the study of Eing et al.(2013), a conductivity increase of $1 \mathrm{mS} \mathrm{cm}^{-1}$ at a biomass concentration of $100 \mathrm{~g} \mathrm{kgDw}^{-1}$ was obtained. Although a relative increase $\left(\sigma_{R}\right)$ was not calculated in those studies, the absolute increase in electrical conductivity after PEF treatment was in the same order of magnitude as the increase obtained in this study.

Next to achieving a reasonable high ion-yield, part of the aim was to further enhance the protein release. Figure 5.3 shows the protein yield as a function of the mass specific energy input $W_{M}$.

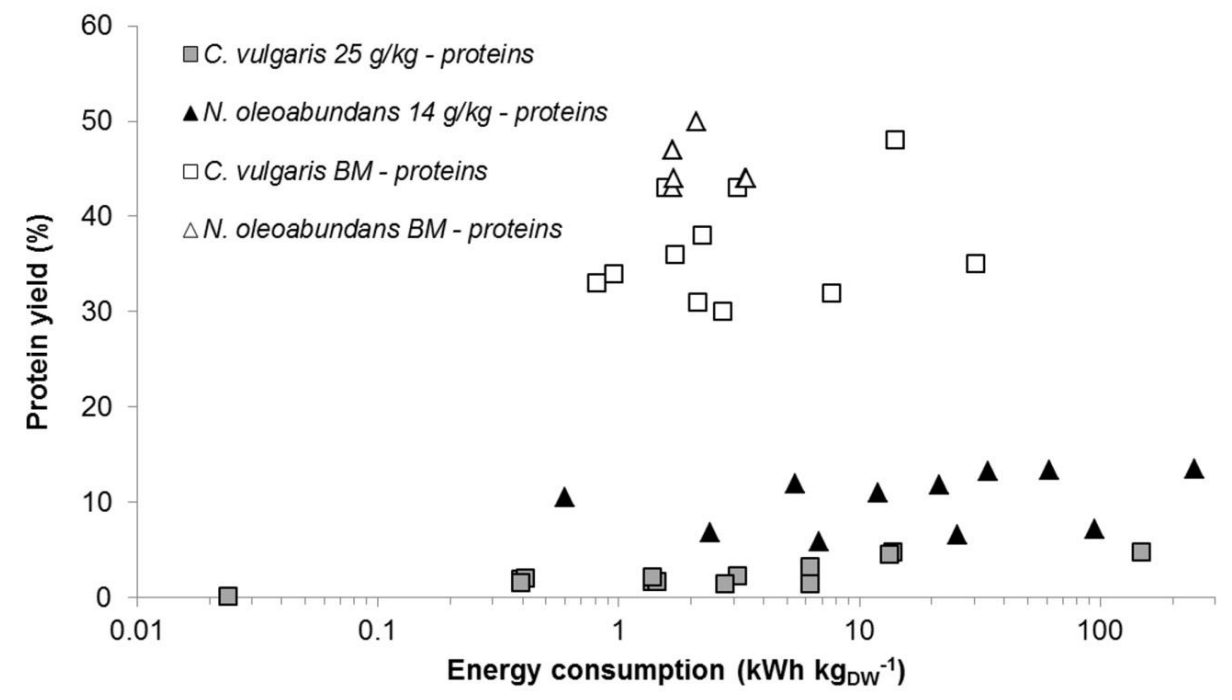

Figure 5.3: Protein yield as function of the specific energy input. Protein release measured $1 \mathrm{~h}$ after application of PEF. Specific energy consumption calculated based on initial conductivity at $25^{\circ} \mathrm{C}$. Benchmark by bead milling BM for C. vulgaris (Postma et al. 2015) and N. oleoabundans (this study). Part of $C$. vulgaris originates from Figure 5.1.

From Figure 5.3 it can be observed that for both strains treated with PEF, the protein release did not exceed $13 \%$. With bead milling however, the protein release ranged between $30-50 \%$ for both $C$. vulgaris and $N$. oleoabundans. Moreover, in the study of Safi et al. (2014), a protein release of $51.7 \%$ was observed after high pressure homogenization of $C$. vulgaris. These results are in agreement with the protein release after bead milling presented in Figure 5.3. Even at energy inputs higher than applied during bead milling, no protein release close to the one by mechanical disruption was observed $(p<0.05)$. 
The results obtained with PEF as shown in Figure 5.3 are in agreement with results reported in other studies as well. Parniakov et al. (2015) reported with Nannochloropsis salina a protein yield of maximal 10\%. In addition, Goettel et al. 2013) reported a protein yield of $<1 \%$ with Auxenochlorella protothecoides (assuming a total protein content of $50 \%$ on DW). Also in the study of Postma et al. (2016), which investigated the effect of processing temperature during PEFtreatment, for $C$. vulgaris, similar protein yields to the ones reported in this study were obtained. Furthermore, Grimi et al. (2013) obtained a protein yield of $3.6 \%$ with $N$. salina. Coustets et al. (2013) measured proteins after PEF-treatment as well. Although it was not possible to calculate a yield, the protein concentrations in the supernatant were equal, or lower than the protein concentrations measured in this study. In addition as already illustrated by Table 5.1, the degree of protein release or disruption was not provided in all studies. Instead only absolute concentrations of components such as carbohydrates, pigments or 'total organic components' were provided (Luengo et al., 2014; Eing et al., 2013). It is therefore difficult to compare our results elaborately with other work.

Overall, the results presented in Figure 5.1, Figure 5.2 and Figure 5.3 suggest that small pores were formed allowing ions to be liberated through the cell wall and membrane. The performance of PEF with respect to protein release was not as efficient as with bead milling limited by the pore formation and/or disruption.

\subsection{Continuous flow PEF}

To quantify the impact of the PEF apparatus design on the observed yields, a continuous flow PEF unit was used and compared to the batch PEF unit. Based on the results presented in Figure 5.1, only the specific energy input was varied in this experiment. By varying the pulse frequency the specific energy input was varied, while keeping the field strength and biomass concentration constant at $20 \mathrm{kV} \mathrm{cm}^{-1}$ and $25 \mathrm{~g} \mathrm{~kg}_{\mathrm{DW}}{ }^{-1}$, respectively. The used of $20 \mathrm{kV} \mathrm{cm}^{-1}$ is in agreement with the range used during batch-electroporation $\left(7.5-30 \mathrm{kV} \mathrm{cm}^{-1}\right)$. 


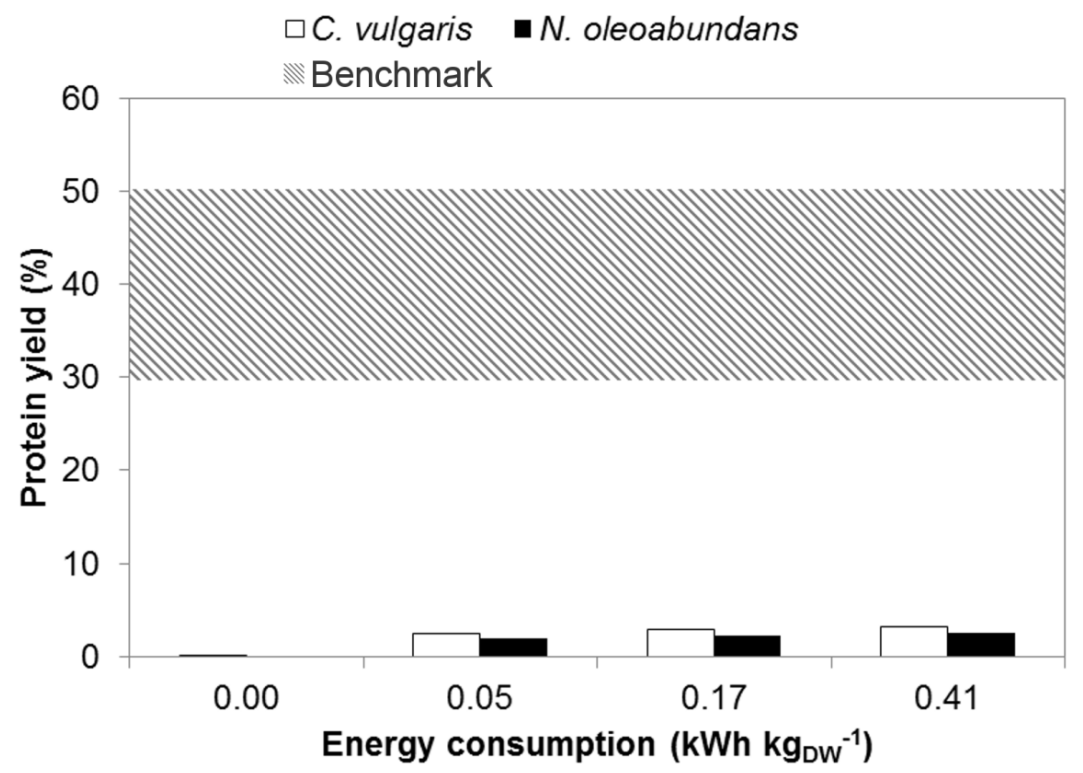

Figure 5.4: Protein release yield measured after $1 \mathrm{~h}$ versus specific energy consumption for continuous flow PEF. Marked area represents benchmark yields range.

Figure 5.4 shows that a protein yield between 2.5 and $3.2 \%$ was obtained for $C$. vulgaris and between 1.9 and $2.5 \%$ for $N$. oleoabundans. These yields are in the same order of magnitude as the ones presented in Figure 5.3, and remained substantially lower than the yields obtained after bead milling. With a similar specific energy consumption of 0.4 and $0.6 \mathrm{kWh} \mathrm{kgDw}^{-1}$ for $C$. vulgaris and $N$. oleoabundans during batch mode PEF yields up to $2.3 \%$ and $10.5 \%$ were obtained, respectively. So, for $N$. oleoabundans even lower protein yields were obtained as with the batch mode PEF. The results of Figure 5.3 and 5.4 imply that regardless of the energy input and the pulse length ( $2 \mu$ s for continuous PEF and $0.05-5$ ms for batch PEF) similar results were obtained.

Both strains were cultivated in fresh water for the experiments shown in Figure 5.4 instead of using artificial seawater medium for $N$. oleoabundans. As more biomass was required for these experiments, $N$. oleoabundans was cultivated in a fully controlled air-lift photobioreactor according to Postma et al. (2017). No proteins were

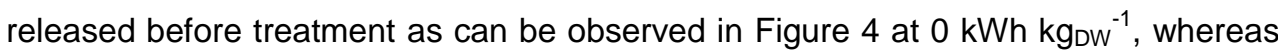
washing of marine cultivated $N$. oleoabundans did release proteins and thus caused 
an osmotic shock (see paragraph 3.1.2). In any case, the results of Figure 5.4 confirm the general trend that proteins remained entrapped intracellular.

\subsection{General discussion}

In this study, the highest yield of proteins of $13 \%$ was obtained with $N$. oleoabundans cultivated in seawater medium in a batch mode PEF. Despite the effect of an osmotic shock that $N$. oleoabundans suffered during the washing treatment, no yields similar to bead milling were obtained. Also in other studies, similar protein yields after PEF were observed (Goettel et al. 2013; Grimi et al. 2014; Parniakov et al. 2014).

This study showed, that regardless of the high amount of released ions, PEF was not feasible yet for either a complete disruption, or for selectively releasing proteins. Although only low protein yields were observed after PEF, several other studies already reported that increased lipid yields could be obtained using extraction after PEF-treatment for both microalgae and also cyanobacteria (Zbinden et al., 2013., Sheng et al., 2011, 2012). It may be that the electroporation performed in this study is sufficient to allow enhanced lipid extraction, making PEF an interesting technology for lipid-scenarios. However, the native state of the soluble proteins is most likely negatively affected diminishing the total biomass value. Therefore, we believe that for a successful biorefinery strategy, first native proteins should be released.

It should be considered that the mode of PEF operation is different from bead milling. Where bead milling causes a complete cell disintegration (Postma et al., 2015), PEF merely electroporates the cell. The kinetics of PEF may therefore require a longer incubation time after PEF compared to bead milling. In the experiments presented in this study, an incubation time of 1 hour was used. Goettel et al. (2013) presented in their work the effect of the diffusion kinetics after PEF. They reported that already $79 \%$ of the total released ions were released in the first hour after PEF treatment, which is in agreement with the results obtained in Figure 1 and 2. In addition, Parniakov et al. (2015), showed in their work the release kinetics of proteins after PEF treatment. According to their results, more than $80 \%$ of the total released proteins, were released in the first hour of resting time. It is therefore likely that an incubation time of 1 hour was sufficiently long to observe at least a substantial release of intracellular components. In addition, other work reported the combined temperature-PEF effect, or combined pH-PEF effect (Parniakov et al., 2015, Postma 
et al., 2016). Neither an elevated $\mathrm{pH}$, nor higher temperatures contributed to the diffusion kinetics.

Besides the reported enhanced lipid extraction from microalgae and cyanobacteria, other work showed that PEF was successful in opening cell membranes to inactivate/ disruption microorganisms lacking a cell wall (Timmermans et al. 2014; Frey et al. 2013). However, microalgae often have an additional rigid cell wall. Recently, Scholz et al. (2014) proposed for example that the Eustigmatophyceae Nannochloropsis gaditana has a bilayered cell wall composed of a thick layer of cellulose and algaenans. It may be that other microalgae such as the species used in this study have similar properties, limiting the performance of PEF. This observation was also done by Azencott et al. (2007) who found that the cell wall of Chlamydomonas reinhardtii was limiting the uptake of relatively large $(66 \mathrm{kDa})$ protein molecules.

Next to the protein yield, the energy consumption is influencing the feasibility of PEF. By assuming a total energy content of $6.82 \mathrm{kWh} \mathrm{kgow}^{-1}$ in combination with an energy input less than $10 \%$, the resulting energy consumption should be equal or lower than $0.682 \mathrm{kWh} \mathrm{kg} \mathrm{Dw}^{-1}$ (Coons et al. 2014). According to this criterion, next to low protein yields, the belonging energy input with PEF was substantially higher than $0.682 \mathrm{kWh}$ $\mathrm{kg}_{\mathrm{DW}}{ }^{-1}$.

\section{Conclusion}

The high release of ions illustrated that the application of PEF for the disruption of fresh and marine cultivated microalgae, resulted in a weakening of the cell membrane suggesting the formation of pores. Nevertheless, with respect to the mechanical benchmark, no sufficient amounts of protein were liberated by the application of PEF. Moreover, the required energy input for PEF was higher than the mechanical benchmark.

\section{Acknowledgements}

Part of this project is financed by the IPOP Biorefinery of Wageningen University and Research Centre (The Netherlands). Part of this work is performed within the TKI AlgaePARC Biorefinery program with financial support from the Netherlands' Ministry 
of Economic Affairs in the framework of the TKI BioBased Economy under contract nr. TKIBE01009. The authors also thank Dominik Eugster from Willy A. Bachofen AG Maschinenfabrik (Muttenz, Switzerland) for providing a bead mill and Ruud Veloo in assisting in the cultivation. 


$$
\text { - }
$$




\section{chapter}

Microalgal biorefinery for bulk and high value products - Design and current bottlenecks in product extraction within cell disruption

Published as:

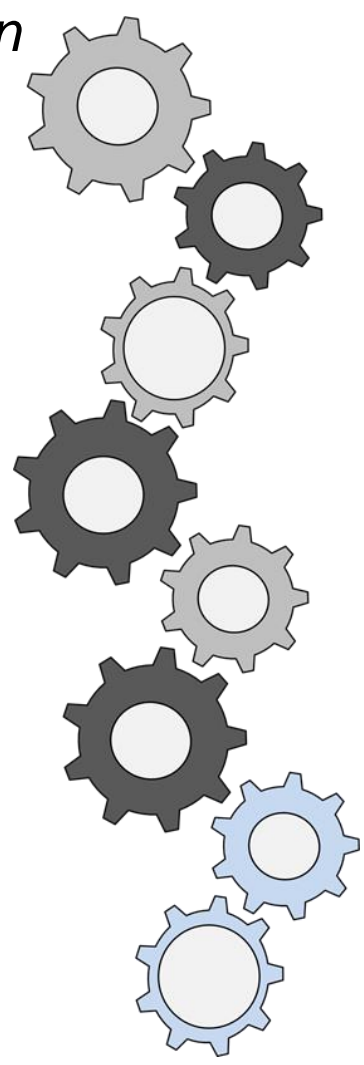

Postma P.R.*, 't Lam G.P.*, Barbosa M.J., Wijffels R.H., Eppink M.H.M., Olivieri G. (2016) 'Microalgal biorefinery for bulk and high value products - Product extraction within cell disintegration'. In Handbook of Electroporation; Miklavcic, D. (Ed), Springer Publishers. p.p: 1-20.

*equal contributions 
icroalgae are a promising source for proteins, lipids and carbohydrates for the cosmetic, nutraceutical, chemical, food/feed and biofuel industry. In comparison with soy and palm oil, microalgae can be produced in a more sustainable way. To make microalgae production economically feasible, all biomass ingredients need to be efficiently utilized, in similarity to petroleum refineries in which oil is fractionated in fuels and a variety of products with higher value. However severe conditions can affect the properties of some components in the biomass. To overcome this, focus needs to be put on biorefinery techniques which are mild and effective. Microalgal biorefinery is a linear process consisting of harvesting, cell disruption, sequential extraction and further fractionation. Among these steps, the cell disruption often represents a bottleneck for the extraction of hydrophilic or hydrophobic components, due to the presence of a tough cell wall in many species. State of the art knowledge on both novel and classical techniques for product extraction within cell disruption is presented. Comparison is made on the basis of two main criteria: yield of disruption and energy consumption. The current work gives also a comprehensive outlook on business cases for microalgae biorefinery. 


\section{Microalgal biorefinery: market opportunities}

Microalgae are very attractive as a feedstock for biobased products due to an aerial productivity superior to traditional agricultural crops: realistic estimates for areal productivity are in the order of magnitude of 40-80 tons of dry matter per hectare per year depending on the technology used and location of production (Tredici 2010). In addition algae can have a low water footprint and production does not compete with agriculture land (Tredici 2010).

Microalgae have been of major interest for producing biofuels in the last decade (Chisti 2007). However, at this moment, microalgae production for biofuel production appears to be still too costly with current process (Wijfels and Barbosa 2010).

Depending on the species and cultivation conditions, microalgae can accumulate high amounts of lipids, proteins and carbohydrates, which can be used for different markets such as bulk and high added value products (Figure 6.1) (Vigani et al. 2015).

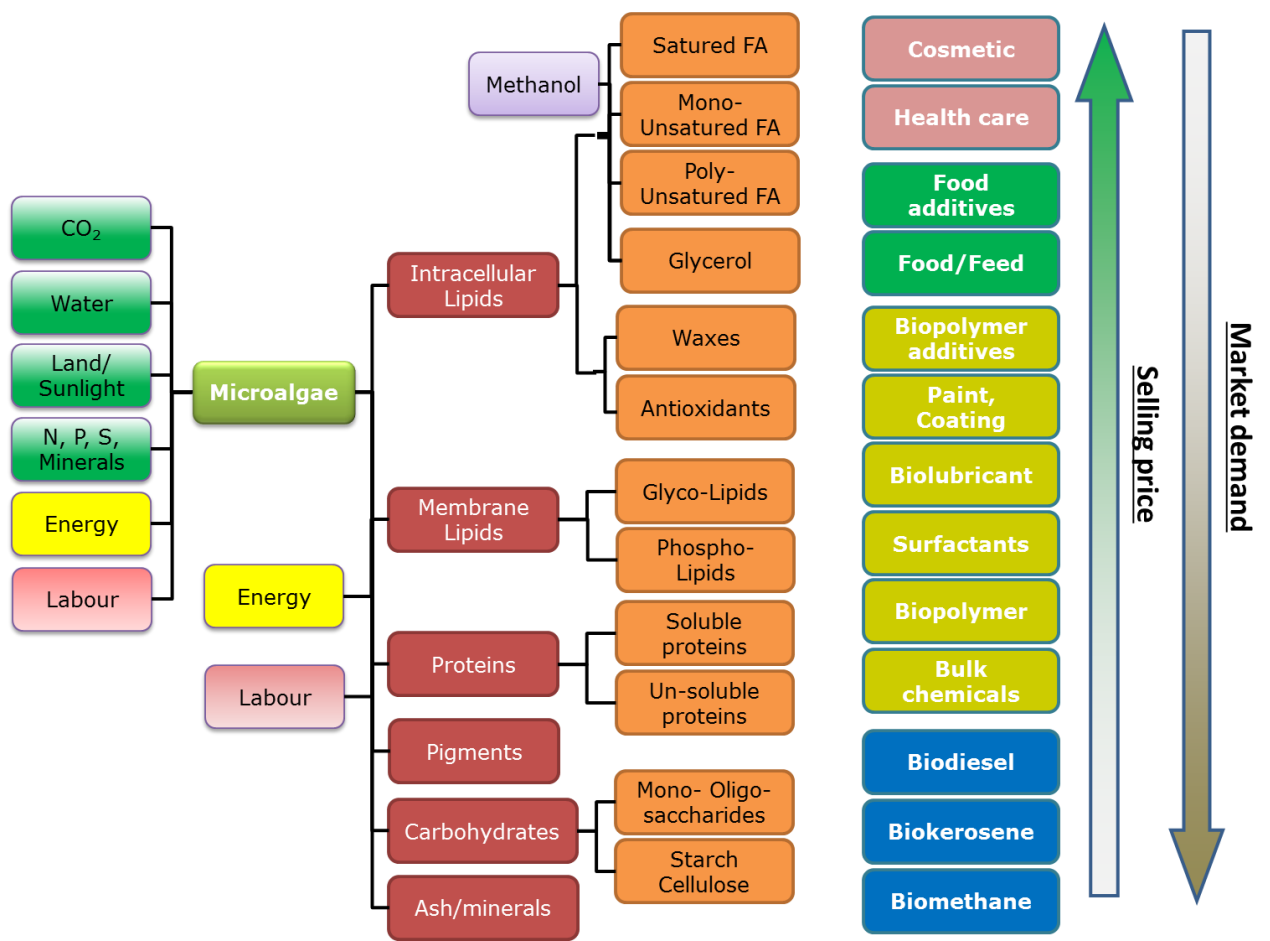

Figure 6.1: Overall spectrum of microalgal component and their possible application.

Lipids and proteins are the most interesting fractions of the microalgae and their concentration is strongly depend on the operation conditions during cultivation. 
Globally the need for lipids and proteins as food, feed and fuel is especially rising in Europe, where currently $44 \%$ of the lipid and $68 \%$ of the protein requirement is imported (Table 6.1). In addition, Europe is the only continent where the amount of arable land is strongly decreasing along the years (source: FAOSTAT), indicating microalgae production as a more efficient source of lipids and proteins.

Table 6.1: Lipids and proteins supply, import, price, and production data in EU in 2013. $\left(^{*}\right)$ data are referred to whole meal containing from $30 \%$ (sunflower) up to $60 \%$ (rapeseed) of pure proteins. Sources: US Dept Agriculture and FAOSTAT.

\begin{tabular}{lrr}
\hline & Lipids & Proteins $\left(^{*}\right)$ \\
\hline \hline Total Supply (* $\left.10^{6} \mathrm{MT}\right)$ & 27 & 56 \\
Production $\left(* 10^{6} \mathrm{MT}\right)$ & 15 & 18 \\
Import $\left(* 10^{6} \mathrm{MT}\right)$ & 12 & 38 \\
Price (€/MT) & 980 & 310 \\
Cultivated Area (10 & 17 & 12 \\
Productivity (MT/ha) & 0.9 & 1.5 \\
\hline
\end{tabular}

However, microalgae are nowadays only produced and commercialized for niche markets, either as whole biomass (food additives and feed for aquaculture) or as extracted valuable components (astaxanthin, beta-carotene, omega-3 fatty acids and phycobiliproteins), with a very low market volume (10,000 MT/y) (Vigani et al. 2015).

When exploiting the whole potential of microalgae components in an overall biorefinery strategy, various products need to be extracted and purified to render in an economic feasible process (Wijffels et al. 2010).

Downstream processing costs are an important part of the total production costs (Coons et al. 2014). Some species have a tough cell wall, which makes them robust for outdoor cultivation, but also requires hard conditions to extract the intracellular components. Literature addressing the market potential of microalgal components is for a large part focused on production of one specific product from the biomass (e.g. lipids). Therefore, ad-hoc extraction methods were only developed for one specific product and the other available and valuable components in the microalgae were not valorized.

To be able to exploit the complete microalgae biomass it is necessary to use mild cell disruption techniques. Conventional disruption by using e.g. bead milling, homogenizers, high pressure, heating, osmotic shock and chemicals, are not 
considered as mild. In addition, they are mainly used to obtain one final product, while damaging the other fractions. As an example, organic solvents, commonly used in lipid extraction techniques, would harm and denature proteins. In this way large part of the soluble proteins become insoluble and lose their techno-functional properties. Biorefinery is a procedure that integrates biomass conversion and separation, in which the objective is to obtain several fractions/products by using mild separation from one single source. To do that, the biorefinery techniques appropriate for mild extraction are relatively new and should therefore be studied thoroughly before commercial use is possible (Wijffels et al. 2010).

\section{Process overview of algal biorefineries}

There are algal-production scenarios in which the biomass is considered as an endproduct and there are scenarios in which biorefinery of the biomass into specific components is used. When one or multiple specific components are desired as end product, a further downstream process is required. Such a downstream process typically consists out of a harvesting step, cell disruption, extraction and possibly a further fractionation (in particular when a biorefinery is foreseen).

In general, in downstream processing both harvesting and cell disruption are recognized as expensive, and therefore the cost limiting process steps. The high harvesting expenditures are often attributed to the low biomass concentrations during cultivation, that commonly range between 0.3-4 $\mathrm{g} \mathrm{L}^{-1}$. In addition, microalgal cells have a small cell size (up to $20 \mu \mathrm{m}$ ) and commonly grow as single cells. Resultantly, a large amount of water needs to be separated from the biomass.

Cell disruption, aims to permeabilize or completely break the cell wall and membrane to allow a simple extraction- or release of intracellular components. As microalgae commonly grow as single cells, or in small colonies, they typically have a welldeveloped cell wall and membrane that serves as a protecting boundary. It is for this reason that cell disruption is next to harvesting an operational ('energy') intensive process. For both harvesting and cell disruption, mechanical processes (centrifugation and filtration for harvesting and bead milling and homogenization for cell disruption) are considered well established technologies that are able to combine a high throughput, with a constant efficiency. Next to those established technologies, alternative technologies have been proposed such as flocculation for harvesting and 
pulsed electric field as cell disruption technology (Toepfl et al. 2006; 't Lam et al. 2015).

After harvesting and disruption the biomass, depending on the foreseen endproduct(s), a product separation using extraction, and a possible further fractionation are applied.

For extracting lipids, several organic solvent are suitable. Generally, methanol/chloroform shows the best yield due to the best polarity index of the mixture for extracting both the lipid classes (Halim et al. 2012). On industrial scale hexane is frequently preferred for oil extraction from oilseeds. The use of organic solvents has two main drawbacks: (i) it denatures proteins losing their functionality; (ii) large quantity of solvent strongly affects the economy of the process due to the high energy demand for recovering it by distillation. In addition, the extraction has lower performance in case of wet biomass. So additional cost of pre-drying the biomass should be included in the overall economic balance. On the other hand, pre-drying might cause side effects like decreased solubility of proteins.

Besides the already available solvents such as Hexane and 'Bligh and Dyer' for hydrophobic components like lipids and pigments, also novel solvents like ionic liquids, supercritical fluids and switchable solvents have been proposed (Herrero and Ibáñez 2015; Yen et al. 2015; Desai et al. 2016).

In the study of Desai et al. (2016), successful extraction of the hydrophobic antioxidant astaxanthin from the microalgae Haematococcus pluvialis was reported. The same study also showed the ability to re-use these ionic liquids in subsequent extractions, making them a sustainable solvent.

Supercritical $\mathrm{CO}_{2}$ is nowadays the most feasible alternative to organic solvents. About 30 companies are using this technique for lipid extraction from oilseeds. It works at temperatures that are between 40 and $60{ }^{\circ} \mathrm{C}$ and pressures ranging from 10 to $70 \mathrm{MPa}$ (Yen et al., 2014; Herrero et al., 2015). The recovery of the solvent is considered to be easy by flashing the mixture at the end and recycling the gas phase. The main advantages are: low temperature, high purity, colorless, odorless and tasteless, low vaporization enthalpy, less energy consumption.

For reducing the extractant cost of the recovery, switchable solvents were developed about a decade ago (Jessop et al. 2012). Switchable solvents are particular liquids 
that can easily and strongly change their polarity by changing the $\mathrm{pH}$ and/or sparging $\mathrm{CO}_{2}$. When they are polar, they can mix with water. When they are non-polar, they are immiscible with water, but they act as good extractant for lipids. Figure 6.2 shows the steps of a typical extraction operation carried out with switchable solvents.

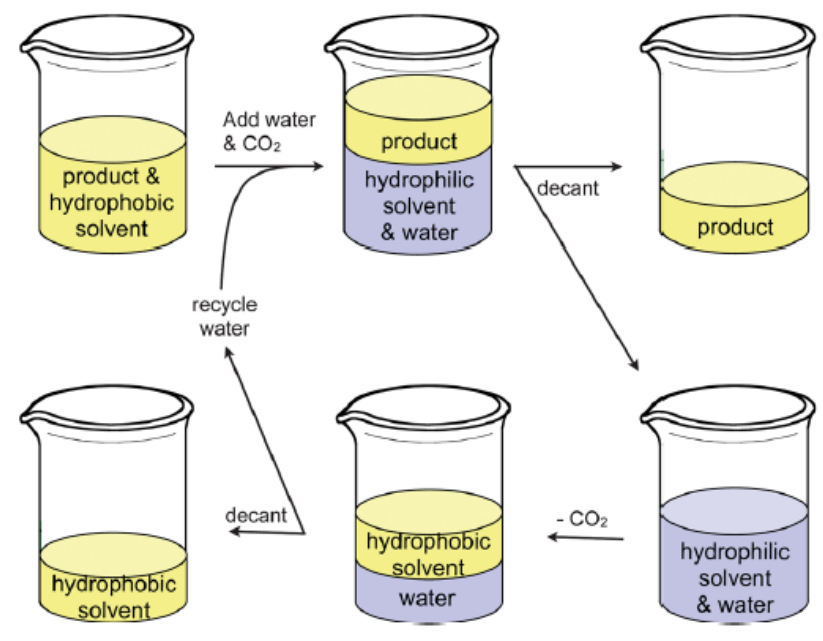

Figure 6.2: The process by which a switchable solvent can be separated from a product and recovered without a distillation step (Jessop et al. 2012, license number 3904040176494).

Next to extracting hydrophobic components, there has been an increased attention for hydrophilic components such as proteins and carbohydrates. As these components are generally fragile components and easily tend to denature (proteins), or degrade at severe conditions such as high temperature, organic solvent usage or a non-neutral $\mathrm{pH}$, an aqueous extraction of those components is foreseen. As this is an emerging field, currently various technologies like ionic liquids for both hydrophobic, and hydrophilic product extraction, and also surfactants are named for separation of those aqueous components.

To summarize the efforts reported in literature, two main areas for a breakthrough can be identified in the microalgal biorefinery: 1) to develop an efficient and low energy consuming cell disruption technique and 2) to improve the yield of extraction of both lipids and proteins.

The following section will focus on the current advances in microalgal cell disruption by providing an overview of current named disruption technologies. In the overview, two types of cell disruption technologies will be addressed based on their working 
principle (Figure 6.3): physical and non-physical (Günerken et al. 2015).The mechanical cell disruption technologies generally apply a physical force (shear, charge, cavitation, etc.) on the cells leading to an opening of those cells. With chemical cell disruption, instead of applying physical force, a chemical stress is applied. Due to chemically induced interactions at the cell wall, a weakening of this cell can be induced resulting in an opening of the microalgal cells.

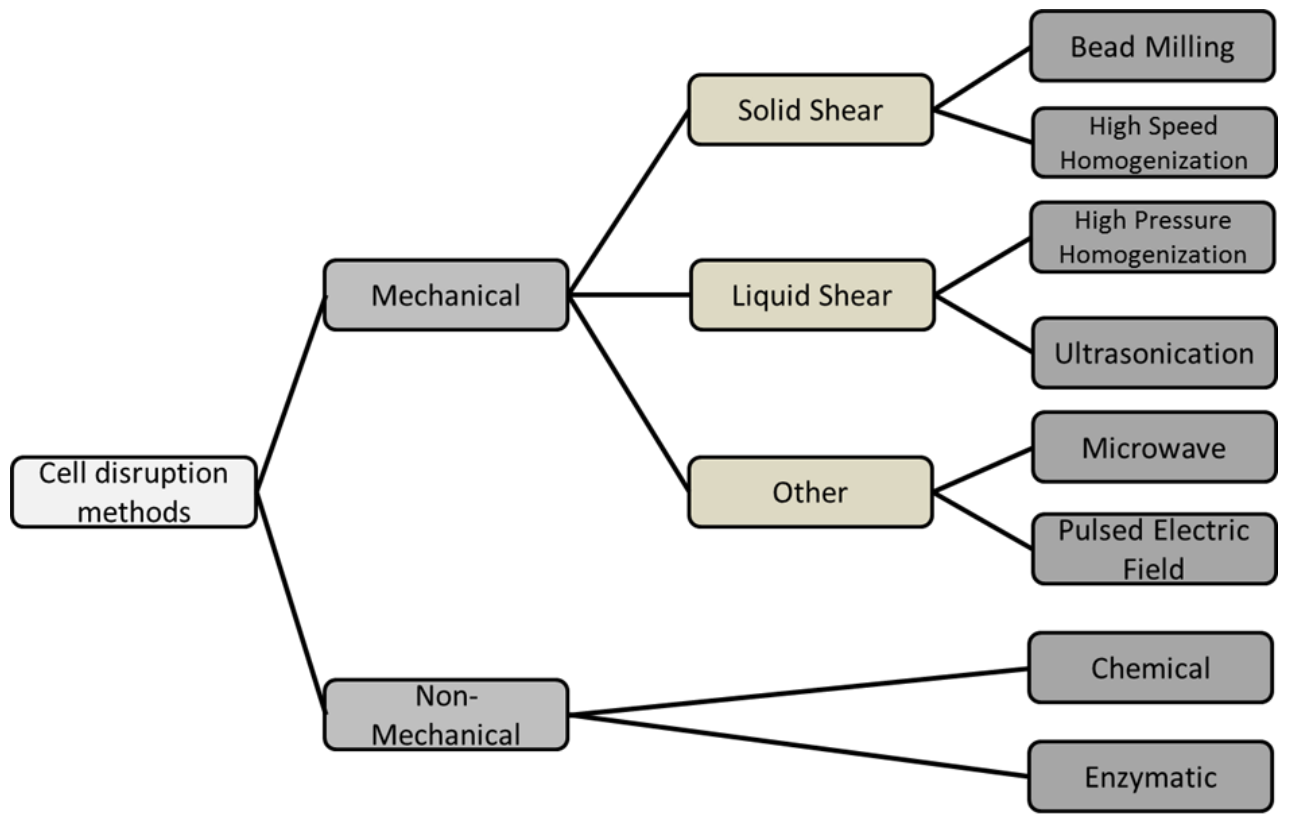

Figure 6.3: Classification of different cell disruption technologies adapted from Günerken et al. (2015, license number 3875351355219 ).

After providing an introduction into the various named cell disruption technologies, a discussion and future outlook are presented in which various recommendations for the further industrialization of microalgal biorefinery from a cell disruption perspective will be provided with a focus on pulsed electric field as potential disruption technology.

\section{Cell disruption}

\subsection{Bead milling}

Bead mills are homogenizers originally designed for the size reduction of paint and lacquer particles but can also be used to disruption biomass suspensions. The basic principle of a bead mill is the rapid stirring of small beads in the presence of a 
microorganisms suspension. Due to differences in the speed of the beads high shear forces are created, besides direct impact of the beads with a microorganism also cause cell disruption. A bead mill consists of a horizontal or vertical jacketed grinding chamber with a shaft through the center. On this shaft disks, rotors or agitators of different designs can be mounted and will impact the kinetic energy towards the beads. The suspension flows through the grinding chamber while the beads are retained in the chamber by a sieve or axial slot (Figure 6.4).

A bead mill can be operated both in batch recirculation mode or in continuous mode, in general an external pump is used to create the suspension flow. For batch mode, the suspension flow rate is of minor importance (i.e. only required to assure sufficient recirculation), while the residence time distribution of the suspension inside the grinding chamber is the only important parameter directly influencing the disruption kinetics. For continuous processing, the flow rate dictates the residence time and therefore the process kinetics.

a)

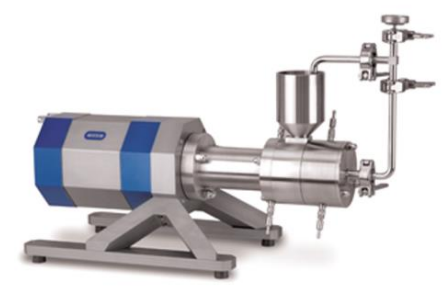

b)

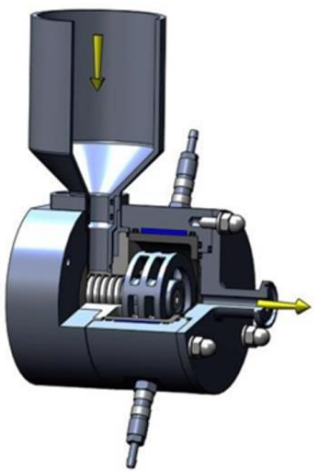

Figure 6.4: Picture of DYNO-Mill Research lab as used by Postma et al. (2015) (a). Schematic overview of suspension flow through milling chamber (b) (pictures kindly provided by Willy $A$. Bachofen AG Maschinenfabrik, Switzerland).

Many other parameters influence the efficiency of the bead milling amongst which; grinding chamber and agitator design, bead size, bead density, bead filling ratio, agitator speed and biomass concentration (Doucha and Lívanský 2008). Doucha and Lívanský (2008) found that high bead filling ratios and high bead density are optimal for the disruption of Chlorella sp.. Disruption levels up to between 58 and $91 \%$ could be achieved using $2.8-10 \mathrm{kWh} \mathrm{kgDw}^{-1}$. Postma et al. (2015) found that low agitator speeds $\left(6 \mathrm{~m} \mathrm{~s}^{-1}\right)$ and high biomass concentrations $\left(87.5-145 \mathrm{gDw} \mathrm{kg}^{-1}\right)$ provide the lowest specific energy consumption of $0.8-1.7 \mathrm{kWh} \mathrm{kg} \mathrm{Dw}^{-1}$ for disruption of $C$. 
vulgaris. Furthermore, water soluble protein yields of $30-35 \%$ were obtained under these conditions using fresh algae.

\subsection{High Pressure Homogenization}

Among the mechanical disruption techniques, high pressure homogenization (HPH) is regarded as a very effective technique and capable of continuous processing. HPH was originally designed to homogenize liquid food products like milk. But it was redesigned for cell disruption of several microorganisms like, bacteria, yeast and microalgae (Middelberg 1995; Safi et al. 2014; Ursu et al. 2014). The HPH consists of two main parts, which are the positive displacement pump and a homogenizer valve. The liquid flow direction is changed twice 90 degrees, by first flowing through the center of the valve seat towards the high pressure valve. After which it is forced through the valve opening and will strike the impact ring. By adjusting the valve, the pressure can be set to a desired target (Figure 6.5a). Figure 6.5b shows a production scale HPH with it high pressure pump and valve (Figure 6.5c).

High liquid shear, turbulence and cavitation forces are acting on the cells in a short time frame when passing through the homogenizer. It should be considered that these extreme conditions might negatively influence the functional properties of vulnerable products like proteins. Besides, the processing temperature is likely to increase sharply at very high pressures.

Successful application of HPH for the release of enzymes from yeast have been reported. Besides, bacteria like Escherichia coli or Bacillus species have also been successfully disruption (Middelberg 1995). For the release of protein from microalgae also successful application has been reported. Safi et al. (2014) found that between $41-90 \%$ of the protein content of 5 microalgae species $\left(20 \mathrm{~g}_{\mathrm{DW} \mathrm{L}} \mathrm{L}^{-1}\right)$ could be solubilized by two passes of $\mathrm{HPH}$ at $270 \mathrm{MPa}\left(7.5 \mathrm{kWh} \mathrm{kg} \mathrm{Dw}^{-1}\right)$. In addition, Ursu et al. (2014) reported $98 \%$ protein release under alkaline conditions $(\mathrm{pH} 12)$ at $2 \times 270$ MPa $\left(11.5 \mathrm{kWh} \mathrm{kgDW}^{-1}\right)$ from C. vulgaris $\left(13 \mathrm{~g}_{\mathrm{DW}} \mathrm{L}^{-1}\right)$. Though it should be considered, that in both cases the biomass was frozen before treatment which might have caused cell damage before the application of $\mathrm{HPH}$. Furthermore, when proteins are extracted at a high $\mathrm{pH}$ (12), the soluble proteins will precipitate and become no longer soluble at the $\mathrm{pH}$ range of 5.5-6 at which functional food proteins are soluble. 

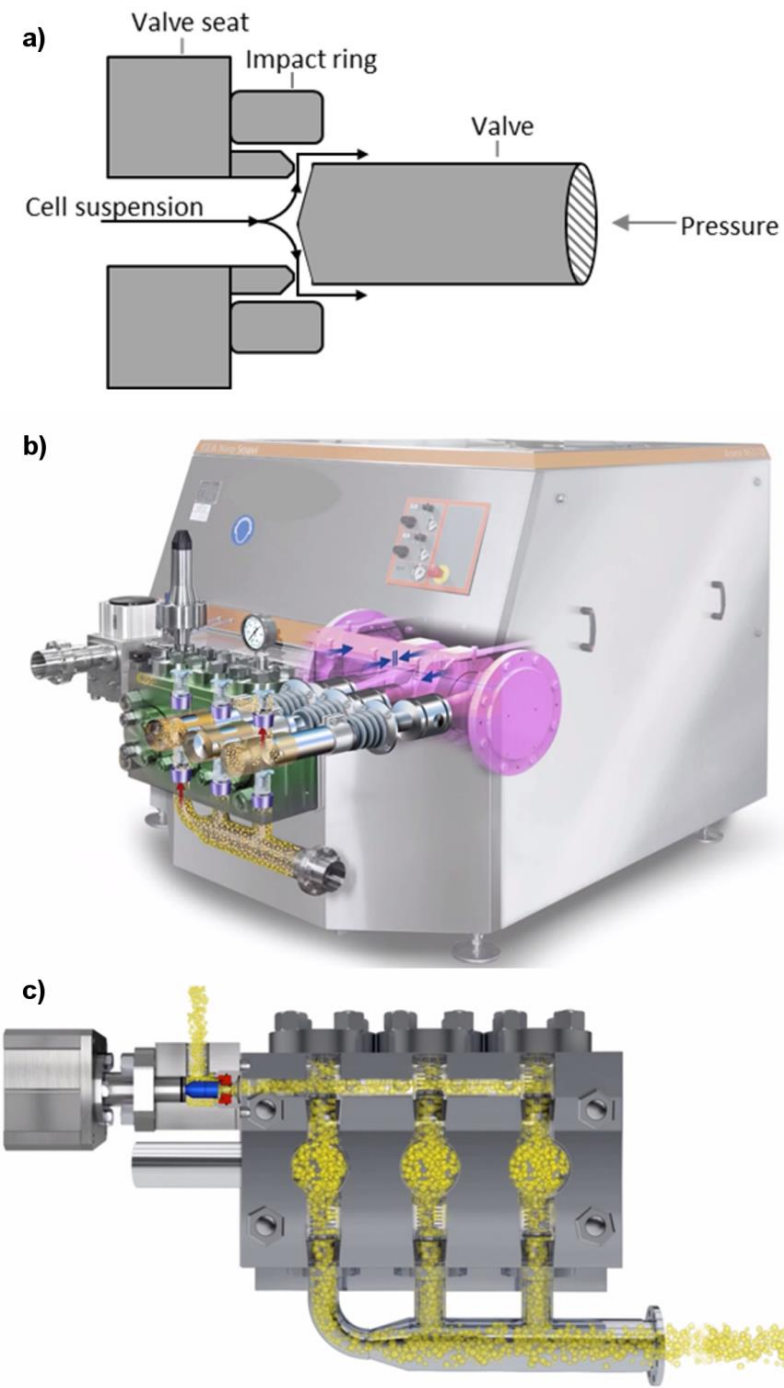

Figure 6.5: a) Schematic overview of high pressure homogenizer valve (authors own drawing), b) production scale high pressure homogeniser and c) high pressure pump and valve detail (picture $b$ and c kindly provided GEA Niro Soavi, The Netherlands).

\subsection{Ultrasound}

During an ultrasonic treatment, the energy of high frequency acoustic waves initiates a cavitation process and a propagating shock wave forms jet streams in the surrounding medium causing cell disruption by high shear forces (Mendes-Pinto et al. 2001). The specific energy consumption ranges from $0.06 \mathrm{kWh} / \mathrm{kg}$ to $100 \mathrm{kWh} \mathrm{kgDW}^{-1}$ (Günerken et al. 2015). The major drawback of ultrasonication of microalgae biomass 
is the relatively low cell disruption efficiency for some microalgae species together with the local and overall heat production. Bubble implosion in acoustic cavitation produce micro-regions of extreme conditions with estimated temperatures as high as $500{ }^{\circ} \mathrm{C}$ and pressures up to $100 \mathrm{MPa}$. During treatment, the sample temperature can increase significantly from 50 to $90{ }^{\circ} \mathrm{C}$ (Günerken et al. 2015) and destroy proteins and other intracellular metabolites. Temperature control during treatment can improve product quality, however, the effectiveness of cell disruption decreases significantly (Sheng et al. 2012). Besides, the energy requirement would increase substantially when taking the costs for cooling into account.

\subsection{Supersonic Flow Fluid}

Supersonic Flow Fluid Processing (SSFF) can be used for both quick and mild cooking of food and cell disruption (Fenton et al. 2014). As reported in Figure 6.6, steam is introduced into a special annular chamber that is wrapped around the core of the unit and injected through nano-pore channels. With increased steam flow, the steam exit velocity becomes supersonic and starts to form a controllable shock wave. This shockwave continues to grow and forms a low density, low temperature, low pressure, supersonic velocity zone across the bore diameter increasing energy transfer and cell disruption. Although steam is used, the temperature does not exceed $35{ }^{\circ} \mathrm{C}$. However, due to the sudden steam condensation during the shockwave, local sharp and fast increase of temperature have to be taken into account. Therefore, this technique does not cause protein or other valuable component to be denatured.

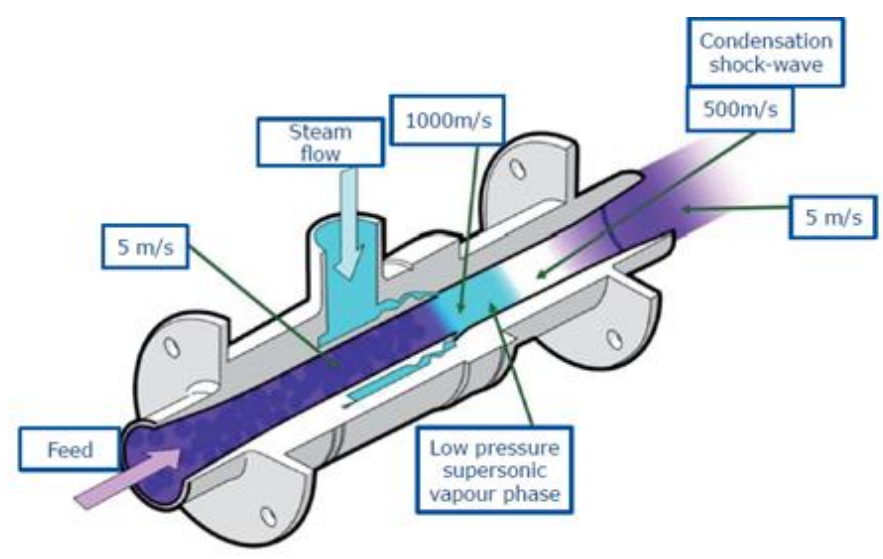

Figure 6.6: Schematic representation of Super Sonic Fluid Feed apparatus developed by PDX. 


\subsection{Pulsed Electrical Field}

Pulsed Electric Field (PEF) emerged the past decade in the field of cell disruption with the claim to be promising to permeabilize the microalgal cell membrane and to enhance the release of components (Toepfl et al. 2006). Up to 27, 80 and 53\% more protein, chlorophyll and carotenoids were released from C. vulgaris, respectively. Because the cells are relatively small $(3-20 \mu \mathrm{m})$, the required field strength is relatively high compared to animal or plant cells. To achieve those electric fields different treatment chambers have been proposed by several research groups who are working on the application of PEF on microalgae (Figure 6.7). The most common applied geometries include cross-field, co-field and co-linear treatment chambers for continuous flow processing. In addition, electroporation cuvettes or similar batch systems have been used as well.

A few years before Toepfl (2006), Ganeva et al. (2003) already showed that PEF can be successfully applied to permeabilize yeast and to release relative large protein molecules. The released proteins were up to $250 \mathrm{kDa}$ large with an overall yield up to $50 \%$ and also $70-90 \%$ of the enzyme activity was maintained.

More recent, the release of multiple components from microalgae (Auxenochlorella protothecoides) was investigated by Goettel et al. (2013). A strong increase in the conductivity was observed suggesting that the cells were effectively permeabilized. Furthermore, they found that about $8 \%$ of the biomass dry weight was released as carbohydrates whose monomers are small molecules compared to proteins. Instead, the protein release was below $1 \%$ for a specific energy consumption of $0.4 \mathrm{kWh}$ $\mathrm{kg}_{\mathrm{DW}}{ }^{-1}$.

A major part of the research on the application of PEF on microalgae was conducted with the focus on a single product. Coustets et al. (2013) focused on the release of water soluble protein from $C$. vulgaris and $N$. salina. Nevertheless, no protein yield was provided, though the obtained protein concentrations were low $\left(<0.04 \mathrm{~g} \mathrm{~L}^{-1}\right)$. The specific energy consumption was estimated by (Günerken et al. 2015) to range between 2.3 and $30.9 \mathrm{kWh} \mathrm{kgDW}^{-1}$. No effect of the pulse time and number of pulses was found, 30 pulses of $1 \mathrm{~ms}$ and 15 pulses of $2 \mathrm{~ms}$ resulted in the same protein release. The effect of PEF in combination with alkaline protein extraction was investigated by Parniakov et al. (2015) who found protein yields of $3 \%, 6 \%$ or $10 \%$ for 
a $\mathrm{pH}$ of $8.5,11$ or 12 , respectively. The specific energy consumption was calculated to be between 0.6 and $4.0 \mathrm{kWh} \mathrm{kg} \mathrm{Dw}^{-1}$.
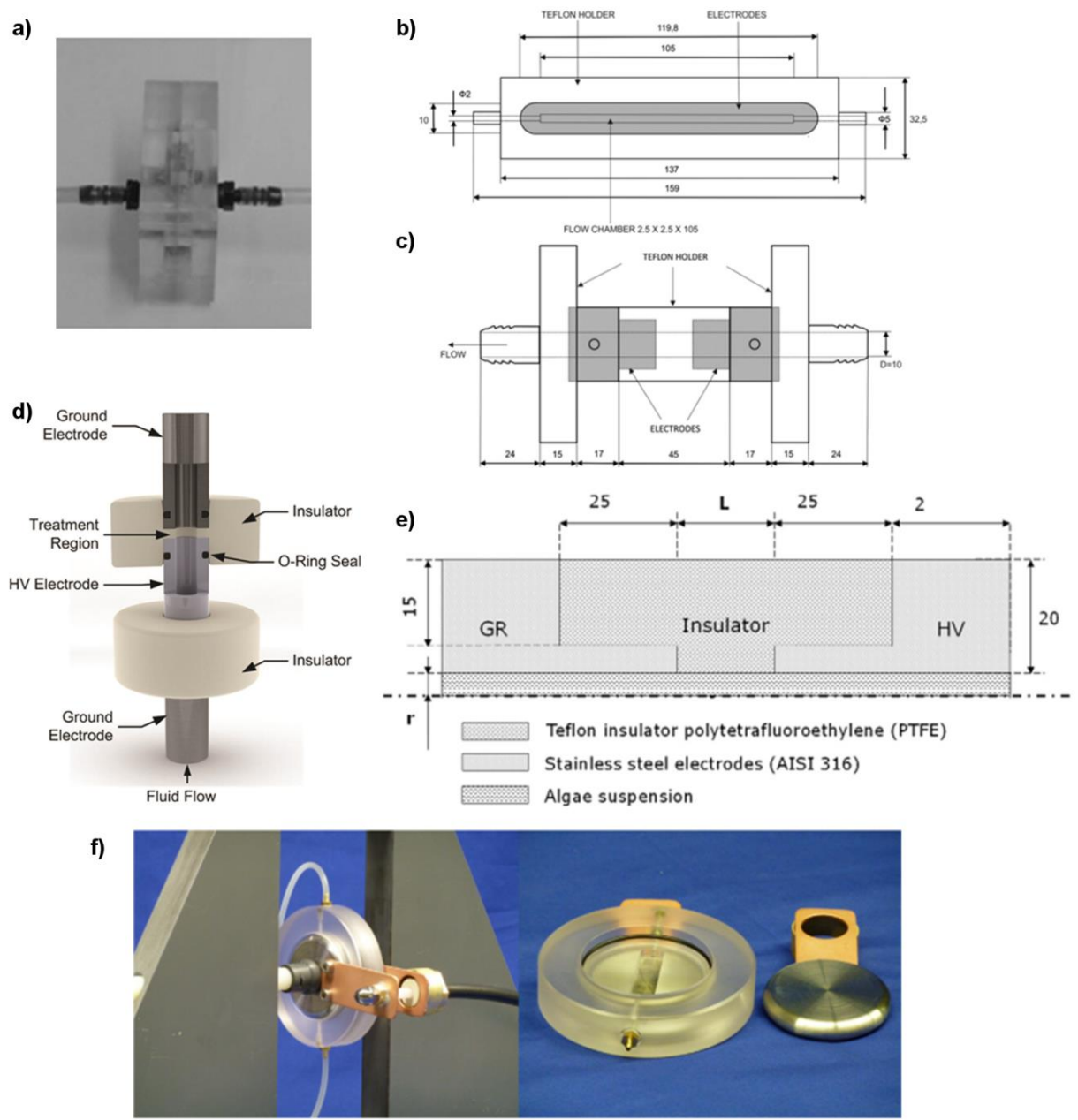

Figure 6.7: a) Flow pulsing chamber (Coustets et al. 2013, license number 3881200496476), b) Cross-field chamber (Flisar et al. 2014, license number 3880671450293), c) co-field chamber (Flisar et al. 2014, license number 3880671450293), d) co-linear treatment chamber (Kindly provided by Diversified Technologies), e) geometry of co-linear treatment chamber (Postma et al. 2016, license number 501148147), f) Cross field flow cell (Goettel et al. 2013, license number 3880670238737). 
The effect of microsecond versus millisecond pules in combination with the electric field strength on the extraction of pigments from $C$. vulgaris was investigated by Luengo et al. (2015b). It was found that a reduction of the pulse length to microsecond order could be successfully compensated with a higher electric field strength and still result in a reduction of the energy usage. Zbinden et al. (2013) looked into the effect of PEF followed by the extraction of lipids from the microalga Ankistrodesmus falcatus and reported a $130 \%$ increase with respect to the control at a specific energy consumption of $5.8 \mathrm{kWh} \mathrm{kgDw}^{-1}$. The combination of a green solvent, ethyl acetate, and PEF could be used to improve the lipid extraction.

The influence of the temperature on the effect of PEF was investigated by Luengo et al. (2015a) for the extraction of the pigment lutein and by Postma et al. (2016) for the extraction of proteins and carbohydrates, both on $C$. vulgaris. The extraction of lutein could be enhanced, from $451 \mu \mathrm{g} \mathrm{gDw}{ }^{-1}$ at $10{ }^{\circ} \mathrm{C}$ to $753 \mu \mathrm{g} \mathrm{gDw}{ }^{-1}$ at $40{ }^{\circ} \mathrm{C}(0.86 \mathrm{kWh}$ $\left.\mathrm{kg}_{\mathrm{Dw}}{ }^{-1}\right)$. However, the cultivation temperature of $C$. vulgaris is only $25^{\circ} \mathrm{C}$ and no major improvement was observed above $30^{\circ} \mathrm{C}$. The optimal processing temperature was found to be between 25 and $30{ }^{\circ} \mathrm{C}$ (Luengo et al. 2015a). Postma et al. (2016) showed that PEF was effective to release up to $75 \%$ and $39 \%$ of ions and carbohydrates, respectively, at a processing temperature up to $55^{\circ} \mathrm{C}(0.55-1.11$ $\left.\mathrm{kWh} \mathrm{kg}_{\mathrm{DW}}{ }^{-1}\right)$. Nevertheless, $95 \%$ of all the proteins were retained in the biomass after PEF. Though, the released protein fraction contained biologically active Rubisco showing that PEF is indeed a mild technique (up to $35^{\circ} \mathrm{C}$ ).

Recently, Gonçalves et al. (2016) successfully applied PEF for the extraction of lipids in an economically viable microalgal production process concerning wastewater treatment.

\subsection{Microwave}

As reported in the overview provided by Günerken et al. (2015), applying microwaves at $2450 \mathrm{MHz}$ results in a selective interaction with dielectric or polar molecules such as water and causes local heating. This principle results in a very efficient cell disruption of algal biomass.

In various studies, it has been reported that the application of microwave treatment resulted in a more efficient extraction of hydrophobic components, such as lipids and pigments (Günerken et al. 2015), making it a potential interesting technology. The 
same studies reported however, that during the microwave treatment, operating temperatures between $90^{\circ} \mathrm{C}$ and $100^{\circ} \mathrm{C}$ were applied. (information extracted from the literature overview as provided by Günerken et al. (2015)). Cell disruption at those conditions will result in a damage of the vulnerable, hydrophilic proteins and carbohydrates. Although microwave cell disruption appears to be promising for extraction of lipids, it still has limitations that should be overcome for successful implementation as general cell disruption technology.

\subsection{Enzymes}

Enzymatic degradation of microalgal cell walls is considered as a promising technology as it is a potential mild, and controllable process. Specific components of the cell wall are foreseen to be degraded, resulting in an opening of the cell wall. Due to the use of selective enzymes in combination with mild incubation conditions such as a low temperature and neutral $\mathrm{pH}$, only the targeted cell wall structures will be degraded, where the intracellular valuables remain intact.

Although enzymatic cell wall disruption is considered as promising, there are still various limitations that should be overcome. One of those limitations are the expenditures of using enzymes. As very specific enzymes are aimed to be used for microalgae cell wall disruption, it is likely that the purchase costs of those enzymes will be reasonable high. In addition, using long incubation times ( $>5$ hours) at elevated temperatures $\left(>35^{\circ} \mathrm{C}\right)$ will result in a high energy consumption for heating. When lower valuable chemicals such as lipids for biofuels are aimed to be extracted, there is still a necessity for cost reduction (Gerken et al. 2013). These kind of costs reduction may be achievable with e.g. immobilizing enzymes. Enzymes have been proposed as well to act as an assisted technology in combination with other cell disruption technologies (Wang et al. 2015).

Next to the existing cost-limitations, another limitation of using enzymatic incubation as cell wall disruption technology is the specificity of these enzymes. Among the various microalgal species there are large differences in cell wall composition, and structure. As a result, for every species, appropriate enzymes should be selected. As up to now, no extensive knowledge on microalgae cell walls is present, applying a rational selection of enzymes is still challenging. 


\subsection{Chemical}

Cell disruption can be chemically caused by applying chemicals such as chelating agents, chaotropes, detergents, solvents, hypochlorites, acids and alkali depending mainly on the cell wall composition of the microorganism (Middelberg 1995). There are several studies on cell disruption of microalgae with these agents (Günerken et al. 2015), but the most common are: solvent induced, acid and alkali.

The use of solvents in literature on the microalgae biorefinery is mainly focused on the extraction of specific biochemicals, e.g., astaxanthin and c-phycocyanin. The main issue is related to the organic nature of the solvent that on one hand enhance the extractability of lipids while on the other hand can cause protein denaturation. Some research combines extraction with disruption in two phase systems (Kleinegris et al. 2011).

Harsh acid treatment has been applied to various microalgae biomasses at high temperature $\left(\approx 160{ }^{\circ} \mathrm{C}\right)$ and generally lead to a higher degree of cell disruption than the same treatments at lower temperatures $\left(\approx 120^{\circ} \mathrm{C}\right)$ (Halim et al. 2011). Alkali treatment also requires high temperatures $\left(120^{\circ} \mathrm{C}\right)$ causing protein denaturation making this technique less favorable for mild microalgae biorefinery, even if it is still considered the benchmark for total protein (soluble and insoluble) extraction (Halim et al. 2011)

\subsection{Conclusions}

The overview of cell disruption technologies presented in subsection 3, illustrated that there are currently various technologies under development or even already applicable at industrial scale. The main aspects of these technologies are summarized in Table 6.2. 
Table 6.2: Summary of cell disruption technologies for main aspects (adapted from Günerken et al. (2015).

\begin{tabular}{llllll}
\hline Method & Mildness & Selectivity & $\begin{array}{l}\text { Optimum biomass } \\
\text { concentration }\end{array}$ & $\begin{array}{l}\text { Energy } \\
\text { consumption }\end{array}$ & $\begin{array}{l}\text { Practical } \\
\text { scalability }\end{array}$ \\
\hline $\begin{array}{l}\text { High Pressure } \\
\text { Homogenization }\end{array}$ & Yes/no & No & Diluted/concentrated & High & Yes \\
$\begin{array}{l}\text { Bead milling } \\
\text { Yes }\end{array}$ & Yes/No & Concentrated & Low/medium & Yes \\
$\begin{array}{l}\text { Pulsed Electric } \\
\text { Field }\end{array}$ & Yes/no & Yes/No & Diluted & Medium/high & Yes \\
Enzymes & Yes & Yes & Diluted & Low & Yes \\
$\begin{array}{l}\text { Supersonic Flow } \\
\text { Fluid }\end{array}$ & Yes/no & n/a & Diluted & Medium/high & Yes/No \\
$\begin{array}{l}\text { Ultrasound } \\
\text { Microwave }\end{array}$ & Yes/No & No & Diluted & Medium/high & Yes/No \\
Chemical & No & Diluted & High & Yes/No \\
\hline
\end{tabular}

Although those technologies have very different mechanisms, they serve the same purpose of enhancing the extractability, or release of intracellular components. When cell disruption in general is developed as a technology that is applicable for various algal downstream process scenarios, it should meet the following two requirements:

- Costs: The overall costs should be minimized. Since there are various scenario's (energy, fuel, bulk commodities) proposed in which the microalgal biomass represents a fairly low value compared to current cultivation costs, decreasing the energy input during cell disruption could contribute to the feasibility of those scenarios. Coons et al. (2014) stated for example that only $10 \%$ of the total combustion energy of microalgae should be spend to cell disruption when a biofuel scenario is foreseen. According to their study, this equals about $0.68 \mathrm{kWh} / \mathrm{kg}_{\text {biomass. }}$.

- Mildness: a high degree of mildness is a prerequisite. Commonly, during cell disruption, harsh conditions such as high pressure, temperature, shear or other extreme environmental conditions like a non-neutral $\mathrm{pH}$ are applied. 
Although those conditions do result in a highly efficient cell disruption with potentially low operational costs, it is likely that next to the cell wall and membrane, also intracellular valuables such as proteins become damaged (denatured). In various applications such as food and feed applications, but also with an integrated biorefinery, extracting components like proteins in their native form is desired. Therefore, a cell disruption technology should combine low expenditures with mild conditions to maintain the integrity of all intracellular components.

The results by several groups who worked on PEF as microalgal cell disruption technique have been summarized in Figure 6.8. Moreover, two mechanical disruption methods (bead milling and high pressure homogenization) are provided as a positive control. In this comparison, the protein yield was taken as an illustrative parameter, as the proteins commonly have the highest value when an integrated bulk-commodity biorefinery is foreseen (Wijffels et al. 2010). In addition, proteins are large molecules, so when proteins are released, other (smaller) components such as carbohydrates will be as well.

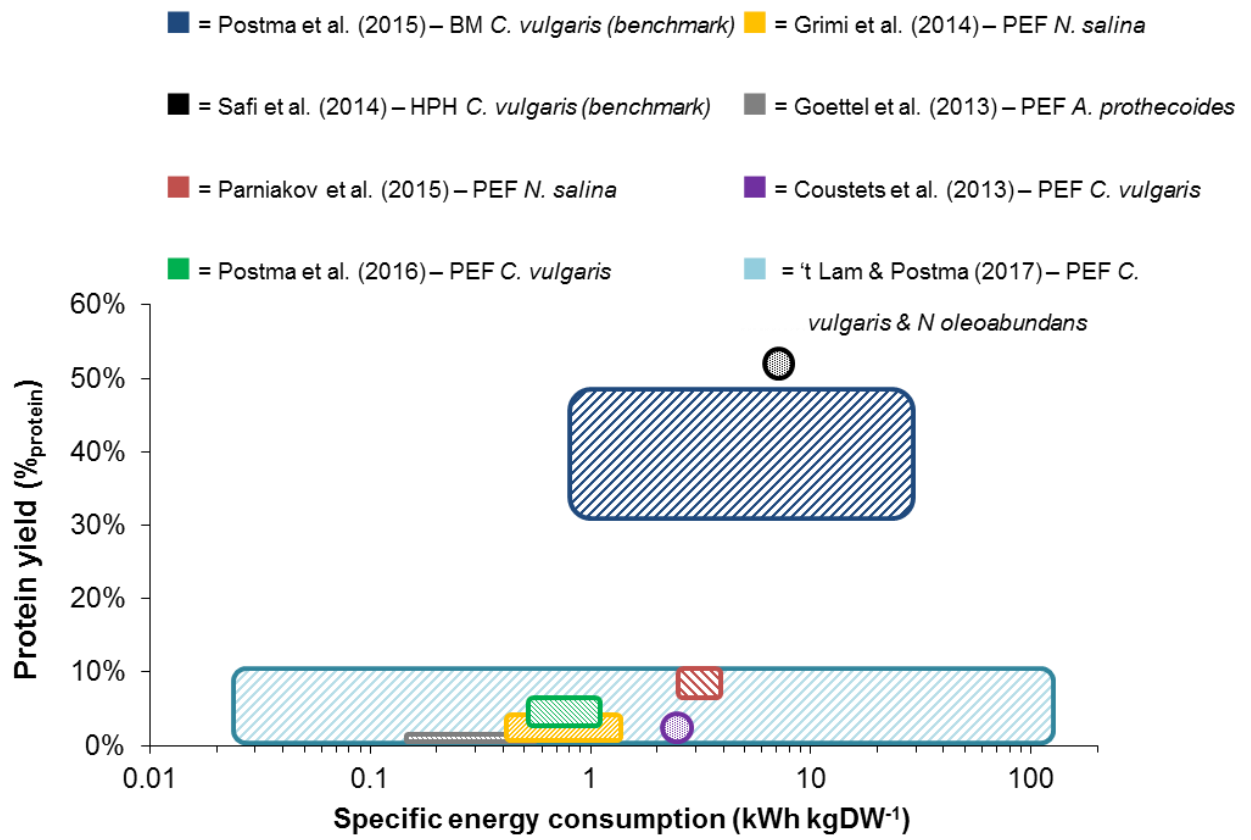

Figure 6.8: Illustrative overview of protein yields as a function of the specific energy input using PEF and mechanical cell disruption, bead milling 'BM' and high pressure homogenization 'HPH'. When an absolute yield was not provided, estimations were made. 
According to this comparison in Figure 6.8, applying PEF on different microalgae did not result in yields similar to positive control at an equal or higher energy input than the benchmark technologies. These results show that PEF as single cell disruption technology is not competitive yet with other technologies for the release of hydrophilic components. However, at the same time, it has been reported that after PEF treatment, the solvent extraction of lipids using the green solvent ethyl-acetate in combination with PEF-treatment resulted in $90 \%$ extraction efficiencies, making it competitive to traditional chloroform-methanol extraction (Zbinden et al. 2013). This increased extractability of lipids in combination with the high ion release (> $80 \%)$ can suggest that only small pores were made in the cell wall. Azencott et al. (2007) showed that only the cell membrane was harmed during PEF treatment, where the outer cell wall remained unaffected. The results of Zbinden et al., (2013) illustrate that PEF is already an interesting technology when only hydrophobic components are foreseen to be extracted using green solvents. However, as a general cell disruption technology that also enables the release of hydrophilic components, still further research is required. Mahnič-Kalamiza et al. (2014) therefore already envisioned that PEF could be better applied in a multi-stage biorefinery approach. Where PEF would be applied as a first disruption step followed by aqueous extraction and mild solvent extraction for hydrophobic components. A similar processing route was proposed by Kotnik et al. (2015) to valorize the complete microalgae biomass.

Examples of further steps are for example optimizing treatment conditions such as the temperature. Postma et al. (2016) reported a 1.7-fold increase in carbohydrate yield when the treatment temperature was increased from $25^{\circ} \mathrm{C}$ up to $55^{\circ} \mathrm{C}$. At a temperature of $55^{\circ} \mathrm{C}$, the carbohydrate yield after PEF treatment $\left(E_{M}=0.55\right.$ $\mathrm{kWh} / \mathrm{kg}_{\text {dry weight }}$ ) was $39 \%$. This yield is in the same order of magnitude as the yield obtained after bead milling (ranging between 48-58\%). In addition, Postma et al., (2016) also showed with this study that the treatment temperature during PEF is very well controllable. As a high treatment temperature is named as one of the causes for a non-mild process, this feature illustrates the potentially high degree of mildness of PEF as cell disruption technology. Despite the increased carbohydrate yields, Postma et al. (2016) did not report a similar increase in protein yield. Nonetheless, this work shows that smart application of operating conditions can result in a better 
process making PEF a very promising, future cell disruption technology for a microalgae biorefinery approach.

\section{Acknowledgements}

Part of this work is performed within the TKI AlgaePARC Biorefinery program with financial support from the Netherlands' Ministry of Economic Affairs in the framework of the TKI BioBased Economy under contract nr. TKIBE01009. Part of this work is performed within the IPOP Biorefinery of Wageningen University and Research Centre. Part of this work was conducted in the framework of a COST TD1104 action (Reference code TD1104-041262 and TD1104-16869) (www.electroporation.net). 



\section{Chapter}

Mild and selective protein release of cell wall deficient microalgae with Pulsed Electric Field

To be submitted as:

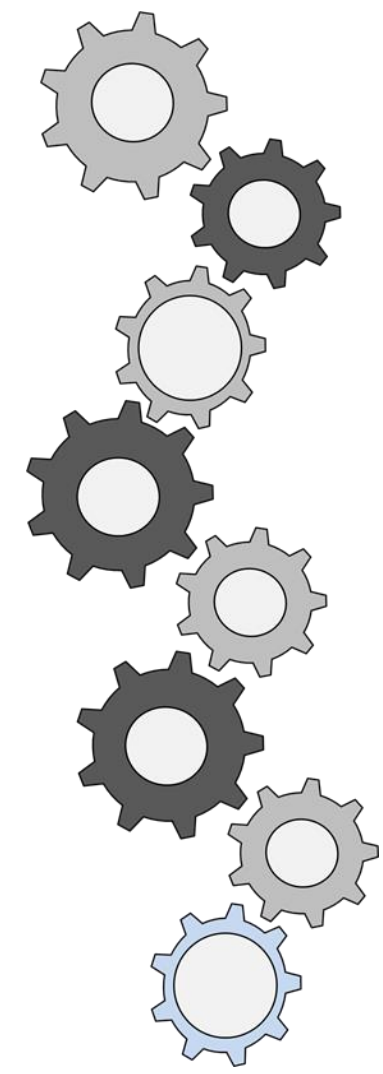

't Lam, G.P., van der Kolk, A.J., Chordia A., Vermuë M.H., Olivieri G, M.H.M. Eppink, Wijffels R.H., Mild and selective protein release of cell wall deficient microalgae with Pulsed Electric Field. 
ulsed Electric Field (PEF) is considered to be a very promising technology for mild cell disruption. The application of PEF for microalgae, however, is hampered by the presence of a rigid outer cell wall. A cell-wall free mutant of C. reinhardtii was used to mimic pre-treated microalgae with removed cell wall, to investigate the possibility of using PEF for protein release from microalgae. A complete release of hydrophilic proteins from the cell-wall free mutants was observed whereas PEF-treatment on the cell wall containing species resulted in substantially lower protein yields. Additional experiments showed that even at extremely low energy input $\left(0.05 \mathrm{kWh} / \mathrm{kg}_{\text {biomass }}\right)$, still about $70 \%$ of the proteins could be released with respect to bead beating as reference. These released proteins were water soluble while the hydrophobic chlorophyll remained mainly entrapped in cell particles. SEM-analysis of these cell particles showed that PEF did not cause complete disintegration. These results indicate that PEF is an energy-efficient cell disruption method for selective release of water soluble proteins, after the microalgal outer cell wall is removed. Enzymatic pretreatment to degrade the cell walls before PEF treatment showed to be an efficient method to remove the cell wall.

\section{Graphical Abstract}

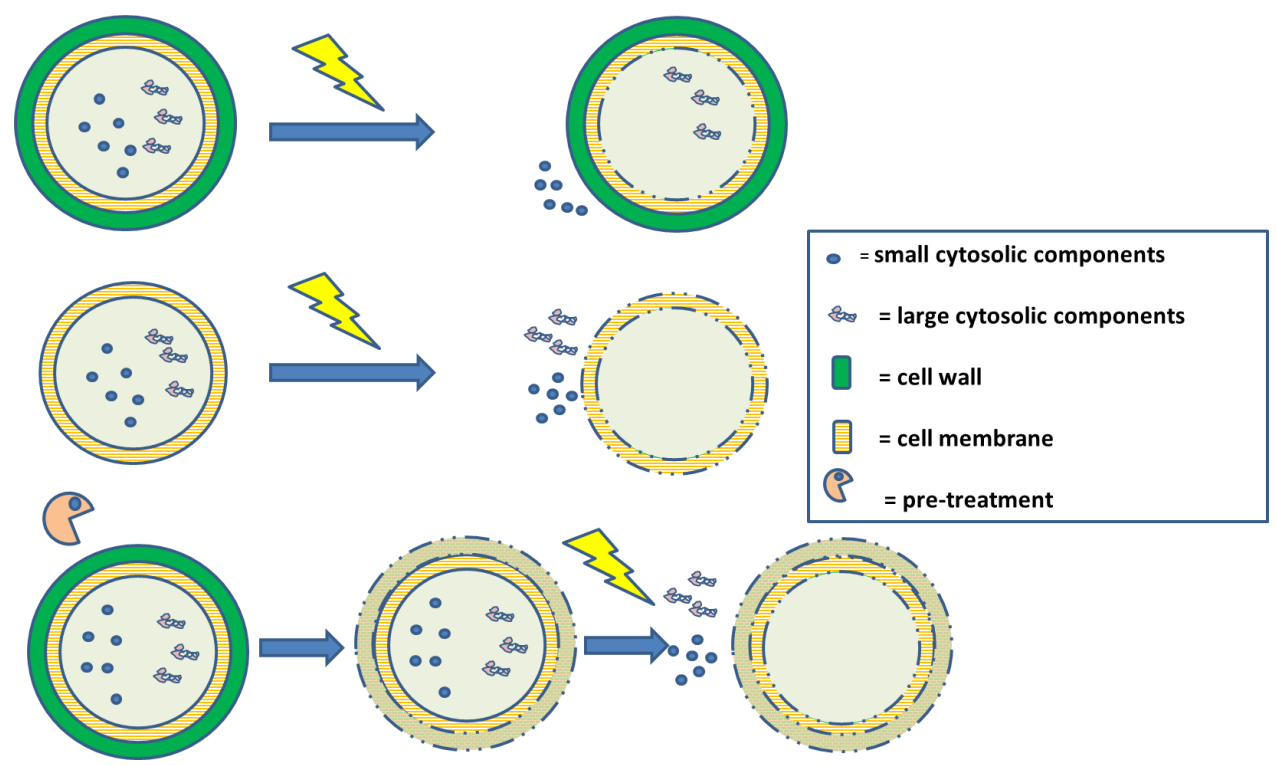




\section{Introduction}

Biorefinery can be used to extract various components (e.g. proteins, carbohydrates, lipids, pigments) from microalgae. A bottleneck in the biorefinery chain is cell disruption. As the soluble proteins are generally a vulnerable, but valuable biomass fraction, cell disruption technologies need to be low-cost and mild. However, current cell disruption methods commonly have high costs and they show shortcomings in mildness (Postma \& 't Lam 2015; Günerken et al. 2015; Vanthoor-Koopmans et al. 2013). Pulsed Electric Field (PEF) has been proposed as a potentially low cost and mild alternative (Günerken et al. 2015; Goettel et al. 2013). Although PEF is regarded as promising, previous work showed that the release of large intracellular components is hampered, making PEF yet unsuitable for microalgal cell disruption ('t Lam \& Postma, 2017; Postma et al. 2016a; Postma et al. 2016b; Goettel et al. 2013).

The success of PEF for various applications is attributed to a reverse in the transmembrane potential (TMP), resulting in an opening of the cell membranes (Kotnik et al. 2015; Weaver and Chizmadzhev 1996). When the change in TMP is sufficiently high, large openings in the membrane are formed. These openings allow the release of cytosolic components (Barba et al. 2015).

Although the application of a sufficiently high field strength may result in an opening of the cell membrane, the rigid outer cell wall of the microalgae may remain unaffected (Azencott et al. 2007). Therefore, as a result of PEF treatment, only small inorganic salts can freely migrate, while large cytosolic molecules remain intracellularly entrapped (Madigan and Martinko 2006). This would explain why only small components such as ions were successfully released in previous research while most proteins remained entrapped after PEF treatment ('t Lam \& Postma et al., submitted; Goettel et al. 2013; Postma et al. 2016b).

The hypothesis that PEF treatment of microalgae is hindered by the rigid outer cell wall, was investigated by subjecting the cell wall containing microalgae $C$. reinhardtii (cc-124) and its cell wall deficient mutant (cc-400) to PEF. By assuming that the cell wall deficient mutant (cc-400) mimics pre-treated microalgal biomass, we could characterize the effect of the operating conditions on treated cell-wall deficient microalgae. The ability to weaken microalgae with potential cell-wall degrading enzymes prior to PEF was tested on the wild-type strain (cc-124). Based on the 
results of this study an outlook on future steps that need to be taken in the development of PEF as novel technology for microalgae is provided.

\section{Materials and Methods}

\subsection{Strain and medium composition}

Both the wild type strain C. reinhardtii cc-124 and the cell-wall deficient mutant strain cc-400 were obtained from the Chlamydomonas Resource Centre. The biomass was cultivated in culture medium adapted from (Breuer et al. 2012): $\mathrm{NaNH}_{4}: 16.8 \mathrm{mM}$; $\mathrm{Na}_{2} \mathrm{SO}_{4}$ : $3.5 \mathrm{mM}$; HEPES: $100.1 \mathrm{mM}$; $\mathrm{MgSO}_{4} .7 \mathrm{H}_{2} \mathrm{O}: 5.0 \mathrm{mM}$; $\mathrm{CaCl}_{2} .2 \mathrm{H}_{2} \mathrm{O}: 2.4 \mathrm{mM}$; $\mathrm{K}_{2} \mathrm{HPO}_{4}$ : $2.5 \mathrm{mM}$; $\mathrm{Na}_{2}$ EDTA.2 $\mathrm{H}_{2} \mathrm{O}: 0.08 \mathrm{mM} ; \mathrm{MnCl}_{2} .4 \mathrm{H}_{2} \mathrm{O}: 0.02 \mathrm{mM} ; \mathrm{ZnSO}_{4} .7 \mathrm{H}_{2} \mathrm{O}$ : $0.004 \mathrm{mM} ; \mathrm{CoCl}_{2} \cdot 6 \mathrm{H}_{2} \mathrm{O}: 0.001 \mathrm{mM} ; \mathrm{CuSO}_{4} .5 \mathrm{H}_{2} \mathrm{O}: 0.001 \mathrm{mM} ; \mathrm{Na}_{2} \mathrm{MoO}_{4} .2 \mathrm{H}_{2} \mathrm{O}: 0.0001$ mM; NaFeEDTA: 0.028 mM., $10.0 \mathrm{mM} \mathrm{NaHCO}_{3}$.

\subsection{Biomass cultivation and pre-treatment}

Shake flask cultivation was used to evaluate PEF-treatment on $C$. reinhardtii wild type (cc-124) and its cell wall deficient (cc-400). The flasks were orbitally shaken at $90 \mathrm{rpm}$ and cultured at $25^{\circ} \mathrm{C}$, illuminated at $50 \mu \mathrm{mol} . \mathrm{m}^{-2} \cdot \mathrm{s}^{-1}$ or $120 \mu \mathrm{mol} \mathrm{m}{ }^{-2} . \mathrm{s}^{-1}$. From this incubator, samples of were taken and used for further experiments.

The screening of operating conditions as well as the evaluation of PEF-treatment at low energy input was performed using the cell-wall deficient mutant $C$. reinhardtii cc400. It was cultivated in a stirred tank reactor with a $2.2 \mathrm{~L}$ working volume (Applikon, the Netherlands). In the reactor, continuous illumination was applied at constant incident light intensity of $200 \mu \mathrm{mol} . \mathrm{m}^{-2} \cdot \mathrm{s}^{-1} \cdot \mathrm{pH}$ was controlled using $\mathrm{CO}_{2}$-dosing on demand at a set point of $\mathrm{pH} 7.0 \pm 0.1$. As the $\mathrm{pH}$ was controlled by $\mathrm{CO}_{2}$-sparging, ammonium was replaced by urea as nitrogen source in the culture medium. The micro-algae were continuously harvested (chemostat operation) and stored for maximal 24 hours in an ice-cooled and dark stored harvesting vessel.

To reduce to conductivity prior to the PEF experiments, the harvested biomass was washed twice by centrifugation at a low shear regime (1500 rpm). For higher energy input PEF-experiments ( $>2 \mathrm{kWh} / \mathrm{kg}_{\mathrm{DW}}$ ), washing proceeded with $0.04 \%_{\mathrm{w} / \mathrm{w}} \mathrm{NaCl}$. For other experiments washing with demi-water was used. To ensure that no cells were 
damaged during the pre-treatment, samples were analysed prior to PEF-treatment (data not shown).

Initial experiments with enzymes as pre-treatment prior to PEF were performed. For these experiments, the wild type $C$. reinhardtii cc-124 was cultivated in shake flasks at a light intensity of $50 \mu \mathrm{mol} . \mathrm{m}^{-2} . \mathrm{s}^{-1}$ using normal air. The cells were harvested at the end of the log-phase and were washed with demi-water before the enzymes were added.

\subsection{Pulsed Electric Field}

The conditions needed for PEF treatment were tested in a batch electroporation apparatus (Gene-Pulser XcellTM Bio-Rad, USA), which was described in 't Lam \& Postma et al., 2017. In the experiments disposable treatment cuvettes were used with a gap width of either 4 or $2 \mathrm{~mm}$ and a treatment volume of respectively $800 \mu \mathrm{L}$ or $400 \mu \mathrm{L}$, (Westburg Pulsestar Electroporation Cuvettes).

In all experiments, square wave monopolar pulses were applied. The number of pulses ranged from $1-15$ pulses, the applied field strength ranged from 0.5 to 15 $\mathrm{kV} / \mathrm{cm}$ and the pulse length was varied between $0.05 \mathrm{~ms}$ and $0.2 \mathrm{~ms}$. Between the pulses, a 10 seconds pulse interval was applied. After treatment, the temperature was measured and it never exceeded $35^{\circ} \mathrm{C}$.

After PEF-treatment, a 1 hour resting time was applied using a rotational mixer to allow the release of cytosolic components. After this incubation time, the samples were centrifuged at 1500 rpm for 10 minutes. The samples taken after PEF treatment and the samples of the washed biomass before PEF treatment were then analysed on dry weight, conductivity, protein and chlorophyll content and particle size distribution.

The results obtained with washed cells subjected to PEF treatment were compared with the results of washed cells that were subjected to bead beating. Bead beating was performed as a positive control. In these experiments, beat beater tubes ('Lysing matrix E', MP biomedicals) were subjected to 3 disruption cycles at $6500 \mathrm{rpm}$ for 1 minute, with a 2 minutes' interval. 


\subsection{Enzyme assisted PEF}

To explore the potential of enzymatic incubation as pre-treatment of the wild type Chlamydomonas cc-124, an initial screening of three potentially cell wall degrading enzymes (cellulase, protease and lysozyme) was performed. From these preliminary tests, only the protease was found to be effective (see supplementary section ' $\mathrm{B}$ ').

The protease was further used to further investigate the potential of using enzymes to remove the rigid outer cell wall prior to PEF treatment. In these experiments, a 6-hour incubation at room temperature and $\mathrm{pH} 7.7$ was performed. After incubation, the cells were washed with milli-Q water to remove the enzymes and a subsequent PEFtreatment was applied. The applied PEF conditions were 5 pulses with $0.1 \mathrm{~ms}$ pulse length at $7.5 \mathrm{kV} / \mathrm{cm}$. As negative control a sample of washed $C$. reinhardtii $\mathrm{cc}-124$ cells that were not treated with the enzyme, was used. The sample was incubated for 6 hours at room temperature and $\mathrm{pH} 7.7$ as well (negative control). As positive control, washed cells treated with bead beating were used and treated similar to the samples of the negative control.

\subsection{Analysis}

\subsubsection{Dry weight and conductivity}

Dry weight analysis was determined according to (Lamers et al. 2010). According to 't Lam \& Postma et al., 2017, the conductivity of the samples was determined.

\subsubsection{Soluble protein release}

Modified Lowry protein assays (Thermo-scientific) were used to analyse the water soluble protein content in the samples taken according to our previous work ('t Lam \& Postma et al., 2017): After colorimetric reaction, absorbance was measured spectrophotometrically at a wavelength of $750 \mathrm{~nm}$. The total protein content was determined using total nitrogen analysis ('Kjehldahl') and a conversion factor for $C$. reinhardtii of 4.58 (Kliphuis et al. 2012).

\subsubsection{Degree of disruption}

Before and after cell disruption, particle size distributions (PSD) were determined using a Beckman Coulter Counter (de Winter et al. 2013). From the observed PSD, it was observed that no biomass was disrupted prior to PEF treatment. 


\subsubsection{Chlorophyll extraction}

After cell disruption, the spectrophotometric method of (Postma et al. 2015) was used to determine the release of pigment in the aqueous phase. The wave length scans were executed at a wavelength from 400 up to $750 \mathrm{~nm}$.

To test if hydrophilic proteins were selectively released after PEF, additional chlorophyll extraction was performed. After cell disruption, the cell debris was separated from the supernatant using centrifugation at $1500 \mathrm{rpm}$ for 10 minutes. After centrifugation, the supernatant was replaced with an equal volume of methanol. Methanol incubation proceeded at $40{ }^{\circ} \mathrm{C}$ for 1 hour. After extraction, the solvent phase was separated again by centrifugation (1500 rpm, 10 minutes) and adsorptions were determined spectrophotometrically according to Safi et al. (2014).

The PEF treated samples were compared with a sample of cells that were beadbeated in methanol and a sample of the pellet obtained after bead-beating, that was subjected to chlorophyll extraction (bead beaten + extraction). In addition, to quantify the release without using solvents nor cell-disruption, samples were subjected to water-extraction at $40{ }^{\circ} \mathrm{C}$.

After extraction, the chlorophyll content was measured and quantified spectrophotometrically in the methanol-solvent phase according to Ritchie (2006).

\subsubsection{SEM analysis}

SEM analysis was performed to reveal how cells were affected by the PEF and bead beating. Samples were prepared according to the protocol described in ('t Lam et al. 2016). They were transferred to a poly-L-lysine cover slip. After 1 hour, the slip was carefully rinsed with a PBS-buffer and the samples were fixated using a $3 \%$ glutaraldehyde solution in PBS buffer for 1 hour. An additional fixation step using a $1 \% \mathrm{OsO}_{4}$ solution and a 1 -hour incubation step were performed. After fixation, cells were dehydrated using ethanol and dried using critical point $\mathrm{CO}_{2}$ drying. The cover slips were finally coated with a $15 \mathrm{~nm}$ Tungsten layer using sputter-coater.

\subsection{Data analysis}

\subsubsection{Energy input}

The applied energy input was calculated using ('t Lam \& Postma et al., 2017): 
$W\left(k W h k g_{D W}^{-1}\right)=\frac{E^{2} \cdot t_{p} \cdot N \cdot \sigma}{C_{x} \cdot 3600000}$

In this equation, $E=$ the electric field applied $(\mathrm{V} / \mathrm{m}) ; t_{p}$ is the pulse length (s) and $N$ are the number of pulses applied. The conductivity ' $\sigma$ ' was measured prior to the PEF treatment $(\mathrm{S} / \mathrm{m})$ and the biomass concentration $\left(C_{x}\right)$ was provided in $\mathrm{kg}$ Dw $/ \mathrm{m}^{3}$.

\subsubsection{Protein yield}

The protein yield was calculated as the increase in water soluble proteins divided over the total protein concentration (Postma et al. 2015):

Protein yield (\%) $=\frac{C_{\text {soluble proteins after cell disruption }}-C_{\text {soluble proteins before disruption }}}{C_{\text {protein total }}} * 100$

\subsubsection{Degree of disruption}

From the particle size distributions, a degree of disruption (\%) was calculated by dividing the amount of particles present in the size interval (3-15 $\mu \mathrm{m})$ after disruption treatment over the amount of particles that were originally present in this size interval:

Degree of disruption $(\%)=\left(1-\left(\frac{\text { Particle count after disruption }(3-15 \mu \mathrm{m})}{\text { Particle count before disruption }(3-15 \mu \mathrm{m})}\right)\right) * 100$

\section{Results and Discussion}

\subsection{Evaluating the performance of PEF}

By subjecting C. reinhardtii (cc-124) and a cell wall deficient mutant $C$. reinhardtii (cc400) to PEF treatment, the effect of a cell wall on the performance of PEF was determined. If the cell wall indeed limits the performance of PEF, a difference in release of intracellular compounds after PEF is expected between the wild type and the cell wall deficient mutant.

Figure 7.1 shows, the obtained protein yield (\%proteins) after PEF-treatment with both strains. In these experiments, a wide range of operating conditions was applied (57,5 kV/cm; $1-10$ pulses and a pule length 0.05-0.2 ms). In addition to the protein yields obtained after PEF-treatment, the protein yields after beat beating are presented as well (positive control). 


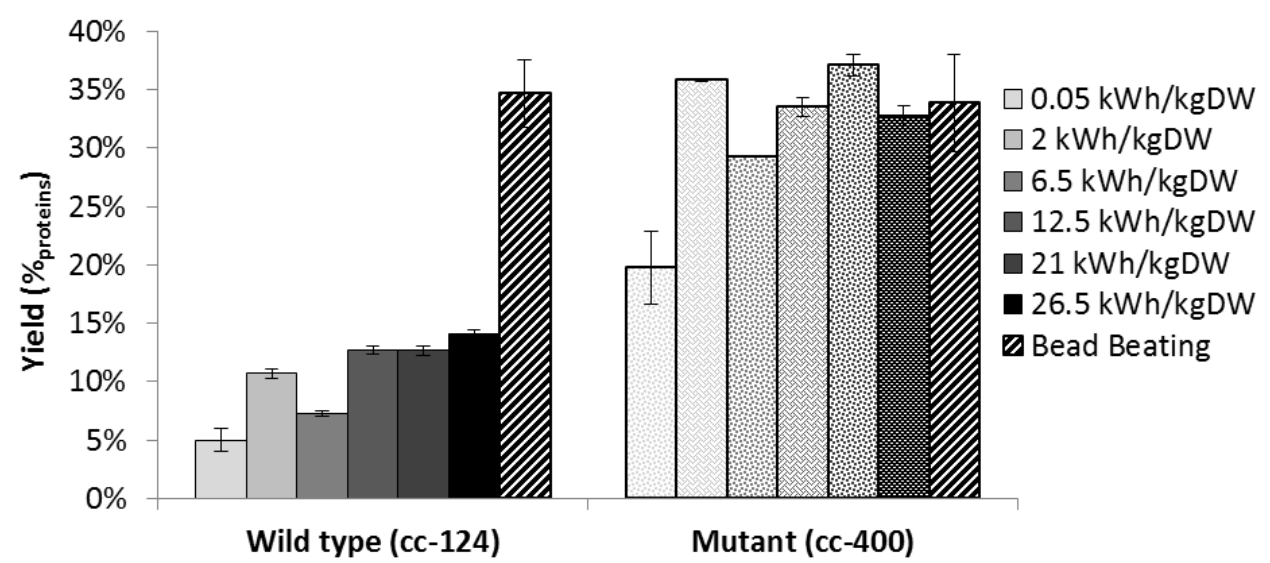

Figure 7.1: Effect of PEF treatment on cell wall containing microalgae and cell wall deficient mutants in comparison to beat beating as positive control. Bead beating was performed biological triplicates as positive control $(n=3)$. PEF experiments are performed in technical replicates $(n=2)$ with the exception of the $0.05 \mathrm{kWh} / \mathrm{kg}_{\mathrm{Dw}}$ experiments (biological replicates, $\mathrm{n}=2$ ).

The protein yields obtained after PEF treatment on the cell wall deficient mutant are on average three times higher as the ones obtained with the wild type $(P<0.05)$ (Figure 7.1). With the cell wall deficient mutant an average protein yield of $31 \pm$ $6 \%$ proteins was obtained. These results thereby illustrate that PEF-treatment on cell wall less microalgae results in protein yields similar to mechanical cell disruption. Applying PEF on the wild type species resulted in an average protein yield of only 11 $\pm 3 \%$ proteins. The protein yields obtained with the wild type (cc-124) after PEF treatment are similar to those found for other microalgae with a rigid outer cell wall, like Chlorella vulgaris and Neochloris oleoabundans (Postma et al. 2016b) and Auxenochlorella protothecoitus (Goettel et al. 2013). The study of 't Lam \& Postma (submitted) even showed that PEF released at least a 4 fold lower protein release than bead milling. It is therefore reasonable that in general, protein release by means of PEF is limited by the presence of an outer cell wall (Postma et al. 2016a).

Additional experiments were performed with the cell wall deficient mutant (cc-400) to confirm the high protein yields at low energy input (Supplementary section ' $A$ '). A low energy input is relevant considering that for a bulk-scenario, the maximum energy input should not exceed $0.68 \mathrm{kWh} / \mathrm{kg}_{\mathrm{DW}}$ (Coons et al., 2014). At an energy input similar to the threshold provided by Coons et al., 2014, the protein yield was still $23 \%$ proteins $\left(0.5 \mathrm{kWh} / \mathrm{kg}_{\mathrm{DW}}\right)$. This high protein release at low energy input was confirmed in 24 independent experiments. With an energy input ranging between 
0.05 and $0.5 \mathrm{kWh} / \mathrm{kg} g_{\mathrm{DW}}$ the protein yield was indeed $23 \%$ proteins \pm 3.3 (Supplementary section ' $A$ '). These results confirm that at an energy input similar to current mechanical cell disruption ( $2 \mathrm{kWh} / \mathrm{kg}_{\mathrm{DW}}$ ) complete release of hydrophilic proteins is possible whereas at extremely low energy inputs still $\sim 70 \%$ of the proteins could be released, compared to bead beating.

To evaluate if PEF is mild, native-PAGE analysis of the released proteins after PEF was performed. This analysis revealed that during the PEF treatment RubisCo kept its native form (Supplementary section 'B'). RubisCo is a well characterized protein with a size of $540 \mathrm{kDa}$. It has therefore been used as a biomarker to confirm the degree of mildness (Postma et al. 2016b). As native RubisCo was present in the supernatant after PEF, it confirms that PEF allows a mild release of proteins.

Interestingly, the high protein yields after PEF are not associated with a high degree of cell disruption. While bead beating resulted in $99 \%$ of disrupted biomass, PEF treatment at low energy input resulted in only $27 \%$ (Supplementary section ' $A$ '). This is in agreement with the low release of chlorophyll. Compared to bead beating as a positive control, PEF yielded only up to $5 \%$ chlorophyll release in the aqueous phase (data not shown). These results indicate that the cells were not complete disintegrated into fine particles. To confirm if the cells after PEF were indeed not completely disintegrated, additional SEM-analysis was performed (Figure 7.2). In Figure 7.2, PEF-treated samples $(7.5 \mathrm{kV} / \mathrm{cm}, 3$ pulses at $0.1 \mathrm{~ms}$ pulse length) and washed but non-treated cells were included as control.

Figure 7.2-A and B illustrate that the untreated cells of the cell wall free mutants (cc400 ) were intact and not broken by either the washing or the applied fixation protocol. The cells have a diameter of approximately $4.5 \mu \mathrm{m}$ and have a smooth surface. After PEF treatment the cells still seem to be intact (Figure 7.2-C and D), which is in agreement with the low degree of disruption that was observed (supplementary section ' $A$ ') and the presence of native RubisCo in the supernatant. It therefore confirms that PEF indeed is does not completely disintegrate the cells. After bead beating, however, no cells, or even cell debris and other biological material could be observed anymore (data not shown). 

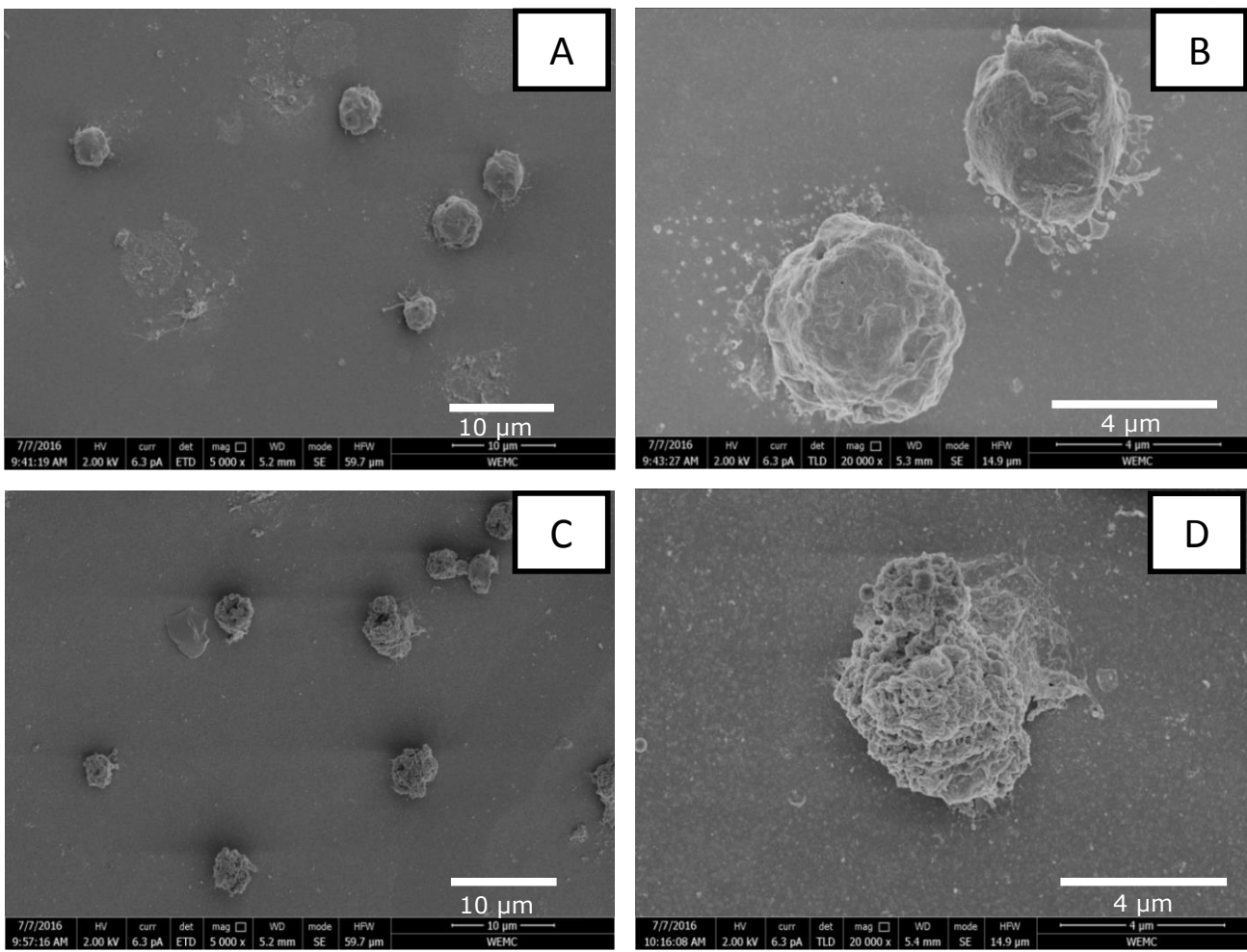

Figure 7.2: SEM-images. Picture A and B: non-treated samples at a 5 000x and 20 000x magnification. Picture $\mathbf{C}$ and $\mathbf{D}$ : Cells treated at $7.5 \mathrm{kV} / \mathrm{cm}, 3$ pulses and $0.1 \mathrm{~ms}$ pulse length at a 20 000x magnification.

\subsection{Influence of operating parameters on the protein yield}

To explore how the operating conditions influence the protein release from cell wall deficient microalgae, a screening of operating conditions was performed using $C$. reinhardtii cc-400. The operating parameters for PEF that were used to evaluate the effect of PEF on protein yield were the number of pulses (1 - 15 pulses), pulse length (0.05 - $0.25 \mathrm{~ms})$, and the applied field strength $(0.5-15 \mathrm{kV} / \mathrm{cm})$. In all experiments, the biomass concentration ranges between 2 and $3 \mathrm{~g} / \mathrm{L}$ and the pulse interval was in all experiments 10 seconds. In all experiments, the energy input did not exceed 0.5 $\mathrm{kWh} / \mathrm{kg}_{\mathrm{DW}}$. The results of this parameter screening are presented in Figure 7.3. 
5

10

Number of pulses (-)

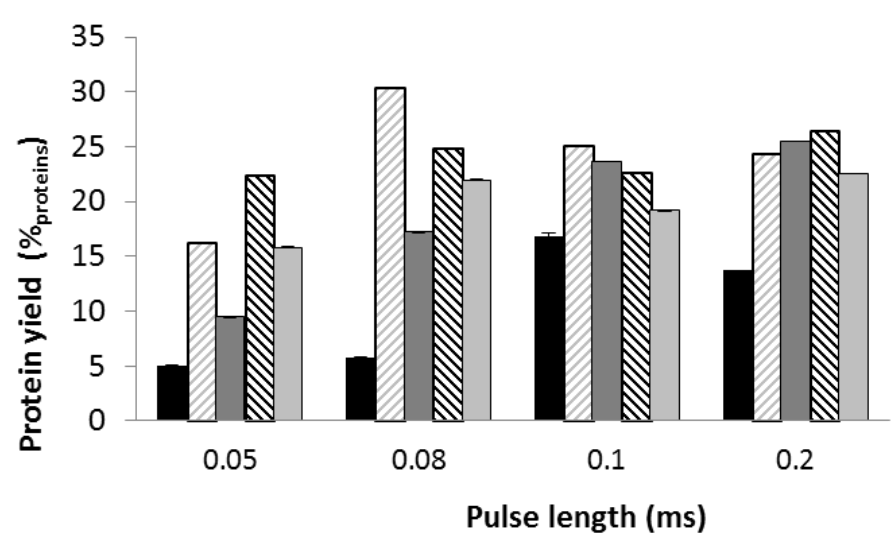

$\mathbf{\Delta} 5 \mathrm{kV} / \mathrm{cm}$

$\square 7.5 \mathrm{kV} / \mathrm{cm}$

圆 $15 \mathrm{kV} / \mathrm{cm}$

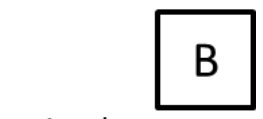

- 1 pulse

$\square 3$ pulse

$\square 5$ pulses

$\mathbf{\nabla} 10$ pulses

$\square 15$ pulses

Figure 7.3: Parameter screening on the cell wall deficient mutant cc-400. The protein yield after PEF treatment is presented as a function of the number of pulses, field strength and pulse length. Error bars represent technical replicates $(n=2)$.

Figure 3-A presents the effect of the number of pulses (pulse length of $0.05 \mathrm{~ms}$ ) at 6 different field strengths. The field strength has a major effect on the release of proteins irrespective of the number of pulses applied (Figure 7.3-A). With a field strength equal or lower than $1.5 \mathrm{kV} / \mathrm{cm}$, only up to $5 \%$ proteins were released. At 2.5 $\mathrm{kV} / \mathrm{cm}$ and $5 \mathrm{kV} / \mathrm{cm}$, however, the yields became already higher ( 5 and $20 \%$ proteins). At field strengths equally or higher than $7.5 \mathrm{kV} / \mathrm{cm}$, in all cases substantial higher protein yields were observed compared to the lower field strengths ( $>10 \%$ proteins difference in yield). The exceptions on this observation are the experiments performed with 1 pulse and 15 pulses. With 1 pulse, only $15 \mathrm{kV} / \mathrm{cm}$ resulted in a substantial higher protein yield. At 15 pulses, already a field strength of $1.5 \mathrm{kV} / \mathrm{cm}$ resulted in higher protein yields. However, it is likely that with 15 pulses Ohmic heating occurred, leading to additional damage of the cells. 
The results shown in Figure 7.3-A strongly indicate the presence of a critical transmembrane potential (c-TMP). According to literature, PEF is only successful in opening the cell-membrane if a field strength is applied that evokes a TMP which is high enough to reverse the charge of the cell membrane. When this C-TMP is reached, reformation and subsequent opening of those membranes occurs (Kotnik et al. 2015).

By using an average cell size of $4.5 \mu \mathrm{m}$ and a field strength ranging between 2.5 and $5 \mathrm{kV} / \mathrm{cm}$, we estimated the c-TMP for $C$. reinhardtii cc- 400 , to be between 1 and 2 volts. Although slightly higher, this range is still in agreement with the critical TMP of $0.4-1.0$ volts reported for $C$. reinhardtii by (Azencott et al. 2007). In their work on the development of a transformation protocol for $C$. reinhardtii using electroporation, they used a cell wall deficient mutant strain as well. They showed that a critical potential up to 1 volt was needed for successful delivery of the protein BSA (Azencott et al. 2007).

After determining that a field strength of $7.5 \mathrm{kV} / \mathrm{cm}$ results in a successful opening of the cell membrane, additional experiments at this field strength were performed to investigate the effect of the pulse length in combination with the number of pulses on the protein yield (Figure 7.3-B). During these experiments, the biomass concentration ranged between 2 and $3 \mathrm{~g} / \mathrm{L}$. The pulse length was varied between 0.05 and $0.2 \mathrm{~ms}$. The number of pulses ranged between 1 and 15 pulses.

The protein yields obtained with the experiments at a pulse length of $0.05 \mathrm{~ms}$ are lower than the ones obtained at other pulse lengths (Figure 7.3-B). Besides the lower yields at a short pulse length $(0.05 \mathrm{~ms})$, it appears that at all pulse lengths, a single pulse treatment results in lower yields compared to the experiments performed with more pulses. The lower yields obtained with either a single pulse or with pulses of 0.05 ms suggest that next to a threshold field-strength, the total treatment time also influences the performance of PEF. It may be that a minimal treatment time is required to allow sufficient charging and reformation of the cell membrane.

Interestingly, the protein yields that are presented in Figure 7.3 are in all cases lower as the protein yields obtained with the cell wall deficient mutant (cc-400) at higher energy input ( $>2 \mathrm{kWh} / \mathrm{kg}_{\mathrm{DW}}$, Figure 7.1$)$. These results suggest that not only the 
operating conditions, but also the energy input as overall parameter affects the protein yield.

\subsection{Selective release of hydrophilic components}

Paragraph 3.1 showed that high protein yields were obtained in combination with a low pigments release at low energy inputs, thereby suggesting that PEF is a selective technology. In addition, no complete disintegration occurred during PEF while only low amounts of chlorophyll were observed in the supernatant. The combination of those observations suggests that it is likely that only hydrophilic proteins were released were the hydrophobic chlorophyll remained entrapped. A selective release of hydrophilic proteins is desired as it may result in a less intensive fractionation in the later biorefinery stages.

As a selective release is advantageous for the further biorefinery, chlorophyll extraction from the treated biomass was performed using methanol. For these studies, additional experiments (above the c-TMP) at $7.5 \mathrm{kV} / \mathrm{cm}, 0.08 \mathrm{~ms}, 3$ pulses and 5 pulses were performed. After disrupting the algae, the pellet was subjected to additional extraction. Besides performing a methanol extraction on PEF-treated and bead beated samples, also bead beating in methanol was performed.

An initial observation revealed that the supernatant after bead beating contains substantially more chlorophyll as the supernatant obtained after PEF treatment (Figure 7.4). The high chlorophyll release during bead beating was confirmed by the low extraction yields using methanol extraction (Figure 7.5). Different from bead beating, methanol extraction from the PEF-treated samples appears to result in high extraction efficiencies (Figure 7.5). 

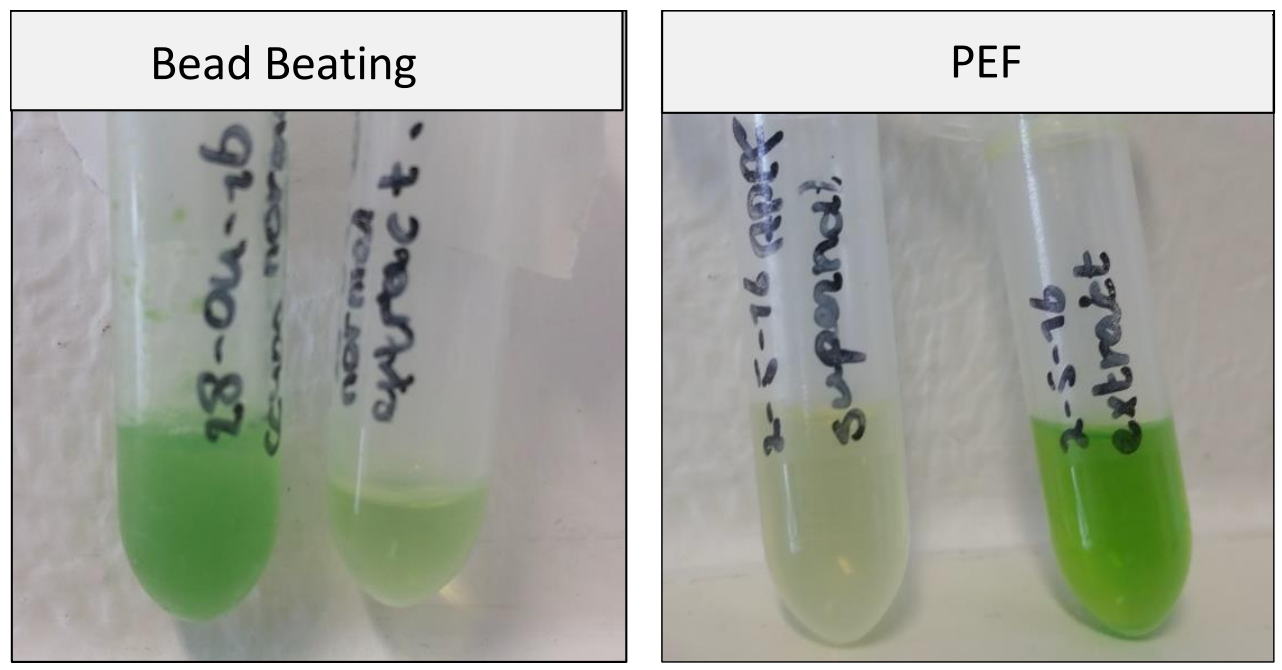

Figure 7.4: Pictures of the supernatant after cell disruption, and the methanol phase after chlorophyll extraction from the remaining cell debris. PEF treatment of $7.5 \mathrm{kV} / \mathrm{cm}, 0.08 \mathrm{~ms}$ and 5 pulses.

The high amount of extracted chlorophyll that is presented in Figure 7.5 confirms that after PEF-treatment, only a small amount of chlorophyll was released. The extraction yield after PEF was approximately 3-fold higher as the yield obtained after bead beating + extraction. This substantial lower extraction efficiency is probably caused by the high degree of disruption in combination with a high chlorophyll release during bead beating. 


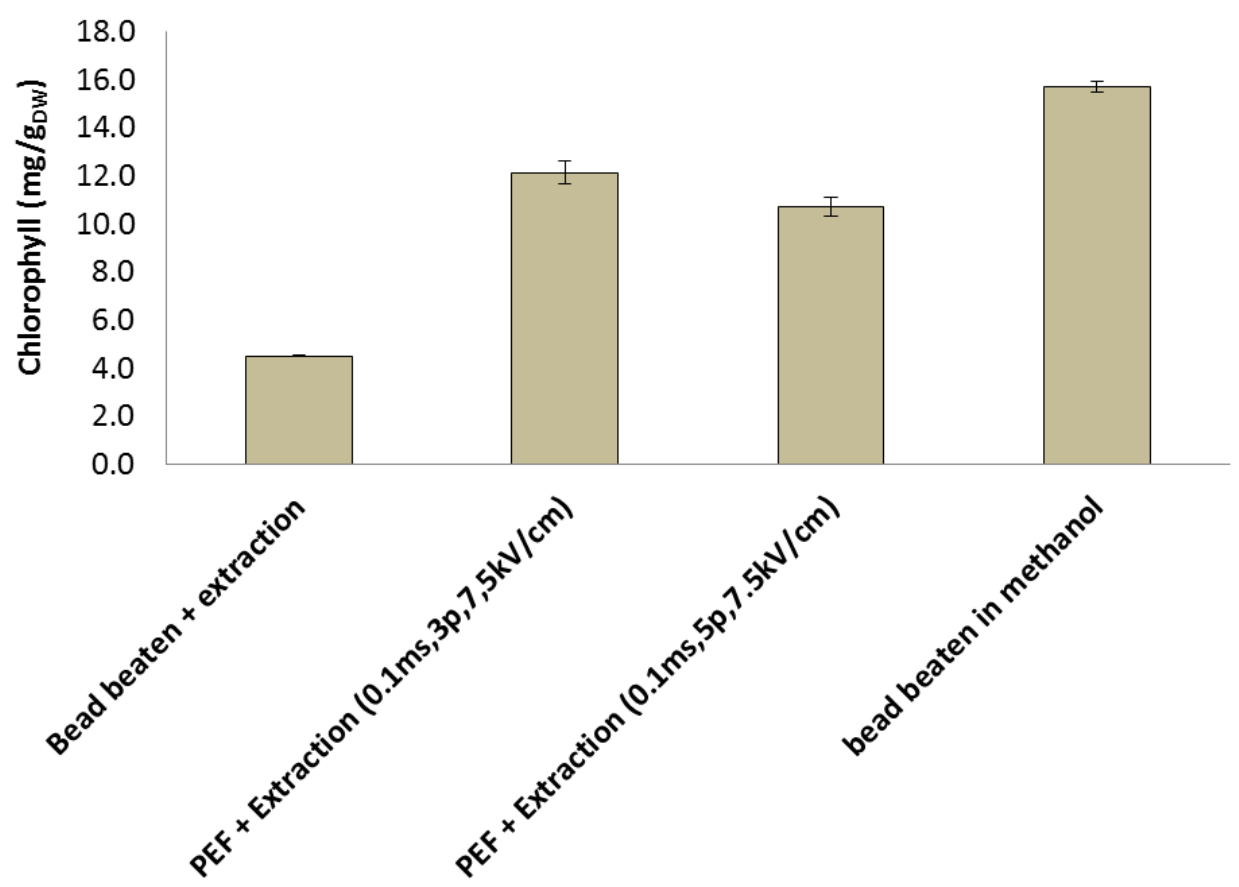

Figure 7.5: Pigment extraction from the pellet obtained after centrifugation the treatment (either PEF or bead beating) with bead beating in methanol as reference. Error bars represent biological replicates $(n=2)$

The results in Figure 7.4 and Figure 7.5 evidently show that PEF treatment on cell wall deficient (cc-400) results in a selective release of hydrophilic proteins, allowing a hydrophobic extraction afterwards. Other work already reported that the combination of PEF with a wet solvent extraction results in increased lipid- or pigment yields (Zbinden et al. 2013; Luengo et al. 2015). In addition to those results, this work shows that a pre-treatment in combination with PEF results in a selective protein release and may facilitate a biorefinery-scenario for valorisation of multiple components.

\subsection{Enzymatic incubation as potential pre-treatment for PEF}

The previous sections showed that PEF is a very promising technology in terms of protein yield combined with low energy input. It also allows an selective release of water-soluble proteins. This is a strong advantage for an integrated biorefinery scenario that requires a further fractionation. 
It is hypothesized that PEF can be successfully applied if cells are pre-treated to remove the cell wall. It has already been suggested to use cell-wall degrading enzymes prior to cell disruption to reduce the energy input during cell disruption (Wang et al. 2015). Similar to such a process, we propose to pre-treat algal cells using an enzyme incubation step. Afterwards, the weakened cells are treated by an additional PEF-treatment ('E-PEF’).

An initial enzyme screening showed that protease incubation of the wild-type strain (cc-124) at $40{ }^{\circ} \mathrm{C}$, resulted in increased protein yield after PEF (Supplementary section ' $C$ '). Additional experiments with the protease were performed at room temperature using an enzyme loading of either $4 \% \mathrm{w} / \mathrm{w}$ or $6 \% \mathrm{w} / \mathrm{w}$ (Figure 7.6 ).

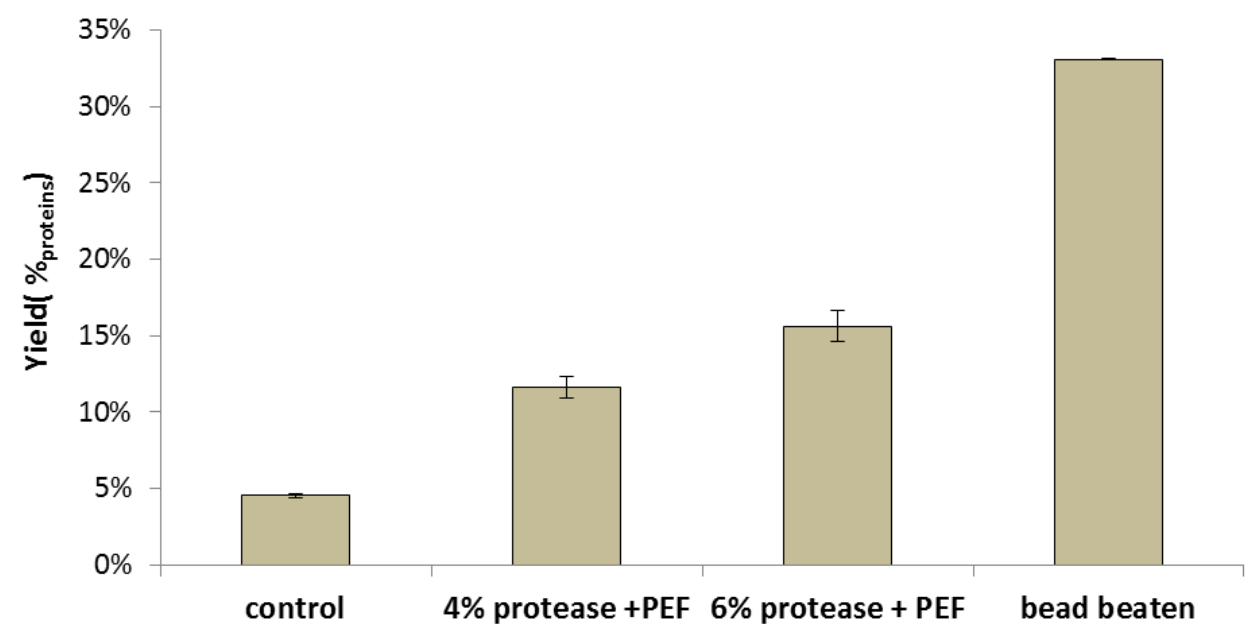

Figure 7.6: E-PEF experiments at room temperature. Samples were loaded with either 4 or $6 \% \mathrm{w} / \mathrm{w}$ enzymes and incubated for 6 hours at room temperature at a pH of 7.7. Control $=$ incubation without enzyme and subsequent washing and PEF treatment (5 pulses of $0.1 \mathrm{~ms}$ at $7.5 \mathrm{kV} / \mathrm{cm}$. Data of control experiment originates from Figure 1. Error bars represent biological replicates $(n=2)$.

PEF treatment without enzyme addition resulted in a protein yield of $5 \%$ protein (Figure 7.6). Enzymatic incubation with protease resulted in a more than twofold increase compared to the control experiment. Although the application of the protease followed by PEF resulted in an increased protein release, compared to PEFtreatment only, the protein yields are still twice as low as those obtained by bead beating.

To further enhance the performance of PEF by means of a pre-treatment, there is a need to further elucidate the structure of microalgal cell walls. When advanced 
knowledge on microalgal cell walls becomes available, rational development of a (enzymatic) pre-treatment becomes possible. Further development of such a pretreatment prior to PEF may result in a promising and competitive alternative for existing technologies as it releases native proteins at a low energy input in a selective way.

\section{Conclusion}

This study showed that the microalgal cell membrane is susceptible for PEF treatment were the outer cell wall remains unaffected. When a successful pretreatment is developed, PEF is a mild disruption technology as it at combines a low energy input and selective release of hydrophilic components from cell wall deficient microalgae. Enzymatic weakening of the outer cell wall resulted in substantial higher protein yields after PEF treatment. Although further research on microalgae cell walls is required, this study not only provided a better understanding of PEF on microalgae, but it also presented E-PEF as a novel and promising cell disruption approach.

\section{Acknowledgement}

This work is performed within the TKI AlgaePARC Biorefinery program with financial support from the Netherlands' Ministry of Economic Affairs in the framework of the TKI BioBased Economy under contract nr. TKIBE01009. The authors thank Anastasia Piltsii for the fruitful discussions and valuable input on enzyme assisted PEF. The authors thank Marcel Giesbers of the Wageningen Electron Microscopy Centre of Wageningen University for his support with SEM-imaging. The authors are grateful for the help received from Wageningen UR Food and Biobased Research and in particular from Jelle van Leeuwen for his help during the total protein determination. The authors are grateful for the help received from Catalina Suarez (Bioprocess Engineering, Wageningen University) with performing Native-PAGE. 


\section{Appendix A - PEF on cell wall deficient microalgae at low energy input}

To confirm that PEF yields in a high protein release at low energy input, additional experiments were performed (Figure S1). The energy input in these experiments ranged between 0.01 and $0.5 \mathrm{kWh} / \mathrm{kg}$ which is lower than the threshold of 0.68 $\mathrm{kWh} / \mathrm{kg}_{\mathrm{DW}}$, provided by (Coons et al. 2014). Interestingly, the used energy input was also substantial lower as the consumptions that are reported by other (mechanical disruption technologies (Günerken et al. 2015). Safi et al. (2014) reported for example an energy consumption of $7.5 \mathrm{kWh} / \mathrm{kg} \mathrm{DW}$ for the disruption of $C$. vulgaris using high pressure homogenisation. In addition, although the energy consumption of bead milling is already strongly reduced, the energy consumption is still between $0.5-1 \mathrm{kWh} / \mathrm{kg}_{\mathrm{DW}}$ ) (Postma et al. 2015).

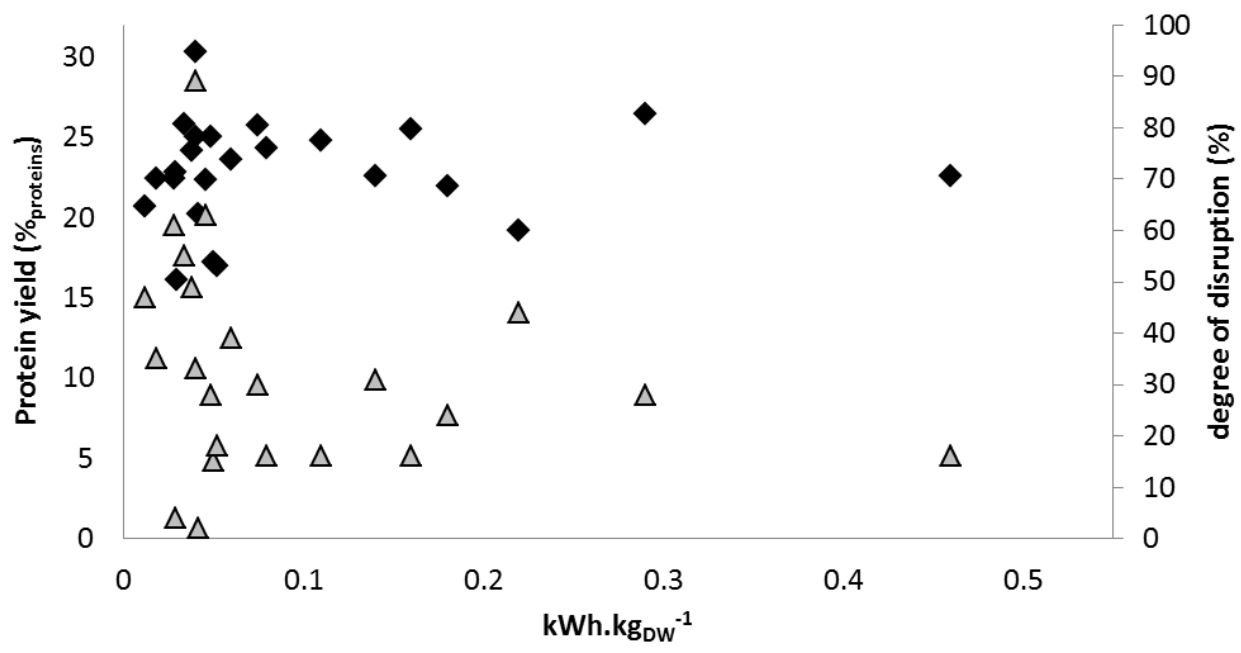

Figure S1: Protein yield and degree of disruption as a function of the applied energy. $\downarrow=$ protein yields after PEF. $\Delta=$ degree of disruption. Operating conditions were $7.5 \mathrm{kV} / \mathrm{cm}, 0.05-0.2 \mathrm{~ms}$ pulse length and 1-15 of pulses. A pulse interval of 10 seconds was applied and samples were washed with demi-water prior to PEF-treatment. DW ranged between 2-5 g/L.

The protein yields obtained after PEF treatment are on average $23 \%$ proteins \pm 3.3 with a maximum of $30 \%$ proteins at $0.04 \mathrm{kWh} / \mathrm{kg}_{\mathrm{DW}}$. Bead beating resulted in an average protein yield of $34 \%$ proteins $\pm 4.2(n=3)$. Thus the average protein yield using PEF was $68 \%$ of the protein yield obtained after bead beating. 


\section{Appendix B - Native PAGE analysis of the released proteins after PEF}

To investigate if the released proteins after PEF-treatment are still native, additional native-PAGE analysis was performed on the biological replicates of the experiments performed at $7.5 \mathrm{kV} / \mathrm{cm}, 0.1 \mathrm{~ms}$ pulse length, 10 seconds pulse interval and either 3 or 5 pulses. The biomass concentration in these experiments was $2.5 \mathrm{~g} / \mathrm{L}$. As a fairly low biomass concentration was present during PEF treatment, a silver staining (Thermo Fischer scientific) was used according to the manufactures protocol.

Figure S2 shows the size distribution of the proteins present in both the marker and the samples. For both experimental conditions, three samples have been analysed.

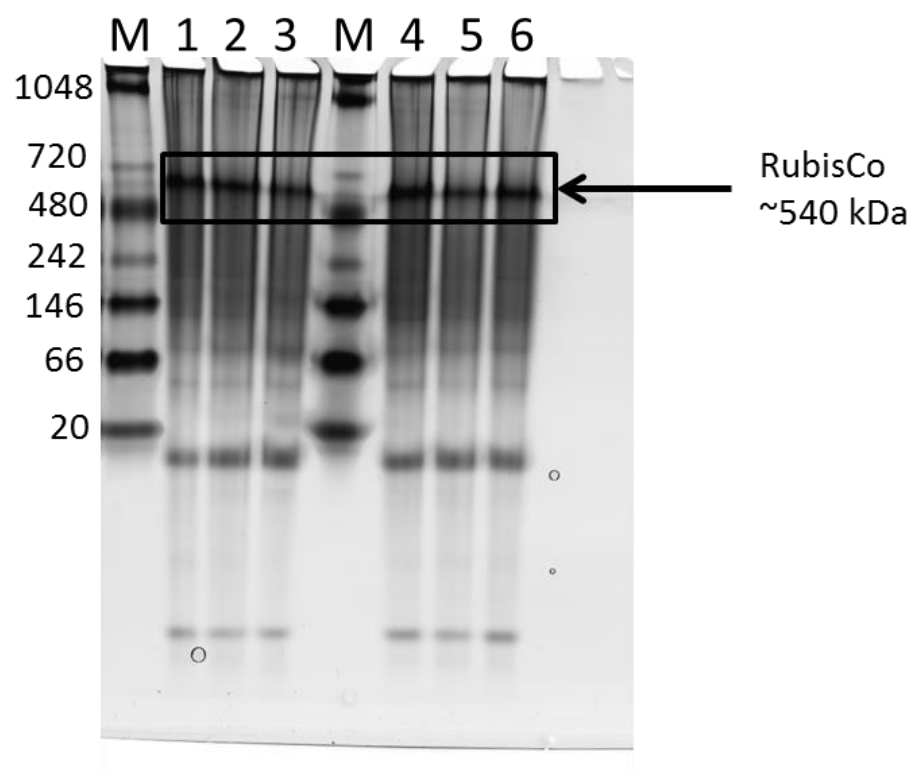

Figure S2: Native-PAGE using Silver staining (Thermo-Scientific). $\boldsymbol{M}=$ marker; $\mathbf{1}, \mathbf{2}$ and $\mathbf{3}=$ biological replicates of $3 p, 7.5 \mathrm{kV} / \mathrm{cm}, 0.1 \mathrm{~ms}$ pulses, $10 \mathrm{sec}$ interval. 4,5 and $6=$ biological replicates of: $5 \mathrm{p}$, $7.5 \mathrm{kV} / \mathrm{cm}, 0.1 \mathrm{~ms}$ pulses and 10 seconds pulse interval.

In this analysis, RubisCo was used as a biomarker to investigate if the proteins remain intact. RubisCo is a protein that is present in large amounts in microalgae, and is active in the photosynthetic machinery of microalgae. RubisCo has a size of approximately $540 \mathrm{kDa}$ and consists of eight small (approx. $13 \mathrm{kDa}$ ) subunits and eight large (approx. $56 \mathrm{kDa}$ ) subunit. The subunits are non-covalently bound to each 
other to form native RubisCo, dissociation of the subunits would destroy the protein and influence the mildness of the treatment.

According to Figure S2, in all 6 experiments there was a clear band visible between 400 and $700 \mathrm{kDa}$, illustrating that intact RubisCo was released in its native form during PEF. Next to the presence of RubisCo after PEF, also other large proteins (between 66 and $480 \mathrm{kDa}$ ) are present in all samples. It is therefore reasonable that $\mathrm{PEF}$ is able to release large proteins without destroying them to a large extend.

Similar observations were already made in the study of (Postma et al.). However, in that study, the cell wall containing microalgae Chlorella vulgaris was subjected to PEF. Due to the presence of a cell wall, and despite some release of native RubisCo, the absolute protein yields remained in all experiments substantial lower as the observed yields during bead milling as reference. 


\section{Appendix C - Enzymatic incubation as potential pre-treatment}

To investigate the potential of an enzymatic pre-treatment, we subjected the wild type C. reinhardtii cc-124 to an enzymatic pre-treatment for 3 hours at neutral pH and 40 ${ }^{\circ} \mathrm{C}$. Both strains were cultivated in shake flasks according to the first part of this work (described in material and methods).

The applied enzyme dosages ranged between 4 and $7 \%$ w/w which is in accordance with applied enzyme dosages of other studies (Wang et al. 2015; Demuez et al. 2015) After incubation, the biomass was washed to remove the enzymes and samples were taken. After sampling, the biomass was PEF-treated, and again samples were taken for further analysis

Figure S3 shows the protein release after enzymatic pre-treatment followed by a PEF-treatment. An experiment with PEF treatment as well as a beat beating treatment without enzymes were performed as reference. On the vertical axis the protein release is presented in '\% $\%_{\text {proteins'. }}$

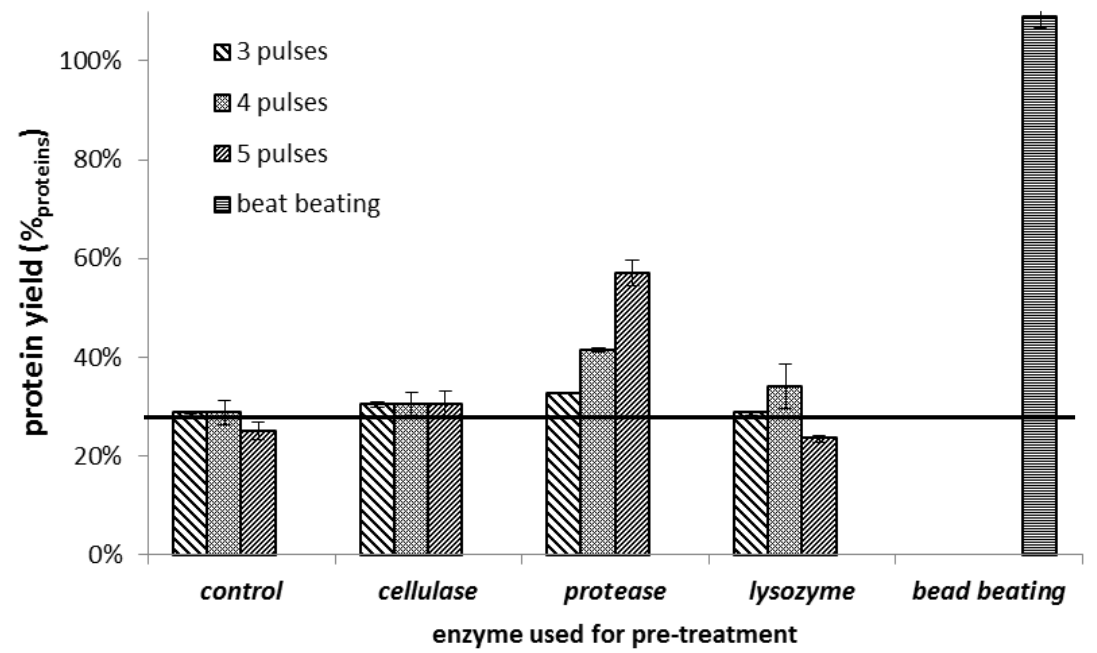

Figure S3: Protein yield after E-PEF treatment using different enzymes. Treatment conditions were: $C_{x}$ of $1.45 \mathrm{~g} / \mathrm{L} 7 \%$ w/w enzymes, $7.5 \mathrm{kV} / \mathrm{cm}, 0.05 \mathrm{~ms}$ pulse length, and 5 pulses. Error bars represent technical duplicates. Beat beating was included as positive control whereas the sample that was incubated without enzymes acted as a negative control. 
Cellulase incubation combined with PEF treatment did not result in substantial higher yields, compared to the control experiment. Although it has been reported that glycoproteins are present in the cell walls of $C$. reinharditii, they appear not to be vulnerable for cellulose treatment (Roberts et al. 1972).

Similar results were obtained after lysozyme incubation and PEF-treatment. Although lysozyme has been reported to be a very promising enzyme for successful weakening of the microalga C. vulgaris (Gerken et al. 2013), no increased protein yield was observed after lysozyme incubation and PEF treatment. The difference in effect with lysozyme between the study of (Gerken et al. 2013) and our results suggest that the effect of an enzymatic pre-treatment is very strain specific. This selectivity of enzymes was also mentioned as a major advantage for specific breakage of cell wall linkages for mild disruption in the review of Demuez et al. (2015). The consequence of this high selectivity is the necessity to optimize the enzymatic processing for each specific algal strain (Demuez et al. 2015).

Protease incubation resulted in a substantial increase in protein release compared to the control experiments. The protein yield was even more than twice as high as the control experiment and compared to the other enzyme treatments (cellulase, lysozyme). These results suggest that the cell wall of $C$. reinhardtii includes protein (like) structures that are vulnerable for a protease incubation. Similar results were reported using proteases for the degradation of $C$. reinhardtii to enhance methane production from the biomass (Mahdy et al. 2014). In addition, Wang et al. (2015) reported successful application of enzymes prior to other cell disruption techniques. In their study, various enzymes were successfully applied as pre-treatment before high pressure homogenization $(\mathrm{HPH})$ and sonification as cell disruption technologies. The conditions that were used during incubation (up to $50^{\circ} \mathrm{C}$ ) as well as cell disruption (e.g. high pressures) may have impact on the protein integrity (Wang et al. 2015). In all the enzyme assisted experiments performed in this study, the measured temperature after PEF-treatment did not exceeded $35{ }^{\circ} \mathrm{C}$. This mild temperature increase, argues in favour of E-PEF as a mild cell disruption technology.

Only incubation at elevated temperatures, without enzymes resulted in a fourfold increase in protein yield for both the control PEF experiment and beat beating (FigureS2), compared to the yields that were obtained at room temperature (Figure 
8). Thus only incubation of $C$. reinhardtii at an increased temperature results in an increase in protein yields. Similar results have been reported in the study of (Postma et al., 2016) as well as in the review published by (Sari et al. 2015) 
Chapter 8

General discussion

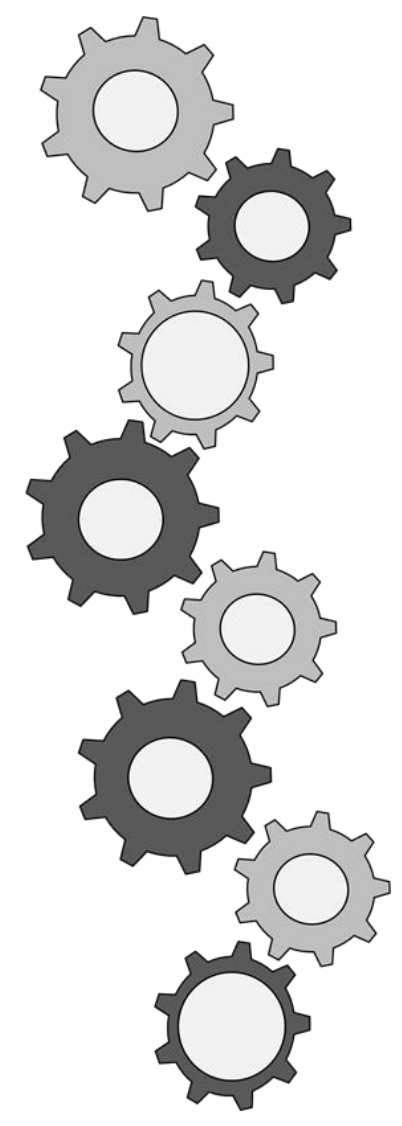




\section{Ithough phototrophic microalgae are a promising feedstock for bulk- commodities, large scale production is still far off. To enhance the economic feasibility, all biomass components for both bulk- and specialty applications}

need to be valorized. A multi-product biorefinery increases the value of the biomass, and would result in economic feasible production of bulk-commodities. So far, harvesting and cell disruption are recognized as main technological hurdles. In this chapter it is shown that harvesting has been optimized and is in most cases no economic bottleneck anymore. Cell disruption and product extraction, however, still impose major bottlenecks. Future research should focus on cell disruption and product extraction. Major steps will be made when simplified processes are developed that require less unit operations. For example, direct and mild extraction of biomolecules from intact biomass such that cell disruption is not needed. Additionally, external fields (e.g. ultrasound) could be used for separation of the oil- and water phases, making solvent extraction redundant. 


\section{Introduction}

Phototrophic microalgae contain large amounts of proteins, carbohydrates, and lipids making them a promising feedstock for bulk-commodities (Carioca et al., 2009; Chisti, 2007; Draaisma et al., 2013; Ruiz et al., 2016; Vigani et al., 2015; Wijffels et al., 2010a). They are a renewable resource because they use $\mathrm{CO}_{2}$ as carbon source and sunlight for energy (Draaisma et al., 2013; Ruiz et al., 2016). Production of microalgae for low value bulk commodities, however, is not economically feasible yet (Ruiz et al., 2016).

To increase the economic feasibility of low value bulk products, a multi-product biorefinery was proposed in which all biomass fractions are valorised (VanthoorKoopmans et al., 2013; Wijffels et al., 2010a). By producing both bulk- and specialty co-products, the revenues will increase (Günerken et al., 2015; Ruiz et al., 2016). For biorefinery of algal biomass several technological hurdles need to be taken (Draaisma et al., 2013; Günerken et al., 2015; Ruiz et al., 2016; Vanthoor-Koopmans et al., 2013; Wijfels et al., 2010b). A biorefinery is generally seen as a cascade- or linear downstream process (DSP) (Figure 8.1) (Vanthoor-Koopmans et al., 2013).

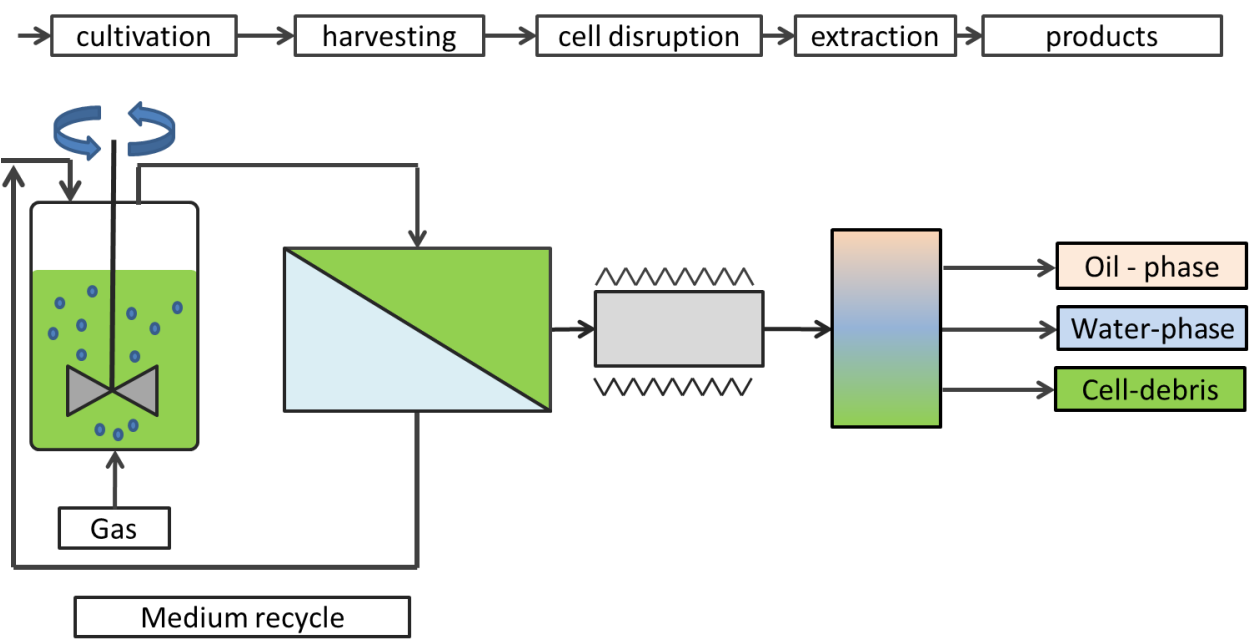

Figure 8.1: Simplified overview of the downstream process.

Such a DSP typically consist of a harvesting, cell disruption, and a product extraction step. Several technologies are under development in this algal biorefinery (Table 8.1). 
Table 8.1: Portfolio of proposed technologies for a microalgae biorefinery that are evaluated in review- and scenariostudies.

\begin{tabular}{lll}
\hline DSP step & listed technologies & Review studies \\
\hline \hline \multirow{3}{*}{ Harvesting } & $\begin{array}{l}\text { centrifugation, filtration, } \\
\text { flocculation-sedimentation, flotation }\end{array}$ & $\begin{array}{l}\text { (Coons et al., 2014; Gerardo et al., } \\
\text { 2015a; Uduman et al., 2010; Vandamme } \\
\text { et al., 2013; Wan et al., 2015) }\end{array}$ \\
\hline & $\begin{array}{l}\text { Mechanical: bead mill, high pressure } \\
\text { homogenization }\end{array}$ & \\
Cell Disruption & $\begin{array}{l}\text { (Bio)chemical: alkali and acid } \\
\text { treatment, enzymes }\end{array}$ & $\begin{array}{l}\text { (Coons et al., 2014; Demuez et al., 2015; } \\
\text { Günerken et al., 2015, Chapter 6) }\end{array}$ \\
& $\begin{array}{l}\text { Physical: microwave, pulsed electric } \\
\text { field, ultrasound. }\end{array}$ & \\
\hline \multirow{3}{*}{ Extraction } & $\begin{array}{l}\text { Organic solvents, aqueous two phase } \\
\text { extraction, alkali extraction, } \\
\text { supercritical fluids }\end{array}$ & (Desai et al., 2016a; Lam \& Lee, 2012; \\
& & Sari et al., 2015) \\
\hline
\end{tabular}

In this Chapter the recent technological achievements are presented and a roadmap towards an economic feasible microalgae biorefinery for bulk-products is shown.

\section{State of development of technology}

\subsection{Harvesting}

Harvesting of microalgae using centrifugation is considered as an energy-intensive and costly process (Vandamme et al., 2013). The techno-economic evaluation of Ruiz et al., (2016) showed, however, that large scale (100 Ha) centrifugation of microalgae that are cultivated in closed photo-bioreactors requires $0.2-0.3 € / \mathrm{kg} \mathrm{DW}$ (Ruiz et al., 2016). This account for only 5-7\% of the total cultivation cost (Ruiz et al., 2016) which is in agreement with other observations (Chauton et al., 2015; Davis et al., 2011; Norsker et al., 2011). In the case of diluted systems (e.g. open ponds), centrifugation still accounts for $20-25 \%$ of the total cultivation costs (Granados et al., 2012; Molina Grima et al., 2003; Ruiz et al., 2016). For those dilute systems, alternative, low-cost harvesting technologies are required.

For dilute cultivation systems (e.g. open ponds), flocculation is considered as a lowcost (pre-) concentration technology (Alam et al., 2016; Japar et al., 2017; Muylaert et al., 2015; Uduman et al., 2010; Vandamme et al., 2013). Flocculation of saltwater microalgae, however, is difficult, as most flocculants are not effective at high salinity (Greenwell et al., 2010; Uduman et al., 2010; Vandamme et al., 2013). In salt water most types of flocculants become shielded by the high amounts of ions present. By 
using cationic polyacrylamides flocculation can be successfully induced in seawater (Chapter 2,3,4; König et al., 2014; Morrissey et al., 2015; Roselet et al., 2015). Cationic polyacrylamides, however, are expensive and toxic. In addition, a general drawback of the used flocculants is that residues remain in the harvested biomass. When the remaining flocculants are toxic, the presence of residues reduces the value of the harvested biomass considerably (Chapter 3,4$)$. The high costs and toxicity of these flocculants need to be resolved by developing alternative (i.e. food-grade and/or recyclable) flocculants (Chapter 4; Eyley et al., 2015; Morrissey et al., 2015).

Another promising technology for harvesting from dilute systems is microfiltration. Currently, the energy consumption of microfiltration can be substantially lower than 1 $\mathrm{kWh} / \mathrm{m}^{3}$ (Bilad et al., 2012; Soomro et al., 2016). Bilad et al., (2012) reported the use of submerged membranes for succesfull harvesting of microalgae at an energy input of only 0.27 to $0.41 \mathrm{kWh} / \mathrm{m}^{3}$ ( 0.64 to $\left.1.32 \mathrm{kWh} / \mathrm{kg}_{\mathrm{DW}}\right)$. Similar energy consumptions were obtained in a pilot study in which a two-step process with a microfiltrationfollowed by a centrifugation-step was used (Baerdemaeker et al., 2013). Membrane filtration can also be used as a single harvesting step. Gerardo et al., (2015b) concentrated biomass from an initial concentration of $0.5 \mathrm{~g} / \mathrm{L}$ to $150 \mathrm{~g} / \mathrm{L}$. Although he energy consumption in this process was slightly higher ( 1 to $3 \mathrm{kWh} / \mathrm{kg} \mathrm{DW})$, the harvesting costs were only between $\sim 0.10$ and $0.35 € / \mathrm{kg}_{\mathrm{DW}}$.

\subsection{Cell disruption}

Three different approaches for microalgal cell disruption can be distinguished: (bio)chemical cell disruption (e.g. enzymatic- or alkali-heat treatment), mechanical cell disruption (e.g. bead milling and high pressure homogenisation), and physical cell disruption (e.g. pulsed electric field, or ultrasound treatment) (Table 8.1).

Cell disruption should be done under mild conditions to maintain functionality of components such as soluble proteins (Desai et al., 2016a; Günerken et al., 2015; Postma et al., 2015; Schwenzfeier et al., 2011). Water soluble, native proteins have a higher value due to their techno-functionality as emulsifiers or foaming agents. Harsh treatment conditions in (bio)chemical processes such as low or high $\mathrm{pH}$ or high incubation temperatures will have a negative effect on these functionalities (Schwenzfeier et al., 2011). 
Alternatively, mechanical processes could be applied as mild cell disruption (Günerken et al., 2015; Schwenzfeier et al., 2011). Mechanical processes -in principle- do not require increased temperatures, nor a low or high $\mathrm{pH}$ (Schwenzfeier et al., 2011) Recent work showed that by bead milling both water soluble and native proteins can be released (Postma et al., 2015; Schwenzfeier et al., 2011).

Even though mechanical processes are mild, the energy consumption is high and as a consequence mechanical disruption is expensive (Günerken et al., 2015; Coons et al., 2014). Recent studies showed that energy consumption in mechanical disruption processes can be reduced. The energy consumption in bead milling was e.g. reduced from 2.8-10 kWh/kg $/ g_{D W}$ (Doucha \& Lívanský, 2008) to $0.5 \mathrm{kWh} / \mathrm{kg}$ DW (Postma et al., 2017).

Although bead milling is no longer regarded as high energy demanding technology, it still has a major drawback. It completely disrupts the cells into smaller fragments. (Günerken et al., 2016; Montalescot et al., 2015; Postma et al., 2015; Postma et al., 2017). Bead milling results in a homogeneous mixture of components, or even a stable emulsion. The separation of the different phases after cell disruption will thus be a difficult process.

Physical cell disruption technologies such as Pulsed Electric Field (PEF) may provide an alternative (Kotnik et al., 2015). PEF is a low-shear and low-temperature technology. It is assumed that PEF only forms pores in the microalgal cell membranes (Goettel et al., 2013; Kotnik et al., 2015; Zbinden et al., 2013). So far the protein release from algal cells after PEF treatment was at least three-fold lower than the yield obtained with mechanical disruption because the presence of a cell wall in algal cells (Chapter 5, 6; Azencott et al., 2007; Postma et al., 2016). In Chapter 7 we proved that by pre-treatment with enzymes the cell wall becomes weaker after which PEF-treatment is more effective. Although this two-step approach is promising, the protein yields were still a twofold lower compared to mechanical cell disruption (Chapter 7). Based on better characterization of the microalgal cell walls more effective techniques should be developed for weakening of the cell wall (Gerken et al., 2013; Günerken et al., 2015; Scholz et al., 2014). 


\subsection{Extraction}

For the separation of the hydrophobic and hydrophilic components from the disrupted algae often organic solvents to extract the lipids and/or pigments are used and the water-soluble and solid fraction remain (Mubarak et al., 2015).

Most often, a drying step is used prior to (lipid-)extraction to increase the extraction yield (Du et al., 2015; Ruiz et al., 2016). To avoid the drying step, amines were used as solvent for wet lipid extraction (Du et al., 2015; Du et al., 2013). These solvents have an inducible polarity (Jessop et al., 2005). By sparging with either $\mathrm{CO}_{2}$ or $\mathrm{N}_{2}$ solvents can reversibly switch from an apolar to a polar solvents (Jessop et al., 2005). This feature facilitates the back-extraction, making it a promising technology for lipid-extraction.

Proteins denature after extraction with organic solvents (Desai et al., 2016a). In a biorefinery framework where we intend to use all biomass fractions and therefore need to use alternatives for these organic solvents (Desai et al., 2016a). For complete biomass utilization it is better to use a two-step extraction process in which first water soluble proteins are extracted, followed by the extraction of the lipids from the cell-debris. For aqueous extraction of water-soluble proteins with aqueous biphasic systems, the proof of concept has been demonstrated. In further research we should better characterize these systems, allowing a better design of mild protein extraction (Desai et al., 2016a; Desai et al., 2014).

Another promising approach is to use ionic-liquid based systems. In recent years, ionic liquids (IL) increasingly received attention in the microalgae downstream process (Orr et al., 2016). Ionic liquids are organic salts which are a liquid at room temperature. Their non-volatile properties make them advantageous over other organic solvents (Desai et al., 2016a; Orr \& Rehmann, 2016). Several ILs are successfully used to weaken microalgae, and to extract lipids from wet biomass (Orr et al., 2016; Teixeira, 2012). Interestingly, Desai et al., (2014) showed that IL-based systems can be mild since the proteins remained native during extraction. ILs can thus be used for primary lipid extraction, followed by a cell disruption and subsequent protein extraction. 


\section{Evaluating the overall biorefinery process}

Ruiz et al., (2016) evaluated a complete biorefinery for fractionation of all biomass components. They showed that a complete biorefinery is economically feasible as the revenues $\left(\sim 31 € / \mathrm{kg}_{\mathrm{DW}}\right)$ are expected to be higher than the total costs $\left(6-7 € / \mathrm{kg}_{\mathrm{DW}}\right)$ (Ruiz et al., 2016). However, they also indicated that there are still technological hurdles in a large-scale biorefinery (Ruiz et al., 2016). In addition, a biorefinery is currently a complex and expensive process that needs additional unit operations for e.g. a solvent recovery (Ruiz et al., 2016). Complete biorefinery accounts for $\sim 50 \%$ of the total costs (Ruiz et al., 2016), which is high compared to other biotechnological bulk-processes (Straathof, 2011) (see Text Box). In a biorefinery, only $~ 5 \%$ of the revenues come from the bulk-products (Ruiz et al., 2016). Altogether, it appears to be more practical to focus on the specialties instead of bulk products.

If the aim is to produce bulk-products at large scale, however, the biorefinery should become less complex and less expensive. To do so, we should not only focus on the specific DSP-unit operations (i.e. harvesting, cell disruption and extraction) but rather on the overall process design as well. By reducing the required number of unit operations and preventing the use of chemical additives we can simplify the process and enhance the (economic) feasibility of a biorefinery. 
Text Box: Relative DSP costs of different biotechnological processes. Table adapted from Straathof (2011)

The cost for a biorefinery scenario is compared with the relative DSP-costs in other fermentative production processes (Straathof, 2011):

\begin{tabular}{|c|c|c|c|c|}
\hline Product & $\begin{array}{l}\text { DSP } \\
\text { (\% of production costs) }\end{array}$ & $\begin{array}{l}\text { Selling price } \\
\left(\$ \mathrm{~kg}^{-1}\right)\end{array}$ & $\begin{array}{l}\text { Plant capacity } \\
\left(10^{3} \mathrm{~kg} \mathrm{a}^{-1}\right)\end{array}$ & Reference \\
\hline Corn ethanol & $21-23$ & - & 45000 & (Krishnan et al., 2000) \\
\hline Corn ethanol & 22 & $0.25^{\mathrm{a}}$ & 30000 & (Arifeen et al., 2007) \\
\hline Corn ethanol & 24 & 0.68 & 120000 & $\begin{array}{l}\text { (Kwiatkowski et al., } \\
2006 \text { ) }\end{array}$ \\
\hline Corn ethanol & 29 & 0.32 & 79000 & (Warren et al., 1994) \\
\hline Penicillin G (crude) & 22 & $16^{\mathrm{a}}$ & 1000 & $\begin{array}{l}\text { (Blanch H.W.; Clark } \\
\text { 1996) }\end{array}$ \\
\hline Lipase (crude solution) & 27 & 78 & 100 & (Castilho et al., 2000) \\
\hline Citric acid & $20-30$ & $2.2 \mathrm{a}$ & 10000 & (Petrides, 2003) \\
\hline Polyhydroxybutyrate & $\sim 28$ & $2.6^{\mathrm{a}}$ & 100000 & (Lee \& Choi, 1998) \\
\hline Polyhydroxybutyrate & $\sim 40$ & $6^{\mathrm{a}}$ & 2850 & (Choi \& Lee, 1997) \\
\hline Lactic acid $(70 \%)$ & 36 & $1^{a}$ & 30000 & $\begin{array}{l}\text { (Åkerberg \& Zacchi, } \\
\text { 2000) }\end{array}$ \\
\hline 1-Butanol & $\sim 40$ & 0.5 & 123000 & $\begin{array}{l}\text { (Qureshi \& Blaschek, } \\
\text { 2001) }\end{array}$ \\
\hline Bt-insecticide & $\sim 55$ & 8 & 1900 & $\begin{array}{l}\text { (Rowe \& Margaritis, } \\
\text { 2004) }\end{array}$ \\
\hline Intracellular protein & 56 & $1300^{a}$ & 5 & $\begin{array}{l}\text { (Blanch H.W.; Clark } \\
\text { 1996) }\end{array}$ \\
\hline Microalgae Biorefinery $^{c}$ & $\sim 50$ & $\sim 33$ & $\sim 6000$ & (Ruiz et al., 2016) \\
\hline Monoclonal antibodies & $45-70$ & 1000000 & $\sim 0.2$ & $\begin{array}{l}\text { (Sommerfeld \& Strube, } \\
\text { 2005) }\end{array}$ \\
\hline Monoclonal antibody & $54-80$ & 2500000 & 0.006 & (Petrides, 2003) \\
\hline$t-P A$ & $62-77$ & 10000000 & 0.015 & (Rouf et al., 2001) \\
\hline Heparinase I & 74 & 560000 & 0.003 & (Ernst et al., 1997) \\
\hline Human insulin & $\sim 75^{\mathrm{b}}$ & 50000 & 1 & (Datar, 1990) \\
\hline Human insulin & $92^{\mathrm{b}}$ & 75000 & 1.8 & (Petrides, 2003) \\
\hline \multicolumn{5}{|c|}{$\begin{array}{l}\boldsymbol{a} \text { No selling price was reported but production costs, which will be lower. } \\
\boldsymbol{b} \text { These DSP costs include expensive enzymatic steps. } \\
c \text { Data from best case large scale plant was assumed ( } 100 \mathrm{Ha} \text {, location: Spain, closed Flat Panel reactor). } \\
\text { According to the overview, typically, a DSP for large capacity bulk commodity processes } \\
\text { accounts for } 20-40 \% \text { of the total costs; whereas the costs for a small capacity DSP for high value } \\
\text { specialties such as biopharmaceuticals account for } 45-92 \% \text { of the total costs (Straathof, 2011) }\end{array}$} \\
\hline
\end{tabular}

\section{Towards simplified downstream processes}

In this section we will discuss two possible approaches to reduce the number of unit operations. In the first approach the number of main DSP-unit operations (i.e. harvesting, cell disruption and extraction) are reduced by integration in a single step. 
The second approach is to avoid the use of chemicals. Chemicals (e.g. flocculants, solvents, etc.) are not only a consumable with associated costs, but they need to be recovered by using additional unit operations as well. These additional unit operations result in a complex process. By using external fields different phases can be separated, resulting in a solvent-free and more simple product separation.

\subsection{Integrated downstream processes}

Table 8.2 presents an overview of studies in which unit operations in a microalgae downstream process were successfully integrated. Integrating harvesting and cell disruption has been proposed several times (Table 8.2). Zheng et al. (2015, 2016) used for example, thermo-responsive polymers. These cationic polymers induce flocculation and in combination with enzymes helped to successfully disrupt Chlorella protothecoides (Zheng et al., 2016). However, complete removal of the flocculant residues from the harvested biomass was not possible yet (Zheng et al., 2015), while the high temperatures $\left(50-70^{\circ} \mathrm{C}\right)$ that are required for the polymer recovery can denature proteins.

Table 8.2: Overview of integrated downstream unit operations for microalgae processing

\begin{tabular}{|c|c|c|c|}
\hline Unit operation & Technology & Application & Reference \\
\hline cultivation/harvesting & $\begin{array}{l}\text { Polymeric } \\
\text { flocculation/de- } \\
\text { flocculation }\end{array}$ & $\begin{array}{l}\text { Single tank polymeric flocculation/de- } \\
\text { flocculation. Allowing an immediate } \\
\text { separation of biomass, clarified } \\
\text { medium and the recyclable flocculant }\end{array}$ & $\begin{array}{l}\text { Morrissey et al. } \\
\text { (2015) }\end{array}$ \\
\hline cultivation/harvesting & $\begin{array}{l}\text { Polymeric } \\
\text { flocculation/de- } \\
\text { flocculation }\end{array}$ & $\begin{array}{l}\text { Thermo-responsive polymers that can } \\
\text { be separated after harvesting. These } \\
\text { polymers also enhance chemical cell } \\
\text { disruption }\end{array}$ & $\begin{array}{l}\text { (Zheng et al. } \\
\text { 2015) }\end{array}$ \\
\hline harvesting/ disruption & $\begin{array}{l}\text { Polymeric flocculation } \\
\text { cell disruption }\end{array}$ & $\begin{array}{l}\text { in-situ harvesting and cell wall } \\
\text { disintegration }\end{array}$ & $\begin{array}{l}\text { (Zheng et al., } \\
\text { 2015; Zheng et } \\
\text { al., 2016) }\end{array}$ \\
\hline harvesting/disruption & $\begin{array}{l}\text { Ferric ions and } \\
\text { peroxide sparging }\end{array}$ & $\begin{array}{l}\text { Controllable and combined } \\
\text { harvesting and cell disruption }\end{array}$ & (Kim et al., 2015) \\
\hline harvesting/ disruption & $\begin{array}{l}\text { cationic surfactant- } \\
\text { decorated Fe304 } \\
\text { nanoparticles }\end{array}$ & $\begin{array}{l}\text { Cationic harvesting and combined cell } \\
\text { wall weakening for lipid extraction }\end{array}$ & (Seo et al., 2016) \\
\hline harvesting/ disruption & $\begin{array}{l}\text { Biopolymer } \\
\text { nanocomposite for } \\
\text { harvesting and cell } \\
\text { disruption }\end{array}$ & $\begin{array}{l}\text { Dual-; and tri-functionalized magnetic } \\
\text { nanocomposites were synthesized } \\
\text { from chitosan for cationic/magnetic } \\
\text { harvesting and photocatalytic cell } \\
\text { disruption }\end{array}$ & $\begin{array}{l}\text { (Dineshkumar, } \\
\text { 2017) }\end{array}$ \\
\hline
\end{tabular}


Table 8.2: Continued

\begin{tabular}{|c|c|c|c|}
\hline disruption/extraction & $\begin{array}{l}\text { Direct extraction by } \\
\text { using ionic liquids }\end{array}$ & $\begin{array}{l}\text { Extraction of pigments in a mild } \\
\text { way, circumventing cell disruption }\end{array}$ & $\begin{array}{l}\text { (Desai et al., } \\
\text { 2016b) }\end{array}$ \\
\hline disruption/extraction & $\begin{array}{l}\text { Cell wall dissolving } \\
\text { using ionic liquids }\end{array}$ & $\begin{array}{l}\text { Dissolving the cell wall and } \\
\text { extracting all hydrophobic } \\
\text { components using ionic liquids at } \\
\text { high temperatures. }\end{array}$ & (Teixeira, 2012) \\
\hline disruption/extraction & $\begin{array}{l}\text { In-situ } \\
\text { transesterification }\end{array}$ & $\begin{array}{l}\text { Addition of } \mathrm{NaOH} \text { in excess methanol } \\
\text { to water containing biomass for } \\
\text { direct FAME production }\end{array}$ & $\begin{array}{l}\text { (Salam et al., } \\
\text { 2016a; Salam et } \\
\text { al., 2016b) }\end{array}$ \\
\hline extraction/fractionation & $\begin{array}{l}\text { Aqueous two phase } \\
\text { extraction }\end{array}$ & $\begin{array}{l}\text { Separation of hydrophilic proteins } \\
\text { from disrupted, wet biomass; } \\
\text { combined with a product } \\
\text { concentration. }\end{array}$ & $\begin{array}{l}\text { (Cunha \& Aires- } \\
\text { Barros, 2002; } \\
\text { Ruiz et al., 2016) }\end{array}$ \\
\hline
\end{tabular}

Another approach to integrate harvesting with cell disruption was presented by Kim et al., (2015). They harvested freshwater microalgae using ferric ions (Kim et al., 2015). By sparging afterwards with peroxide, a Fenton-like reaction occurred and induced disruption of the cell walls (Kim et al., 2015). These conditions, however, are not mild and will lead to protein damage.

The examples of integrated harvesting and cell disruption processes (Table 8.2), illustrate that it may be a very interesting route towards simplified processes. However, it is worthwhile to focus on integrated cell disruption and extraction processes as well (highlighted green area Table 8.2, Figure 8.2).

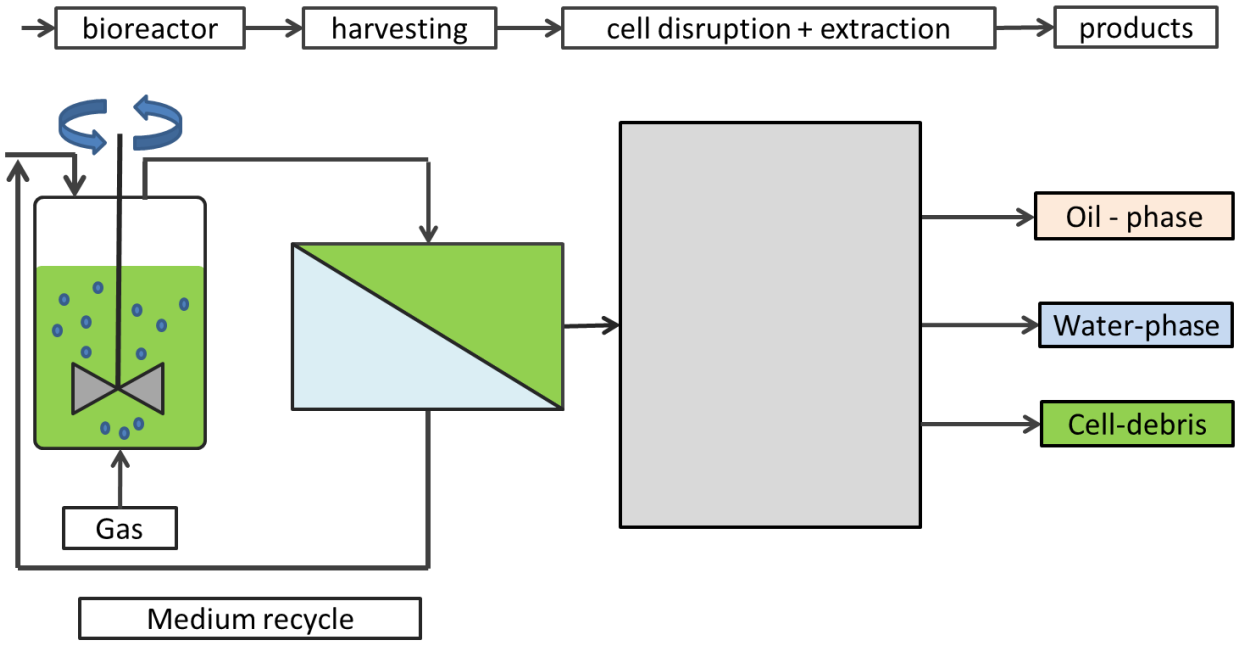

Figure 8.2: Simplified overview of a downstream process with integrated cell disruption and extraction. 
In biorefinery integrated cell disruption and extraction methods should be used which are applicable on multiple products. An interesting approach for such an integrated and multi-product process is the use of an ionic-liquid based aqueous biphasic system (ABS). Ionic-Liquids (ILs) are already used to extract lipids from wet and nonbroken biomass in a single step (Orr et al., 2016). They were also used to weakenand promote extraction of astaxanthin from non-broken Haematococcus pluvialis (Desai et al., 2016b). Besides their use in direct lipid-extraction, ILs can induce an ABS for mild isolation of native proteins from a mixture of components (Desai et al., 2014). Instead of adopting a two-step approach in which first the lipids are extracted followed by the proteins (section 2.3), cell wall weakening and mild protein extraction could be combined (Figure 8.3).

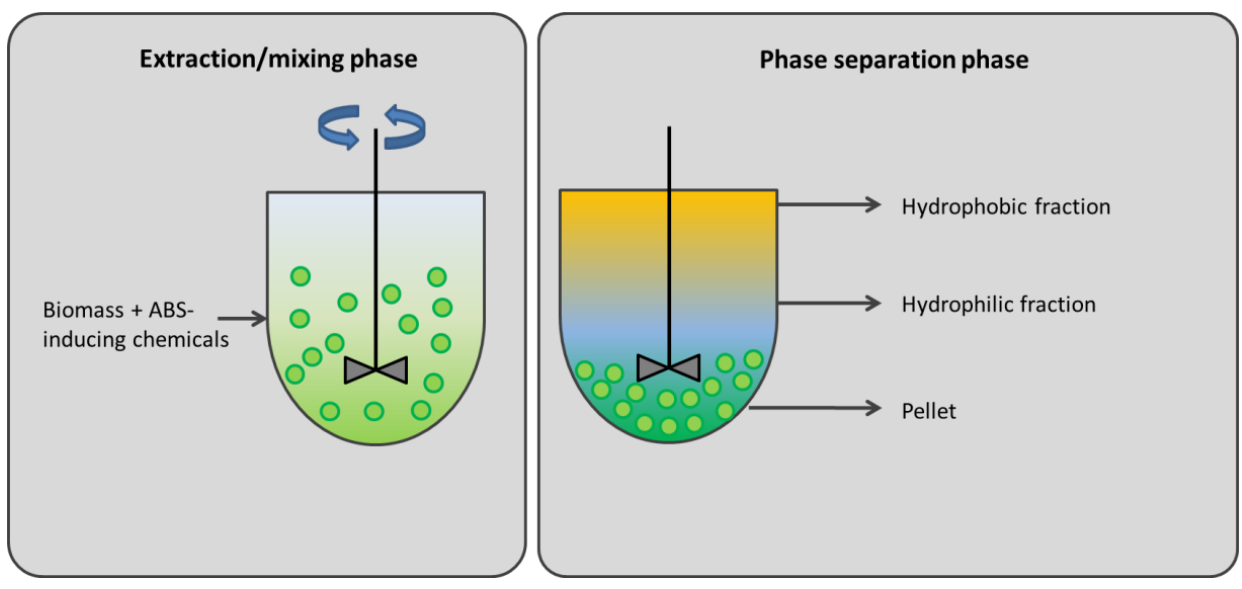

Figure 8.3: Simplified overview of the foreseen direct product extraction from non-broken, wet biomass.

A main challenge in developing IL-based ABS for direct product extraction is the ability to extract the hydrophilic proteins from intact biomass. Proteins are typically larger molecules than the lipid molecules and are thus difficult to extract from whole cells.

As extracting the large proteins from intact cells is difficult, an alternative could be to first completely dissolve the cell walls instead of merely weakening them, followed by extraction. For example, Teixeira (2012) used ionic liquids to completely dissolve wet cells except for lipids, allowing direct isolation of hydrophobic from hydrophilic components. They applied incubation temperatures higher than $100{ }^{\circ} \mathrm{C}$, making this particular process not mild (Teixeira, 2012). In more recent work the cell wall of 
Chlorella vulgaris was completely dissolved at room temperature followed by a lipid extraction using ionic liquids in an aqueous system (Orr et al., 2016). As dissolving cell walls can take place in aqueous systems at room temperature, it will become possible to extract native proteins. The current focus in research on ionic liquids for microalgae is still predominantly on the recovery of lipids and pigments (Orr \& Rehmann, 2016). Even though there is no evidence available yet that a similar direct extraction approach results in a mild and integrated cell disruption and extraction of water-soluble proteins, it is worthwhile to further investigate these processes.

\subsection{Preventing usage of chemicals in the downstream process}

The direct product extraction using IL-based ABS could make cell disruption redundant, and this makes it is a very promising route to simplify a biorefinery process design. However, it still involves the use of costly solvents which need to be recovered. Therefore, the development of downstream process in which the use of chemicals is avoided may be a more economically viable approach.

External fields could be applied as alternative for application of chemicals (Table 8.2). Some external fields were already proposed for mild and low cost cell disruption of microalgae, such as electrical fields and ultrasound treatment (Chapter 5,6,7; Günerken et al., 2015). To our knowledge, application of external fields is not feasible yet for microalgae cell disruption because of the high energy consumption, costs, the low efficiency, or difficulties with temperature control (Chapter 5, 6, 7).

Table 8.2: External fields used for separation of particles. Table adapted from (Watarai, 2013)

\begin{tabular}{lll}
\hline Field & Involved force & Separation mechanism \\
\hline \hline Gravity & Centrifugal/gravitational force & density \\
Electrical fields & Electrostatic force & charge difference \\
Laser-light fields & Scattering force, photophoresis & complex refractive index \\
Magnetic fields & Magnetic force & magnetic susceptibility \\
Ultrasonic waves & Acoustic radiation & density, compressibility \\
\hline
\end{tabular}

Besides cell disruption, external fields may simplify the extraction (Figure 8.4). In other areas, external fields were already studied for separation of the lipids from an aqueous phase. Mhatre et al., (2015) described 'electrostatic demulsification' for separation of oil-in-water emulsions. By polarizing small dispersed oil droplets resulting in dipolar droplets, they will merge into larger droplets (Mhatre et al., 2015). 
Similar to electrostatic demulsification, pulsed electric field was recently used for separation of the extracellular lipids from Botryococcus braunii (Guionet et al., 2017). This microalga grows in colonies, and excretes hydrocarbons and polysaccharides. As it is likely that the biomass is not harmed during the treatment, they proposed a process that continuously separates the lipids from the culture broth (Guionet et al., 2017).

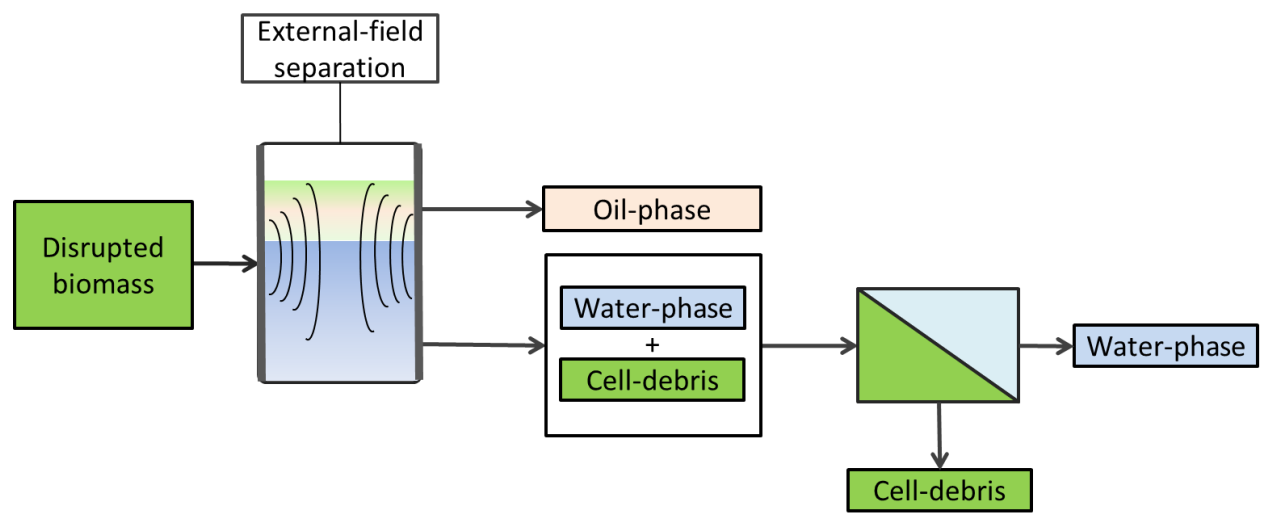

Figure 8.4: Illustration of separation of the hydrophobic (lipid) phase from the aqueous phase using external fields.

In other work ultrasound waves for phase separation was used. Mohsin and Meribout (2015) reported the successful breakage of a stable emulsion of diesel in water, and subsequent phase separation by means of ultrasound treatment. In their study the aim was to remove water from diesel to prevent corrosion of pipes in the petrochemical industry (Mohsin \& Meribout, 2015).

Analogous to these applications, we can separate the oil phase from the aqueous phase after cell disruption. With that a solvent free, simple and potentially mild extraction/separation process becomes reality (Figure 8.4).

\section{Conclusion}

Although strong technological improvements in microalgal biorefinery were made, a multi-product biorefinery for bulk commodities is not feasible yet.

To reduce the costs, simplified downstream processes should be developed that require less unit operations. 
Besides the costs and the overall process design, mildness should remain a keycriterion in microalgal biorefinery research. Complete valorisation of all components in a biorefinery will facilitate the transition from current small-scale production of specialties from microalgae towards future large-scale production of bulk commodities. 


$$
\text { - }
$$


References 


\section{A}

Åkerberg, C., Zacchi, G. 2000. An economic evaluation of the fermentative production of lactic acid from wheat flour. Bioresour. Technol., 75, 119-126.

Alam, A., Vandamme, D., Chun, W., Zhao, X., Foubert, I., Wang, Z., Muylaert, K., Yuan, Z. 2016. Bioflocculation as an innovative harvesting strategy for microalgae. Rev. Environ. Sci. Bio., 15, 573-583.

Al-Hashmi, A. R. and P. F. Luckham (2010). "Characterization of the adsorption of high molecular weight non-ionic and cationic polyacrylamide on glass from aqueous solutions using modified atomic force microscopy." Colloids Surfaces A 358: 142-148.

Amulya, K., Dahiya, S., Venkata Mohan, S., Prasad, M.N.V. 2016. Chapter 19 Building a Bio-Based Economy Through Waste Remediation: Innovation Towards Sustainable Future. in: Bioremediation and Bioeconomy, Elsevier, pp. 497-521.

Arifeen, N., Wang, R., Kookos, I.K., Webb, C., Koutinas, A.A. 2007. Process Design and Optimization of Novel Wheat-Based Continuous Bioethanol Production System. Biotechnol. Pro. 23, 1394-1403.

Azencott HR, Peter GF, Prausnitz MR (2007) Influence of the cell wall on intracellular delivery to algal cells by electroporation and sonication. Ultrasound Med. Biol. 33:1805-1817.

\section{$B$}

Baerdemaeker, T.D., Lemmens, B., Dotremont, C., Fret, J., Roef, L., Goiris, K., Diels, L. 2013. Benchmark study on algae harvesting with backwashable submerged flat panel membranes. Bioresour. Technol., 129, 582-591.

Banerjee C., Ghosh S., Sen G., Mishra S., Shukla P., Bandopadhyay R. (2013). Study of algal biomass harvesting using cationic guar gum from the natural plant source as flocculant. Carbohydrate Polymers 92: 675-681.

Barba FJ, Parniakov O, Pereira SA, Wiktor A, Grimi N, Boussetta N, Saraiva JA, Raso J, Martin-Belloso O, Witrowa-Rajchert D, Lebovka N, Vorobiev E (2015) Current applications and new opportunities for the use of pulsed electric fields in food science and industry. Food Res. Int. 77, Part 4:773-798. 
Beach, E. S., M. J. Eckelman, Z. Cui, L. Brentner and J. B. Zimmerman (2012). "Preferential technological and life cycle environmental performance of chitosan flocculation for harvesting of the green algae Neochloris oleoabundans." Bioresour. Techno.l 121: 445-449.

Becker E.W., (2007) Micro-algae as a source of protein, Biotechnol. Adv. 25 207210.

Bilad, M.R., Vandamme, D., Foubert, I., Muylaert, K., Vankelecom, I.F.J. 2012. Harvesting microalgal biomass using submerged microfiltration membranes. Bioresour. Technol., 111, 343-352.

Bilanovic, D., Shelef, G., Sukenik, A. 1988. Flocculation of microalgae with cationic polymers - Effects of medium salinity. Biomass, 17, 65-76.

Blanch H.W.; Clark, D.S. 1996. Biochemical Engineering. Dekker, New York, NY.

Bolto, B., and Gregory, J., (2007). "Organic polyelectrolytes in water treatment." Water Res. 41: 2301-24.

Breuer, G., Lamers, P.P., Martens, D.E., Draaisma R.B., Wijffels, R.H. (2012). "The impact of nigrogen starvation on the dynamics of triacylglycerol accumulation in nine microalgae strains." Bioresour. Technol. 124: 217-226.

\section{C}

Carioca, J.O.B., Hiluy Filho, J.J., Leal, M.R.L.V., Macambira, F.S. 2009. The hard choice for alternative biofuels to diesel in Brazil. Biotechnol. Adv., 27, 10431050.

Castilho, L.R., Polato, C.M.S., Baruque, E.A., Sant'Anna Jr, G.L., Freire, D.M.G. 2000. Economic analysis of lipase production by Penicillium restrictum in solidstate and submerged fermentations. Biochem. Eng. J., 4, 239-247.

Chatsungnoen, T. and Chisti, Y., (2016). Harvesting microalgae by flocculationsedimentation. Algal Res. 13: 271-283.

Chauton, M.S., Reitan, K.I., Norsker, N.H., Tveterås, R., Kleivdal, H.T. 2015. A techno-economic analysis of industrial production of marine microalgae as a source of EPA and DHA-rich raw material for aquafeed: Research challenges and possibilities. Aquacult., 436, 95-103.

Chauton, M.S., Olsen, Y., Vadstein, O. 2013. Biomass production from the microalga Phaeodactylum tricornutum: Nutrient stress and chemical composition in exponential fed-batch cultures. Biomass Bioenergy, 58, 87-94. 
Cheng, Y.-S., Y. Zheng, J. M. Labavitch and J. S. VanderGheynst (2011). The impact of cell wall carbohydrate composition on the chitosan flocculation of Chlorella. Process Biochem. 46: 1927-1933.

Chisti Y (2007) Biodiesel from microalgae. Biotechnol. Adv. 25:294-306.

Chow K.-C., Tung W. L., (1999) Electrotransformation of Chlorella vulgaris, Plant Cell Rep. 18 778-780.

Choi, J.I., Lee, S.Y. 1997. Process analysis and economic evaluation for poly(3hydroxybutyrate) production by fermentation. Bioprocess Eng., 17, 335-342.

Coons J.E., Kalb D.M., Dale T., Marrone B.L. (2014) Getting to low-cost algal biofuels: A monograph on conventional and cutting-edge harvesting and extraction technologies. Algal Res. 6, Part B:250-270.

Coustets M, Al-Karablieh N, Thomsen C, Teissié J., (2013) Flow Process for Electroextraction of Total Proteins from Microalgae. J. Membr. Biol. 246:751760.

Coustets M., Joubert-Durigneux V., Hérault J., Schoefs B., Blanckaert V., Garnier J. P, Teissié J., (2015) Optimization of protein electroextraction from microalgae by a flow process, Bioelectrochemistry. 103 74-81.

Cunha, T., Aires-Barros, R. 2002. Large-scale extraction of proteins. Mol. Biotechnol., 20, 29-40.

\section{$D$}

Davis, R., Aden, A., Pienkos, P.T. 2011. Techno-economic analysis of autotrophic microalgae for fuel production. Appl. Energy, 88, 3524-3531.

de Winter L., Klok A.J., Cuaresma Franco M., Barbosa M.J., Wijfels R.H. (2013). The synchronized cell cycle of Neochloris oleoabundans and its influence on biomass composition under constant light conditions. Algal Res. 2: 313-320.

Demuez M, Mahdy A, Tomás-Pejó E, González-Fernández C, Ballesteros M (2015) Enzymatic cell disruption of microalgae biomass in biorefinery processes. Biotechnol. Bioeng. 112:1955-1966.

Desai R.K., Streefland M., Wijffels R.H., Eppink M.H.M. (2016) Novel astaxanthin extraction from Haematococcus pluvialis using cell permeabilising ionic liquids. Green Chem. 18: 1261-1267. 
Desai, R.K., Streefland, M., Wijfels, R.H., Eppink, M.H.M. 2016. Extraction of Proteins with ABS. in: Ionic-Liquid-Based Aqueous Biphasic Systems: Fundamentals and Applications, G.M. Freire (Ed.), Springer Berlin Heidelberg. Berlin, Heidelberg, pp. 123-134.

Dineshkumar, R., Paul, A., Gangopadhyay, M., Pradeep Singh, N.D., Sen, R. 2017. Smart and Reusable Biopolymer Nanocomposite for Simultaneous Microalgal Biomass Harvesting and Disruption: Integrated Downstream Processing for a Sustainable Biorefinery. ACS Sustain. Chem. Eng., 5, 852-861.

Divakaran, R. and Pillai V. N. S. (2002). Flocculation of algae using chitosan. J. Appl. Phycol. 14: 419-422.

Donsì F., Ferrari G., Pataro G., (2010) Applications of Pulsed Electric Field Treatments for the Enhancement of Mass Transfer from Vegetable Tissue, Food Eng. Rev. 2 109-130.

Doucha J., Lívanský K. (2008) Influence of processing parameters on disintegration of Chlorella cells in various types of homogenizers. Appl. Microbiol. Biotechnol. 81:431-440.

Draaisma, R.B., Wijffels, R.H., Slegers, P.M., Brentner, L.B., Roy, A., Barbosa, M.J. 2013. Food commodities from microalgae. Curr. Opin. Biotechnol., 24, 169177.

Du, Y., Schuur, B., Kersten, S.R.A., Brilman, D.W.F. 2015. Opportunities for switchable solvents for lipid extraction from wet algal biomass: An energy evaluation. Algal Res., 11, 271-283.

Du, Y., Schuur, B., Samorì, C., Tagliavini, E., Brilman, D.W.F. 2013. Secondary amines as switchable solvents for lipid extraction from non-broken microalgae. Bioresour. Technol., 149, 253-260.

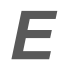

Eppink M.H.M., Barbosa M.J., Wijffels R.H., (2012) Biorefining of microalgae: Production of high value products, bulk chemicals and biofuels, in: Posten C., Walter T.C. (Eds.), Microalgal Biotechnol. Integr. Econ., De Gruyter, Berlin.

Eing C., Bonnet S., Pacher M., Puchta H., Frey W., (2009) Effects of nanosecond pulsed electric field exposure on Arabidopsis thaliana, Dielectr. Electr. Insul. IEEE Trans. On. 16 1322-1328. 
Eing C., Goettel M., Straessner R., Gusbeth C., Frey W., (2013) Pulsed Electric Field Treatment of Microalgae - Benefits for Microalgae Biomass Processing, IEEE Trans. Plasma Sci. 41 2901-2907.

Ernst, S., Garro, O.A., Winkler, S., Venkataraman, G., Langer, R., Cooney, C.L., Sasisekharan, R. 1997. Process simulation for recombinant protein production: Cost estimation and sensitivity analysis for heparinase I expressed in Escherichia coli. Biotechnol. Bioeng., 53, 575-582.

Eyley S., Vandamme D., Lama S., Van den Mooter G., Muylaert K., Thielemans W., $\mathrm{CO} 2$ controlled flocculation of microalgae using $\mathrm{pH}$ responsive cellulose nanocrystals, Nanoscale. 7 (2015) 14413-14421.

Farid, M.S., Shariati, A., Badakhshan, A., Anvaripour, B. 2013. Using nano-chitosan for harvesting microalga Nannochloropsis sp. Bioresour. Technol., 131, 555559.

Fenton M.B.M., Koroleva O., Gothard M.G.E., Drake C., (2014) An apparatus and method of processing microorganisms. EU Pat., 2723849A1, US Pat., $20130337523 \mathrm{~A} 1$.

Flisar K., Meglic S.H., Morelj J., Golob J., Miklavcic D., (2014) Testing a prototype pulse generator for a continuous flow system and its use for E. coli inactivation and microalgae lipid extraction. Bioelectrochemistry 100:44-51.

Frey W., Gusbeth C., Schwartz T., (2013) Inactivation of Pseudomonas putida by Pulsed Electric Field Treatment: A Study on the Correlation of Treatment Parameters and Inactivation Efficiency in the Short-Pulse Range, J. Membr. Biol. 246 769-781.

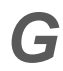

Garzon-Sanabria, A. J., Ramirez-Cabellero, S. S., Moss, F. E. P., Nikolov, Z. L. (2013) "Effect of algogenic organic matter (AOM) and sodium chloride on Nannochloropsis salina flocculation efficiency." Bioresour. Technol. 143: 231 237.

Ganeva V., Galutzov B., Teissié J., (2003) High yield electroextraction of proteins from yeast by a flow process. Anal. Biochem. 315:77-84. 
Gerardo, M.L., Van Den Hende, S., Vervaeren, H., Coward, T., Skill, S.C. $2015 a$. Harvesting of microalgae within a biorefinery approach: A review of the developments and case studies from pilot-plants. Algal Res., 11, 248-262.

Gerardo, M.L., Zanain, M.A., Lovitt, R.W. 2015b. Pilot-scale cross-flow microfiltration of Chlorella minutissima: A theoretical assessment of the operational parameters on energy consumption. Chem. Eng. J., 280, 505-513.

Gerken H.G., Donohoe B., Knoshaug E.P., (2013) Enzymatic cell wall degradation of Chlorella vulgaris and other microalgae for biofuels production. Planta 237:239-253.

Godfray, H.C.J., Beddington, J.R., Crute, I.R., Haddad, L., Lawrence, D., Muir, J.F., Pretty, J., Robinson, S., Thomas, S.M., Toulmin, C. 2010. Food Security: The Challenge of Feeding 9 Billion People. Science, 327, 812-818.

Goettel M., Eing C., Gusbeth C., Straessner C., Frey W., (2013) Pulsed electric field assisted extraction of intracellular valuables from microalgae. Algal Res. 2: 401-408.

Gonçalves A.L., Alvim-Ferraz M.C.M., Martins F.G., Simões M. Pires J.C.M., (2016) Integration of Microalgae-Based Bioenergy Production into a Petrochemical Complex: Techno-Economic Assessment. Energies 9: 224.

Granados, M.R., Acién, F.G., Gómez, C., Fernández-Sevilla, J.M., Molina Grima, E. 2012. Evaluation of flocculants for the recovery of freshwater microalgae. Bioresour. Technol., 118, 102-110.

Greenwell, H.C., Laurens, L.M.L., Shields, R.J., Lovitt, R.W., Flynn, K.J. 2010. Placing microalgae on the biofuels priority list: A review of the technological challenges. J. R. Soc. Interface, 7, 703-726.

Gregory, J. (1973). Rates of flocculation of latex particles by cationic polymers. J. Colloid Interf. 42: 448-456.

Grimi N., Dubois A., Marchal L., Jubeau S., Lebovka N.I., Vorobiev E., (2014) Selective extraction from microalgae Nannochloropsis sp. using different methods of cell disruption, Bioresour. Technol. 153: 254-259.

Guionet, A., Hosseini, B., Teissié, J., Akiyama, H., Hosseini, H. 2017. A new mechanism for efficient hydrocarbon electro-extraction from Botryococcus braunii. Biotechnol. Biofuel., 10, 39.

Günerken E., D'Hondt E., Eppink M.H.M., Garcia-Gonzalez L., Elst K., Wijfels R.H., (2015) Cell disruption for microalgae biorefineries. Biotechnol. Adv. 33: 243260. 
Günerken, E., D'Hondt, E., Eppink, M., Elst, K., Wijffels, R. 2016. Influence of nitrogen depletion in the growth of $\mathrm{N}$. oleoabundans on the release of cellular components after beadmilling. Bioresour. Technol., 214, 89-95.

H

Halim R., Gladman B., Danquah M.K., Webley P.A., (2011) Oil extraction from microalgae for biodiesel production. Bioresour Technol 102: 178-185.

Halim R., Harun R., Danquah M.K., Webley P.A., (2012) Microalgal cell disruption for biofuel development. Appl Energy 91: 116-121.

Harith, Z.T., Yusoff, F.M., Mohamed, M.S., Mohamed Din, M.S., Ariff, A.B. 2009. Effect of different flocculants on the flocculation performance of microalgae, Chaetoceros calcitrans, cells. Afr. J. Biotechnol., 8, 5971-5978.

Herrero M., Ibáñez E., (2015) Green processes and sustainability: An overview on the extraction of high added-value products from seaweeds and microalgae. $J$ Supercrit. Fluids 96: 211-216.

Henderson, R.K., Parsons, S.A., Jefferson, B. 2008. Successful removal of algae through the control of zeta potential. Sep. Sci. Technol., 43, 1653-1666.

Japar, A.S., Takriff, M.S., Yasin, N.H.M. 2017. Harvesting microalgal biomass and lipid extraction for potential biofuel production: A review. J. Env. Chem. Eng., 5, 555-563.

Jessop, P.G., Heldebrant, D.J., Li, X., Eckertt, C.A., Liotta, C.L. 2005. Green chemistry: Reversible nonpolar-to-polar solvent. Nature, 436, 1102.

Jessop P.G., Mercer S.M., Heldebrant D.J., (2012) CO2-triggered switchable solvents, surfactants, and other materials. Energy Environ. Sci. 5: 7240-7253.

\section{K}

Kamm, B., Kamm, M. 2007. Biorefineries - Multi Product Processes. in: White Biotechnology, (Eds.) R. Ulber, D. Sell, Springer Berlin Heidelberg. Berlin, Heidelberg, pp. 175-204. 
Kleinegris D.M.M., Janssen M., Brandenburg W.A., Wijffels R.H., (2011) Two-phase systems: Potential for in situ extraction of microalgal products. Biotechnol. Adv. 29: 502-507.

Kilian O., Benemann C.S.E., Niyogi K.K., Vick B., (2011) High-efficiency homologous recombination in the oil-producing alga Nannochloropsis sp., Proc. Natl. Acad. Sci. 108: 21265-21269.

Kim, D.-Y., Oh, Y.-K., Park, J.-Y., Kim, B., Choi, S.-A., Han, J.-I. 2015. An integrated process for microalgae harvesting and cell disruption by the use of ferric ions. Bioresour. Technol., 191, 469-474.

Kliphuis A.M.J., de Winter L., Vejrazka C., Martens D.E., Janssen M., Wijffels R.H., (2010) Photosynthetic efficiency of Chlorella sorokiniana in a turbulently mixed short light-path photobioreactor, Biotechnol. Prog. 26: 687-696.

Kliphuis AM, Klok AJ, Martens DE, Lamers PP, Janssen M, Wijffels RH (2012) Metabolic modeling of Chlamydomonas reinhardtii: energy requirements for photoautotrophic growth and maintenance. J Appl Phycol 24: 253-266.

König, R. B., R. Sales, F. Roselet and P. C. Abreu (2014). "Harvesting of the marine microalga Conticribra weissflogii (Bacillariophyceae) by cationic polymeric flocculants." Biomass Bioenergy 68: 1-6.

Kotnik T., Frey W., Sack M., Meglič S.H., Peterka M., Miklavčič D., (2015) Electroporation-based applications in biotechnology. Trends Biotechnol. 33:480-488.

Krishnan, M.S., Taylor, F., Davison, B.H., Nghiem, N.P. 2000. Economic analysis of fuel ethanol production from corn starch using fluidized-bed bioreactors. Bioresour. Technology, 75, 99-105.

Kwiatkowski, J.R., McAloon, A.J., Taylor, F., Johnston, D.B. 2006. Modeling the process and costs of fuel ethanol production by the corn dry-grind process. Ind. Crops Prod., 23, 288-296.

\section{$L$}

Lai Y. S., Parameswaran P., Li A., Baez M., Rittmann B.E., (2014) Effects of pulsed electric field treatment on enhancing lipid recovery from the microalga, Scenedesmus, Bioresour. Technol. 173: 457-461.

Lam, M.K., Lee, K.T. 2012. Microalgae biofuels: A critical review of issues, problems and the way forward. Biotechnol. Adv., 30, 673-690. 
Lamers P.P., van de Laak C.C.W., Kaasenbrood P.S., Lorier J., Janssen M., de Vos R.C.H., Bino R.J., Wijfels R.H. (2010) Carotenoid and fatty acid metabolism in light-stressed Dunaliella salina. Biotech. Bioeng. 106: 638-648.

Lee, S.Y., Choi, J.I. 1998. Effect of fermentation performance on the economics of poly(3-hydroxybutyrate) production by Alcaligenes latus. Polym. Degrad. Stabil., 59, 387-393.

Lee K. E., Teng T.T., Morad N., Poh B.T., Hong Y.F. (2010). Flocculation of kaolin in water using novel calcium chloride-polyacrylamide (CaCl2-PAM) hybrid polymer. Separation and Purification Technology 75: 346-351.

Lee, C. S., J. Robinson and M. F. Chong (2014). "A review on application of flocculants in wastewater treatment." Process Saf. Environ. 92: 489-508.

Luengo E.I., Condón-Abanto S., Álvarez I., Raso J., (2014) Effect of Pulsed Electric Field Treatments on Permeabilization and Extraction of Pigments from Chlorella vulgaris, J. Membr. Biol. 247: 1269-1277.

Luengo E, Martínez JM, Bordetas A, Álvarez I., Raso J., (2015a) Influence of the treatment medium temperature on lutein extraction assisted by pulsed electric fields from Chlorella vulgaris. Innov. Food Sci. Emerg. Technol. 29:15-22.

Luengo E, Martínez JM, Coustets M, Álvarez I., Teissié J., Raso J., (2015b) A Comparative Study on the Effects of Millisecond- and Microsecond-Pulsed Electric Field Treatments on the Permeabilization and Extraction of Pigments from Chlorella vulgaris. J. Membr. Biol. 248: 883-891.

\section{M}

Mabire F., Audebert R. and Quivoron C. (1984). Flocculation properties of some water-soluble cationic copolymers toward silica suspensions: A semiquantitative interpretation of the role of molecular weight and cationicity through a "patchwork" model. J. Colloid Interf. 97: 120-136.

Madigan MT, Martinko JM (2006) Brock Biology of Microorganisms. Pearson Prentice Hall, London.

Mahdy A, Mendez L, Ballesteros M, González-Fernández C (2014) Enhanced methane production of Chlorella vulgaris and Chlamydomonas reinhardtii by hydrolytic enzymes addition. Energy Convers. Manage. 85: 551-557.

Mahnič-Kalamiza S., Vorobiev E., Miklavčič D. (2014) Electroporation in Food Processing and Biorefinery. J. Membr. Biol. 247: 1279-1304. 
Mendes-Pinto M.M., Raposo M.F.J., Bowen J., Young A.J., Morais R., (2001) Evaluation of different cell disruption processes on encysted cells of Haematococcus pluvialis: effects on astaxanthin recovery and implications for bio-availability. J. Appl. Phycol. 13: 19-24.

Mhatre, S., Vivacqua, V., Ghadiri, M., Abdullah, A.M., Al-Marri, M.J., Hassanpour, A., Hewakandamby, B., Azzopardi, B., Kermani, B. 2015. Electrostatic phase separation: A review. Chem. Eng. Res. D., 96, 177-195.

Middelberg A.P., (1995) Process-scale disruption of microorganisms. Biotechnol. Adv. 13:491-551.

Miklavcic, D., Davalos, R.V. 2015. Electrochemotherapy (ECT) and irreversible electroporation (IRE) -advanced techniques for treating deep-seated tumors based on electroporation. BioMed. Eng. OnLine, 14, I1-I1.

Milledge, J. and S. Heaven (2013). A review of the harvesting of micro-algae for biofuel production. Rev. Environ. Sci. Biotechnol. 12: 165-178.

Mohsin, M., Meribout, M. 2015. Oil-water de-emulsification using ultrasonic technology. Ultrason. Sonochem., 22, 573-579.

Molina Grima, E., Belarbi, E.H., Acién Fernández, F.G., Robles Medina, A., Chisti, Y. 2003. Recovery of microalgal biomass and metabolites: process options and economics. Biotechnol. Adv. 20, 491-515.

Moncada, J., Tamayo, J.A., Cardona, C.A. 2014. Integrating first, second, and third generation biorefineries: Incorporating microalgae into the sugarcane biorefinery. Chem. Eng. Sci., 118, 126-140.

Montalescot, V., Rinaldi, T., Touchard, R., Jubeau, S., Frappart, M., Jaouen, P., Bourseau, P., Marchal, L. 2015. Optimization of bead milling parameters for the cell disruption of microalgae: Process modeling and application to Porphyridium cruentum and Nannochloropsis oculata. Bioresour. Technol., 196, 339-346.

Morrissey K. L., He C., Wong M.H., Zhao X., Chapman R. Z., Bender S.L., Prevatt W. D., Stoykovich M.P. (2014) Charge-tunable polymers as reversible and recyclable flocculants for the dewatering of microalgae. Biotech. Bioeng. 112: 74-83.

Mubarak, M., Shaija, A., Suchithra, T.V. 2015. A review on the extraction of lipid from microalgae for biodiesel production. Algal Res., 7, 117-123.

Muylaert, K., Vandamme, D., Foubert, I., Brady, P.V. 2015. Harvesting of Microalgae by Means of Flocculation. in: Biomass and Biofuels from Microalgae: Advances in Engineering and Biology, (Eds.) N.R. Moheimani, M.P. McHenry, K. de Boer, P.A. Bahri, Springer International Publishing. Cham, pp. 251-273. 


\section{$N$}

Norsker, N.-H., Barbosa, M.J., Vermuë, M.H., Wijffels, R.H. 2011. Microalgal production - A close look at the economics. Biotechnol. Adv., 29, 24-27.

\section{0}

Orr, V.C.A., Plechkova, N.V., Seddon, K.R., Rehmann, L. 2016. Disruption and Wet Extraction of the Microalgae Chlorella vulgaris Using Room-Temperature lonic Liquids. ACS Sustain. Chem. Eng., 4, 591-600.

Orr, V.C.A., Rehmann, L. 2016. Ionic liquids for the fractionation of microalgae biomass. Curr. Opin. Green Sustain. Chem., 2, 22-27.

Parniakov O., Barba F.J., Grimi N., Marchal L., Jubeau S., Lebovka N., Vorobiev E., (2015) Pulsed electric field and $\mathrm{pH}$ assisted selective extraction of intracellular components from microalgae Nannochloropsis. Algal Res. 8: 128-134.

Parniakov O., Barba F.J., Grimi N., Marchal L., Jubeau S., Lebovka N., Vorobiev E. (2015), Pulsed electric field assisted extraction of nutritionally valuable compounds from microalgae Nannochloropsis spp. using the binary mixture of organic solvents and water, Innov. Food Sci. Emerg. Technol. 27 (2015) 7985.

Petrides, D. 2003. Bioprocess design and economics. in: Bioseparation Science and Engineering, Harrison R.G., Todd P.W., Rudge S.R., Petrides D. (Eds.), Oxford University Press. Oxford, pp. 319-372.

Popovich, C.A., Damiani, C., Constenla, D., Martínez, A.M., Freije, H., Giovanardi, M., Pancaldi, S., Leonardi, P.I. 2012. Neochloris oleoabundans grown in enriched natural seawater for biodiesel feedstock: Evaluation of its growth and biochemical composition. Bioresour. Technol., 114, 287-293.

Postma P.R., Miron T.L., Olivieri G., Barbosa M.J., Wijfels R.H., Eppink M.H.M., (2015) Mild disintegration of the green microalgae Chlorella vulgaris using bead milling. Bioresour. Technol. 184: 297-304. 
Postma P.R., Pataro G., Capitoli M., Barbosa M.J., Wijffels R.H., Eppink M.H.M., Ferrari G., (2016) Selective extraction of intracellular components from the microalga Chlorella vulgaris by combined pulsed electric field-temperature treatment. Bioresour. Technol. 203: 80-88.

Postma P.R., 't Lam G.P., Barbosa M.J., Wijffels R.H., Eppink M.H.M., Olivieri G. (2016) 'Microalgal biorefinery for bulk and high value products - Product extraction within cell disintegration'. In Handbook of Electroporation; Miklavcic, D. (Ed), Springer Publishers, Switzerland. p.p. 1-20.

Postma, P.R., Suarez-Garcia, E., Safi, C., Yonathan, K., Olivieri, G., Barbosa, M.J., Wijffels, R.H., Eppink, M.H.M. 2017. Energy efficient bead milling of microalgae: Effect of bead size on disintegration and release of proteins and carbohydrates. Bioresour. Technol., 224, 670-679.

Pushparaj, B., Pelosi, E., Torzillo, G., Materassi, R. 1993. Microbial biomass recovery using a synthetic cationic polymer. Bioresour. Technol., 43, 59-62.

\section{Q}

Qureshi, N., Blaschek, H.P. 2001. ABE production from corn: A recent economic evaluation. J. Ind. Microbiol. Biotechnol., 27, 292-297.

Rashid, N., S. U. Rehman and J.-I. Han (2013). "Rapid harvesting of freshwater microalgae using chitosan." Process Biochem. 48: 1107-1110.

Rattanakawin, C. and Hogg R. (2001). Aggregate size distributions in flocculation. Colloids Surfaces A 177: 87-98.

Renault F., Sancey B., Badot P.-M., Crini G. (2009). Chitosan for coagulation/flocculation processes - An eco-friendly approach. Eur. Pol. J. 45: 1337-1348.

Ritchie R (2006) Consistent Sets of Spectrophotometric Chlorophyll Equations for Acetone, Methanol and Ethanol Solvents. Photosynth. Res. 89: 27-41.

Roberts K, Gurney-Smith M, Hills GJ (1972) Structure, composition and morphogenesis of the cell wall of Chlamydomonas reinhardi: I. Ultrastructure and preliminary chemical analysis. J. Ultrastruct. Res. 40: 599-613. 
Rogner, H.-H., D. Zhou, R. Bradley. P. Crabbé, O. Edenhofer, B.Hare (Australia), L. Kuijpers, M. Yamaguchi. 2007. Introduction. Climate Change 2007: Mitigation. Contribution of Working Group III to the Fourth Assessment Report of the Intergovernmental Panel on Climate Change.

Roselet, F., Vandamme D., Roselet M., Muylaert K., Abreu P. C. (2015). Screening of commercial natural and synthetic cationic polymers for flocculation of freshwater and marine microalgae and effects of molecular weight and charge density. Algal Res. 10: 183-188.

Rouf, S.A., Douglas, P.L., Moo-Young, M., Scharer, J.M. 2001. Economics of fedbatch operation: A computer-aided approach. Bioprocess Biosyst. Eng., 24, 65-71.

Rowe, G.E., Margaritis, A. 2004. Bioprocess design and economic analysis for the commercial production of environmentally friendly bioinsecticides from Bacillus thuringiensis HD-1 kurstaki. Biotechnol. Bioeng., 86, 377-388.

Runkana V., Somasundaran P., Kapur P.C. (2004). Mathematical modeling of polymer-induced flocculation by charge neutralization. J. Colloid Interf. Sci. 270: 347-358.

Run C., Fang L., Fan J., Fan C., Luo Y., Hu Z., Li Y., (2016) Stable nuclear transformation of the industrial alga Chlorella pyrenoidosa, Algal Res. 17: 196-201.

Ruiz, J., Olivieri, G., de Vree, J., Bosma, R., Willems, P., Reith, J.H., Eppink, M.H.M., Kleinegris, D.M.M., Wijfels, R.H., Barbosa, M.J. 2016. Towards industrial products from microalgae. Energy Environ. Sci.

\section{$S$}

Safi C., Charton M., Ursu A.V., Laroche C., Zebib B., Pontalier P.-Y., Vaca-Garcia C., (2014) Release of hydro-soluble microalgal proteins using mechanical and chemical treatments, Algal Res. 3: 55-60.

Safi C, Liu DZ, Yap BHJ, Martin GJO, Vaca-Garcia C, Pontalier PY (2014) A twostage ultrafiltration process for separating multiple components of Tetraselmis suecica after cell disruption. J Appl Phycol 1-9.

Safi C., Ursu A.V., Laroche C., Zebib B., Merah O., Pontalier P.-Y., Vaca-Garcia C., (2014) Aqueous extraction of proteins from microalgae: Effect of different cell disruption methods. Algal Res. 3: 61-65. 
Salam, K.A., Velasquez-Orta, S.B., Harvey, A.P. 2016a. Kinetics of fast alkali reactive extraction/in situ transesterification of Chlorella vulgaris that identifies process conditions for a significant enhanced rate and water tolerance. Fuel Process. Technol., 144, 212-219.

Salam, K.A., Velasquez-Orta, S.B., Harvey, A.P. 2016b. A sustainable integrated in situ transesterification of microalgae for biodiesel production and associated co-product-a review. Renewable and Sustainable Energy Reviews, 65, 11791198.

Salerno M.B., Lee H.-S., Parameswaran P., Rittmann B.E., (2009) Using a Pulsed Electric Field as a Pretreatment for Improved Biosolids Digestion and Methanogenesis, Water Environ. Res. 81: 831-839.

Salim S. Bosma R., Vermuë M.H., Wijffels R.H. (2011). Harvesting of microalgae by bio-flocculation. J. Appl. Phycol. 23: 849-855.

Salim S. Vermuë M.H., Wijffels R.H. (2012). Ratio between autoflocculating and target microalgae affects the energy-efficient harvesting by bio-flocculation. Bioresour. Technol 118: 49-55.

Salim, S., Shi, Z., Vermuë, M. H., Wijffels, R.H., (2013). "Effect of growth phase on harvesting characteristics, autflocculation and lipid content of Ettlia texensis for microalgal biodiesel production." Bioresour. Technol. 138: 214-221.

Salim, S., Kosterink, N.R., Tchetkoua Wacka, N.D., Vermuë, M.H., Wijffels, R.H. (2014). Mechanism behind autoflocculation of unicellular green microalgae Ettlia texensis. J. Biotechnol., 174, 34-38.

Sari YW, Mulder WJ, Sanders JPM, Bruins ME (2015) Towards plant protein refinery: Review on protein extraction using alkali and potential enzymatic assistance. Biotechnol. J. 10: 1138-1157.

Schenk P., Thomas-Hall S.R., Stephens E., Marx U.C., Mussgnug J.H., Posten C., Kruse O., Hankamer B. (2008). Second Generation Biofuels: High-Efficiency Microalgae for Biodiesel Production. Bioenerg. Res. 1: 20-43.

Scholz M.J., Weiss T.L., Jinkerson R.E., Jing J., Roth R., Goodenough U., Posewitz M.C., Gerken H.G., (2014) Ultrastructure and Composition of the Nannochloropsis gaditana Cell Wall, Eukaryot. Cell. EC.00183-14.

Schwenzfeier, A., Helbig, A., Wierenga, P.A., Gruppen, H. 2013a. Emulsion properties of algae soluble protein isolate from Tetraselmis $\mathrm{sp}$. Food Hydrocoll, 30, 258-263.

Schwenzfeier, A., Lech, F., Wierenga, P.A., Eppink, M.H.M., Gruppen, H. 2013b. Foam properties of algae soluble protein isolate: Effect of $\mathrm{pH}$ and ionic strength. Food Hydrocoll, 33, 111-117. 
Schwenzfeier, A., Wierenga, P.A., Gruppen, H. 2011. Isolation and characterization of soluble protein from the green microalgae Tetraselmis sp. Bioresour. Technol., 102, 9121-9127.

Seo, J.Y., Praveenkumar, R., Kim, B., Seo, J.-C., Park, J.-Y., Na, J.-G., Jeon, S.G., Park, S.B., Lee, K., Oh, Y.-K. 2016. Downstream integration of microalgae harvesting and cell disruption by means of cationic surfactant-decorated Fe3O4 nanoparticles. Green Chem., 18, 3981-3989.

Sheng J., Vannela R., Rittmann B.E. (2012) Disruption of Synechocystis PCC 6803 for lipid extraction. Water Sci. Technol. 65: 567.

Singh J., Gu S., (2010) Commercialization potential of microalgae for biofuels production, Renew. Sustain. Energy Rev. 14: 2596-2610.

Silva Benavides, A.M., Torzillo, G., Kopecký, J., Masojídek, J. 2013. Productivity and biochemical composition of Phaeodactylum tricornutum (Bacillariophyceae) cultures grown outdoors in tubular photobioreactors and open ponds. Biomass Bioenergy, 54, 115-122.

Şirin, S., Trobajo, R., Ibanez, C., Salvadó, J. 2012. Harvesting the microalgae Phaeodactylum tricornutum with polyaluminum chloride, aluminium sulphate, chitosan and alkalinity-induced flocculation. J. Appl. Phycol. 24, 1067-1080.

Smoluchowski M. (1917). Versuch einer mathematische theorie der koagulationskinetik kolloider lösungen. Z. Phys. Chem. 92, 129-168.

Sommerfeld, S., Strube, J. 2005. Challenges in biotechnology production - Generic processes and process optimization for monoclonal antibodies. Chemical Engineering and Processing: Process Intensification, 44, 1123-1137.

Soomro, R.R., Ndikubwimana, T., Zeng, X., Lu, Y., Lin, L., Danquah, M.K. 2016. Development of a Two-Stage Microalgae Dewatering Process - A Life Cycle Assessment Approach. Frontiers in Plant Science, 7, 113.

Spilling, K., Seppälä, J., Tamminen, T. 2011. Inducing autoflocculation in the diatom Phaeodactylum tricornutum through $\mathrm{CO} 2$ regulation. J. Appl. Phycol., 23, 959-966.

Spolaore, P., Joannis-Cassan, C., Duran, E., Isambert, A. 2006. Commercial applications of microalgae. J. Biosci. Bioeng., 101, 87-96.

Straathof, A.J.J. 2011. 2.57 - The Proportion of Downstream Costs in Fermentative Production Processes A2 - Moo-Young, Murray (Ed). in: Comprehensive Biotechnology (Second Edition), Academic Press. Burlington, pp. 811-814. 
Sukenik, A., Shelef, G. 1984. Algal autoflocculation - Verificatuion and proposed mechanism. Biotech. Bioeng. 26, 142-147.

\section{$T$}

't Lam, G. P., M. H. Vermuë, G. Olivieri, L. A. M. van den Broek, M. J. Barbosa, M. H. M. Eppink, R. H. Wijffels and D. M. M. Kleinegris (2014) "Cationic polymers for successful flocculation of marine microalgae." Bioresour. Technol. 169: 804807.

't Lam G. P., Zegeye E. K., Vermuë M .H., Kleinegris D. M .M., Eppink M. H. M., Wijffels R. H., Olivieri G. (2015) Dosage effect of cationic polymers on the flocculation efficiency of the marine microalga Neochloris oleoabundans, Bioresour. Technol. 198: 797-802.

't Lam, G.P. , Giraldo, J.B., Vermuë, M.H, Olivieri, G., Eppink, M.H.M., Wijffels, R.H. (2016) Understanding the salinity effect on cationic polymers in inducing flocculation of the microalga Neochloris oleoabundans. J. Biotechnol. 225C: 10-17.

't Lam, G.P., Postma P.R., Fernandes D.A., Timmermans R.A.H., M.H. Vermuë, M.J. Barbosa, M.H.M. Eppink, Wijffels R.H. Olivieri G. (2017) Pulsed Electric Field for protein release of the microalgae Chlorella vulgaris and Neochloris oleoabundans. Algal Res. 24A: 181-187.

Teixeira, R.E. 2012. Energy-efficient extraction of fuel and chemical feedstocks from algae. Green Chem., 14, 419-427.

Tekin, N., A. Dinçer, Ö. Demirbaş and M. Alkan (2010). "Adsorption of cationic polyacrylamide (C-PAM) on expanded perlite." Appl. Clay Sci. 50: 125-129.

Tenney, M.W., Echelberger, W.F., Schuessler, R.G., Pavoni, J.L. 1969. Algal flocculation with synthetic organic polyelectrolytes. Appl. microbiol., 18, 965971.

Thomas D. N., Judd S.J., Fawcett N. (1999). Flocculation modelling: a review. Water Res. 33: 1579-1592.

Timmermans R.A.H., Mastwijk H.C., Knol J.J., Quataert M.C.J., Vervoort L., der Plancken I.V., Hendrickx M.E., Matser A.M., (2011) Comparing equivalent thermal, high pressure and pulsed electric field processes for mild pasteurization of orange juice. Part I: Impact on overall quality attributes, Innov. Food Sci. Emerg. Technol. 12: 235-243. 
Timmermans R.A.H., Nierop Groot M.N., Nederhoff A.L., van Boekel M.A.J.S., Matser A.M., Mastwijk H.C., (2014) Pulsed electric field processing of different fruit juices: Impact of $\mathrm{pH}$ and temperature on inactivation of spoilage and pathogenic micro-organisms, Int. J. Food Microbiol. 173: 105-111.

Toepfl S., Heinz V., Knorr D., (2006) Applications of Pulsed Electric Fields Technology for the Food Industry. In: Raso J, Heinz V (eds) Pulsed Electric Fields Technology for the Food Industry. Springer US, pp 197-221.

Tredici M.R. (2010) Photobiology of microalgae mass cultures: understanding the tools for the next green revolution. Biofuels 1: 143-162.

Tricot, M. (1984). "Comparison of experimental and theoretical persistence length of some polyelectrolytes at various ionic strengths." Macromolecules 17: 16981704.

\section{$U$}

Uduman N., Qi Y., Danquah M.K., Forde G.M., Hoadley A. (2010). Dewatering of microalgal cultures: A major bottleneck to algae-based fuels. J. Renewable Sustainable Energy 2(1).

Ursu A.-V., Marcati A., Sayd T., Sante-Lhoutellier V., Djelveh G., Michaud P., (2014) Extraction, fractionation and functional properties of proteins from the microalgae Chlorella vulgaris. Bioresour. Technol. 157: 134-139.

Vandamme, D., Foubert, I., Meesschaert, B., Muylaert, K. 2010. Flocculation of microalgae using cationic starch. J. Appl. Phycol. 22, 525-530.

Vandamme, D., Foubert, I., Muylaert, K. 2013. Flocculation as a low-cost method for harvesting microalgae for bulk biomass production. Trends Biotechnol., 31, 233-239.

Vanthoor-Koopmans M., Wijfels R.H., Barbosa M.J., Eppink M.H.M., (2013) Biorefinery of microalgae for food and fuel, Bioresour. Technol. 135: 142-149.

Vigani M., Parisi C., Rodríguez-Cerezo E., Barbosa M.J. Sijtsma L., Ploeg M., Einzing C.,(2015) Food and feed products from micro-algae: Market opportunities and challenges for the EU. Trends Food Sci. Technol. 42: 81-92. 


\section{W}

Wan, C., Alam, M.A., Zhao, X.-Q., Zhang, X.-Y., Guo, S.-L., Ho, S.-H., Chang, J.-S., Bai, F.-W. 2015. Current progress and future prospect of microalgal biomass harvest using various flocculation technologies. Bioresour. Technol. 184, 251257.

Wang D., Li Y., Hu X., Su W., Zhong M., (2015) Combined Enzymatic and Mechanical Cell Disruption and Lipid Extraction of Green Alga Neochloris oleoabundans. Int. J. Mol. Sci. 16: 7707-7722.

Warren, R.K., Macdonald, D.G., Hill, G.A. 1994. The design and costing of a continuous ethanol process using wheat and cell recycle fermentation. Bioresour. Technol., 47, 121-129.

Watarai, H. 2013. Continuous Separation Principles Using External Microaction Forces. Annual Review of Analytical Chemistry, 6, 353-378.

Weaver JC, Chizmadzhev YA (1996) Theory of electroporation: A review. Bioelectrochem. Bioenerg. 41: 135-160.

Wong S. S., Teng T.T., Ahmad A.L., Zuhairi A., Najafpour G. (2006). Treatment of pulp and paper mill wastewater by polyacrylamide (PAM) in polymer induced flocculation. J. Hazard. Mater 135: 378-388.

Wu, Z., Y. Zhu, W. Huang, C. Zhang, T. Li, Y. Zhang and A. Li (2012). "Evaluation of flocculation induced by $\mathrm{pH}$ increase for harvesting microalgae and reuse of flocculated medium." Bioresour. Technol. 110: 496-502.

Wijffels, R.H., Barbosa, M.J. 2010. An Outlook on Microalgal Biofuels. Science, 329(5993), 796-799.

Wijffels, R.H., Barbosa, M.J., Eppink, M.H.M. 2010. Microalgae for the production of bulk chemicals and biofuels. Biofuels, Bioprod. Biorefin., 4, 287-295.

Williams, P.J.I.B., Laurens, L.M.L. 2010. Microalgae as biodiesel \& biomass feedstocks: Review \& analysis of the biochemistry, energetics \& economics. Energy Environ. Sci. 3, 554-590.

\section{$X$}

Xu, Y., S. Purton and F. Baganz (2013). "Chitosan flocculation to aid the harvesting of the microalga Chlorella sorokiniana." Bioresour. Technol. 129: 296-301. 
Yamakawa, H. (1971). "Modern theory of polymer solutions." Department of polymer chemistry, Kyoto University, Japan. Harper \& Row Publishers.

Yen H.-W., Yang S.-C., Chen C.-H., Jessica, Chang J.-S. (2015) Supercritical fluid extraction of valuable compounds from microalgal biomass. Bioresour. Technol. 184: 291-296.

Yen H.-W., Hu I.-C., Chen C.-Y., Ho S.-H., Lee D.-J., Chang J.-S., (2013) Microalgae-based biorefinery - From biofuels to natural products, Bioresour. Technol. 135: 166-174.

Zahrim A. Y., Tizaoui C., Hilal N. (2010). Evaluation of several commercial synthetic polymers as flocculant aids for removal of highly concentrated C.I. Acid Black 2010 dye. J. Hazard. Mater 182: 624-630.

Zbinden M.D.A., Sturm B.S.M., Nord R.D., Carey W.J., Moore D., Shinogle H., Stagg-Williams S.M., (2013) Pulsed electric field (PEF) as an intensification pretreatment for greener solvent lipid extraction from microalgae. Biotechnol. Bioeng. 110: 1605-1615.

Zheng, Y., Roberts, M., Kelly, J., Zhang, N., Walker, T. 2015. Harvesting microalgae using the temperature-activated phase transition of thermoresponsive polymers. Algal Res., 11, 90-94.

Zheng, Y., Xiao, R., Roberts, M. 2016. Polymer-enhanced enzymatic microalgal cell disruption for lipid and sugar recovery. Algal Res., 14, 100-108. 
Summary 
Microalgae are a potential feedstock for the production of a wide spectrum of products. They are currently already used for commercial production of several highvalue products such as natural pigments, and as feedstock for aquaculture hatcheries. As microalgae pre-dominantly consist out of proteins, carbohydrates and lipids, they are also a promising feedstock for production of lower value bulkcommodities. For large-scale production of bulk-commodities, however, a strong reduction of the production costs need to be realized. In addition to a cost reduction, a biorefinery approach that aims to valorise multiple instead of a single product is necessary. To valorise all biomass fractions in a biorefinery approach, damaging of the components should be prevented. Mild processing technologies are thus required (Chapter 1).

The first steps in the downstream process consist out of biomass harvesting followed by cell disruption after which intracellular compounds are released or extracted. However, harvesting with a benchmark disc-stacked centrifuge and cell disruption using conventional technologies (e.g. bead milling, high pressure homogenisation) are generally expensive. Development of alternative low-cost and mild harvestingand disruption technologies are needed (Chapter 1).

In the first part of this thesis, flocculation of marine microalgae was investigated as a potential low-cost and mild technology for (pre)concentrating the biomass. Although flocculation is already a widely applied technology, there were still challenges to induce flocculation of microalgae at seawater salinity. Chapter 2 reports a screening of commercial available polymeric flocculants for flocculation of the marine microalga Phaeodactylum tricornutum and the marine cultivated Neochloris oleoabundans. Cationic polymers, and in particular polyacrylamides, successfully induced flocculation of marine microalgae. The use of those cationic polymers resulted in biomass recoveries higher than $90 \%$ and a concentration factor ranging between 5 and 10 after 2 hours of sedimentation.

In Chapter 3 we continued with investigating the effect of the flocculant dosage on the biomass recovery. A positive effect of increasing flocculant dosages on the biomass recovery was observed with the marine cultivated microalga $N$. oleoabundans. After reaching an optimum in biomass recovery (>95\%), higher flocculant dosages did not enhance the biomass recovery. Further increasing the 
flocculant dosage even resulted in decreasing biomass recoveries. These results suggest that repulsion between positively charged flocculant and positively charged flocs occurred at exceeding high flocculant dosages, and could explain the lower biomass recovery at elevated dosage. This mechanism of charge attraction at low flocculant dosage and repulsion at high flocculant dosage was translated into a mathematical model. The model describes the biomass recovery as a function of the flocculant dosage, the initial biomass concentration and the microalgae cell diameter. The model was validated and used to predict optimal flocculant dosages to harvest the microalga $N$. oleoabundans to be around $70 \mathrm{mg}_{\text {flocculant }} / g_{\text {biomass. }}$ This dosage in combination with the cost price of the flocculants makes polymeric flocculation rather expensive. In addition, the currently available cationic polyacrylamides are toxic, making them inappropriate for a microalgae biorefinery. There is thus a need for alternative and low-cost flocculants for successful flocculation at high salinities (Chapter 3).

Before alternative flocculants can be selected or rationally designed, it is important to understand why in particular the cationic poly-acrylamides were so successful in inducing flocculation at high salinities. A general accepted hypothesis is that coiling of the polymers at increasing salinities causes a lower functionality as they become unable to form bridges between single cells. Based on this hypothesis, the used cationic polyacrylamides would be less sensitive for saline induced coiling. Chapter 4 describes the effect of the medium salinity on the apparent polymer length and net cationic charge of a successful polyacrylamide and a less successful natural polymer. Although the cationic polyacrylamide became coiled at increasing salinities, it still induced flocculation. The cationic charge plays instead a more important role. This was also supported by the large differences in cationic charge between the two flocculants. Additional experiments confirmed that indeed the cationic polymeric charge is a dominant parameter for flocculation. In future flocculant design, the cationic charge should therefore be used as important selection criterion (Chapter 4).

In the second part of this thesis the potential of 'pulsed electric field' (PEF) as a low cost and mild microalgal cell disruption technology was investigated. PEF is a common described technology for food processing and for medical treatment of tumors. To determine the state-of-development of PEF for microalgae, a screening of operating parameters was performed on the seawater grown microalgae Neochloris 
oleoabundans and the freshwater grown species Chlorella vulgaris. Applying a wide variety of operating conditions using two different set-ups (batch, and continuous treatment) resulted in a successful release of small components (ions), which suggests that the cells were successfully perforated. The observed protein yield after PEF was, however, in all cases at least two- to threefold lower than the yields observed with bead milling as reference benchmark technology (Chapter 5). These results suggest that despite the successful perforation of the cells, the openings are insufficiently large to release large components such as hydrophilic proteins.

To compare PEF with other technologies, a literature survey on available cell disruption technologies was performed (Chapter 6). Other studies on PEF for disruption of microalgae reported similar low protein yields, and confirm the low efficiency of PEF for the release of proteins (Chapter 6).

Various microalgae have an outer cell wall that may hinder the successful release of large cytosolic components with PEF (Chapter 7). Subjecting the microalga Chlamydomonas reinhardtii and its cell wall deficient mutant to PEF-treatment resulted in low protein yields for the wild type whereas PEF-treatment on the cell-wall less mutant yielded in more than a twofold higher protein yield ( $>30 \%$ proteins). As the outer cell wall limits PEF, a pre-treatment is required to weaken, or possibly remove the outer cell wall prior to the PEF-treatment (Chapter 7).

Before developing a pre-treatment, PEF as (secondary) disruption technology was further characterized (Chapter 7). The cell wall less mutant of $C$. reinhardtii was used to mimic pre-treated biomass during PEF treatment. Characterization of the treatment conditions confirmed the presence of a critical transmembrane potential. To exceed the critical transmembrane potential a sufficiently high electric field strength should be applied. This makes the electric field strength an important operating parameter. PEF treatment on the cell-wall less microalgae at an energy input similar to the ones reported for mechanical disruption ( $2 \mathrm{kWh} / \mathrm{kg}_{\mathrm{DW}}$ ) yielded in protein releases equal to mechanical disruption (>30\%proteins). Even when an energy input lower than 0.25 $\mathrm{kWh} / \mathrm{kg}_{\mathrm{DW}}$ was applied, still $\sim 70 \%$ of the proteins could be released compared to bead beating. After PEF-treatment, the protein RubisCo was found in its native state in the aqueous phase, which suggests that PEF allows the release of large hydrophilic proteins without denaturing them. Mild release of hydrophilic, native 
proteins is relevant considering that these proteins may have a high value due to their techno-functionality for food applications.

The low degree of disruption ( $25 \%$ ), in combination with the low release of chlorophyll ( $<5 \%$ with respect to bead beating) suggest that PEF is selective in releasing hydrophilic proteins. The selectivity of PEF during treatment of cell-wall less microalgae was confirmed by comparing the chlorophyll extraction efficiency of PEFtreated biomass with bead beated biomass (Chapter 7 ). These results showed that $\mathrm{PEF}$ is a selective technology in releasing hydrophilic components from cell wall less microalgae.

As PEF-treatment on cell-wall less microalgae is mild and selective, it is a promising, secondary technology. It is thus worthwhile to develop a primary pre-treatment to weaken- or remove the outer cell wall. Enzymes may be a promising pre-treatment prior to PEF. The wild type $C$. reinhardtii was incubated with protease at roomtemperature for a 6 hour duration followed by a washing step to remove the enzymes prior to PEF. This pre-treatment rendered in more than a twofold increase in protein yield, compared to merely PEF-treatment. Even though the obtained protein yields were not as high as with mechanical bead beating, a proof of concept of enzymeassisted PEF ('E-PEF') as novel cell disruption strategy was confirmed in Chapter 7.

In the general discussion (Chapter 8), the technological advances in the three main downstream processing unit operations (i.e. harvesting, cell disruption and extraction) were evaluated. This evaluation showed, that harvesting microalgae is in most cases no bottleneck anymore for a multi-product biorefinery. Cell disruption and extraction, however, still need to be improved, to make a biorefinery economically feasible.

The latter can be achieved by simplifying the overall biorefinery process i.e. reducing the number of unit operations (Chapter 8). By developing unit operations in which different steps in the biorefinery chain are integrated, or by avoiding the use of chemicals that are difficult to recycle, the biorefinery chain will become less complex. Development of such simplified processes is essential to bring the multi-product microalgae biorefinery towards economic feasibility. 

Samenvatting 
Microalgen zijn een veelbelovende grondstof voor verschillende producten. Op dit moment worden microalgen al commercieel gekweekt als grondstof voor de productie van hoogwaardige producten zoals kleurstoffen en de aquacultuur (Hoofdstuk 1). Microalgen bestaan voor een groot gedeelte uit eiwitten, suikers en vetten. Hierdoor zijn ze ook veelbelovend als grondstof voor de minder hoogwaardige bulkproducten. Om de productie van deze bulkproducten haalbaar te maken, moeten de huidige kosten dalen. Daarnaast is een bioraffinage scenario voorgesteld waarin meerdere producten, in plaats van één enkel product, uit de gekweekte biomassa worden verkregen. Om deze multi-product bioraffinage te bewerkstelligen moeten de verschillende biomassa-fracties niet beschadigen tijdens het verwerkingsproces. Er moeten dus goedkope, en milde technologieën worden ontwikkeld (Hoofdstuk 1).

De eerste stappen in het verwerkingsproces zijn het oogsten van de biomassa en de celdisruptie, waarin de intracellulaire componenten worden vrijgemaakt. Het oogsten van microalgen met bestaande technologieën (centrifugatie) wordt gezien als duur en heeft een relatief hoog energieverbruik. Hetzelfde geldt voor de reeds bestaande mechanische celdisruptie technologieën (bijvoorbeeld 'bead milling'). Er is dus behoefte aan een alternatief oogst- en celdisruptie proces (Hoofdstuk 1).

In het eerste gedeelte van dit proefschrift, is flocculatie nader onderzocht als alternatieve technologie voor het oogsten van microalgen. Flocculatie is een proces waarbij losse cellen aggregeren tot vlokken die vervolgens zinken naar de bodem van een sedimentatietank. Flocculatie wordt vaak geïnduceerd door het toevoegen van een additief ('flocculanten'). Alhoewel flocculatie al een veel gebruikte technologie is, ook voor het oogsten van microalgen, blijkt flocculatie van zoutwater microalgen nog steeds lastig. Door de hoge zoutconcentratie in het zeewater zijn veel flocculanten niet toereikend om voldoende vlok-vorming te induceren. Daarom hebben we eerst een uitgebreide screening van verschillende organische flocculanten uitgevoerd (Hoofdstuk 2). Hieruit bleek dat cationische polymeren -en in het bijzonder cationische polyacrylamiden- succesvol gebruikt kunnen worden voor het flocculeren van de zoutwater microalg Phaeodactylum tricornutum en de in zeewater gekweekte microalg Neochloris oleoabundans. Het gebruik van deze cationische polymeren resulteerde na een sedimentatietijd van 2 uur in een oogst- 
efficiëntie hoger dan $90 \%$, terwijl een concentratiefactor tussen de 5 en 10 werd bereikt.

Nadat was aangetoond dat cationische polymeren succesvol flocculatie van zoutwater microalgen induceerden, werd het effect van de flocculanten dosering op de oogst-efficiëntie bepaald (Hoofdstuk 3). Initieel werd bij toenemende flocculantendosering de efficiëntie van het oogsten van de zoutwater gecultiveerde microalg Neochloris oleoabundans hoger. Nadat een optimum in oogst-efficiëntie (>95\%) was bereikt, droeg het verder verhogen van de flocculanten dosering echter niet extra bij aan de oogst-efficiëntie. Het verder verhogen van de flocculanten dosering leidde zelfs tot een lagere oogst-efficiëntie. Dit suggereert dat deeltjes die volledig bedekt zijn met flocculant, positief geladen zijn en hierdoor elkaar en de flocculanten gaan afstoten als er nog meer flocculant wordt toegevoegd. Het mechanisme van ladings-gedreven flocculeren bij lage dosering en afstoten bij hoge doseringen is vervolgens vertaald naar een wiskundig model. Dit model beschrijft de relatie tussen de flocculanten-dosering en oogst-efficiëntie als functie van de flocculanten-dosering, de initiële biomassa concentratie en de diameter van de algencellen. Het model is vervolgens gevalideerd en simulaties laten zien dat de optimale flocculanten dosering (met cationische polyacrylamiden) voor $N$. oleoabundans in zeewater rond de $70 \mathrm{mg}$ flocculant $/ g_{\text {biomassa }}$ ligt. Deze dosering is betrekkelijk hoog en dat in combinatie met typische kostprijzen voor dergelijke flocculanten zorgt ervoor dat flocculatie betrekkelijk duur is. Daarnaast zijn de gebruikte polyacrylamiden toxisch, en ze zijn daarom niet gewenst in een bioraffinage proces. Er is daarom behoefte aan alternatieve flocculanten (Hoofdstuk 3).

Voordat er alternatieve flocculanten geselecteerd, of mogelijk ontwikkeld kunnen worden, is het belangrijk om te weten waarom juist de gebruikte cationische polyacrylamiden zo succesvol zijn bij hoge zoutconcentraties. Een algemeen geaccepteerde hypothese is dat polymerische flocculanten onder invloed van hoge zoutconcentraties oprollen ('polymeric coiling'). Deze compacte conformatie zorgt ervoor dat de polymeren niet meer instaat zijn om bruggen te vormen tussen individuele cellen. Uitgaande van deze hypothese is het dus aannemelijk dat polyacrylamiden minder sterk ineen kronkelen bij hoge zout concentraties. In Hoofdstuk 4 hebben we een goedwerkende cationische polyacrylamide met een 
minder goed werkende, natuurlijk cationisch polymeer vergeleken op basis van ogenschijnlijke polymeer-lengte en ladingsdichtheid. Dit onderzoek is uitgevoerd bij verschillende zoutconcentraties van het medium. Alhoewel de goedwerkende cationische polyacrylamide sterk oprolde bij hogere zoutconcentraties, bleef deze succesvol flocculeren. Dit duidt erop dat er een andere reden dan polymeric coiling moet zijn, die het succes van de polyacrylamiden kan verklaren. Verder onderzoek liet zien dat de cationische polyacrylamide een hogere ladingsdichtheid hebben dan het natuurlijke cationische polymeer. De ladingsdichtheid lijkt dus logischerwijs een eigenschap die overwegend de mate van succes bepaald. Dit werd bevestigd door flocculanten met een verschillende ladingsdichtheid met elkaar te vergelijken op basis van oogst-efficiëntie. De ladingsdichtheid is daarmee een belangrijke parameter voor het selecteren, dan wel ontwerpen van alternatieve flocculanten voor microalgen (Hoofdstuk 4).

In het tweede gedeelte van dit proefschrift hebben we de mogelijkheden van het toepassen van 'Pulsed Electric Field' (PEF) als alternatieve celdisruptie technologie onderzocht. PEF is een technologie die al veelvuldig is onderzocht en toegepast in bijvoorbeeld de levensmiddelenindustrie en in de medische sector voor behandeling van tumoren. Om te bepalen hoe succesvol PEF is in het ontsluiten van microalgen, is er een screening uitgevoerd (Hoofdstuk 5). In deze screening zijn tijdens de PEF behandeling diverse condities getest op de zoetwater microalg Chlorella vulgaris en op de in zoutwater gecultiveerde microalg Neochloris oleoabundans. Uit het onderzoek bleek, dat PEF behandeling, ongeacht de gebruikte condities, doorgaans resulteerde in het succesvol vrijmaken van ionen. Dit duidt erop dat tijdens PEF de cellen worden opengemaakt. In geen van de experimenten werd echter een hoge eiwit-opbrengst waargenomen. De lage eiwit opbrengst illustreert dat de cellen weliswaar waren ontsloten voor ionen, maar dat deze ontsluiting onvoldoende was voor het vrijmaken van grotere moleculen zoals hydrofiele eiwitten.

Om een beter beeld te krijgen van de mate van succes van PEF behandeling is een literatuurstudie uitgevoerd (Hoofdstuk 6). Deze analyse van de reeds gepubliceerde data over toepassing van PEF voor celdisruptie en vrijmaken van eiwitten uit microalgen liet zien dat vergelijkbare resultaten zijn verkregen. 
Veel microalgen hebben naast een celmembraan, ook een celwand. Deze celwand limiteert mogelijk het succesvol vrijmaken van grote componenten. Om deze hypothese te testen, is de microalg Chlamydomonas reinhardtii vergeleken met zijn celwand-deficiënte mutant. De celwand-deficiënte mutant bleek na PEF behandeling een minstens twee keer hogere eiwit-opbrengst (>30\% proteins) te geven, dan de wild type alg. Dit onderzoek toonde aan dat de celwand de limiterende factor is voor het vrijmaken van eiwit en dat er een voorbehandeling nodig is om de celwand te verzwakken of zelfs af te breken, voorafgaand aan PEF behandeling (Hoofdstuk 7).

Voordat een voorbehandeling wordt ontwikkeld is het goed om eerst PEF beter te karakteriseren. Voor dit onderzoek is de celwand deficiënte mutant van $C$. reinhardtii gebruikt als een substituut van wild-type cellen waarvan de celwand is verzwakt na een voorbehandeling. Uit dit onderzoek bleek dat microalgen een kritisch transmembraan potentiaal hebben. Als dit potentiaal wordt overschreden, breken de cellen open. Om de kritische transmembraan potentiaal te overschrijden moet er een voldoende hoge veldsterkte worden opgelegd. Daarmee is de veldsterkte een belangrijke behandelingsparameter.

Daarnaast bleek dat PEF een even hoge eiwit-opbrengst gaf (>30\%proteins) als mechanische celdisruptie bij een vergelijkbaar energieverbruik ( $2 \mathrm{kWh} / \mathrm{kg} \mathrm{DW})$. Zelfs bij een erg laag energieverbruik $\left(0.25 \mathrm{kWh} / \mathrm{kg}_{\mathrm{DW}}\right)$ gaf PEF nog steeds circa $70 \%$ van de eiwit-opbrengst die verkregen was met bead beating als referentie. $\mathrm{Na}$ de PEFbehandeling bleek dat in het vrijgemaakte eiwit, het eiwit RubisCo in zijn natieve vorm kon worden aangetoond. Dit duidt erop dat tijdens PEF geen extreme condities aanwezig zijn die leiden tot denaturatie van gevoelige water-oplosbare eiwitten zoals RubisCo. Het intact houden van water-oplosbaar, natief eiwit is belangrijk omdat deze eiwitfractie een mogelijk hoge(re) waarde heeft, als de aanwezige eiwitten hun techno-functionele eigenschappen behouden.

Alhoewel er een hoge eiwitopbrengst is waargenomen, werd maar circa $25 \%$ van de cellen kapot gemaakt, ten opzichte van bead beating. Daarnaast bleek dat tijdens de PEF behandeling maar circa $5 \%$ chlorofyl ten opzichte van bead beaten werd vrijgemaakt. Terwijl het water-oplosbaar eiwit dus voor een groot deel was vrijgekomen, bleef het chlorofyl in de celresten achter. Dit geeft aan dat PEF als 
secundaire technologie na de primaire pretreatment om de celwand te verzwakken, ingezet kan worden om selectief en mild eiwitten vrij te maken (Hoofdstuk 7).

Omdat PEF duidelijke voordelen kan hebben als celdisruptie technologie is ook getest of enzymen gebruikt kunnen worden als voorbehandeling van het wild type $C$. reinhardtii. Incubatie met een protease gevolgd door een was-stap om de enzymen te verwijderen, resulteerde in een meer dan twee keer zo hoge eiwit-opbrengst bij PEF behandeling (Hoofdstuk 7). De eiwit-opbrengst was echter nog niet zo hoog als na bead beaten. Desondanks is met dit onderzoek een duidelijk 'proof-of-concept' gegeven voor 'enzyme-assisted PEF' (E-PEF).

In de algemene discussie van dit proefschrift (Hoofdstuk 8) zijn de technologische ontwikkelingen binnen het oogsten, de celdisruptie en de product-extractie geevalueerd. De evaluatie liet zien dat in veel gevallen het oogsten van microalgen geen economisch probleem meer is in een multi-product bioraffinage. Celdisruptie en de product-extractie hebben echter nog een aantal technologische- en economische beperkingen en daarom moeten deze twee processtappen verder ontwikkeld worden.

De technische beperkingen van de huidige celdisruptie en extractie technologieën maken de huidige bioraffinage scenario's doorgaans erg complex en daardoor duur. Daarom zullen alternatieve celdisruptie en extractie processen moeten worden ontwikkeld, die het bioraffinage proces vereenvoudigen. Wanneer we bijvoorbeeld celdisruptie en extractie kunnen integreren tot 1 stap, of als we het gebruik van chemicaliën zoals bijvoorbeeld oplosmiddelen kunnen vermijden, hebben we minder processtappen ('unit operations') nodig en wordt het proces eenvoudiger en goedkoper. Dit kan bijdragen aan het vergroten van de economische haalbaarheid van groot-schalige multi-product bioraffinage van microalgen (Hoofdstuk 8) 
Dankwoord 
De afgelopen jaren heb ik van ongelooflijk veel mensen hulp, steun en afleiding gekregen. Ik heb geprobeerd jullie allemaal te noemen. Mocht ik je onverhoopt vergeten zijn, dan heb ik dat niet expres gedaan.

Ik wil beginnen met mijn promotors René en Michel. René, lk wil je heel erg bedanken voor het vertrouwen dat je me hebt gegeven. We hebben veel discussies gehad over mijn onderzoek. Heel erg bedankt voor je open, kritische blik. Het heeft mijn werk absoluut naar een hoger plan getild. Michel, elke vrijdag zit je op de vakgroep, druk bezig met van alles en nog wat. Ik vond het erg fijn dat je ondanks je drukke agenda geregeld tijd wist te maken om bij mij op kantoor eens even te buurten. Ik vond het fijn om het reilen en zeilen van mijn project met je te kunnen bespreken. Bedankt voor je input, en kritische kijk op mijn werk. René en Michel, de afgelopen jaren waren voor mij ook persoonlijk erg turbulent. Ondanks jullie drukke agenda's hadden jullie wel alle tijd van de wereld om mij waar nodig te ondersteunen. Ik wil jullie hiervoor bedanken.

Marian, ik ben samen met jou aan dit avontuur begonnen. Naast je (drukke) rooster als studieadviseur had je namelijk ook een gaatje vrij om mij als AlO te begeleiden. Ik wil je heel erg bedanken voor je betrokkenheid, vele lessen, en uiteraard voor de gezelligheid. Giuseppe, halfway my project, you were added to my 'supervisionteam'. I really learned a lot from you. Even though you are now working in Italy, we continued to have a warm contact. Thanks for all your advices and valuable input. Thanks for everything. Grazie di tutto!

Corjan, jij bent het afgelopen jaar op de groep gekomen om samen met Michel de 'bioraffinage-kar' te trekken. In die rol heb je me van heel veel waardevolle input voorzien tijdens het schrijven van mijn discussie. Bedankt hiervoor!

All supervisors, looking back to the past 4 years, I can only conclude that I learned a lot from all of you. Thanks for the valuable lessons and experiences.

My research was part of a large project, and I received a lot of help from the other project partners. Hans R., jij bent wat mij betreft als projectcoördinator de grote spil in het web van AlgaePARC: Biorefinery. Dank voor je hulp, input en leuke praatjes tijdens mijn onderzoek. Maria, ook jij was als projectleider ontzettend belangrijk voor het project. Op de eerste plaats dank voor de goede organisatie. Jouw positieve 
energie en lach zijn erg besmettelijk. Dank voor je kritische blik op mijn werk, en je interesse. Rob, Lolke, Giuseppe, and Corjan, you were as work package leader involved in my research. Thank you for the good organization of WP1, valuable input and interest in my work. I would also like to thank the other members of the AlgaePARC: Biorefinery project for their input. Your valuable input stimulated me to improve my work.

During my PhD, I had the pleasure to team-up with some MSc. and BSc. students. Elias, Benjamin and Javier, during your thesis, you helped me with tackling various challenges within flocculation. Your valuable input resulted in 2 of my chapters. I am grateful for all the hard work you performed. Diana, Anastasia, Jelmer and Akshita, together with you, I worked on PEF. A novel and challenging topic. We continuously arrived at new hurdles. Your perseverance was a key-ingredient to overcome those hurdles. Your help resulted in 2 chapters. I want to thank all of you for the valuable lessons I learned. I hope that we will meet or even collaborate in the future again.

The 'biorefinery-theme' is one the themes within BPE. Michel, Giuseppe and Corjan thank you for organizing our monthly theme-meetings. All the thememembers (staff, PhD's and students) thank you very much for your input. I always enjoyed the discussions we had about each other's work.

Tijdens mijn onderzoek heb ik erg veel hulp gehad van de technicians. Fred, Sebastiaan, Wendy, Snezana, Bregje, Ruud V. en Rick bedankt voor jullie hulp en ondersteuning op lab, met o.a. mijn reactor, het opzetten van nieuwe experimenten en het bestellen van al mijn benodigdheden. Daarnaast heb ik ook hulp gekregen van andere mensen, buiten de vakgroep. Jos (FPE), Marcel G. (SEM-centrum), Ben en Jelle (FBR) dank voor jullie raad en daad.

Miranda en Marina, als vakgroep secretariaat zijn jullie het zenuwcentrum van alle roddels. Regelmatig kwam ik bij jullie op bezoek om het laatste vakgroepgerelateerde nieuws door te nemen, en tevens te voorzien van een ongenuanceerde mening. Heel erg bedankt voor alle gezellige momenten, roddels en praatjes.

I would like to thank some other collegues in particular: Arjen and Douwe bedankt voor alle koffie-automaat gesprekken, en jullie open mening. Rouke bedankt voor alle gezelligheid en interesse in mijn werk. Ik vind het erg leuk dat ik via jou en 
Jeroen op de vakgroep als AIO ben gekomen. Joao \& Lenneke, thanks for all the morning-runs we have had. Ellen, bedankt voor de gezellige (roddel)pauzes en lunches. Marjon, bedankt voor de gezelligheid, etentjes, en avondjes thee. Guido, jij ook bedankt voor alle gezelligheid tijdens etentjes en rondjes mountainbiken. Richard, bedankt voor de samenwerking op het gebied van PEF. Rupali, Mitsue(+Martin), Jorijn, Marta(+Paulo), Jorijn, Xiao and Agi thanks for the dinners and fun evenings.

I also want to mention the people I shared an office with: Ruchir, Xiao, Luci, Fabian, and Pieter. Thanks for the nice atmosphere in our office. Jorijn, we zijn samen begonnen in 619, in het Biotechnion. Sindsdien hebben we altijd samen op kantoor gezeten. Bedankt voor al je gezelligheid en adviezen. Ook wil ik je heel erg bedanken voor je tijd. Ik had namelijk altijd wat te klagen, of te roddelen en ik kon je hier altijd voor storen.

I would like to thank my colleagues of the department for all the nice talks, fun coffee breaks and interest in my research: Brenda, Rafael, Lolke, Dorinde, Ruud W., Dirk, Marcel, Kim, Gerrit, Shirley, Packo, Mark S., Diana R., Mathieu, Rik B., Hans T., Youri, Abdulaziz, Kylie, Pauline, Enrico, Stephanie, Camillo, Elisa, Catalina, Edgar, Anne, Lenny, Guido, Luci, Gosia, Edwin, Ward, Carl, Tim, Kiira, Giulia, Jeroen, lago, Michiel, Christian and Anna.

De Gouden 4 moet natuurlijk niet onvermeld blijven. Via Argo kennen we elkaar nu alweer een hele tijd. Bedankt voor de gezelligheid!

Jan en Marit, ik wil jullie heel erg bedanken voor alles. De laatste jaren hebben we veel samen gedeeld. Ik ben erg blij dat we zoveel met elkaar optrekken.

Ook wil ik mijn jaarclub, Stratos heel erg bedanken voor alle afleiding. Het is heel erg fijn om i.p.v. onderzoek gewoon een avond in de Kroeg te hebben en te ouwehoeren over van alles en nog wat. We hebben veel dingen samen meegemaakt. Ik verwacht dat er nog vele memorabele momenten zullen volgen. Bedrankt.

Stijn en Bas, we kennen elkaar via de club. Samen met de rest van Stratos hebben we al heel veel beleefd. Ik ben heel erg blij dat jullie mijn paranimf willen zijn. 
Ik wil ook erg graag de familie uit Friesland bedanken voor hun interesse in mijn onderzoek, en de vele leuke momenten die we hebben gehad. Fokko en Tea, ik kan me nog goed herinneren dat ik met een bloedende bovenlip samen met jullie kasteel Doorwerth heb bezocht. Niet lang daarna gingen we met z'n allen op wintersport. Ik ben erg blij dat jullie mij zo warm hebben onthaald, en ik hoop dat er nog vele leuke momenten komen. Ellen en Freerk, ik vind het erg gezellig om bij jullie op bezoek te zijn, of samen wat te doen. Zoals het avondje sc Heerenveen eerder dit jaar. Bedankt voor jullie interesse, en gezelligheid. Natuurlijk niet onbelangrijk, Finn. Ergens halverwege mijn onderzoek kwam jij om de hoek kijken. Je zorgt voor veel leven in de brouwerij, en zorgt voor veel leuke momenten.

Aart-Jan, Maja en Greet, we kennen elkaar al heel erg lang. Of beter gezegd, jullie kennen mij heel erg lang, want de afgelopen jaren waren we elkaar uit het oog verloren. Ik ben erg blij dat dit contact weer is opgepakt. Het is altijd heel erg gezellig met/bij jullie, en ik hoop dat er nog veel leuke momenten zullen volgen.

Dan natuurlijk de tantes en ooms (tante Wilma en oom Ton, tante Barbara oom Coen en tante Maud oom Jeroen). Ik hoor wel eens verhalen van andere mensen die zelden hun ooms en tantes spreken. Ik kan me hier eigenlijk weinig bij voorstellen. Zolang als ik kan herinneren zagen we elkaar geregeld, wat altijd zorgde voor gezellige momenten. De kracht van een hechte band is dat je niet alleen leuke dingen kunt hebben/uitspreken maar ook de minder leuke momenten. Dat hebben wij, en dat is wat mij betreft een groot goed. Uiteraard bestaat de familie niet alleen uit ooms en tantes, maar ook uit neven en nichten. Ik denk dat we een diverse club bij elkaar zijn. Ik vind het leuk dat jullie op mijn promotie komen, en hoop dat er nog veel leuke momenten zullen volgen. Jullie hebben allemaal veel interesse getoond in mijn promotie. Ik realiseer me dat het soms erg moeilijk was om te doorgronden waar ik het nu over had ('is het nou een studie of niet?'). Desalniettemin hadden jullie een onverminderde mate van interesse. Ik het vind het hierom hartstikke leuk dat jullie bij mijn promotie willen zijn.

Opa, ik wil jou ook heel erg bedanken voor je interesse. Je volgt het algen-onderzoek op de voet. Altijd als er een krantenartikel werd gepubliceerd, hield je dat apart voor mij en Ilse. Ik vind het geweldig fijn dat je dit deed. 
Papa en Mama, ik wil jullie ongelooflijk bedanken voor alle lessen die jullie mij hebben geleerd, jullie onuitputtelijke interesse en de vele fijne momenten die ik bij jullie gehad. Het is jullie uitspraak 'goed je best doen op school' die er voor heeft gezorgd dat ik zover ben gekomen. Hiermee is dit proefschrift ook jullie prestatie. De afgelopen jaren waren ontzettende turbulent. $\mathrm{lk}$ heb heel veel bewondering voor de manier hoe jullie je er doorheen hebben geslagen. Ik kan me hierom geen groter voorbeeld wensen.

Ilse, ik wil je heel erg bedanken voor alles. We hebben het ongelooflijk fijn samen. Je hebt me heel erg geholpen met je relativerende, en nuchtere kijk op van alles en nog wat. Bedankt voor je steun en luisterend oor en alle andere dingen.

Marjoleine, ik denk dat we qua karakter echt totaal verschillend zijn. Ik een praatjesmaker die vaak meer zegt dan verteld, terwijl jij heel stil was. Bij papa en mama thuis, maar ook zeker toen je in Wageningen kwam wonen trokken we veel met elkaar op. Ik heb heel veel gezellige avondjes (film) met je gehad. Jij hebt altijd een geweldige motivatie gehad om te leren. Ik denk dat deze motivatie jouw geheim is voor de successen die je hebt behaald. Want jij hebt verschillende grote prestaties geleverd. Hiermee ben je voor mij een voorbeeld. Jij bent het bewijs dat motivatie, en karakter sleutel ingrediënten zijn voor (onmogelijke) prestaties. Alhoewel je hier beneden niet meer bent, weet ik dat je nog heel dicht bij me bent. Je hebt me altijd geweldig gesteund en geholpen. Dit proefschrift is hierom net zoveel van jou als van mij. Ik hoop dat je er met net zoveel plezier naar kijkt als ik.

\section{Cover and Thesis design}

Cogs ('tandwielen') are the theme of the lay-out as I aimed to move a multiproduct microalgae biorefinery towards a (future) large scale industrial process. Such an industrial process is symbolized with the cogs of a machine.

At the same time, I wanted to advance our level of understanding. This means that I wanted to know how all 'the little cogs are spinning in the machine'. 
About the author 


\section{Curriculum Vitae}

Gerard 't Lam was born on 28-06-1990 in Arnhem, the Netherlands. Gerard followed his secondary education at Mondriaan College in Oss, and graduated in 2007.

In 2007, he started with a Bachelor in Chemical Engineering at Saxion Hogeschool in Enschede (the Netherlands). He did an

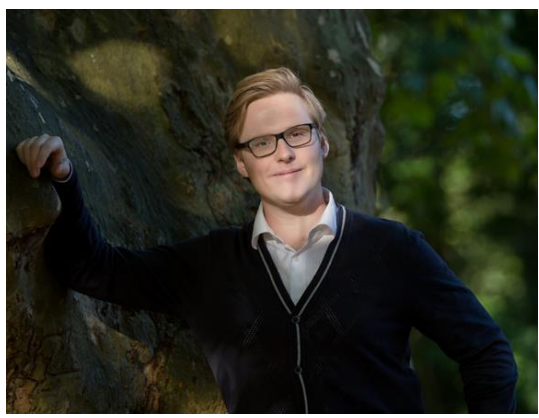
internship at VION Ingredients in Son (the Netherlands) where he tested the feasibility of an UASB reactor and an Anammox reactor for wastewater treatment. Gerard continued with his thesis at Witteveen+Bos (Deventer, the Netherlands) on autotrophic denitrification for nitrogen removal from waste water. He obtained in 2011 his Bachelor-degree.

In the same year he continued pursuing a Master degree at Wageningen University. In Wageningen, he did a thesis at the sub-department of Environmental Technology Wageningen University on a scaled up microbial electrolysis cell. He continued with a second thesis at the department of Bioprocess Engineering at Wageningen University on the effect of temperature and light on microalgal biomass productivities. Gerard obtained in 2013 his Master-degree (M.Sc.) in Environmental Technology and Bioprocess Engineering.

After graduating, he started in 2013 a doctorate-research (Ph.D.) on microalgae biorefinery at the department of Bioprocess Engineering, Wageningen University. The results of his research are described in this thesis. 


\section{List of publications}

\section{Published}

't Lam, G.P., Postma P.R., Fernandes D.A., Timmermans R.A.H., M.H. Vermuë, M.J. Barbosa, M.H.M. Eppink, Wijffels R.H. Olivieri G. (2017) Pulsed Electric Field for protein release of the microalgae Chlorella vulgaris and Neochloris oleoabundans. Algal Res. 24A: 181-187.

Postma, P.R. 't Lam, G.P. Barbosa M.J., Wijfels R.H., Eppink M.H.M., Olivieri. G. (2016) Microalgal biorefinery for bulk and high value products - Product extraction within cell disintegration. in Handbook of Electroporation pp 1-20, D. Miklavčič (Ed.). Springer International Publishing, Switzerland. ISBN: 978-3-319-32887-4.

't Lam G.P. , Giraldo J.B., Vermuë M.H, Olivieri G., Eppink M.H.M., Wijffels R.H. (2016) Understanding the salinity effect on cationic polymers in inducing flocculation of the microalga Neochloris oleoabundans. J. Biotechnol. 225C: 10-17

't Lam G.P., Zegeye E.K., Vermuë M.H., Kleinegris D.M.M., Eppink M.H.M., Wijffels R.H., Olivieri G. (2015) Dosage effect of cationic polymers on the flocculation efficiency of the marine microalga Neochloris oleoabundans, Bioresour. Technol. 198: $797-802$

't Lam, G.P., Vermuë M.H., Olivieri G., van den Broek L.A.M., Barbosa M.J., Eppink M.H.M., Wijffels R.H., Kleinegris D.M.M. (2014) Cationic polymers for successful flocculation of marine microalgae. Bioresour. Technol. 169: 804-807.

Dekker A., Menkveld H.W.H., Hermans P.G.B., Panjer M.A.C., ‘t Lam G.P. (2011) Zwavel in de rwzi: Autotrofe denitrificatie en zwavelterugwinning als zuiveringstechniek voor rwzi's - een haalbaarheidsstudie. STOWA. ISBN 978-905773-530-1

\section{Submitted for Publication}

‘t Lam G.P., Vermuë M.H., Janssen M., Barbosa M.J., Wijffels R.H., Eppink M.H.M., van den Berg C. Microalgae: From biobased curiosity towards a bulk feedstock. Intensification of Bio-Based Processes, A. Górak and A. Stankiewicz (Eds.). RSC Publishing, United Kingdom. Submitted

't Lam, G.P., van der Kolk, A.J., Chordia A., Vermuë M.H., Olivieri G, M.H.M. Eppink, Wijfels R.H., Mild and selective protein release of cell wall deficient microalgae with Pulsed Electric Field. In preparation

‘t Lam, G.P., Vermuë, M.H., van den Berg, C., Eppink, M.H.M., Wijffels, R.H., Multiproduct microalgae biorefineries. In preparation 


\section{Overview of completed training activities}

\section{Discipline Specific Activities}

\section{Conferences}

Mini-symposium: 'microalgae biotechnology: towards industrial strains and processes (2013 - Wageningen NL) ${ }^{1}$

Mini-symposium: 'The box of Pandora: what came out? (2014 - Wageningen, $\mathrm{NL})^{1}$

$2^{\text {nd }}$ International Conference on Algal Biorefinery (2014 - Lyngby, DK) ${ }^{3}$

$10^{\text {th }}$ European Symposium for BioEngineering Sciences (2014 - Lille, FR) ${ }^{3}$

$6^{\text {th }}$ International Forum on Industrial BioProcesses (2014 - Lille, FR) ${ }^{3}$

AlgaePARC Open Workshop (2014 - Wageningen, NL) ${ }^{2}$

Mini-symposium: 'The dynamics of oil accumulation' (2015 - Wageningen, $\mathrm{NL})^{1}$

Dutch National Biotechnology Symposium 'NBC-16: Biotechnology the Next Level' (2016 - Wageningen, NL) ${ }^{3}$

$12^{\text {th }}$ Renewable Resources and Biorefineries (2016 - Gent, BE) ${ }^{2}$

\section{Courses and Meetings}

School on applications of PEF for food processing (2015 - Salerno, IT)

Seminar 'Continuous Processing for biotherapeutic proteins' (2015 - Oss, NL)

Lecture at $1^{\text {st }}$ International course on microalgae biorerfinery (2016 -

Wageningen, $\mathrm{NL})^{3}$

- TKI AlgaePARC 6 monthly consortium meetings (2013-2017 - Wageningen,

$\mathrm{NL})$

- BPE internal biorefinery meetings (2013-2017 - Wageningen, NL)

\section{General Courses}

- VLAG PhD week (2013 - Baarlo, NL)

- WGS PhD Carousel day (2014 - Wageningen, NL)

- Essentials of Scientific Writing and Presenting (2014 - Wageningen, NL)

- Young AFSG 'Know your neighbours - FBR' (2015 - Wageningen, NL)

- Biobusiness Summerschool (2016 - Amsterdam \& Leiden, NL)

- Entrepreneurship In and Outside Science (2016 - Wageningen, NL)

\section{Optional}

- Preparation of research proposal (2013)

PhD study trip to Portugal (2014) ${ }^{2,3}$

- 6 monthly PhD-days (2013-2017)

- Young AFSG and Young WUR committee meetings (2016)

\section{Teaching}

- Bioprocess Design (2013-2016)

- Advanced Biorefinery (2013-2016)

- Biorefinery (2015-2017)

- Process Engineering Basics (2017)

- Supervision of 6 MSc. and 1 BSc. thesis-students (2014-2016) 
This study was carried out at the department of Bioprocess Engineering of Wageningen University, Wageningen, The Netherlands. The research described in this thesis is performed within the TKI AlgaePARC Biorefinery program with financial support from the Netherlands' Ministry of Economic Affairs in the framework of the TKI BioBased Economy under contract nr. TKIBE01009.

Printed by: Uitgeverij Boxpress || proefschriftmaken.nl 
